PNL-3376

TIC-0114

UC-71

\title{
An Assessment of the Risk of Transporting Liquid Chlorine by Rail
}

W. B. Andrews

Project Coordinator

March 1980

Prepared for the U.S. Department of Energy under Contract DE-AC06-76RLO 1830

Pacific Northwest Laboratory Operated for the U.S. Department of Energy by Battelle Memorial Institute 
NOTICE

This report was prepared as an account of work sponsored by the United Stares Government. Neither the United States nor the Department of Energy, nor any of their employees, nor any of their contractors, subcontractors. or their employees, makes any warranty, express or implied, or assumes any legal tiability or respiansibility for the accuracy. completeness or usefulness of any information, apparatus, product or process disclosed, or represents thar its use would not infringe privately owned rights.

The views. opinions and conclusions contained in this report are those of the contractor and do not necessarily represent those of the United States Covernment or the United States Department of Energy.

\author{
PACIFIC NORTHWEST LABORATORY \\ operated by \\ BATTELLE \\ for the \\ UNITED STATES DEPARTMENT OF ENERGY \\ Under Contract DE-AC06-76RLO 1830
}

\author{
Printed in the United States of America \\ Avallable from \\ National Technical Information Service \\ United States Department of Commerce \\ 5285 Port Royal Road \\ Springtield, Virginia 22151
}

Price: Prinied Copy S, -. Microtiche 53,00

NTIS

-Pages: Selling Price

001-025 $\quad 5400$

026-050 \$4.50

$051-075 \quad 55.25$

076-100 $\$ 6.00$

$101.125 \quad 56.50$

$126-150 \quad 57.25$

$151-175 \quad 58.00$

$176.200 \quad 59.00$

201-225 $\quad 59.25$

$226-250 \quad \$ 9.50$

251-275 510.75

$276-300 \quad 371.00$ 
AN ASSESSMENT OF THE RISK OF TRANSPORTING LIQUID CHLORINE BY RAIL

W. B. Andrews

Project Coordinator

Technical Contributors

M. L. Clark

J. R. Friley

D. J. McNaughton

T. Buckingham

B. A. Ross

March 1980

Prepared for

the U.S. Department of Energy

under Contract DE-AC06-76RLO 1830

Pacific Northwest Laboratory

Richland, Washington 99352 


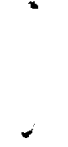




\section{PREFACE}

This study was initiated in FY79 in the Transportation Safety Studies Project performed at Pacific Northwest Laboratory for DOE's Division of Environmental Control Technology. In FY80, responsibility for this work was transferred to the Division of Transportation and Fuel Storage and overview of the work was assigned to the Transportation Technology Center (TTC) at Sandia Laboratories, DOE's lead Taboratory for Nuclear Materials Transportation Technology. This work was substantially complete when assigned to TTC overview and TTC funds were used only for incorporation of review comments and for publication. Funds for completion and publication of this study have been provided to PNL through TTC. 

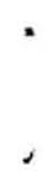


\section{CONTENTS}

PREFACE

FIGURES

TABLES

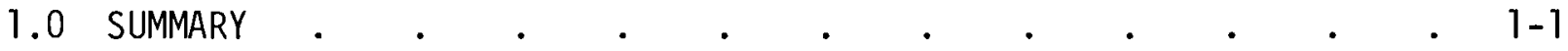

2.0 INTRODUCTION $\cdot$.

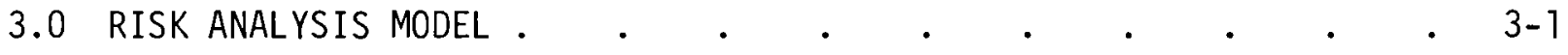

3.1 RISK MODEL DESCRIPTION .

3.1.1 System Description . . . . . . . . . $3-3$

3.1.2 Release Sequence Identification . . . . . 3-4

3.1.3 Release Sequence Evaluation . . . . . . . 3-6

3.1.4 Risk Calculation and Assessment . . . . . 3-7

4.0 CHLORINE SHIPPING REQUIREMENTS . . . . . . . . . 4-1

5.0 TRANSPORTATION ACCIDENT ENVIRONMENT $. \quad \cdot \quad \cdot \quad \cdot \quad \cdot \quad \cdot 5-1$

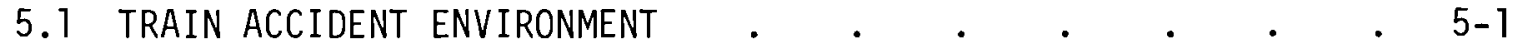

5.1 .1 Fire $. \quad . \quad . \quad . \quad . \quad . \quad . \quad . \quad . \quad .5-2$

5.1 .2 Impact . . . . . . . . . . . $5-2$

5.1 .3 Crush $. \quad . \quad . \quad . \quad . \quad . \quad . \quad . \quad . \quad . \quad .5-4$

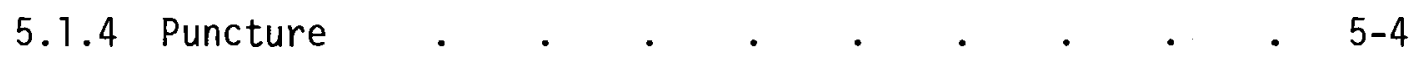

6.0 CHLORINE TANK CAR FAILURE THRESHOLDS . . . . . . . . . $6-1$

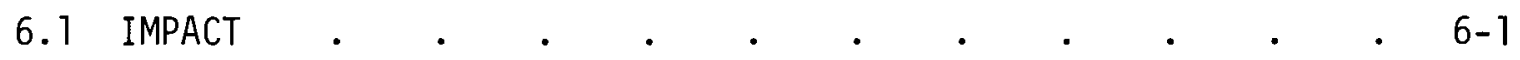

6.2 PUNCTURE . . . . . . . . . . . . . . $6-2$

6.3 CRUSH . . . . . . . . . . . . . . . . $6-2$

6.4 THERMAL $. \quad . \quad . \quad . \quad . \quad . \quad . \quad . \quad . \quad . \quad .6-3$

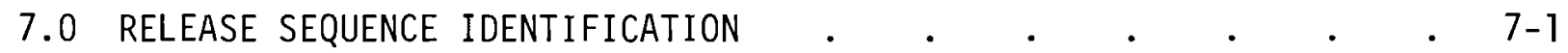

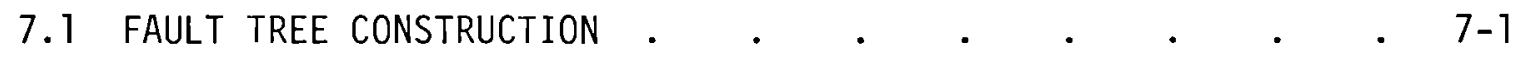

7.2 FAULT TREE FOR SHIPMENT OF LIQUID CHLORINE BY RAIL . . 7-3

7.3 RELEASE SEQUENCES . . . . . . . . . . . .

8.0 RELEASE SEQUENCE EVALUATION

8.1 BASIC EVENT PROBABILITIES .

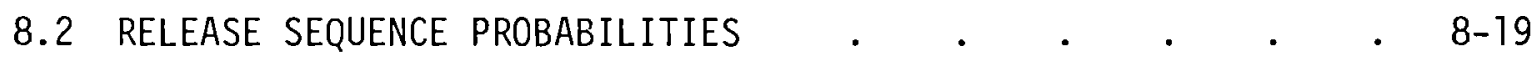

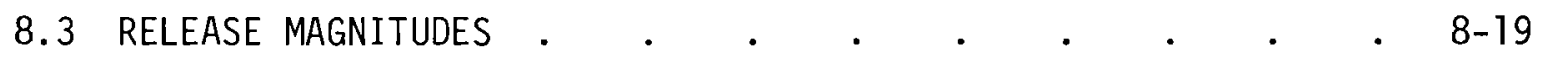


9.0 EVALUATION OF THE CONSEQUENCES OF CHLORINE RELEASES . . . 9-1

9.1 HEALTH EFFECTS . . . . . . . . . . . . . . . $9-1$

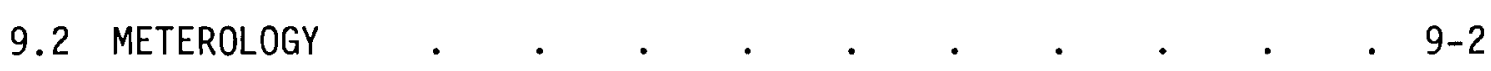

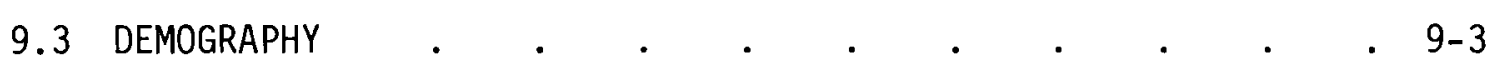

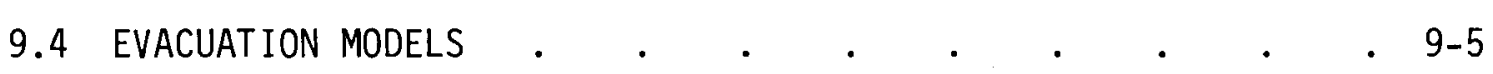

9.5 ATMOSPHERIC DISPERSION MODEL . . . . . . . . . . 9-11

9.6 ESTIMATED EXPOSURE FREQUENCY • • . . . . • . . . 9-12

9.7 PROBABILISTIC CONSEQUENCES OF CHLORINE RELEASES . • . . 9-16

10.0 THE RISK OF SHIPPING LIQUID CHLORINE BY RAIL . . . . 10-1

10.1 RISK EVALUATION FOR CHLORINE SHIPMENTS . . . . . . 10-1

10.2 RISK SENSITIVITY EVALUATIONS . . . . . . . . 10-5

10.3 COMPARISONS TO PREVIOUS STUDIES . . . . . . . . . 10-14

APPENDIX A--CHLORINE TANK CAR DESCRIPTION AND OPERATING PROCEDURES . A-1 APPENDIX B--PROPERTIES OF CHLORINE . . . . . . . . . . B-1 APPENDIX C--MECHANICAL AND THERMAL ANALYSIS OF 90-TON CHLORINE TANK CARS C-1 APPENDIX D--CHLORINE VAPORS RELEASED FROM 90-TON CAPACITY RAILROAD TANK

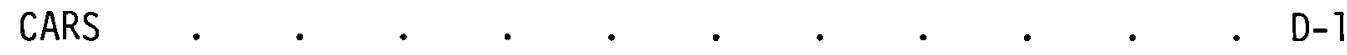
APPENDIX E--ATMOSPHERIC DISPERSION OF VAPORS FROM CHLORINE SPILLS . E-1 


\section{FIGURES}

1.1 Risk Spectrum for Chlorine Shipments by Rail in 1985 . . . . 1-3

3.1 Model to Calculate the Risk of Shipping Hazardous Material • . . • . . . . . . . 3-2

3.2 Information Required to Describe Transport System . . . . 3-5

5.1 Duration Probability of Train-Fire Accidents Involving $5-2$

5.2 Cumulative Distribution for the Expected Severity of Impact Forces in Rail Accidents . . . . . . . . 5-3

5.3 Cumulative Distribution of Total Crush Load . . . . . . 5-5

7.1 Chlorine Railcar Transportation Fault Tree . . . . . . 7-4

8.1 Remaining Steps in the Risk Evaluation . . . . . . . 8-1

9.1 Map of the U.S. Showing Census Divisions and Regions . . . 9-4

9.2 Chlorine Release Consequence Analysis . . . . . . . . 9-14

10.1 Risk Spectrum for Rail Shipments of Chlorine in 1985 . . . 10-2

10.2 Effect on Risk of Increasing the Accident Rate by a
Factor of 10.
.

10.3 Effect on Risk of Increased Frequency of Off Design Package Conditions. . . . . . . . . . 10-8

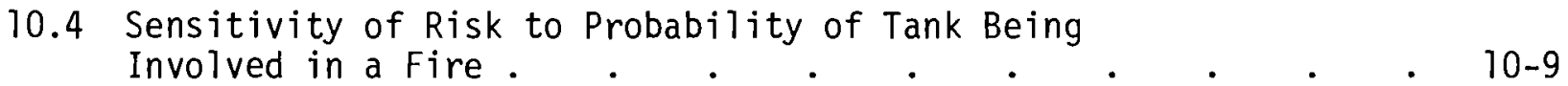

10.5 Effect on Risk of Increasing Tank Impact Resistance
by a Factor of 10.0.
.

10.6 Sensitivity of Risk to Increased Evacuation Fraction . . . 10-11

10.7 Effect on Risk of Increasing the Joint Fire/Impact Probability $10-12$

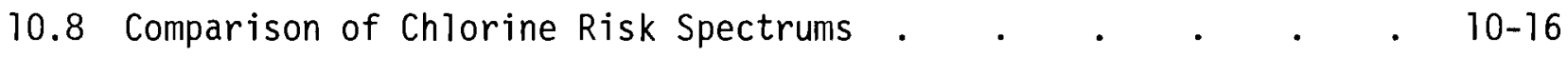

A.1 Photograph of Chlorine Tank Car . . . . . . . . A-2

A.2 Chlorine Tank Car Assembly . . . . . . . . . . . A-3 
A.3 Loading and Unloading Arrangement for Liquid Chlorine Cars . . A-4

A.4 Chlorine Institute Standard Angle Valve . . . . . . . A-6

A.5 Excess-Flow Valve for Single-Unit Tank Car . . . . . . A-7

A.6 Chlorine Institute Standard Safety Relief Valve . . . . A-7

A.7 Samples of Chlorine Tank Car Loading Check Lists . . . . A-10

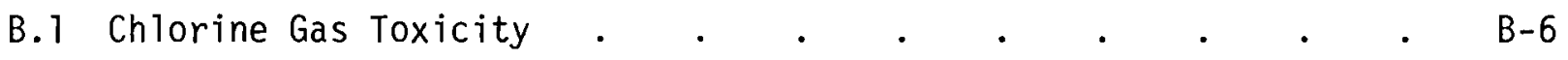

C. 1 Crush Configuration . . . . . . . . . . . . . . . C 6

C.2 Crush Load Versus Gas Void Fraction . . . . . . . . C-9

D. 1 Percent Liquid Chlorine Flashed Versus Liquid Temperature • . D-2

D.2 $\mathrm{Cl}_{2}$ - Maximum Flow of Liquid Chlorine Through Orifice • • • D-5

D.3 Rate of Pool Surface Area Growth Versus Time of Pool Liquid
Input for $2.54 \times 10-2 \mathrm{~m}(1 \mathrm{in.})$ Deep Pool
. 


\section{$\underline{T A B L E S}$}

1.1 Individual Risk from Various Accidents and Natural

Disasters . . . . . . . . . . . 1-4

4.1 Chlorine Rail Shipment Distances . . . . . . . 4-1

5.1 Frequency of Various Rail Car Collision Types, Given that

a Collision has 0ccurred . . . . . . . . 5-4

5.2 Probability of Puncture . . . . . . . . . 5-5

7.1 Fault Tree Symbolism . . . . . . . . . 7-2

7.2 Listing of Basic Events for Chlorine Rail Car
Transportation Fault Tree . . . . . 7-17

7.3 Listing of Gate Logic Rectangle Labels for

Chlorine Rail Car Transportation Fault Tree . . . . . 7-19

7.4 Listing of Chlorine Rail Car Transportation Fault

Tree Release Sequences . . . . . . . . . 7-21

8.1 Release Sequence Probabilities . . . . . . . 8-20

8.2 Release Magnitudes for Chlorine Tank Car Failure . . . 8-22

9.1 Average Windspeed/Stability Characteristics . . . . . 9-3

9.21974 Census Data . . . . . . . . . . . . . 9-6

9.3 Projected 1985 Census Data . . . . . . . . . . 9-7

9.4 Average Sizes of Urban Places in the U.S. - 1985 . . . . 9-8

9.5 Transportation Related Evacuations . . . . . . 9-9

9.6 Predicted Regional Evacuation Times . . . . . . 9-10

9.7 Probabilistic Chlorine Fatalities . . . . . . . 9-16

10.1 Individual Risk From Various Accidents and Natural
Disasters . . . . . . . . . . . . . 10-4

10.2 Sensitivity of the Expected Number of Fatalities from
Chlarine Releases to the Value of Various System Parameters . 10-6

10.3 Chlorine Risk from Five Analysis . . . . . . . 10-15 
B. 1 Properties of Saturated Liquid and Vapor Chlorine . . . B-3

B.2 Properties of Superheated Chlorine Vapor . . . . . . . B-4

B.3 Specific Heat Data for Chlorine . . . . . . . . . B-5

E.1 Dispersion Parameters for an Instantaneous Chlorine Release . E-5

E.2 Dispersion Parameters for a Continuous Chlorine Release . . E-6

E.3 Furthest Extent and Area of Hazardous Concentrations:

Relief Valve Venting Liquid Temperature $155^{\circ} \mathrm{F}(9.8 \mathrm{~kg} / \mathrm{s})$. . E-8

E.4 Furthest Extent and Areas of Hazardous Concentrations: Continuous Gas Release $(3.9 \mathrm{~kg} / \mathrm{s})$. . . . . . . E-9

E.5 Furthest Extent and Areas of Hazardous Concentrations: Tank Collapse; Liquid Temperature $70^{\circ} \mathrm{F}(17 \%$ release $)$. . . E-10

E.6 Furthest Extent and Areas of Hazardous Concentrations: Tank Collapse; Liquid Temperature $155^{\circ} \mathrm{F}$ (32\% release) . . . E-11 


\subsection{SUMMARY}

This report presents the risk of shipping liquid chlorine by rail. This is the eighth in a series of reports on the risks of transporting energy materials. While chlorine is not an energy material, there are several benefits to studying chlorine transportation risks. First, chlorine, like energy materials, is widely used as a feedstock to industry. Second, it is the major purification agent in municipal water treatment systems and therefore, provides direct benefits to the public. Finally, other risk assessments have been completed for liquid chlorine shipments in the U.S. and Europe, $(1,2,3)$ which provide a basis for comparison with this study. None of the previous PNL energy material risk assessments have had other studies for comparison. For these reasons, it was felt that a risk assessment of chlorine transportation by rail could provide information on chlorine risk levels, identify ways to reduce these risks and use previous studies on chlorine risks to assess the strengths and weaknesses of the PNL risk assessment methodology.

The risk assessment methodology used in this study was developed in the first report in this series. ${ }^{(4)}$ The methodology is summarized in Section 3. The methodology is presented in the form of a risk assessment model which is constructed for ease of periodic updating of the data base so that the risk may be reevaluated as additional data become available. The report is sectioned to correspond to specific analysis steps identified in the model. The transport system and accident environment are described in Sections 4 and 5. The response of the transport system to accident environments is described in Section 6. Release sequences are postulated in Section 7 and evaluated in Sections 8 through 10 to determine both the likelihood and possible consequences of a release. Supportive data and analyses are given in the appendices.

The risk assessment results are related to the year 1985 to allow a direct comparison with other reports in this series. For the assessment certain assumptions about the chlorine shipping industry were made. These assumptions included:

- $70 \%$ of all liquefied chlorine shipments are made by rail.

- All shipments are made in a DOT specification 105A500W tank car. 
- The rail shipment volume of chlorine increases at an average of $3.5 \%$ per year from 1976-1985.

Based on these assumptions the following industry characteristics for 1985 were calculated:

- Total liquid chlorine shipped by rail in $1985-4.49 \times 10^{9} \mathrm{~kg}$.

- Average shipment quantity $-8.2 \times 10^{4} \mathrm{~kg}$ (90 tons).

- Average shipment distance - $450 \mathrm{~km}$.

Based on these shipping assumptions and a train accident rate of $6.2 \times 10^{-6}$ per kilometer, ${ }^{(5)}$ it is estimated that trains carrying chlorine tank cars will be involved in 150 accidents in 1985. It is further estimated that 1.8 of these accidents will result in a release of a substantial amount of the chlorine. The expected number of fatalities from the chlorine releases in 1985 is 9.4 .

The risk spectrum for shipment of chlorine by rail is presented in Figure 1.1. The risk spectrum is a plot of the expected frequency (in events/yr) of events versus the number of fatalities that are predicted from those events. The curve is produced by summing event frequencies for various levels of consequences. The curve shows that, for the 1985 shipping levels used in the analysis, about one accident per year will occur, which results in one or more fatalities from the release of chlorine. Accidents that produce ten or more fatalities are estimated to occur at a rate of $5.8 \times 10^{-2}$ per year, or one accident in about 17 years. The risk curve shows that an event resulting in one or more deaths can be expected each year from chlorine releases, but that larger consequence events occur relatively infrequently. The maximum number of fatalities as a result of a chlorine release is less than 1,000. Chlorine shipping risks are compared to other risks in society in Table 1.1. The table illustrates that the annual probability of death for any individual in society from chlorine shipments is much less than the risk from lightning or tornadoes and comparable to risks from air crashes to persons on the ground.

A comparison of this report to historic accident experience shows this report to predict a greater incidence of chlorine releases and public fatalities than have actually occurred. The frequency of minor releases (those of 


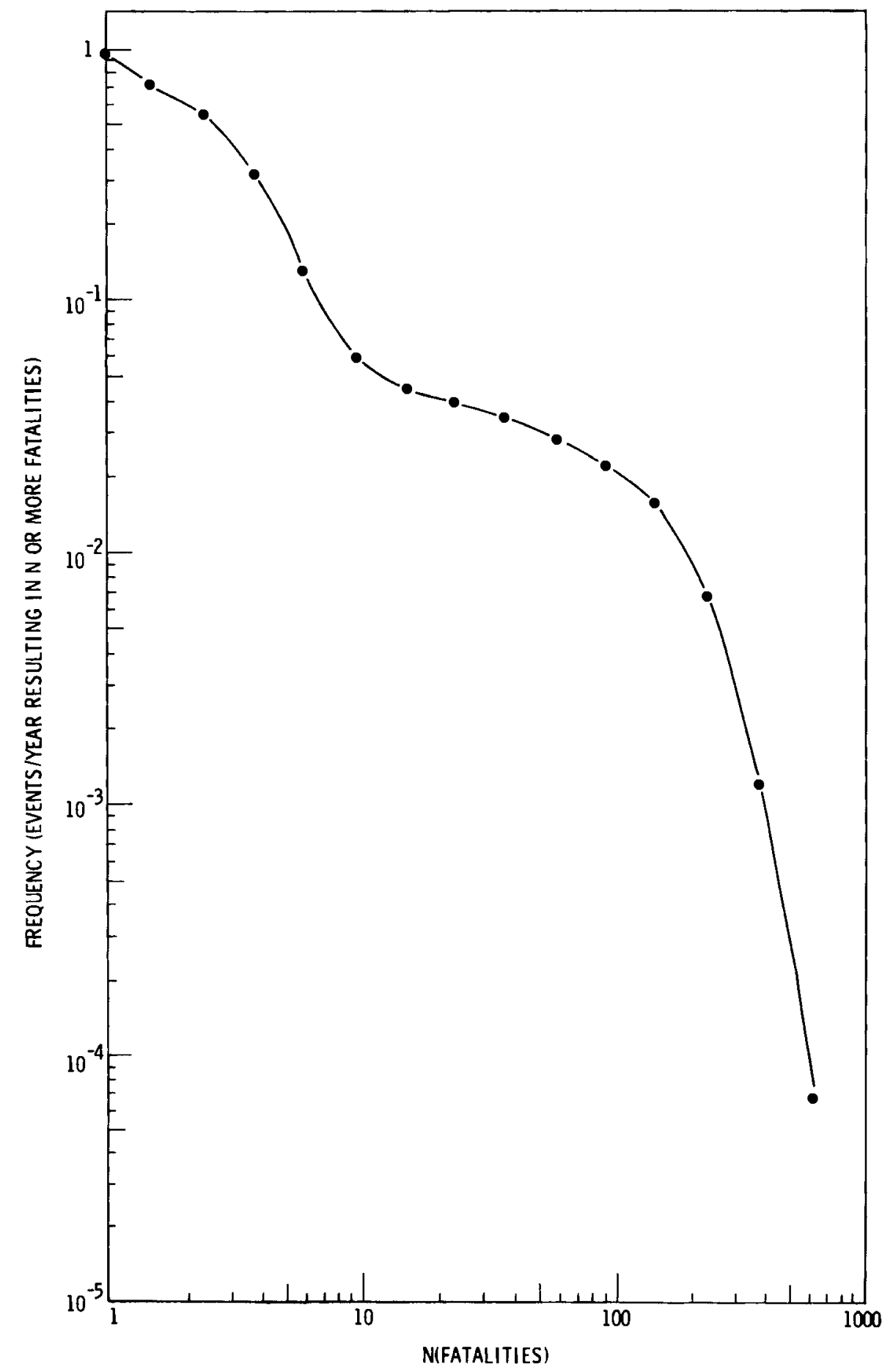

FIGURE 1.1. Risk Spectrum for Chlorine Shipments by Rail in 1985 
TABLE 1.1. Individual Risk from Various Accidents and Natural Disasters(a)

\section{Accident Type}

A11 Accidents

Motor Vehicle Accident

A11 Industrial Accidents $(b)$

Falls

Drowning

Fires

Poisoning

Airplane Crashes

Railway Accidents

Lightning (d)

Tornadoes (e)

Dam Failures (d)

Gasoline Tank Truck Accidents $(f)$

Propane Transportation Accidents $(g)$

Chlorine Rail Car Accidents $(h)$

Air Crashes (persons on ground) $(e)$

\section{Total Fatalities Individual Risk per Year}

$\begin{array}{cl}115,821 & 1 \text { in } 2,000 \\ 55,511 & 1 \text { in } 4,000 \\ 14,100 & 1 \text { in } 6,000 \text { (c) } \\ 16,506 & 1 \text { in } 13,000 \\ 7,152 & 1 \text { in } 29,000 \\ 6,503 & 1 \text { in } 32,000 \\ 5,335 & 1 \text { in } 40,000 \\ 1,668 & 1 \text { in } 130,000 \\ 789 & 1 \text { in } 250,000 \\ 160 & 1 \text { in } 1,300,000 \\ 90 & 1 \text { in } 2,300,000 \\ 35 & 1 \text { in } 5,700,000 \\ 28 & 1 \text { in } 7,400,000 \\ 15 & 1 \text { in } 15,000,000 \\ 9.4 & 1 \text { in } 22,300,000 \\ 6 & 1 \text { in } 33,000,000\end{array}$

(a) Data from Reference 6 unless otherwise indicated.

(b) Reference 7.

(c) Only workers included in population at risk.

(d) Reference 8.

(e) Reference 7. Average value for several years.

(f) in 1980. (Reference 9)

(g) in 1985. (Reference 10)

(h) in 1985.

no significant consequences) is about $80 \%$ less than data in this report predict. The actual frequency of significant sizes is about $20 \%$ less than this report. Fatalities predicted by this report are about ten times historic levels. Conservative assumptions made in the calculation of consequences due to chlorine releases are the main cause of this discrepency. For example, the effectiveness of population evacuation models used in this report is low compared to the limited actual experience. Risk levels are inversely proportional to this assumption. 
Sensitivity studies were performed to determine the most important contributors to risk. It was found that tank shell failures due to impact accidents produce over $90 \%$ of the chlorine transportation risk. Three possible design changes to reduce risk from chlorine releases in tank car accidents were investigated. The first method involved making the tank 10 times more resistant to impact failures. This reduced the expected number of fatalities to 4.3 per year. The second method postulated the addition of head shields to improve head puncture resistance. Shields conforming to requirements in 49 CFR $179.100-23$ are predicted to reduce risk by $4 \%$. The third method postulated was replacing existing pressure relief valves with a higher capacity model to prevent over-pressurization during overturn fire accidents. This design change had no observable effect on risk.

A comparison of results of this study with results of previous chlorine risk studies showed this study to be less conservative than studies of similar systems, but more conservative than studies of European designed systems. These comparisons, however, are limited to expected consequences because historic accident data and methodologies used in the other studies do not provide complete risk spectrums or information on major contributors to risk.

Judgments about the acceptability of the risks from shipping chlorine by rail are beyond the scope of this analysis, but the information presented here can provide input to such decisions. The analysis has shown that the risk from chlorine shipments is less than many other commonly accepted risks to society. As mentioned before, there is a clear health and material benefit to society from the use of chlorine. The risks and benefits are spread throughout society so that the population exposed to risk also receives the benefits. Any analysis of this type is generally conservative; i.e., the calculated risk is usually somewhat higher than the actual risk might be if it could be measured. This is a result of assumptions and simplifications made to make the analysis tractable. Every attempt has been made to make these assumptions as realistic as possible, but lacking information, a generally conservative assumption was made. Sensitivity studies were used to test the effect of key assumptions on the analysis results. It is felt that the results presented are the most realistic possible using existing information. 


\section{REFERENCES}

1. R. Lautkaski and T. Mankamo, Chlorine Transportation Risk Assessment. Technical Research Centre of Finland, October 1976.

2. J. A. Simmons, R. C. Erdmann and B. A. Naft, "Risk Assessment of Large Spills of Toxic Materials." Science Applications Inc., McLean, VA, From: Control of Hazardous Material Spills, Proceedings of the 1974 Natural Conference on Control of Hazardous Material Spills, American Institute of Chemical Engineers, San Francisco, CA, August 25-28, 1974.

3. G. W. Westbrook, The Bulk Distribution of Toxic Substances: A Safety Assessment of the Carriage of Liquid Chlorine. Management Services Department Mond Division, Imperial Chemical Industries Limited, The Heath, Runcorn, Cheshire, England, 1974.

4. T. I. McSweeney, R. J. Hall et al., An Assessment of the Risk of Transporting Plutonium Oxide and Liquid Plutonium Nitrate by Truck. BNWL-1846, Pacific Northwest Laboratory, Richland, WA, 1975.

5. A. W. Dennis et al, Severities of Transportation Accidents Involving Large Packages. SAND77-0001, Sandia Laboratories, A1buquerque, NM, May 1978.

6. U.S. Bureau of the Census, Statistical Abstract of the United States: 1975. U.S. Department of Commerce, Washington DC, p. 66, 1975.

7. Accident Facts 1973. National Safety Council, Chicago, IL, 1974.

8. Reactor Safety Study. WASH-1400, U.S. Nuclear Regulatory Commission, Washington DC, October, 1975, p. 3.

9. R. E. Rhoads et al., An Assessment of the Risk of Transporting Gasoline by Truck. PNL-2133, Pacific Northwest Laboratory, Richland, WA, November 1978.

10. C. A. Geffen et a1., An Assessment of the Risk of Transporting Propane by Truck and Train, PNL-3308, Pacific Northwest Laboratory, Richland, WA, September 1980.

11. Code of Federal Regulations. Title 49, Part 179, U.S. Government Printing Office, Washington DC. 


\subsection{INTRODUCTION}

To insure the health and safety of the general public, industry and government agencies are continually improving their level of understanding of the safety-related aspects of transporting energy materials. Research programs are one method of improving the level of understanding. Such a research program is being conducted by Pacific Northwest Laboratory for the Environmental Control Technology Division in the Department of Energy. The objective of this continuing program is to develop a methodology for quantitatively assessing the safety of transporting energy materials and to apply it to current and future shipping systems. Risk analysis was the technique selected for this assessment. Through analysis of risk, consequences of postulated releases of energy materials during transport can be put into perspective by viewing the events relative to their frequency of occurrence.

Risk, as used in the context of this report, is the product of the magnitude of a possible loss and the frequency of occurrence of the loss. There are two measures of the risk that are of importance in a risk assessment. The first is the total risk, obtained by summing risks for all potential losses associated with hazardous material releases from the system. In order to perform the summation, all risks have to be expressed with respect to the same time interval (e.g., per year). Although the total risk is an important measure, it gives only the loss that would be expected on the average during the reference time interval. The range of losses which could be experienced is not discernable. For example, the risk associated with an accident that occurs once a year and results in one fatality is the same (i.e., one fatality/ year) as that from an accident which occurs once in ten years but results in ten fatalities. In a plot of the estimated frequency of $N$ or more fatalities as a function of $N$, these two accidents would appear as discrete points. The second measure of risk is a curve called a risk spectrum, which is generated by connecting such points. The risks associated with two activities are similar only if they have the same total risk (risk magnitude) and the same risk spectrum. Both risk measures are used in this report. 
This risk methodology was initially applied to the shipment of plutonium $(1,2,3)$ and has subsequently been applied to the shipment of spent fuel, ${ }^{(4)}$ uranium hexafluoride, ${ }^{(5)}$ gasoline ${ }^{(6)}$ and propane. (7)

This report has two purposes: 1) to assess the risk of shipping liquid chlorine by rail and present the general risk methodology; and 2) to compare the results of this study with other reports which calculate chlorine risk values. This comparison will serve as an indicator of the relative strengths and weaknesses of the methodologies used.

\section{REFERENCES}

1. T. I. McSweeney, R. J. Hall et al., An Assessment of the Risk of Transporting Plutonium Oxide and Liquid Plutonium Nitrate by Truck. BNWL-1846, Pacific Northwest Laboratory, Richland, WA 99352, August 1975.

2. R. J. Hall et al., An Assessment of the Risk of Transporting Plutonium Dioxide and Liquid Plutonium Nitrate by Train. BNWL-1996, Pacific Northwest Laboratory, Richland, WA, February 1977.

3. T. I. McSweeney and J. F. Johnson, An Assessment of the Risk of Transporting Plutonium Dioxide by Cargo Aircraft. BNWL-2030, Pacific Northwest Laboratory, Richland, WA, July 1976.

4. H. K. Elder et al., An Assessment of the Risk of Transporting Spent Nuclear Fuel by Truck. PNL-2588, Pacific Northwest Laboratory, Richland, WA, November 1978.

5. C. A. Geffen, J. F. Johnson et a1., An Assessment of the Risk of Transporting Uranium Hexafluoride by Truck and Train. PNL-2221, Pacific Northwest Laboratory, Richland, WA, August 1978.

6. R. E. Rhoads et a 1., An Assessment of the Risk of Transporting Gasoline by Truck. PNL-2133, Pacific Northwest Laboratory, Richland, WA, November 1978.

7. C. A. Geffen et a1., An Assessment of the Risk of Transporting Propane by Truck and Train. PNL-3308, Pacific Northwest Laboratory, Richland, WA, September 1980. 


\subsection{RISK ANALYSIS MODEL}

Risk, as used throughout this report, is defined as the likelihood of occurrence of an event and the consequences of that event. The risk model described in this section has been developed from methodologies used in prior risk assessments. A detailed description of the risk model used in this report is provided in Reference 1. The model was developed to evaluate the risk of transporting radioactive materials. By generalizing some of the component designations, it has been applied here to shipments of liquid chlorine.

\subsection{RISK MODEL DESCRIPTION}

The risk assessment model provides a systematic method for handling the data germane to analys is of the safety of the transport environment. The steps involved in applying the methodology are illustrated in Figure 3.1. The figure shows the logic process that is followed in developing the information required to perform the actual risk assessment.

The model uses one fundamental equation:

$$
R=\sum_{\mathbf{i}} R_{\mathbf{i}}
$$

The total system risk $R$ is the sum of the risks of all accidental releases as denoted by the subscript $i$. Only accidental releases are considered in the mode1. The risk of an individual release is the product of the consequences of the release and the probability of its occurrence. The equation could be expanded into a single, long, complex equation. In the current formulation of the mode1, each term in Equation 3-1 is expanded into two expressions which have more physical significance. The expanded equation for $R_{i}$ is:

$$
R_{i}=P_{R_{i}} \times \underset{q}{\sum} C_{E_{i, q}} \times P_{E_{q}}
$$




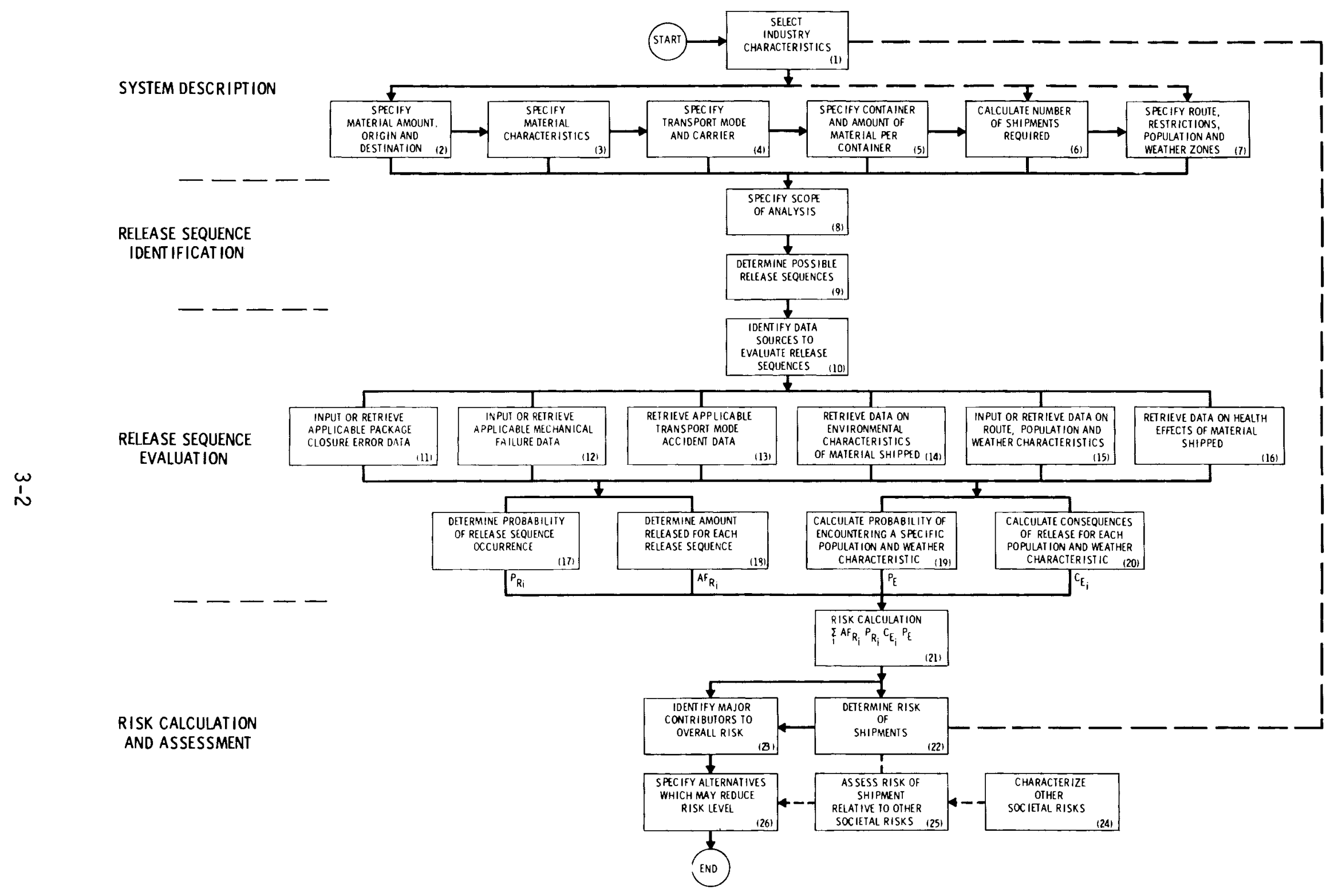

FIGURE 3.1. Model to Calculate the Risk of Shipping Hazardous Material 
The first factor, $\mathrm{P}_{\mathrm{R}_{\mathbf{i}}}$, is the probability that the release sequence will happen during transport. The amount and rate of material released is a characteristic of each release sequence.

The factor $C_{E_{j}, q}$ in the second part of Equation $3-2$ is the consequence of the material release described by the first factor. The subscript $q$ is added to show that the factor is a function of the specific weather conditions existing at the time of the release and the population exposed to the release. The final factor, $P_{E_{q}}$ is the probability of encountering a particular set of weather conditions within a specific population zone. The expression $\sum_{q}\left(C_{E_{i}, q} \times P_{E_{q}}\right)$ can be thought of as the consequences of material release under probabilistically weighted weather conditions and population distributions.

Equation $3-2$ is the basic equation in the risk model. Four basic steps are followed in the evaluation of this equation:

- System Description

- Event Sequence Identification

- Event Sequence Evaluation

- Risk Calculation and Assessment.

The relationship between these steps is shown in Figure 3.1. A discussion of the type of information developed and analys is performed in each of these steps is presented below.

\subsubsection{System Description}

The basic information on the shipping system to be analyzed is collected in this step. The industry being studied is characterized by gathering data on facility locations and industry shipping requirements. The type of material shipped, the shipping packages used, and the shipment quantities are determined for each transport mode used in the industry. Information on the physical and chemical properties of the materials transported is collected and the population distributions and weather characteristics along the shipping routes are characterized. As shown in Figure 3.1, this process has seven components. 
1. Select Industry Characteristics

2. Specify Material Amount, Origin and Destination

3. Specify Material Characteristics

4. Specify Transport Mode and Carrier

5. Specify Container and Amount of Material per Container

6. Calculate Number of Shipments Required

7. Specify Route, Restrictions, Population and Weather Zones.

Figure 3.2 shows the type of information called for by these components to describe the chlorine shipping system.

\subsubsection{Release Sequence Identification}

Activities during this step identify possible sequences of events that can result in consequences to transportation workers or the general public during transportation of the hazardous materials being studied. The limits of the analysis are defined before these activities begin by specifying the kinds of events that will be considered during the event sequence identification step. For example, in this step one specifies whether loading and unloading accidents will be considered or if acts of sabotage are within the scope of the analysis.

Several methods are available for identifying event sequences. These methods are summarized briefly below. The method selected for application to a particular system depends on the complexity of the system, how comprehensive the analysis must be, and the availability of data to evaluate the event probabilities. A combination of these methods may also be employed.

- Historical Data/Experience. Sequences of events leading to a system failure are identified from historical data on accidents that have occurred with the shipping system being studied or similar systems.

- Direct Postulation. Event sequences are identified based on the judgment of an experienced analyst who examines the shipping system and postulates the failure modes directly. 


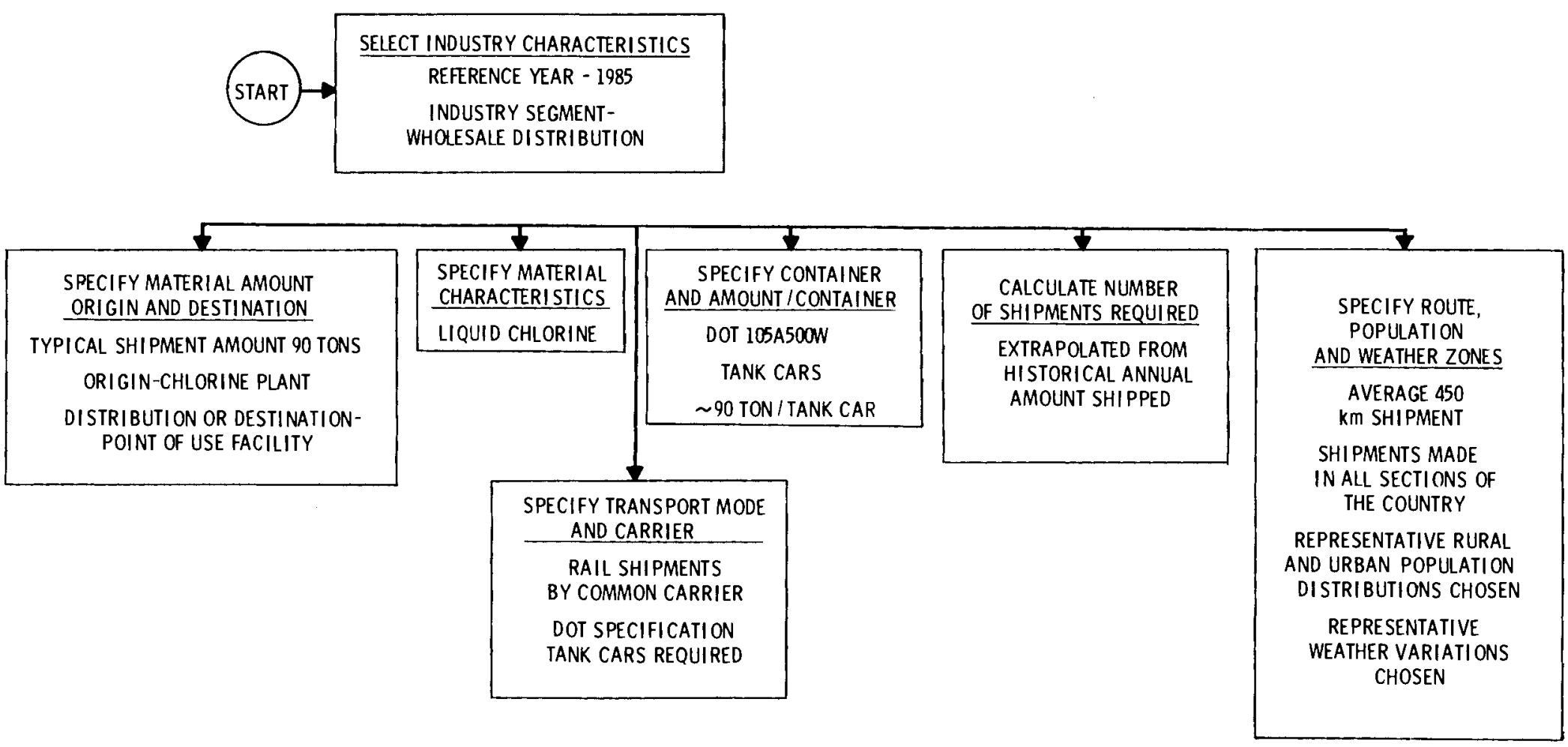

FIGURE 3.2. Information Required to Describe Transport System 
- Deductive Reasoning. This is the "how can this happen" approach. Event sequences are identified by assuming that the undesired event has occurred and working backward to identify the sequences of events that must occur to cause this system failure. Fault tree analysis is a formalized way of performing these deductive reasoning processes.

- Inductive Reasoning. This is the "what happens if" approach. Event sequences are identified by starting with a system component failure and identifying the sequence of succeeding events that lead to a system failure. Event tree analysis is a formalized method for performing those reasoning processes.

For the present analysis, consideration is given only to the risks from failure sequences resulting from transportation accidents involving filled tank cars. The possible release sequences within the scope of the assessment are identified by the use of fault tree analysis and historical accident data.

\subsubsection{Release Sequence Evaluation}

This step consists of two basic parts: 1) estimation of event sequence probabilities; and 2) evaluation of the potential consequences of each event sequence. Event sequence probabilities are obtained by estimating the probability of each of the events that must occur to produce a system failure. This requires either historical data or development of information on the response of the shipping system to normal and transport accident forces (to determine the level of forces required to produce a system failure) and knowledge of the forces. Mathematical analysis or data available from testing programs are generally used to determine system failure thresholds. This can be combined with accidental environment data such as that developed at Sandia Laboratories $(2)$ or statistical analysis of other accident data to determine failure probabilities. Section 9 of this report details this analysis for the chlorine shipping system.

The consequences of a system failure depend on the type of failure that has occurred, the location of the failure along the shipping route and the 
weather and population conditions at the time of failure. The consequences of the failure sequences may be determined by mathematical modeling, from historical accident data and/or from information on tests that have been conducted with the material being shipped. In general, consequences must be evaluated for each type of failure that can occur for each combination of weather condition and population distribution that can be encountered along the route. The probability of encountering the various population distributions and weather conditions along the route must also be determined.

The model uses relevant historical information to evaluate the probability of experiencing a given set of weather conditions and population characteristics. The $P_{E}$ term in Equation 3-2 is the probability associated with the weather and population characteristics. The expanded form of this term is given:

$$
P_{E_{j, k, 1}}=P_{j / k} \times P_{k} \times P_{1}
$$

The subscripts $j, k$, and 1 refer to the multiplicity of environmental conditions which could exist at the location of the accident. The variable $P_{j / k}$ is the probability of experiencing the $j^{\text {th }}$ atmospheric stability classification when the $k^{\text {th }}$ windspeed exists. The variable $P_{k}$ is the probability of encountering the $k^{\text {th }}$ windspeed category. The variable $P_{1}$ is the probability of encountering a specified population distribution.

\subsubsection{Risk Calculation and Assessment}

The information developed in the previous steps is used to calculate the risk for the shipping system being studied. Both the total risk and a risk spectrum are calculated. The results are then analyzed to determine the primary contributors to the risk and to specify and evaluate alternatives that could reduce the system risk, if the current risk is judged by society to be unacceptable. Since the information to perform the risk assessment has been developed in discrete data blocks, sensitivity studies can also be carried out to test the effect on the system risk of assumptions and approximations 
that were made to develop key pieces of information. This may identify areas where further analysis is required or delineate the limitations of the assessment.

In this report, the risk of transporting liquid chlorine by rail will be calculated and then compared with other accidental risks. The results of this study will also be compared to previously reported risk analyses on transporting other hazardous materials. Such comparisons place the risks of shipping liquid chlorine in perspective.

\section{REFERENCES}

1. T. I. McSweeney, R. J. Hall et al., An Assessment of the Risk of Transporting Plutonium 0xide and Liquid Plutonium Nitrate by Truck. BNWL-1846, Pacific Northwest Laboratory, Richland, WA, August 1975.

2. A. W. Dennis et al., Severities of Transportation Accidents Involving Large Packages. SAND77-0001, Sandia Laboratories, A7buquerque, NM, May 1978. 


\subsection{CHLORINE SHIPPING REQUIREMENTS}

Liquid chlorine is typically shipped from the production plants to distribution plants and points of end use by truck, barge, or rail tank car. The rail transportation step is considered in this analysis. The Chlorine Institute Inc. indicates that between 1970 and 1976, the volume of liquid chlorine shipped increased from $3.54 \times 10^{9} \mathrm{~kg}$ to $4.78 \times 10^{9} \mathrm{~kg}$. Extrapolating this trend through 1985 predicts an annual shipment volume of $6.41 \times 10^{9} \mathrm{~kg}$. It was further estimated by the Chlorine Institute Inc. that $70 \%$ of this volume will be shipped by rail tank car. An annual rail shipment volume of $4.49 \times 10^{9} \mathrm{~kg} /$ year for 1985 was used in this study.

To determine the distances and volumes of chlorine shipped in different regions of the country, $1 \%$ waybill statistics were used. (1) Annual shipment volumes and mileage traveled in each of nine census regions were compiled. This was done by summing intra-regional shipments with inter-regional shipments. Inter-regional shipments contributed mileage to regions along the route and in the destination region. Table 4.1 (column 3) shows $2.19 \times 10^{7}$ car- $\mathrm{km}$ for 1976. An average loaded trip length of $450 \mathrm{~km}$ was reported.

TABLE 4.1. Chlorine Rail Shipment Distances

\begin{tabular}{lrrrr}
\multicolumn{1}{c}{ Region } & \% of Total $\mathrm{km}$ & & $\frac{1976(\mathrm{~km})}{1985(\mathrm{~km})}$ \\
\cline { 1 - 3 } Pacific & 12 & & $2.61 \times 10^{6}$ & $2.96 \times 10^{6}$ \\
Mountain & 5 & & $1.09 \times 10^{6}$ & $1.23 \times 10^{6}$ \\
West North Central & 3 & & $6.53 \times 10^{5}$ & $7.40 \times 10^{5}$ \\
West South Central & 27 & & $6.10 \times 10^{6}$ & $6.66 \times 10^{6}$ \\
East North Central & 12 & & $2.61 \times 10^{6}$ & $2.96 \times 10^{6}$ \\
East South Central & 12 & & $2.61 \times 10^{6}$ & $2.96 \times 10^{6}$ \\
South Atlantic & 23 & & $5.00 \times 10^{6}$ & $5.67 \times 10^{6}$ \\
Middle Atlantic & 5 & & $1.09 \times 10^{6}$ & $1.23 \times 10^{6}$ \\
New England & 1 & & $2.17 \times 10^{5}$ & $\underline{2.47 \times 10^{5}}$ \\
$\quad$ Total & 100 & & $2.19 \times 10^{7}$ & $2.47 \times 10^{7}$
\end{tabular}


According to Reference 2, over half of all railcars in current chlorine service have a capacity of $7.7 \times 10^{4}$ to $8.2 \times 10^{4} \mathrm{~kg}$ ( 85 to 90 tons). The current trend is toward building only these large cars. For these reasons, the 1985 shipping fleet was assumed to consist of only $8.2 \times 10^{4} \mathrm{~kg}$ (90 ton) cars. A total of $5.48 \times 10^{4}$ shipments will be required using this car in 1985. The fleet of larger cars were assumed to have an average loaded trip length near current levels. Thus increasing fleet size reduces the number of car-km traveled per $\mathrm{kg}$ of chlorine. Table 4.1 (column 4) shows projected car-km for each region after adjustments for car size and shipping volumes. Risk is generally proportional to the number of car-km that are traveled.

The reference shipping system for this study is a 90-ton car built to DOT specification 105A500W. The car is basically a cylindrical pressure vessel measuring $12.4 \mathrm{~m}$ by $2.6 \mathrm{~m}$. Draft sills which contain the braking mechanisms for the trucks and other running gear are attached to the ends of the car. Loading, unloading and relief valves are located on the top of the car. A heavy steel dome is provided to protect the valves from impact. The dome also covers a manway cover, which allows access to the tank interior for inspection and maintenance. The entire chlorine tank car is insulated for protection in a fire environment. A detailed description of the reference railcar is in Appendix A.

\section{REFERENCES}

1. U.S. Bureau of the Census, Census of Transportation, 1972. Volume III, Commodity Transportation Survey, U.S. Government Printing Office, Washington DC, 1976.

2. Summary of North American Tank Cars. The Chlorine Institute, Inc., New York, NY, September 1977. 


\subsection{TRANSPORTATION ACCIDENT ENVIRONMENT}

Failure of a chlorine rail tank car during an accident occurs when the forces generated in the accident either exceed the mechanical strength of the container affected or activate controlled release mechanisms like a pressure relief valve. This section discusses the forces or stresses that may be generated in rail accident environments. Section 6.0 discusses the mechanical strength of the chlorine tank cars and their controlled release features. The use of information from Sections 5.0 and 6.0 to estimate the likelihood of container failure in an accident is demonstrated in Section 8.0.

The rail accident environment data summarized here were developed by Sandia Laboratories. (1) These data represent the most comprehensive accident environment information currently available. In Sandia's analysis, the accident environment is categorized by five accident stresses: impact, crush, puncture, fire, and immersion. Impact forces act over periods of a few milliseconds whereas crush forces can exist for several seconds following the accident. Impact forces are applied to one side whereas crush forces are applied from several directions. Impact and crush forces are adequately differentiated by comparing the force exerted by a hammer blow to the same force exerted by a press. Puncture stresses occur when a container is struck by an object that has potential for penetrating the container. Immersion failure of chlorine tank cars was not considered in this analysis because the low probability of this failure mechanism makes it a negligible contributor to the system risk.

The following paragraphs briefly summarize the Sandia results. The likelihood of an accident is discussed first. Sections discussing the fire, impact, crush and puncture environments follow.

\subsection{TRAIN ACCIDENT ENVIRONMENT}

Train accidents defined by Sandia ${ }^{(1)}$ include all accidents that result in fatalities, injuries or property damage of $\$ 750$ or more. The accident rate selected by Sandia which was used in this study is $6.2 \times 10^{-6}$ train accidents per train kilometer. This rate is based on reports of freight train accidents on Class I and Class II line haul railroads in 1972. 


\subsubsection{Fire}

Sandia's accident environment study ${ }^{(1)}$ estimates the probability of a fire occurring in any train accident, to be 0.0165 . Loaded tank cars are involved in $14 \%$ of all rail fires. Sandia further determined that the average fire temperature is $1010^{\circ} \mathrm{C}\left(1850^{\circ} \mathrm{F}\right)$. Figure 5.1 is a plot of cumulative probabilities as a function of fire duration. For example, the probability of a fire lasting 60 minutes or longer is 0.15 .

\section{1 .2 Impact}

A description of the impact environment for accidents involving railcars was obtained from information supplied by Sandia Laboratories. (1) The Sandia data were produced by analyzing existing accident data to develop a cumulative distribution for the expected severity of impact forces in rail accidents.

Rail cars undergo impact forces, expressed as net velocity changes, only in the event of a collision or derailment, which represent 90 percent of all rail accidents. Other accidents were considered to be unimportant in impact analysis. The distribution of the expected severity of impact forces in rail accidents is shown in Figure 5.2.

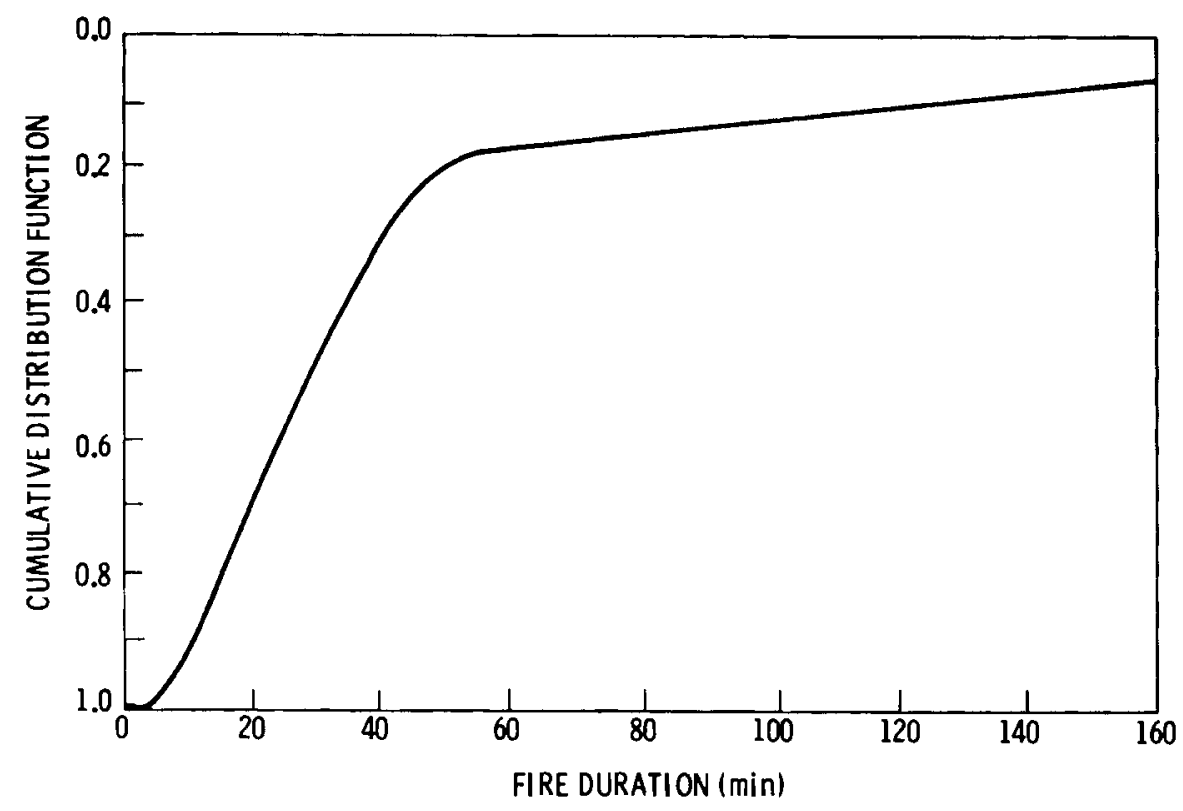

FIGURE 5.1. Duration Probability of Train-Fire Accidents Involving Large Packages (fom (Reference 1) 


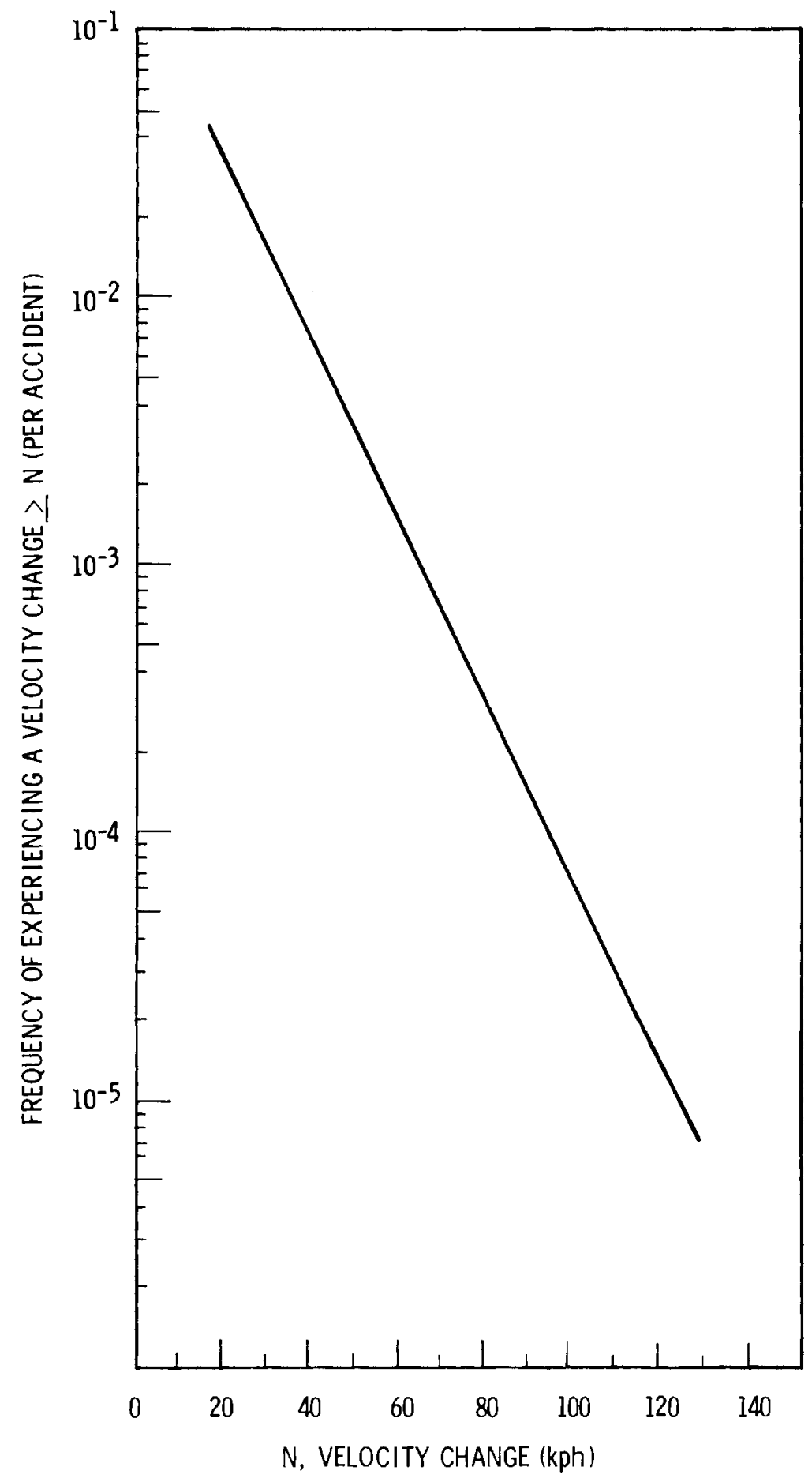

FIGURE 5.2. Cumulative Distribution for the Expected Severity of Impact Forces in Rail Accidents (Reference 1) 
The orientation of the car during impact is obtained from information presented by Sandia for rail collision accidents. The probabilities of various car positions, given a rail collision, are shown in Table 5.1. Collisions account for $7 \%$ of all accidents. It was assumed for this risk assessment that derailment accidents, which comprise $83 \%$ of all rail accidents, result in primarily end impacts. The effect of this assumption on the overall results is believed small due to similar failure thresholds for end and side impacts (see Section 6).

TABLE 5.1. Frequency of Various Rail Car Collision Types, Given that a Collision has Occurred

\begin{tabular}{|c|c|}
\hline Orientation & Probabili \\
\hline Rear-end Collision & 0.191 \\
\hline Head-on Collision & 0.067 \\
\hline Broken-train Collision & 0.157 \\
\hline Side/Raking Collision & 0.315 \\
\hline $\begin{array}{l}\text { Collision of Train or Cars } \\
\text { Not in Train }\end{array}$ & 0.27 \\
\hline
\end{tabular}

\section{1 .3 Crush}

Information on the crush environment in railcar accidents has been obtained from studies by Sandia Laboratories. (1) Crush is defined as forces on a package (the tank car) resting between the ground and a derailed car or locomotive. The probability of crush, given a derailment or collision accident, is about $2.0 \times 10^{-3}$ per car accident. The cumulative distribution of total crush load expected is given in Figure 5.3 .

\section{1 .4 Puncture}

A description of the puncture environment associated with railroad tank cars was obtained from information developed by Sandia. (1) Puncture probes represented by train couplers, are assumed present in all accident situations. Estimated probabilities of puncture are presented in Table 5.2. 


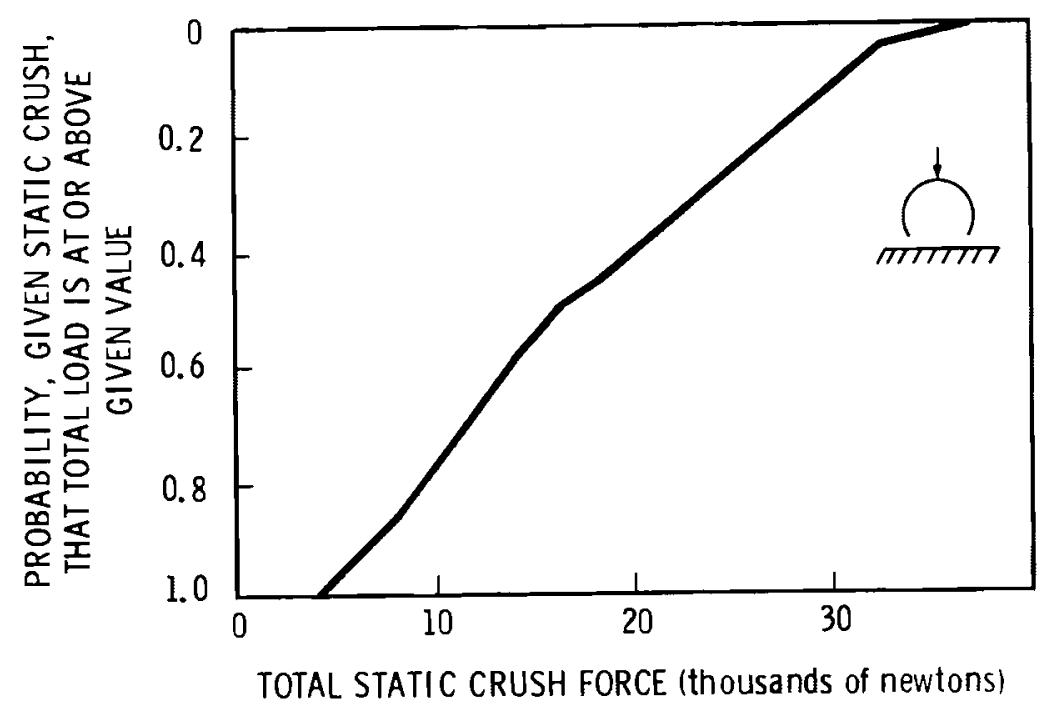

FIGURE 5.3. Cumulative Distribution of Total Crush Load (Reference 1)

TABLE 5.2. Probability of Puncture (Reference 1)

\begin{tabular}{|c|c|c|}
\hline $\begin{array}{c}\text { Package Wal1 } \\
\text { Thickness } \\
\text { (in.)(a) } \\
\end{array}$ & $\begin{array}{l}\text { Probability } \\
\text { Per Reportable } \\
\text { Accident } \\
\end{array}$ & $\begin{array}{c}\text { Probability per } \\
\text { Reportable Collision } \\
\text { or Derailment Accident }\end{array}$ \\
\hline 0.4375 & $7.41 \times 10^{-4}$ & $8.23 \times 10^{-4}$ \\
\hline 0.50 & $6.90 \times 10^{-4}$ & $7.67 \times 10^{-4}$ \\
\hline 0.75 & $5.85 \times 10^{-4}$ & $6.50 \times 10^{-4}$ \\
\hline 1.00 & $4.90 \times 10^{-4}$ & $5.44 \times 10^{-4}$ \\
\hline 1.25 & $4.18 \times 10^{-4}$ & $4.64 \times 10^{-4}$ \\
\hline 1.50 & $3.37 \times 10^{-4}$ & $3.74 \times 10^{-4}$ \\
\hline 1.75 & $2.43 \times 10^{-4}$ & $2.70 \times 10^{-4}$ \\
\hline 2.00 & $1.52 \times 10^{-4}$ & $1.69 \times 10^{-4}$ \\
\hline 2.50 & $3.15 \times 10^{-5}$ & $3.50 \times 10^{-5}$ \\
\hline 3.00 & $4.70 \times 10^{-6}$ & $5.22 \times 10^{-6}$ \\
\hline 4.00 & $5.54 \times 10^{-8}$ & $6.16 \times 10^{-8}$ \\
\hline 5.00 & $9.41 \times 10^{-12}$ & $1.05 \times 10^{-11}$ \\
\hline 6.00 & --- & --- \\
\hline
\end{tabular}

(a) 1 in. $=2.54 \mathrm{~cm}$. 


\section{REFERENCES}

1. A. W. Dennis, J. T. Foley, W. F. Hartman and D. W. Larson, Severities of Transportation Accidents Involving Large Packages. SAND77-0001, Sandia Laboratories, Albuquerque, NM, May 1978. 


\subsection{CHLORINE TANK CAR FAILURE THRESHOLDS}

The previous section describes the accident environment associated with rail transport of liquid chlorine in bulk tanks. The tank car considered in

this analysis is a DOT specification 105A500W 90-ton $\left(8.18 \times 10^{4} \mathrm{~kg}\right)$ tank car as described in Appendix A. Results of calculations of the response of the chlorine tank cars to the accident environment are summarized below. Substantiating calculations appear in Appendix C. Response to the most significant stresses imposed in rail accidents is quantified in terms of failure thresholds. A failure threshold is the level of applied thermal or mechanical stresses that produces a release of lading (chlorine) in an accident. Thresholds are related to the minimum energy (or corresponding vehicle velocity) required to produce the failure.

The most significant types of accident-imposed stresses are:

- impact

- puncture

- crush

- thermal (external fire)

The response of the chlorine tank car tank to each type of stress associated with the accident environment is calculated independently. Thermal stresses, in some cases, were considered to be applied following impact stresses. However, for other accident situations, no attempt was made to predict the lowered level of failure when the applied stresses act simultaneously or sequentially. The affect of these simplifications on the overall risk analysis was determined to be small.

The analytical approach used for prediction of response of the chlorine car is, in most cases, rather simplified. A more comprehensive analytical treatment was felt to be not warranted because of the lack of quantitative information on the rail accident environment.

\subsection{IMPACT}

To simplify the analysis, the failure threshold for impact was calculated by representing the tank as a side-or end-loaded cylinder. Cases analyzed 
were side- and end-impact of both defective and normal tanks into a target which was assumed to absorb $50 \%$ of the pre-accident kinetic energy. This was considered a reasonable assumption because the most likely impact target is another rail car of similar mass and rigidity. Minimum failure velocities are tabulated below. Defective tanks were assumed to fail due to "water hammer" effects during impact. Normal cars were assumed to fait when sufficient energy was absorbed to cause a 5\% diametral expansion in the impact zone.

End Impact
Side Impact
Minimum Velocity (kph) Minimum Velocity (kph)

Impact of a defective car

Impact of a normal car

\subsection{PUNCTURE}

Puncture failure probabilities are directly available as a function of mild steel tank wall thickness (see Section 5.0). Further analysis of puncture failures for the reference tank was not necessary.

As a sensitivity case, it was postulated that head shields are added to the tank as a means of increased puncture resistance. To use the available puncture data, it is necessary to calculate an equivalent wall thickness. This was done by equating the energy required to puncture the shield and tank head with that of a thicker tank head. This analysis resulted in postulating an increase in head thickness from the normal $2.06 \mathrm{~cm}$ to $2.93 \mathrm{~cm}$.

\subsection{CRUSH}

The crush load is assumed to be uniformly distributed along the entire length of the tank. This could result from the weight of a heavy relatively flat object; e.g., a flat car. By neglecting end effects, this analysis was assumed applicable to all crush configurations. The crush failure threshold used in this analysis is $480 \mathrm{~N} / \mathrm{cm}$ of tank length. Failure occurs when the internal tank volume is reduced by shel! deformation to the point where hydrostatic pressure exceeds the tank rupture pressure. 


\subsection{THERMAL}

Three failure mechanisms exist for the chlorine car exposed to an $1850^{\circ} \mathrm{F}$ fire. A car that is weakened by accident forces or has a faulty relief valve is assumed to fail at the relief valve set pressure due to pressure forces. A car can also fail at relief pressure if local high temperature metal fatigue or corrosion occurs. Failure is assumed to occur when the tank is half empty. The third type of failure could occur if the tank is overturned after the accident and liquid chlorine is being discharged from the relief valve. Under these conditions it was found that pressure increases in the tank due to the relief valve liquid discharge characteristics. A maximum pressure of $3.45 \mathrm{MPa}$ (500 psi) is assumed to rupture the tank. This value is conservative in that all tanks in service are periodically tested to these pressures. Design pressure for the tank is $8.62 \mathrm{MPa}$ (1250 psi). The fire duration for each of these failure modes is dependent on the condition of the insulation at the initiation of the fire.

The minimum fire durations for tank failure are tabulated below:

\begin{tabular}{|c|c|c|}
\hline Tank Condition & \multicolumn{2}{|c|}{ Fire Duration (minutes) } \\
\hline & $\begin{array}{r}\text { Insulation } \\
\text { Undamaged }\end{array}$ & $\begin{array}{l}10 \% \text { insula- } \\
\text { tion Damage }\end{array}$ \\
\hline $\begin{array}{l}\text { Tank reaches } \\
\text { relief pressure }\end{array}$ & 100 & 35 \\
\hline $\begin{array}{l}50 \% \text { Lading loss } \\
\text { (tank upright) }\end{array}$ & 287 & 100 \\
\hline $\begin{array}{c}3.45 \mathrm{MPa} \text { exceeded } \\
\text { (tank overturned) }\end{array}$ & 164 & 55 \\
\hline
\end{tabular}

As a sensitivity case, a valve with favorable liquid release characteristics to preclude overpressure failures in overturned tanks was postulated. If a valve with sufficient capacity to prevent any pressure rise above the relief pressure is used, the fire duration required to cause tank failure decreases because a half-full tank condition occurs sooner. This condition results in a metal fatigue failure. If the tank pressure is allowed to rise such that the half full tank condition occurs simultaneously with a tank pressure of $3.45 \mathrm{MPa}$, then two valve designs are possible depending on the amount 
of tank insulation considered intact in an accident situation. For a $100 \%$ insulated tank a liquid relief rate of $13 \mathrm{~kg} / \mathrm{sec}$ would be required to satisfy these conditions. For a $90 \%$ insulated tank, a rate of $36 \mathrm{~kg} / \mathrm{sec}$ is needed. The following is a listing of fire failure times for each of the relief valve design points:

\begin{tabular}{ccc} 
Tank Condition & \multicolumn{2}{c}{ Fire Duration (minutes) } \\
\cline { 2 - 3 } & $\frac{13 \mathrm{~kg} / \mathrm{sec}}{36 \mathrm{~kg} / \mathrm{sec}}$ \\
\cline { 2 - 3 } & 175 & 140 \\
$90 \%$ insulated & 57 & 60
\end{tabular}

A liquid relief rate of $13 \mathrm{~kg} / \mathrm{sec}$ improves fire failure times for both undamaged and damaged railcars over the base case. A rate of $36 \mathrm{~kg} / \mathrm{sec}$ improves the damaged car case but decreases the fire failure time of an undamaged car. These two sensitivity cases were input to the risk model to determine the effect of relief valve liquid discharge rates on overall risk. 


\subsection{RELEASE SEQUENCE IDENTIFICATION}

Several chlorine releases from rail tank car accidents have occurred in the United States. The statistical accident information available from state and federal agencies does not provide a sufficient basis to identify the mechanisms that caused these tanks to fail in the accident. Historical data with few failures also may not identify important failure mechanisms that could contribute to risk, but are of such low frequency that they have not been observed. Therefore, possible ways that releases could occur (sequences of events leading to a release of "release sequences") must be identified by a reasoning process. This section describes a formalized procedure for identifying possible release sequences. The first step in the procedure is to develop fault trees using the techniques described in Section 7.1. Section 7.2 presents the fault tree developed for shipment of liquid chlorine by rail. Analysis of the fault tree provides the release sequences. The release sequences identified from the liquid chlorine rail transportation fault tree are presented in Section 7.3.

\subsection{FAULT TREE CONSTRUCTION}

The fault tree analysis technique was developed in the 1960s in the aerospace industry to identify design deficiencies before actual space flight of the equipment. Basically the procedure is to assume a failure and work backwards to identify component failures which could cause or contribute to the failure. The fault tree should be related to individual components for which failure data are available. For instance, in an electronic circuit the basic failure might occur in a resistor. In practice, fault trees seldom are developed to that degree. What occurs instead is development of fault trees in terms of basic system modules. Using the electronic example, one would carry the possible failure back through the fault tree only to the amplifier which contained the resistor. Such a fault tree is called a Top Level Fault Tree since it usually identifies only large systems which could result in a failure. Table 7.1 gives the various fault tree symbols and their meanings. 
TABLE 7.1. Fault Tree Symbolism

SYMBOL

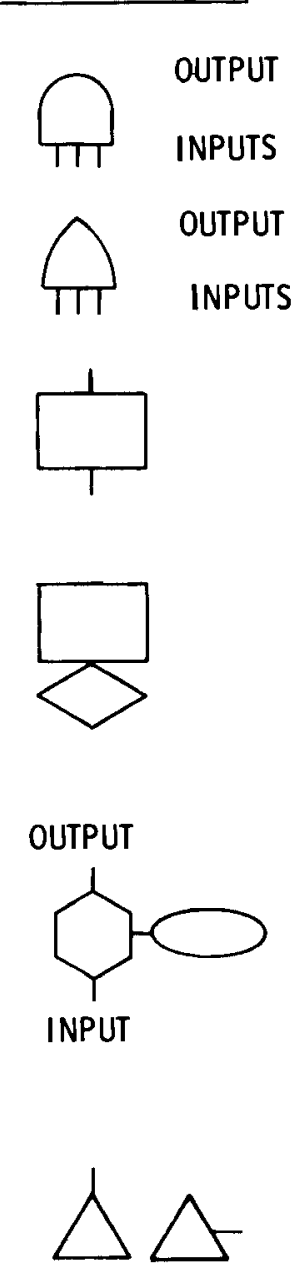

MEANING AND USE

"AND" LOGIC GATE. THE SIMULTANEOUS OCCURRENCE OF INPUTS IS REQUIRED TO CAUSE AN OUTPUT.

"OR" LOGIC GATE. THE OCCURRENCE OF ANY ONE OF THE INPUTS WILL RESULT IN AN OUTPUT.

FAULT EVENT THAT RESULTS FROM THE LOGICAL OPERATION OF TWO OR MORE FAULT EVENTS. IT IS ALWAYS THE OUTPUT FROM A LOGIC GATE.

INFERRED FAULT EVENT. ANY FAILURE EXCEPT A PRIMARY FAILURE WHICH IS NOT DEVELOPED FURTHER DUE TO LACK OF INFORMATION, TIME OR MONEY OR DUE TO THE LOW PROBABILITY OF OCCURRENCE. IT CAN ALSO BE USED WHERE OTHER ANALYSES GIVE SUFFICIENT INFORMATION TO INDICATE THAT FURTHER ANALYSIS WOULD BE REDUNDANT.

"INHIBIT" GATE. THE CONDITION SPECIFIED IN THE OVAL IS REQUIRED FOR AN INPUT FAULT EVENT TO A RESULT IN AN OUTPUT EVENT. THIS CONDITION IS FREQUENTLY A DESIGN LIMIT WHICH WILL NOT TRANSMIT A FAILURE UNTIL THE DESIGN LIMITS HAVE BEEN EXCEEDED.

TRANSFER SYMBOL DENOTING THAT FAILURE ALSO IMPACTS ON OTHER BRANCHES OF FAULT TREE. A LINE AT THE APEX OF THE TRIANGLE REPRESENTS A 'TRANSFER IN." A LINE IN THE SIDE REPRESENTS A "TRANSFER OUT." A NUMBER IS PLACED IN THE TRIANGLE TO IDENTIFY TRANSFER LOCATIONS.

The methodology applied to transportation of chlorine involves postulation of a release of chlorine during transport and then examination of the series of events which must have occurred to cause the release. This form of reasoning is thought to be much more inclusive than beginning with an initiating event and working toward a release, (i.e., constructing accident scenarios or event trees). When properly applied, the accident scenarios obtained from using the fault tree methodology should be more complete than the alternative method of trying to list all the accident scenarios without the aid of any formalized reasoning process. The tree constructed using the fault tree methodology is used as the basis for estimating the total release probability. 


\subsection{FAULT TREE FOR SHIPMENT OF LIQUID CHLORINE BY RAIL}

The fault tree for shipment of filled 90-ton liquid chlorine railcars has been developed for routine transport on primary rail rights of way in the U.S. The effects of sabotage or natural disasters were not included in the analys is. It is assumed for this analysis that all chlorine is shipped in 90-ton DOT specification 105A500W pressure tank cars. The rationale for selecting this vehicle type and a description of the 105A500W tank car used in the analysis is contained in Appendix $A$.

The fault tree developed for shipment of liquid chlorine in a 105A500W tank car is shown in Figure 7.1 . This figure was produced using the fault tree plotting computer code ACORN. (1) A list of identified events that could contribute to a release of liquid chlorine are shown in Table 7.2 and the input labels for the gate logic rectangles are presented in Table 7.3.

The fault tree is constructed with branches for each of the major chlorine retaining parts of the tank car. These include the tank heads, walls, manway cover and valves. Each major branch is then divided for releases during normal transport and releases due to transportation accidents. Branches covering releases during normal transport were developed to consider operational data and other potential releases due to package conditions or normal deterioration. The branches that consider chlorine releases in transportation accidents were developed to consider generic data on accident forces and a range of package conditions. Impact, fire, puncture and crush environments were considered.

\subsection{RELEASE SEQUENCES}

The fault tree can be thought of as a compact notation for identifying and displaying large numbers of release sequences. For large trees, it is convenient to use computer programs to perform the Boolean algebra that reduces the tree to a series of release sequences of "cut sets." The computer code FAULT $^{(2)}$ was used for this analysis. 


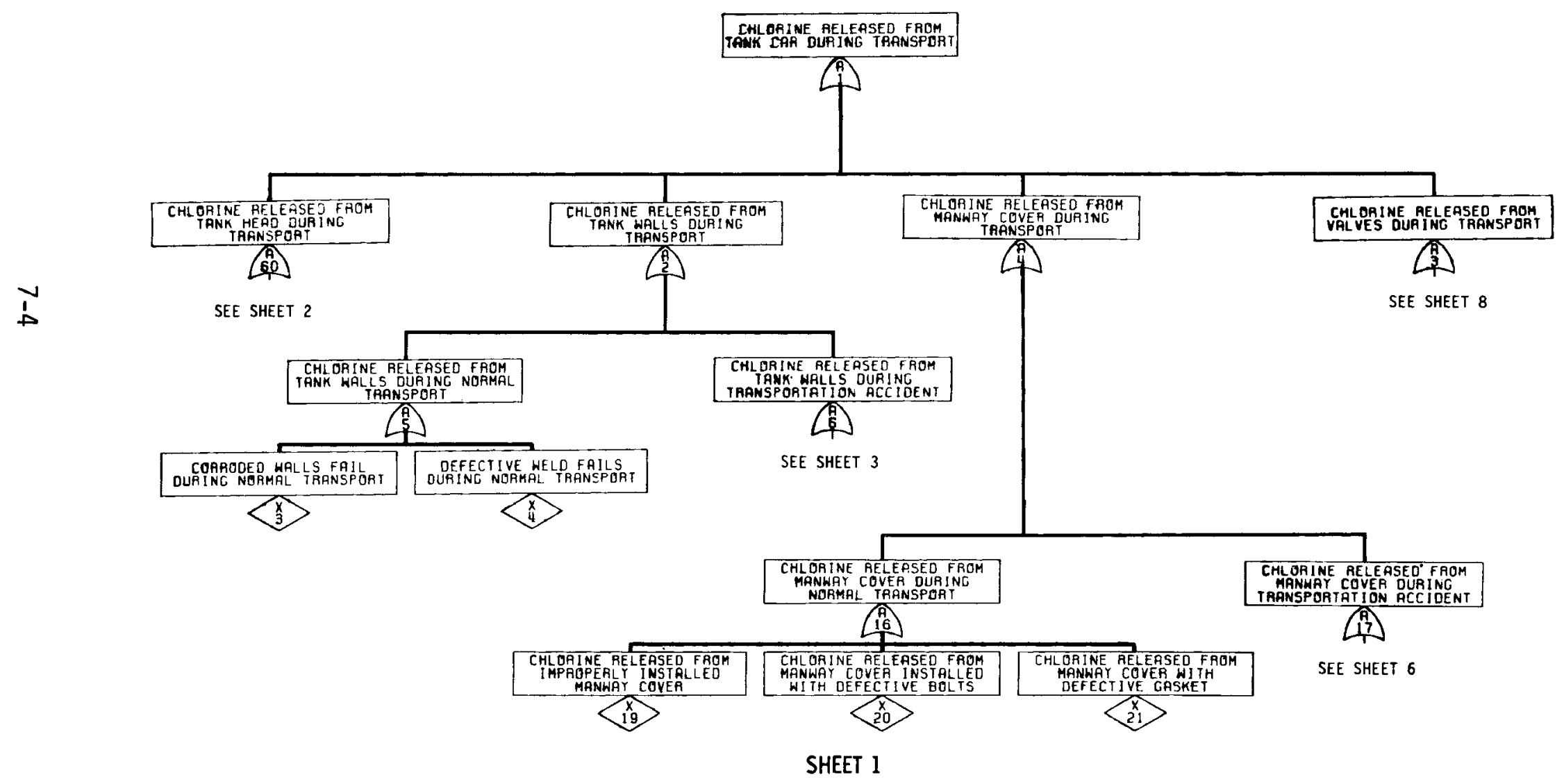

FIGURE 7.1. Chlorine Railcar Transportation Fault Tree 


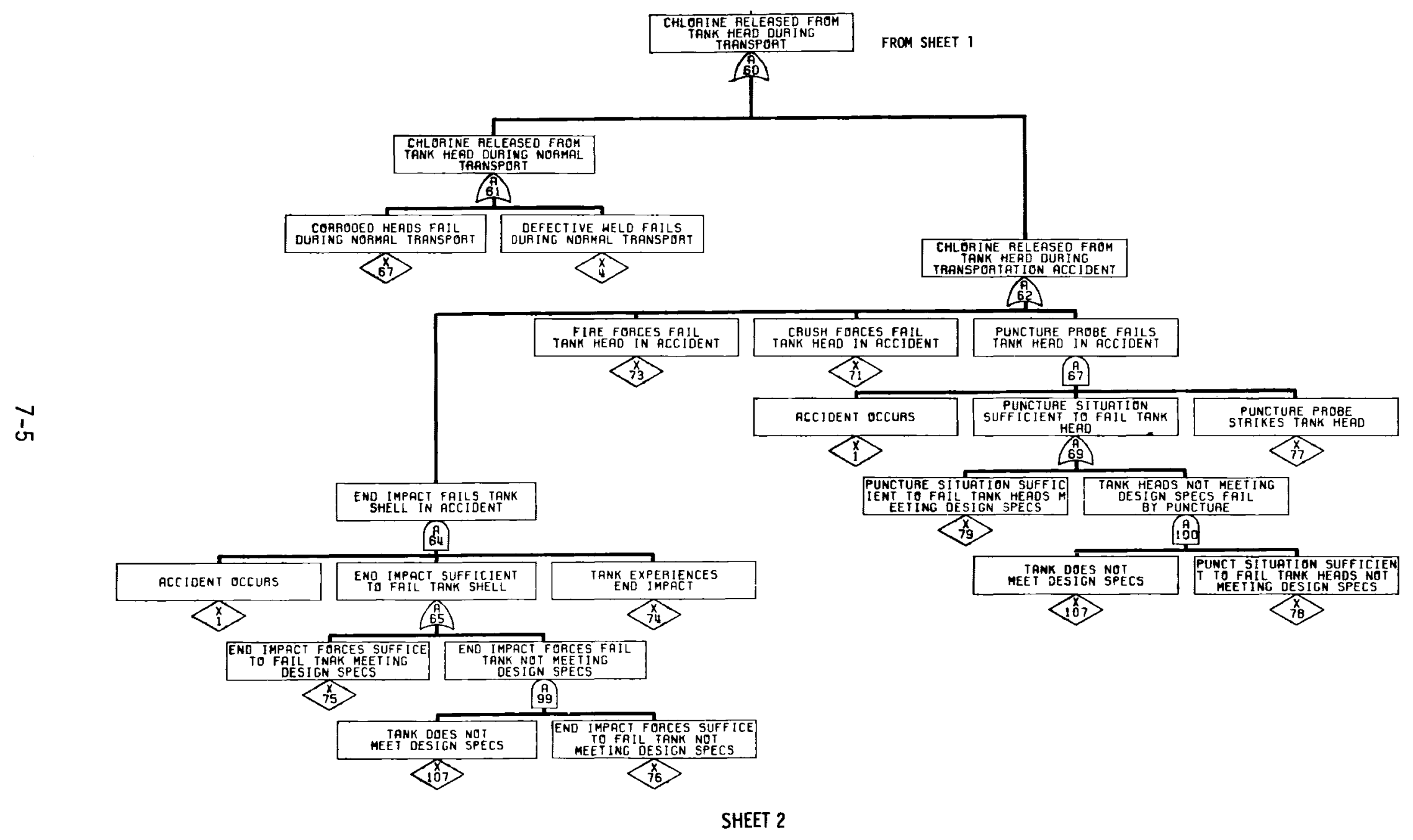

FIGURE 7.1. (cont'd) 


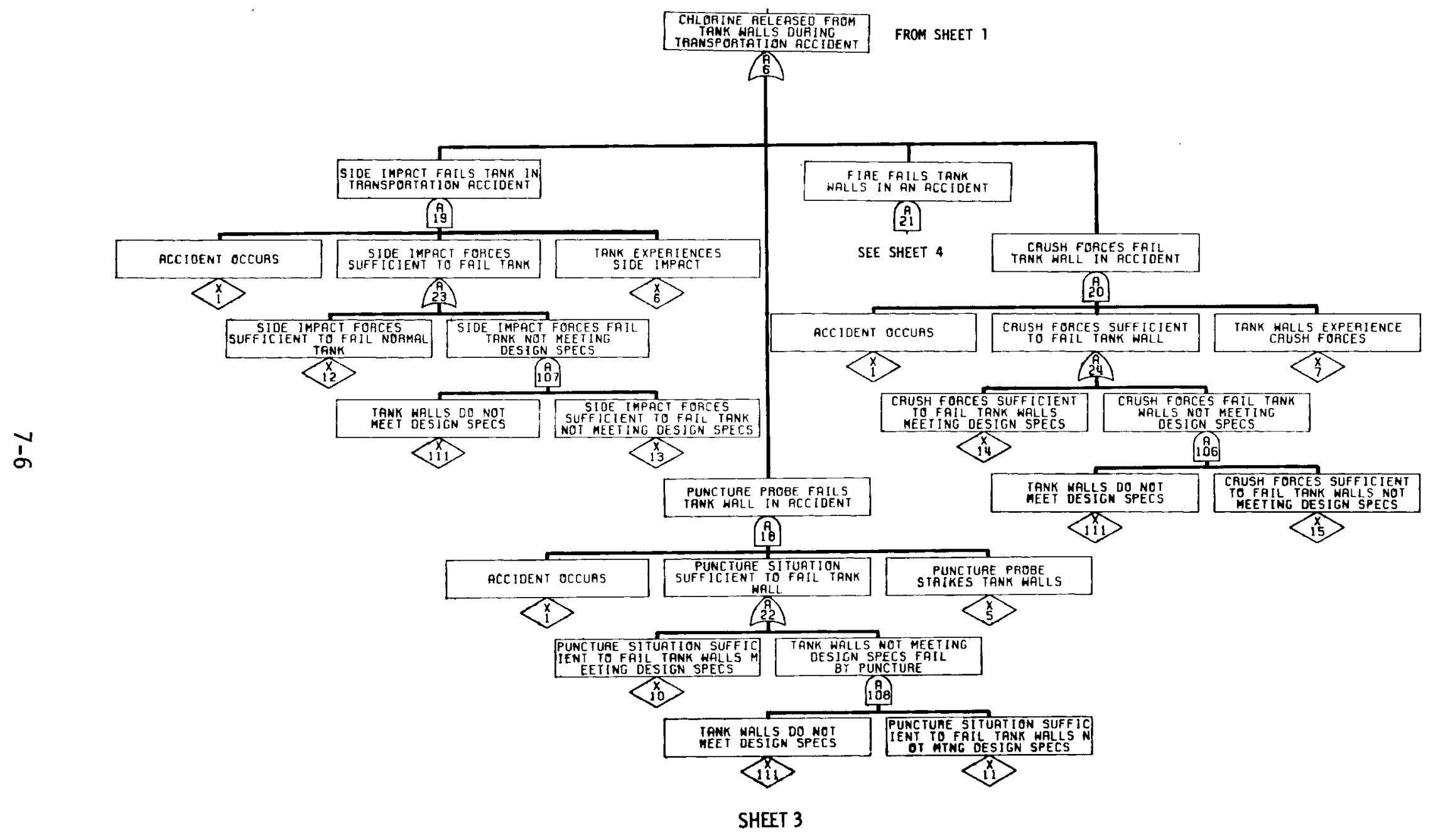

FIGURE 7.1. (cont'd) 


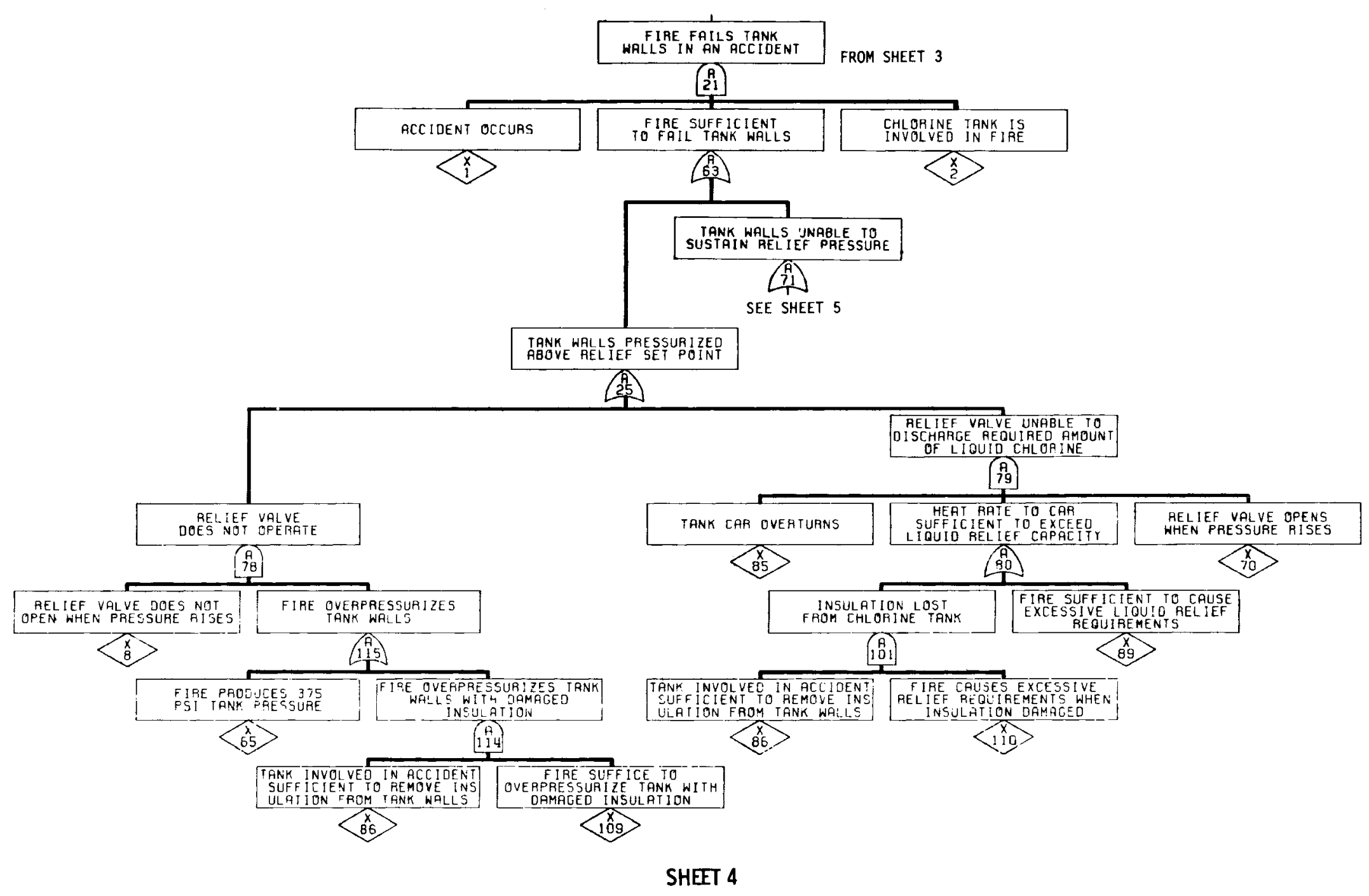

FIGURE 7.1. (cont'd) 


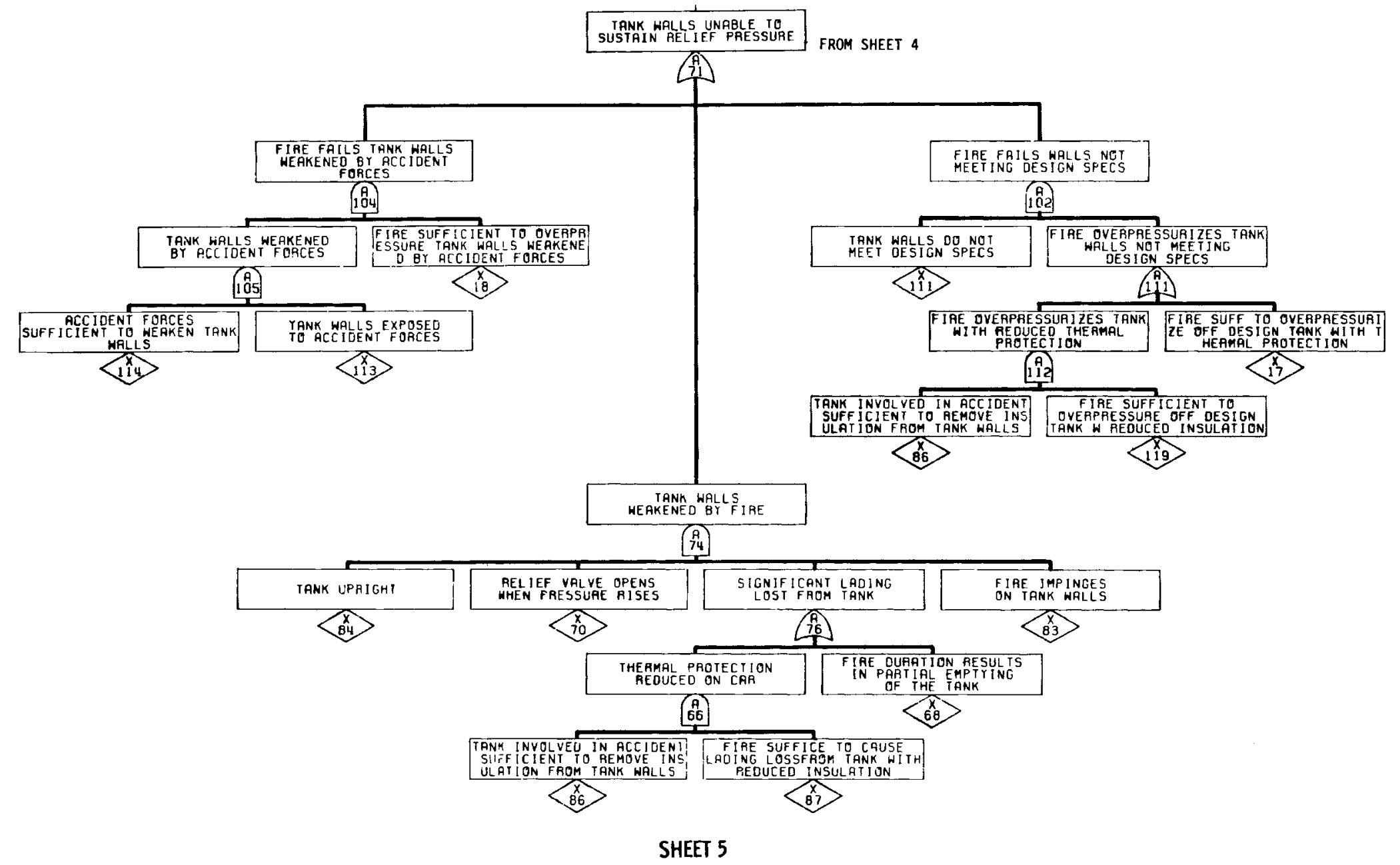

FIGURE 7.1 . (cont'd) 


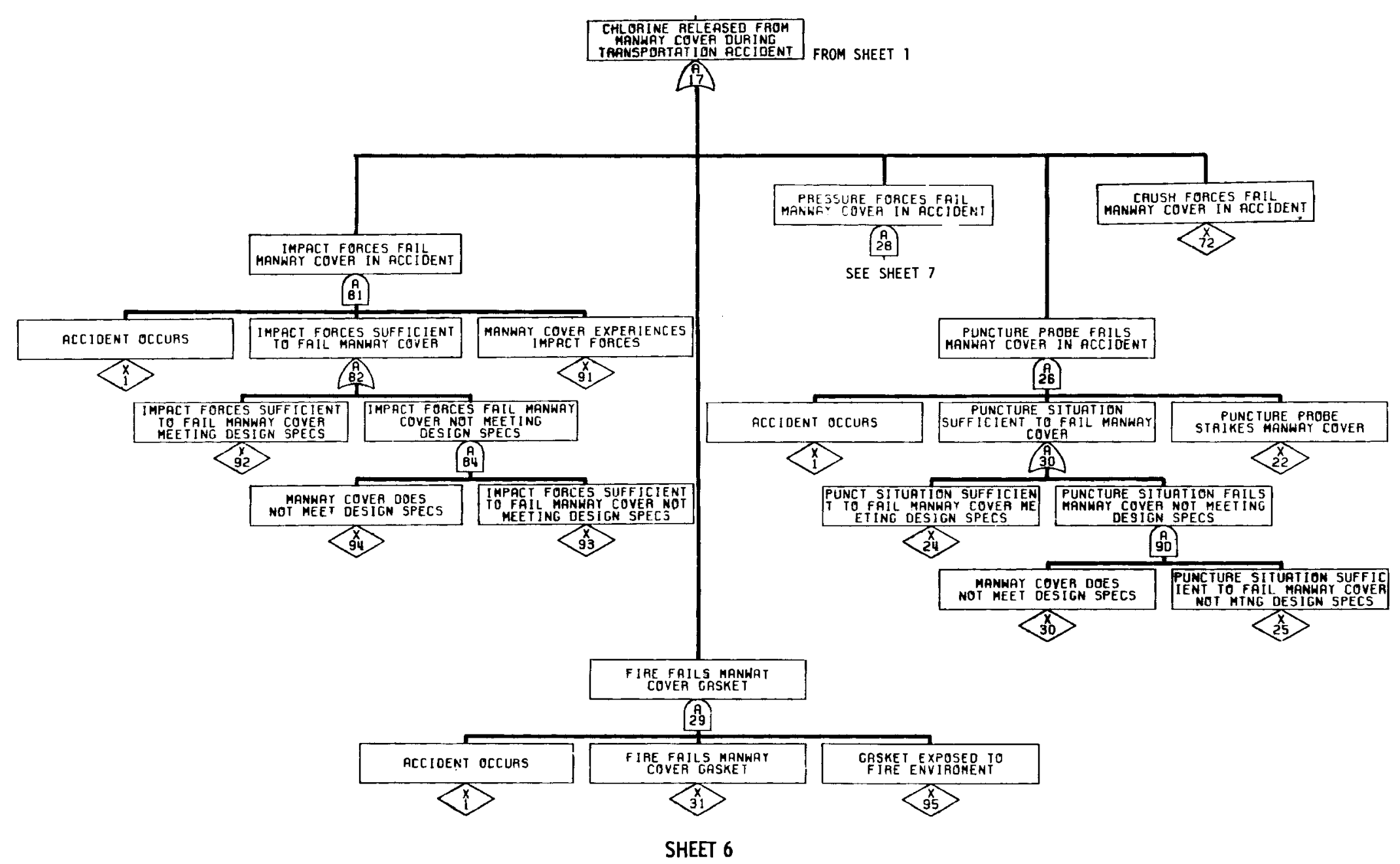

FIGURE 7.1. (cont'd) 


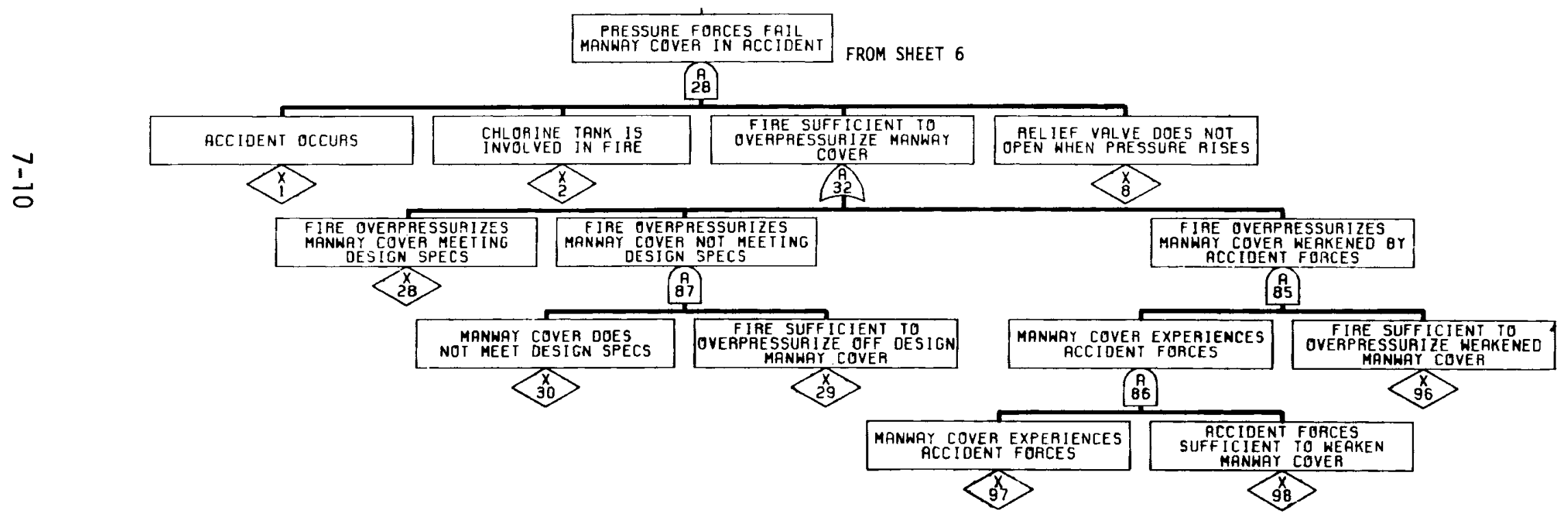

SHEET 7

FIGURE 7.1 . (cont'd) 


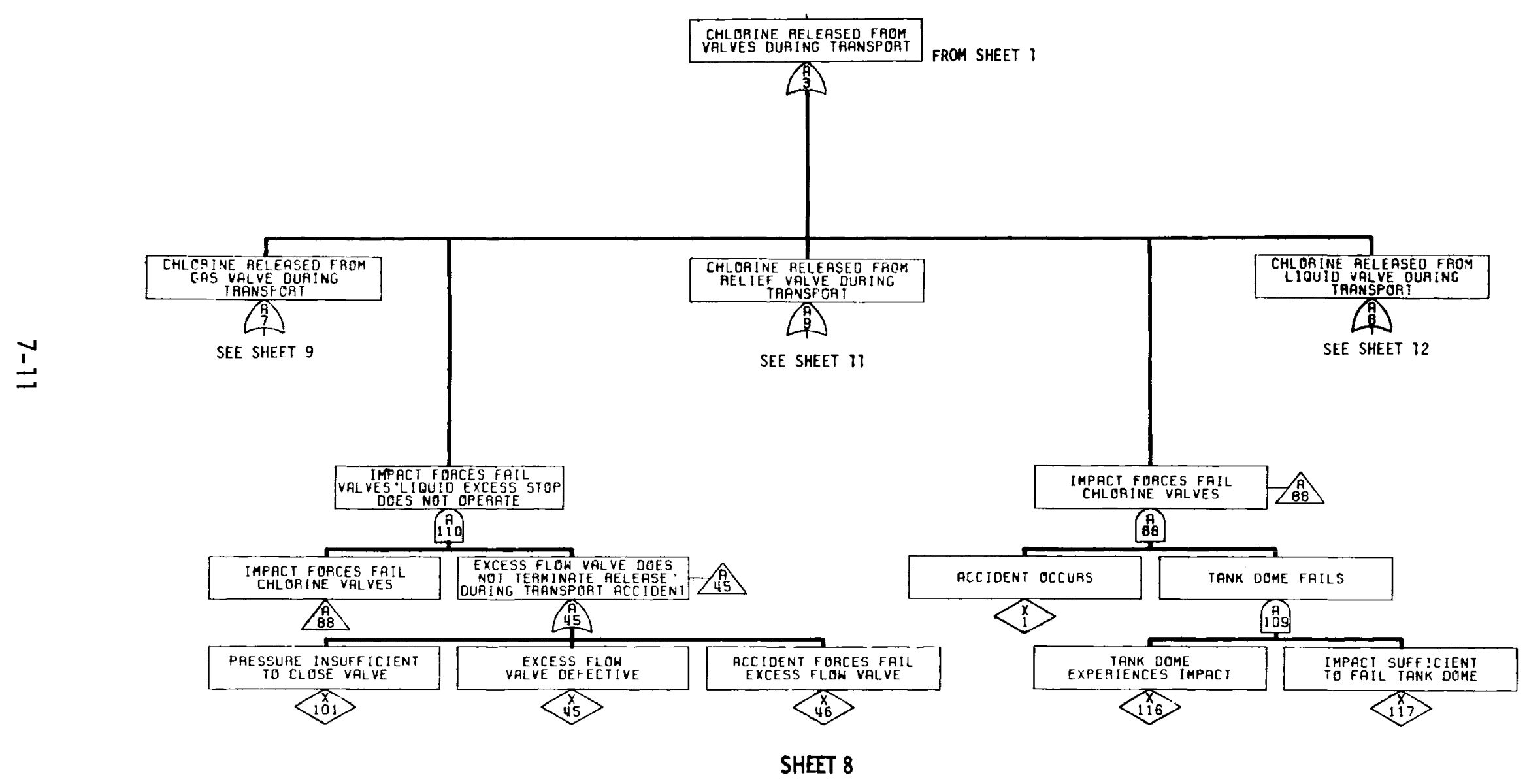

FIGURE 7.1. (cont'd) 


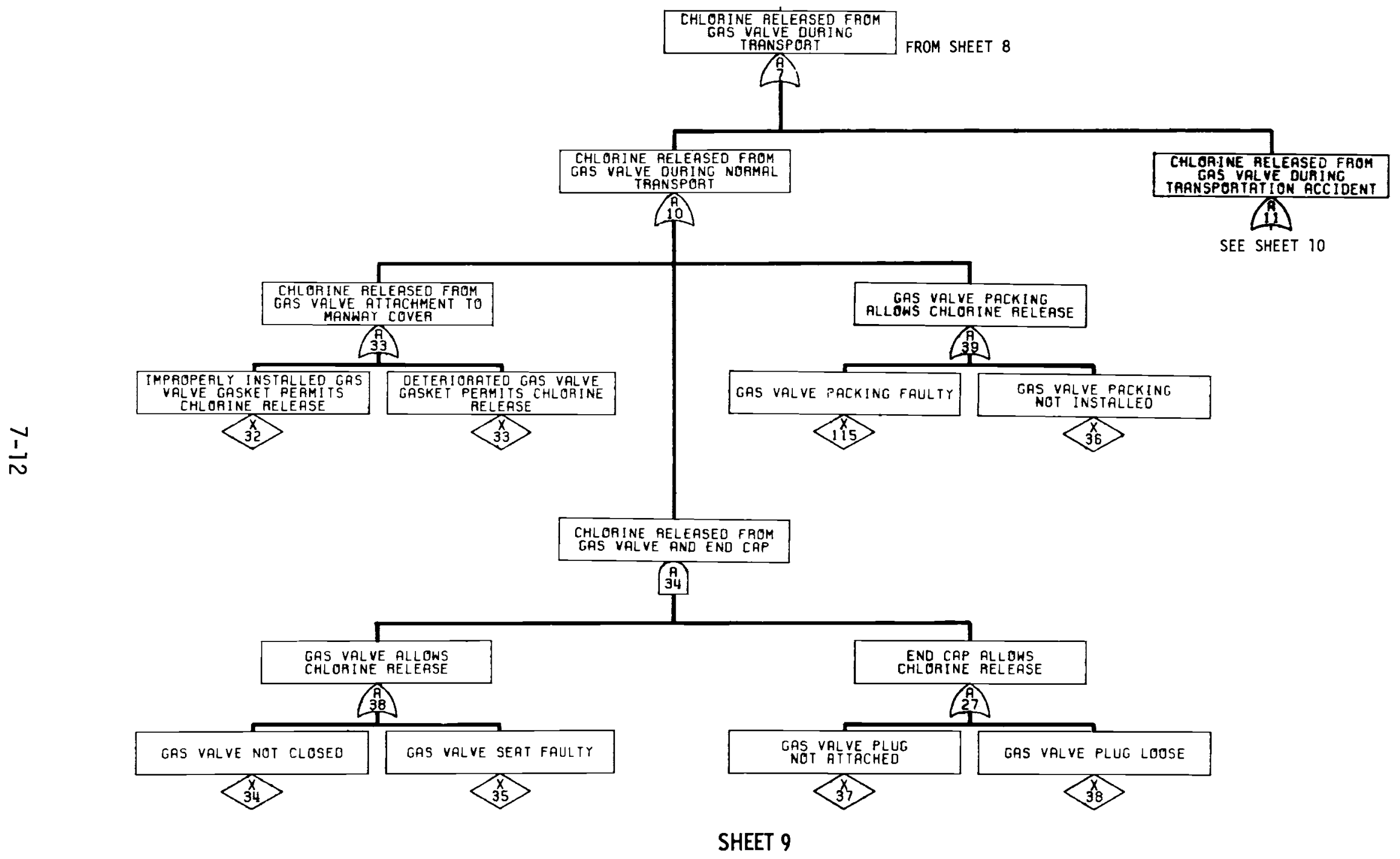

FIGURE 7.I. (cont'd) 


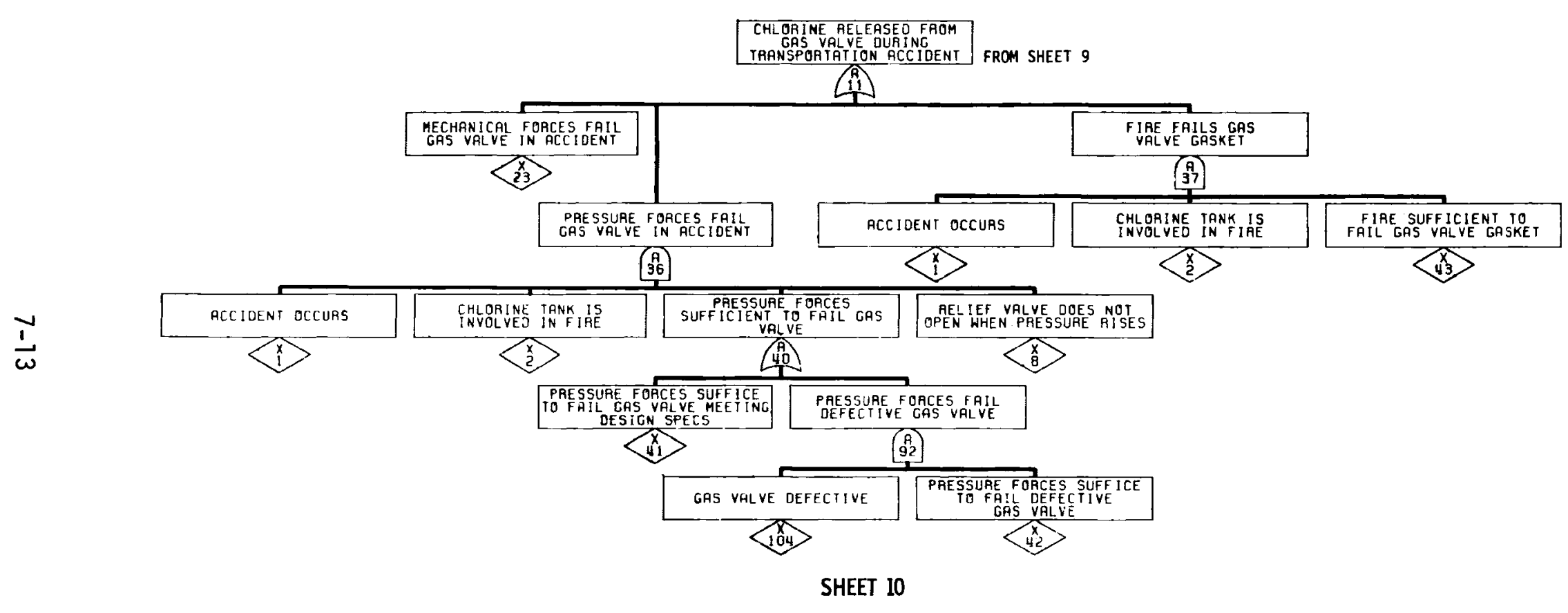

FIGURE 7.1. (cont'd) 


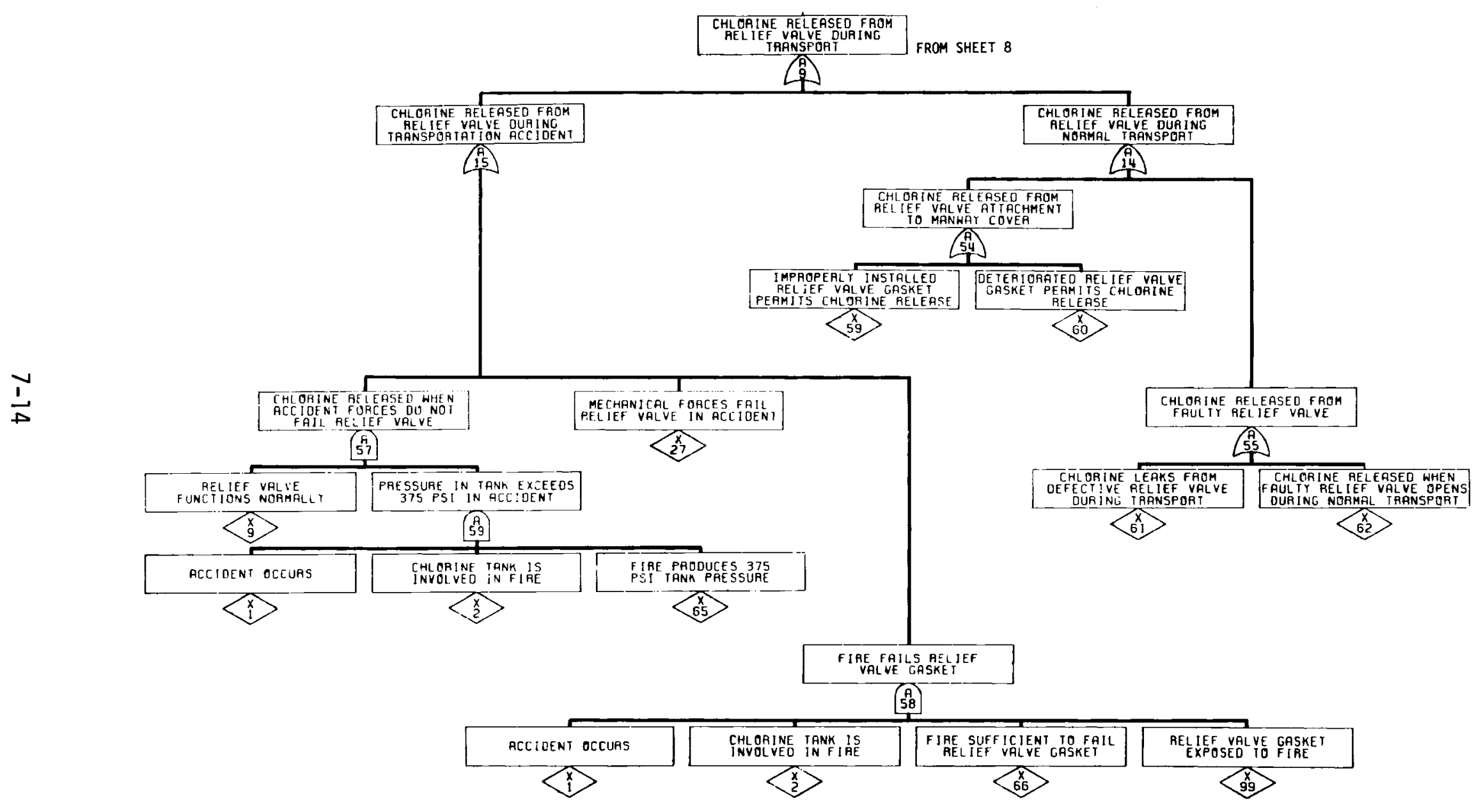

FIGURE 7.1 . (cont'd) 


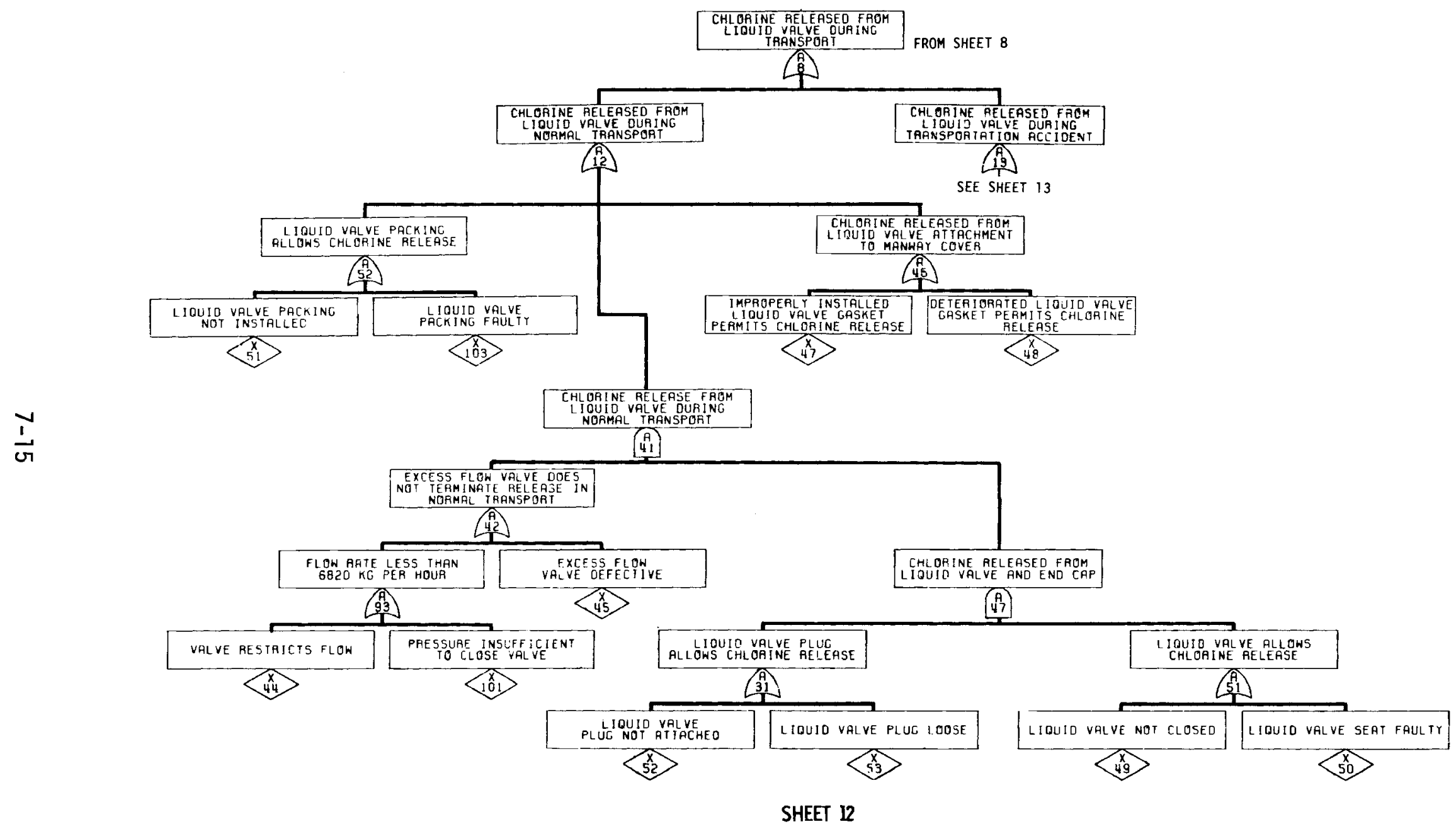

FIGURE 7.1. (cont'd) 


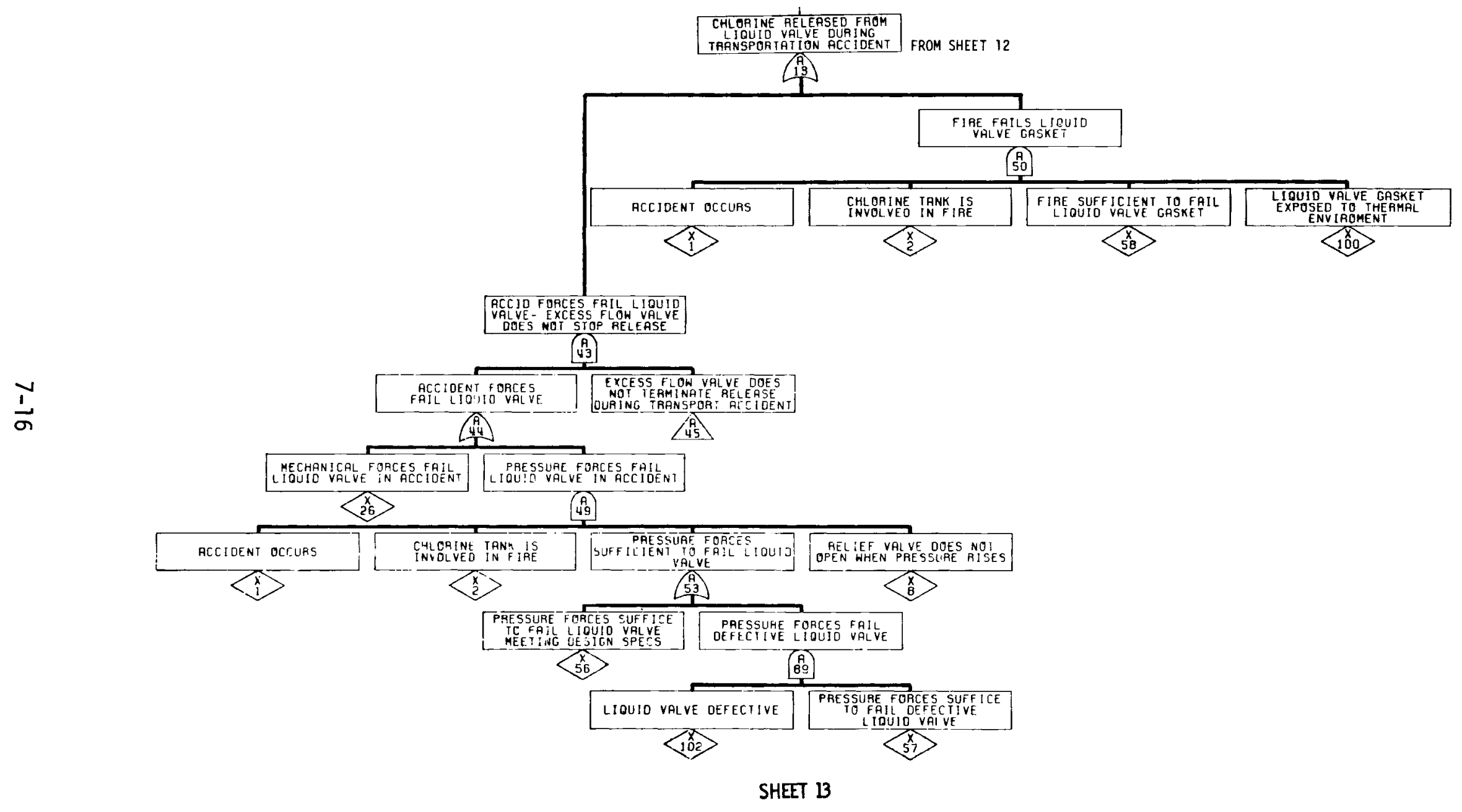

FIGURE 7.1. (cont'd) 


\section{TABLE 7.2. Listing of Basic Events for Chlorine Rail Car Transportation Fault Tree}

$X \quad 1$ ACCIDENT OCCURS

$x \quad 2$ CHLORINE TANK IS INVOLVED IN FIRE

$X \quad 3$ CORRODED WALLS FAIL DURING NORMAL TRANSPORT

$x \quad 4$ DEFECTIVE WELD FAILS DURING NORMAL TRANSPORT

$X \quad 5$ PUNCTURE PROBE STRIKES TANK WALLS

$X \quad 6$ TANK EXPERIENCES SIDE IMPACT

$X \quad 7$ TANK WALLS EXPERIENCE CRUSH FORCES

$X \quad 8$ RELIEF VALVE DOES NOT OPEN WHEN PRESSURE RISES

$X \quad 9$ RELIEF VALVE FUNCTIONS NORMALLY

$X \quad 10$ PUNCTURE SITUATION SUFFICIENT TO FAIL TANK WALLS MEETING DESIGN SPECS

$X 11$ PUNCTURE SITUATION SUFFICIENT TO FAIL TANK WALLS NOT MEETING DESIGN SPECS

$x \quad 12$ SIDE IMPACT FORCES SUFFICIENT TO FAIL NORMAL TANK

$x 13$ SIDE IMPACT FORCES SUFFICIENT TO FAIL TANK NOT MEETING DESIGN SPECS

$x \quad 14$ CRUSH FORCES SUFFICIENT TO FAIL TANK WALLS MEETING DESIGN SPECS

$X \quad 15$ CRUSH FORCES SUFFICIENT TO FAIL TANK WALLS NOT MEETING DESIGN SPECS

$X 17$ FIRE SUFFICIENT TO OVERPRESSURIZE OFF DESIGN TANK WITH THERMAL PROTECTION

$X 18$ FIRE SUFFICIENT TO OVERPRESSURE TANK WALLS WEAKENED BY ACCIDENT FORCES

$X 19$ CHLORINE RELEASED FROM IMPROPERLY INSTALLED MANWAY COVER

$X 20$ CHLORINE RELEASED FROM MANWAY COVER INSTALLED WITH DEFECTIVE BOLTS

$X 21$ CHLORINE RELEASED FROM MANWAY COVER WITH DEFECTIVE GASKET

$X 22$ PUNCTURE PROBE STRIKES MANWAY COVER

$X 23$ MECHANICAL FORCES FAIL GAS VALVE IN ACCIDENT

$x 24$ PUNCTURE SITUATION SUFFICIENT TO FAIL MANWAY COVER MEETING DESIGN SPECS

$X 25$ PUNCTURE SITUATION SUFFICIENT TO FAIL MANWAY COVER NOT MEETING DESIGN SPECS

$x 26$ MECHANICAL FORCES FAIL LIQUID VALVE IN ACCIDENT

$X 27$ MECHANICAL FORCES FAIL RELIEF VALVE IN ACCIDENT

$x \quad 28$ FIRE OVERPRESSURIZES MANWAY COVER MEETING DESIGN SPECS

$X \quad 29$ FIRE SUFFICIENT TO OVERPRESSURIZE OFF DESIGN MANWAY COVER

$X$ MONWAY COVER DOES NOT MEET DESIGN SPECS

$X \quad 31$ FIRE FAILS MANWAY COVER GASKET

$x \quad 32$ IMPROPERLY INSTALLED GAS VALVE GASKET PERMITS CHLORINE RELEASE

$X 33$ DETERIORATED GAS VALVE GASKET PERMITS CHLORINE RELEASE

$X \quad 34$ GAS VALVE NOT CLOSED

$X \quad 35$ GAS VALVE SEAT FAULTY

$X 36$ GAS VALVE PACKING NOT INSTALLED

$X \quad 37$ GAS VALVE PLUG NOT ATTACHED

$X \quad 38$ GAS VALVE PLUG LOOSE

$X \quad 41$ PRESSURE FORCES SUFFICE TO FAIL GAS VALVE MEETING DESIGN SPECS

$X \quad 42$ PRESSURE FORCES SUFFICE TO FAIL DEFECTIVE GAS VALVE

$X \quad 43$ FIRE SUFFICIENT TO FAIL GAS VALVE GASKET

$X \quad 44$ VALVE RESTRICTS FLOW

$X \quad 45$ EXCESS FLOW VALVE DEFECTIVE

$X \quad 46$ ACCIDENT FORCES FAIL EXCESS FLOW VALVE

$X \quad 47$ IMPROPERL $Y$ INSTALLED LIQUID VALVE GASKET PERMITS CHLORINE RELEASE

$X \quad 48$ DETERIORATED LIQUID VALVE GASKET PERMITS CHLORINE RELEASE

$X \quad 49$ LIQUID VALVE NOT CLOSED

$X \quad 50$ LIQUID VALVE SEAT FAULTY

$X \quad 51$ LIQUID VALVE PACKING NOT INSTALLED

$x \quad 52$ LIQUID VALVE PLUG NOT ATTACHED

$X 53$ LIQUID VALVE PLUG LOOSE

$x \quad 56$ PRESSURE FORCES SUFFICE TO FAIL LIQUID VALVE MEETING DESIGN SPECS

$X 57$ PRESSURE FORCES SUFFICE TO FAIL DEFECTIVE LIQUID VALVE

$\chi \quad 58$ FIRE SUFFICIENT TO FAIL LIQUID VALVE GASKET

$X 59$ IMPROPERLY INSTALLED REL IEF VALVE GASKET PERMITS CHLORINE RELEASE

$x \quad 60$ DETERIORATED RELIEF VALVE GASKET PERMITS CHLORINE RELEASE

$X 61$ CHLORINE LEAKS FROM DEFECTIVE RELIEF VALVE DURING TRANSPORT

$x \quad 62$ CHLORINE RELEASED WHEN FAULTY RELIEF VALVE OPENS DURING NORMAL TRANSPORT

$X \quad 65$ FIRE PRODUCES 375 PSI TANK PRESSURE

$x \quad 66$ FIRE SUFFICIENT TO FAIL RELIEF VALVE GASKET

$X 67$ CORRODED HEADS FAIL DURING NORMAL TRANSPORT

$x \quad 68$ FIRE DURATION RESULTS IN PARTIAL EMPTYING OF THE TANK

$X 70$ RELIEF VALVE OPENS WHEN PRESSURE RISES 


\section{TABLE 7.2. (cont'd)}

$X 71$ CRUSH FORCES FAIL TANK HEAD IN ACCIDENT

$X 72$ CRUSH FORCES FAIL MANWAY COVER IN ACCIDENT

$X 73$ FIRE FORCES FAIL TANK HEAD IN ACCIDENT

$X 74$ TANK EXPERIENCES END IMPACT

$X 75$ END IMPACT FORCES SUFFICE TO FAIL TANK MEETING DESIGN SPECS

$X 76$ END IMPACT FORCES SUFFICE TO FAIL TANK NOT MEETING DESIGN SPECS

$X 77$ PUNCTURE PROBE STRIKES TANK HEAD

$x 78$ PUNCTURE SITUATION SUFFICIENT TO FAIL TANK HEADS NOT MEETING DESIGN SPECS

$X 79$ PUNCTURE SITUATION SUFFICIENT TO FIAL TANK HEADS MEETING DESIGN SPECS

$X 83$ FIRE IMPINGES ON TANK WALLS

$X$ 84 TANK UPRIGHT

$X 85$ TANK CAR OVERTURNS

$X$ 86 TANK INVOLVED IN ACCIDENT SUFFICIENT TO REMOVE INSULATION FROM TANK WALLS

$X 87$ FIRE SUFFICE TO CAUSE LADING LOSS FROM TANK WITH REDUCED INSULATION

$X \quad 89$ FIRE SUFFICIENT TO CAUSE EXCESSIVE LIQUID RELIEF REQUIREMENTS

$X 91$ MANWAY COVER EXPERIENCES IMPACT FORCES

$X 92$ IMPACT FORCES SUFFICIENT TO FAIL MANWAY COVER MEETING DESIGN SPECS

$X 93$ IMPACT FORCES SUFFICIENT TO FAIL MANWAY COVER NOT MEETING DESIGN SPECS

$X 94$ MANWAY COVER DOES NOT MEET DESIGN SPECS

$X 95$ GASKET EXPOSED TO FIRE ENVIRONMENT

$X \quad 96$ FIRE SUFFICIENT TO OVERPRESSURIZE WEAKENED MANWAY COVER

$X 97$ MANWAY COVER EXPERIENCES ACCIDENT FORCES

$X 98$ ACCIDENT FORCES SUFFICIENT TO WEAKEN MANWAY COVER

$X 99$ RELIEF VALVE GASKET EXPOSED TO THERMAL ENVIRONMENT

$X 100$ LIQUID VALVE GASKET EXPOSED TO THERMAL ENVIRONMENT

$X 101$ PRESSURE INSUFFICIENT TO CLOSE VALVE

$X 102$ LIQUID VALVE DEFECTIVE

$X 103$ LIQUID VALVE PACKING FAULTY

$X 104$ GAS VALVE DEFECTIVE

$X 107$ TANK DOES NOT MEET DESIGN SPECS

$X 109$ FIRE SUFFICE TO OVERPRESSURIZE TANK WITH DAMAGED INSULATION

$x 110$ FIRE CAUSES EXCESSIVE RELEIF REQUIREMENTS WHEN INSULATION DAMAGED

$X 111$ TANK WALLS DO NOT MEET DESIGN SPECS

$x 113$ TANK WALLS EXPOSED TO ACCIDENT FORCES

$X 114$ ACCIDENT FORCES SUFFICIENT TO WEAKEN TANK WALLS

$X 115$ GAS VALVE PACKING FAULTY

$X 116$ TANK DOME EXPERIENCES IMPACT

$X 117$ IMPACT SUFFICIENT TO FAIL TANK DOME

$X 119$ FIRE SUFFICIENT TO OVERPRESSURE OFF DESIGN TANK WITH REDUCED INSULATION 
TABLE 7.3. Listing of Gate Logic Rectangle Labels for Chlorine Rail Car Transportation Fault Tree

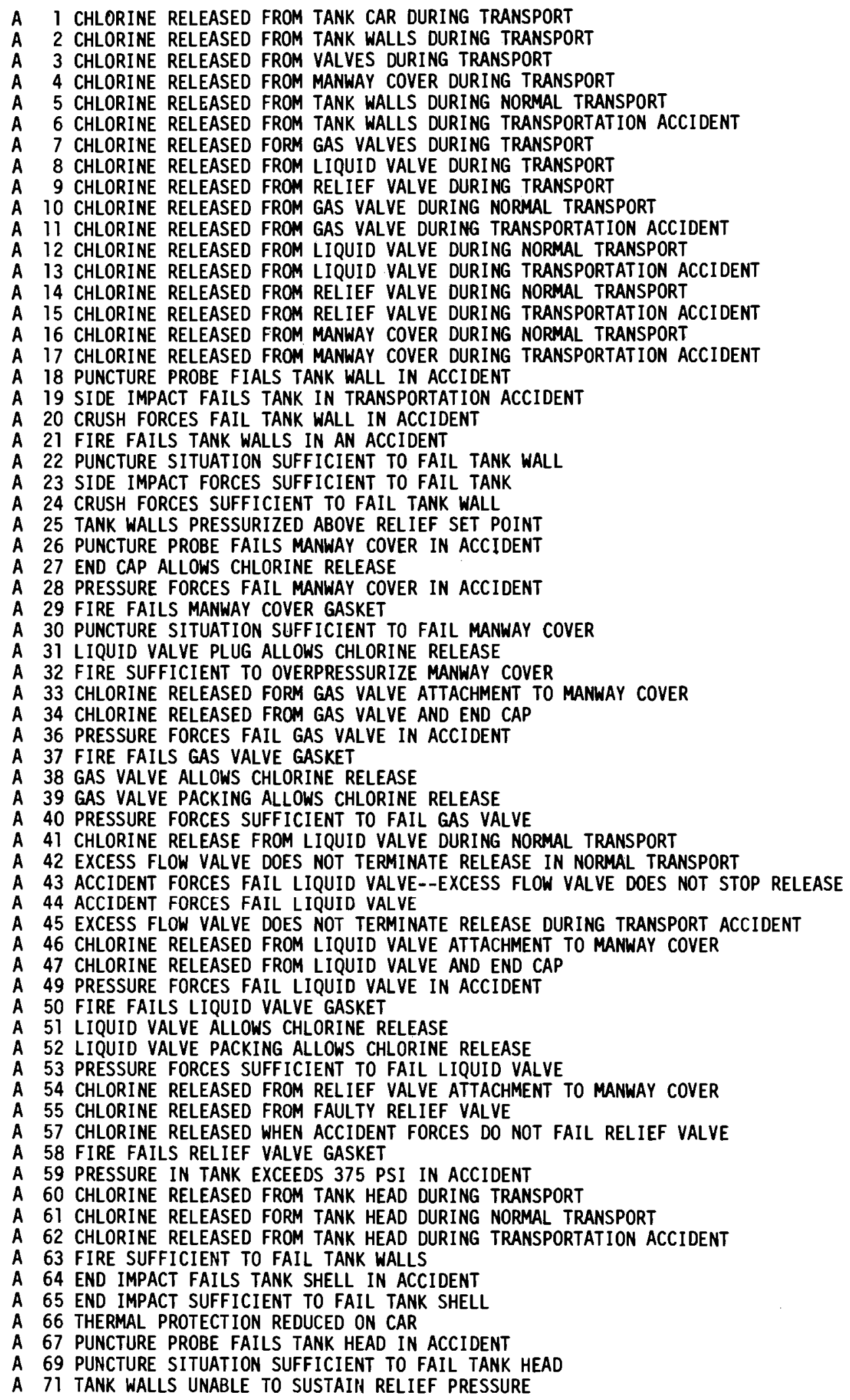




\section{TABLE 7.3. (cont'd)}

A 74 TANK WALLS WEAKENED BY FIRE

A 76 SIGNIFICANT LADING LOST FROM TANK

A 78 RELIEF VALVE DOES NOT OPERATE

A 79 RELIEF VALVE UNABLE TO DISCHARGE REQUIRED AMOUNT OF LIQUID CHLORINE

A 80 HEAD RATE TO CAR SUFFICIENT TO EXCEED LIQUID RELIEF CAPACITY

A 81 IMPACT FORCES FAIL MANWAY COVER IN ACCIDENT

A 82 IMPACT FORCES SUFFICIENT TO FAIL MANWAY COVER

A 84 IMPACT FORCES FAIL MANWAY COVER NOT MEETING DESIGN SPECS

A 85 FIRE OVERPRESSURIZES MANWAY COVER WEAKENED BY ACCIDENT FORCES

A 86 MANHAY COVER EXPERIENCES ACCIDENT FOREES

A 87 FIRE OVERPRESSURIZES MANWAY COVER NOT MEETING DESIGN SPECS

A 88 IMPACT FORCES FAIL CHLORINE VALVES

A 89 PRESSURE FORCES FAIL DEFECTIVE LIQUID VALVE

A 90 PUNCTURE SITUATION FAILS MANWAY COVER NOT MEETING DESIGN SPECS

A 92 PRESSURE FORCES FAIL DEFECTIVE GAS VALVE

A 93 FLOW RATE LESS THAN 6820 KG PER HOUR

A 99 END IMPACT FORCES FAIL TANK NOT MEETING DESIGN SPECS

A 100 TANK HEADS NOT MEETING DESIGN SPECS FAIL BY PUNCTURE

A 101 INSULATION LOST FROM CHLORINE TANK

A 102 FIRE FAILS WALLS NOT MEETING DESIGN SPECS

A 104 FIRE FIALS TANK WALLS WEAKENED BY ACCIDENT FORCES

A 105 TANK WALLS WEAKENED BY ACCIDENT FORCES

A 106 CRUSH FORCES FAIL TANK WALLS NOT MEETING DESIGN SPECS

A 107 SIDE IMPACT FORCES FAIL TANK NOT MEETING DESIGN SPECS

A 108 TANK WALLS NOT MEETING DESIGN SPECS FAIL BY PUNCTURE

A 109 TANK DOME FAILS

A 110 IMPACT FORCES FAIL VALVES--LIQUID EXCESS STOP DOES NOT OPERATE

A 111 FIRE OVERPRESSURIZES TANK WALLS NOT MEETING DESIGN SPECS

A 112 FIRE OVERPRESSURIZES TANK WALLS WITH REDUCED THERMAL PROTECTION

A 114 FIRE OVERPRESSURIZES TANK WALLS WITH DAMAGED INSULATION

A 115 FIRE OVERPRESSURIZES TANK WALLS 
A partial listing of the release sequences identified from the chlorine rail transporation fault tree is presented in Table 7.4. There are a total of 103 possible release sequences in the fault tree. These have been screened

TABLE 7.4. Listing of Chlorine Rail Car Transportation Fault Tree Release Sequences

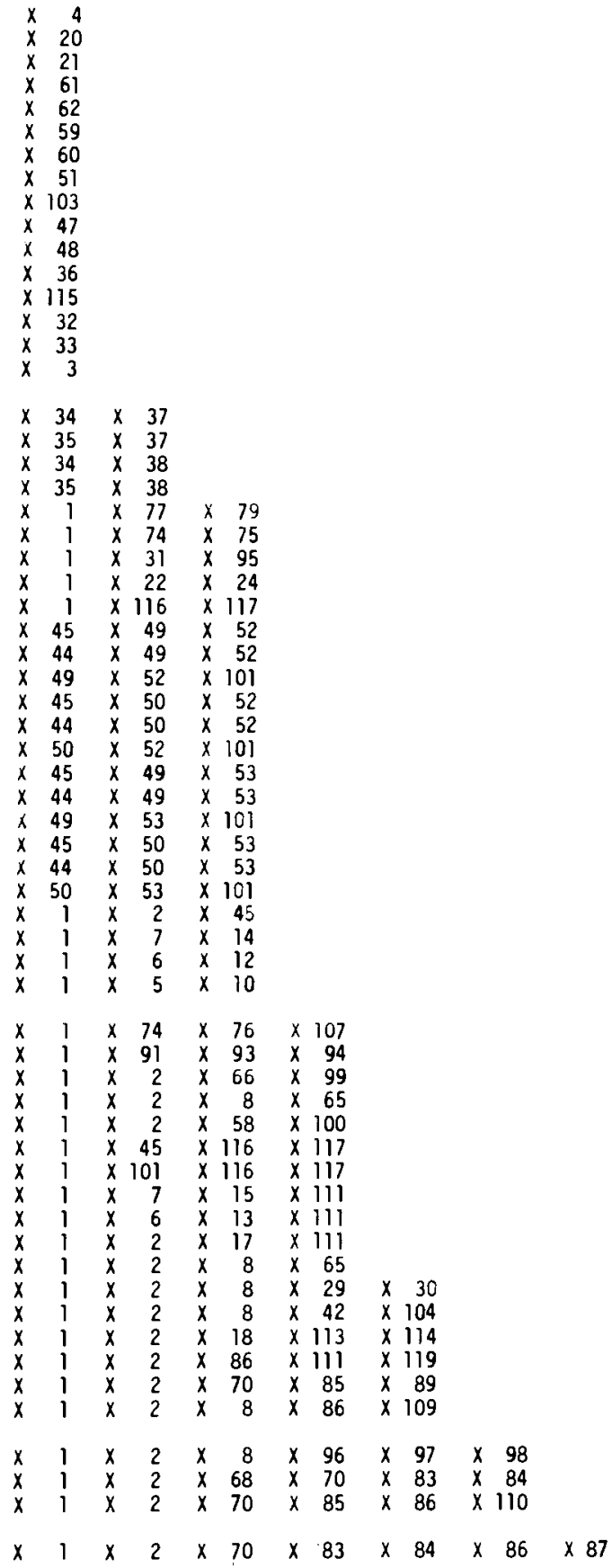


for presentation here to eliminate those sequences that have a probability of occurrence of less than once in $10^{15}$ shipments (see Section 8 ). All release sequences were studies in the analysis.

\section{REFERENCES}

1. J. L. Carter, ACORN: A Computer Program for Plotting Fault Trees. BNWL-2144, Pacific Northwest Laboratory, Richland, WA, November 1977.

2. P. J. Pelto and W. L. Purcell, MFAULT: A Computer Program for Analyzing Fault Trees. BNWL-3745, Pacific Northwest Laboratory, Richland, WA, November 1977. 


\subsection{RELEASE SEQUENCE EVALUATION}

The previous section presented the fault tree for the shipment of chlorine by rail and listed the more important release sequences. Figure 8.1 illustrates the remaining steps in the risk evaluation and the inputs to these steps. It is necessary to assign a frequency of occurrence and a release magnitude to each release sequence. This section presents the information used to evaluate these terms for each release sequence. The release magnitude is input to the environmental consequence model described in Section 9. The consequence of each release sequence is multiplied by its probability and this product is summed for all release sequences to determine the total risk.

LIST OF RELEASE SEQUENCES SECTION 7

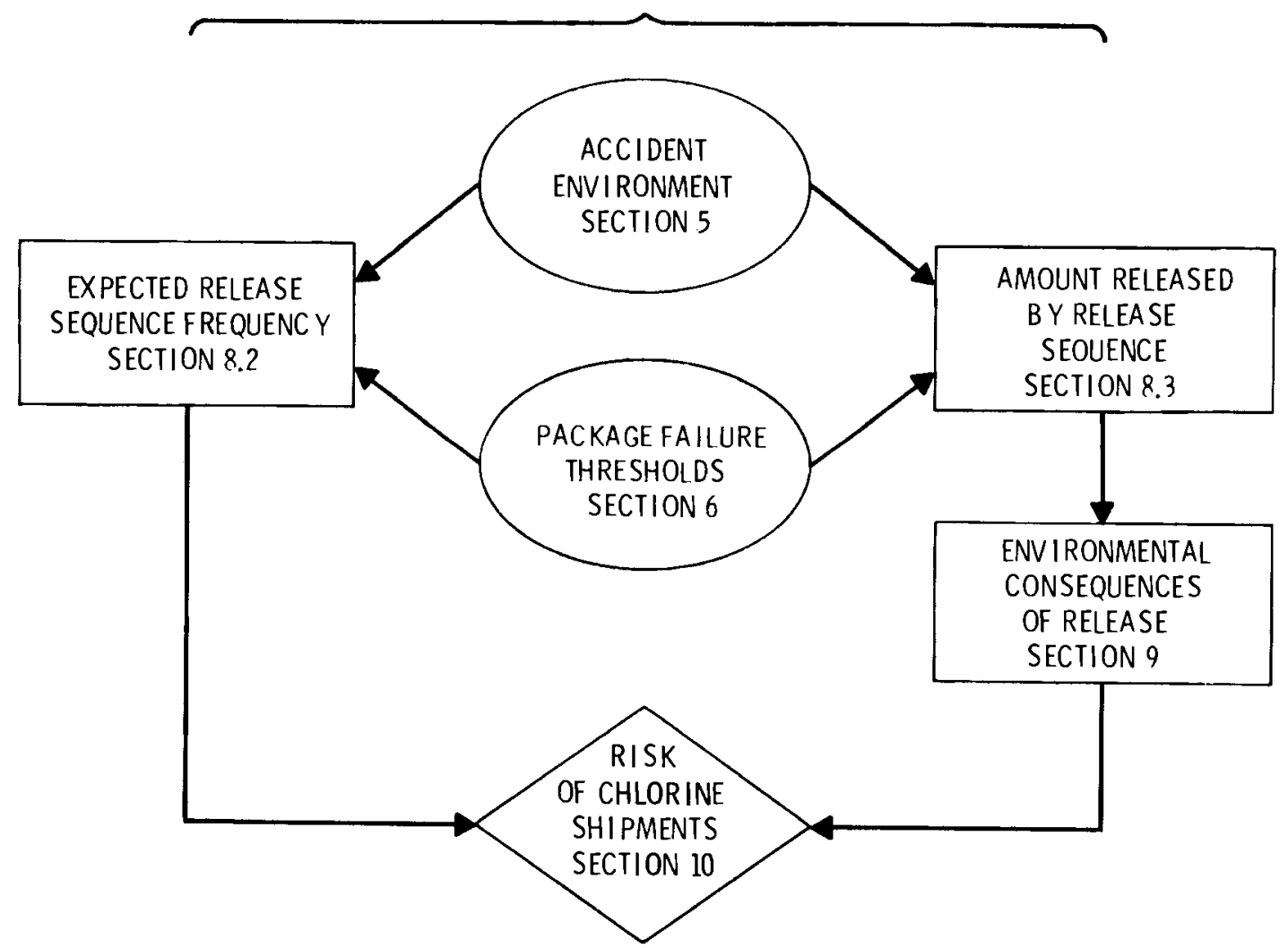

FIGURE 8.1. Remaining Steps in the Risk Evaluation 


\subsection{BASIC EVENT PROBABILITIES}

The expected frequency of each release sequence is obtained by taking the product of each event in the sequence. The estimates of the event probabilities are presented below. The failure frequencies developed in this section are the result of evaluating historic data for chlorine systems or systems of similar design. Where data were not available, engineering judgment and analysis were used to arrive at best estimates for true values. Section 5 presents results of the failure analyses. References to failure data are included at the end of this section.

Transportation Accident Occurs (X1)

Accidents in rail transport occur once every $1.6 \times 10^{5} \mathrm{~km}\left(1.0 \times 10^{5}\right.$ miles $)$, i.e., a rate of $6.2 \times 10^{-6(1)}$ rail accidents per kilometer. The average loaded shipping distance for chlorine tank cars is estimated in Section 4.0 to be $450 \mathrm{~km}$. For this shipping distance the expected accident frequency is $2.8 \times 10^{-3}$ accidents per shipment. This value is used in the analysis. Chlorine Tank is Involved in Fire (X2)

An analysis of data from collision and derailment accidents in Reference 1 (see Section 5) indicates that fire occurs in approximately $1.65 \times 10^{-2}$ of these accidents. It is further estimated that $14 \%$ of these fires would involve the chlorine tank car. A value of $2.3 \times 10^{-3}$ was used in the analysis. Corroded Wall Fails During Normal Transport (X3)

No data are available for chlorine rail tank cars. Data in Reference 7 report that conventional pressure vessels fail due to corrosion at a rate of $26 / 10^{6}$ years or $2.6 \times 10^{-5}$ /year. A single $450-\mathrm{km}$ shipment lasts $4.4 \times 10^{-3}$ of a year. The probability of this event was taken as the product of these two factors; $1.1 \times 10^{-7}$. The effect of this value on the overall risk result was determined to be small.

Defective Weld Fails During Normal Transport (X4)

No data on defective welds in chlorine cars are available. Initial and subsequent pressure tests of the tank are believed to detect most faulty welds. 
Pressure vessel failure data ${ }^{(2)}$ indicate a failure rate due to manufacturing defects of $1.5 \times 10^{-5} / \mathrm{yr}$. A trip lasts $4.4 \times 10^{-3}$ of a year. A probability of $6.6 \times 10^{-8}$ was used for this event. The effect of this value on the overall risk result was determined to be small.

Puncture Probe Strikes Tank Walls (X5)

For the period of 1965 to 1970 punctures were observed in 13 insulated pressure type welded cars. Five of these occurred in the tank wal1. (3) The probability of this event was taken as $5 / 13$ or 0.38 .

Tank Experiences Side Impact (X6)

The probability that a tank car experiences a side impact, given that the car is involved in an impact accident, was estimated from information in Reierence 1. Impacts were assumed to occur only during collision or derailment accidents. The probability that an impact is the result of a derailment accident is 0.632 . The probability that an impact is the result of a collision accident is 0.368 . By assuming that all raking collisions and half of all collisions with other cars result in side impacts, it was estimated that 0.449 of impacts which result from collision accidents were side impacts. No side impacts were assumed for derailment accidents. The probability of this event is the product of the probability that an impact is the result of collision accident $(0.368)$ and the probability that the collision causes a side impact (0.449). A probability of 0.165 was used for this event.

Tank Walls Experience Crush Forces (X7)

It is estimated that a container will experience static crush in $2 \times 10^{-3}$ of all accidents. (1) This event also includes possible crush forces experienced by the tank heads.

Relief Valve Does Not Open when Pressure Rises (X8)

Reference 4 gives a probability of $1 \times 10^{-5}$ for a nuclear quality valve not opening on demand. To be conservative, a value of $10^{-4}$ per demand was used in this study. 
Relief Valve Functions Normally (X9)

The probability of this event is approximately unity due to the small value used in event $(x 8)$.

Puncture Situation Sufficient to Fail Tank Walls Meeting Design Specs (X10)

This probability of puncture per reportable accident is estimated from Table 5.2 for a wall thickness of $2 \mathrm{~cm}\left(0.787\right.$ in.) to be $5.7 \times 10^{-4}$. Puncture Situation Sufficient to Fail Tank Walls Not Meeting Design Specs (X11)

It is expected that off-design package conditions would not appreciably affect puncture resistance. Therefore, the probability of this event has been included in event $\times 10$. A value of zero was used here. Side Impact Forces Sufficient to Fail Normal Tank (X12)

An upper bound of two calculated side impact failure thresholds was used here (see Appendix C). This value is $29 \mathrm{~km} / \mathrm{hr}$ and from Figure 5.2 has a probatility of $1.29 \times 10^{-2}$ per reportable accident. Side Impact Forces Sufficient to Fail Tank Walls Not Meeting Design Specs (X13)

A lower bound side impact failure threshold of $14 \mathrm{~km} / \mathrm{hr}$ (see Appendix C) was used as the off-design failure threshold. A probability of $3.5 \times 10^{-2}$ per accident was obtained for this event from om Figure 5.2. (1) Crush Forces Sufficient to Fail Tank Walls Meeting Design Specs (X14)

A crush 1 oad applied to the tank at $26.7^{\circ} \mathrm{C}\left(80^{\circ} \mathrm{F}\right)$ must exceed $480 \mathrm{~N} / \mathrm{cm}$ for failure to occur (see Appendix $\mathrm{C}$ ). This requires a loading of $5.45 \times 10^{5} \mathrm{~N}$ (tank $11.3 \mathrm{~m}$ long) for the entire car. Figure 5.3 reports a probability of 0.16 for this event given that crush forces are present. Crush Forces Sufficient to Fail Tank Walls Not Meeting Design Specs (X15)

For off design crush failures, it was assumed that the shell material would fail at $80 \%$ of design stresses on $2.75 \times 10^{4} \mathrm{~N} / \mathrm{cm}^{2}$. This corresponds to a loading of $4.24 \times 10^{5} \mathrm{~N}$ with a probability from Figure 5.3 of 0.36 for accidents involving crush. 
Fire Sufficient to Overpressurize off Design Tank with Thermal Protection (X17)

Shell full condition occurs at pressures below that of the relief set point (see Appendix C). It was assumed that failure of an off-design tank would occur at this time. A 100-minute fire with a probability from Figure 5.1 of 0.13 is required given the car is involved in a fire.

Fire Sufficient to Overpressurize Tank Walls Weakened by Accident Forces (X18)

It was assumed for this event, that $10 \%$ of the tank car insulation was removed due to accident forces. If this occurs, a fire duration of 35 minutes is required to reach shell full condition. It was assumed for this event that failure occurs when shell full conditions exist. The probability from Figure 5.1 of such a fire, given a fire occurs and the car is involved, is 0.42 . (1)

Chlorine Released from Improperly Installed Manway Cover (X19)

Proper manway cover installation is required to complete the tank car loading. It was therefore assumed that this event has a conservative probability of $9 \times 10^{-6}$ (see X32).

Chlorine Released from Manway Cover Installed with Defective Bolts (x20)

A general rate of defective part manufacture and failure of inspection procedures to detect the defects is given in Reference 2 as $3 \times 10^{-3} /$ trial (see event $\times 30$ ). It was assumed in this analysis that at least three of the twenty bolts must be defective to result in significant releases from the manway cover. The probability of this event is $2.7 \times 10^{-8}$ per car. Releases from this type failure are expected to be small. This event was determined to have a small effect on overall risk levels.

Chlorine Released from Manway Cover with Defective Gasket (X21)

The probability of a defective gasket was assumed to be $3 \times 10^{-3} /$ gasket (see $\times 30$ ). The gasket area of the manway cover is inspected before each trip using chemical detection equipment. An error of omission for this type test is $3 \times 10^{-3}$. (4) A probability of $9 \times 10^{-6}$ was used for this event. Releases from this event are expected to be small and have negligible effect on overall risk levels. 
Puncture Probe Strikes Manway Cover (X22)

It is estimated that one third of puncture probes strike the tank walls and two thirds the tank heads. (3) If the area of the dome represents a puncture target area for the manway cover, the probability of a puncture probe striking the manway cover is $3.3 \times 10^{-2}$. This value was obtained by dividing the dome area by the projected tank surface area and weighting it by considering both tank head and wall areas.

Mechanical Forces Fail Gas Valve in Accident (X23)

The gas valve is expected to experience mechanical forces only during a dome failure. This possibility is considered in events $\times 116$ and $\times 117 . A$ value of zero was used for this event.

Puncture Situation Sufficient to Fail Manway Cover Meeting Design Specifications (X24)

For a steel plate $5.7 \mathrm{~cm}$ thick, the probability per reportable accident of a puncture is given in Table 5.2. This value is $9.175 \times 10^{-5}$.

Puncture Situation Sufficient to Fail Manway Cover Not Meeting Design Specifications (X25)

The puncture resistance of an off design cover was assumed to be similar to that of a normal cover and was included in event $\times 24$. A value of zero was for this event.

Mechanical Forces Fail Liquid Valve in Accident (X26)

The 1 iquid valve is expected to experience mechanical forces only during a tank dome failure. This possibility is considered in events $\times 116$ and $\times 117$. A value of zero was used for this event.

Mechanical Forces Fail Relief Valve in Accident (X27)

The relief valve is expected to experience mechanical forces only during a tank dome failure. This possibility is considered in event $\times 116$ and $\times 117$. A value of zero was assigned to this event. 
Fire Overpressurizes Manway Cover Meeting Design Specifications (X28)

Pressure caused failures are governed by the thinner tank walls; therefore, this event was assigned a probability of zero.

Fire Sufficient to Overpressurize Off-Design Manway Cover (X29)

If the faulty manway cover is the weakest pressure retaining part of the car, failure is conservatively assumed to occur when shell full conditions are needed. A minimum fire duration of 100 minutes is required to reach shell full conditions. The probability of a 100-minute or longer fire given that the chlorine car is involved in a fire was obtained from Figure 5.1 and has a value of 0.13 .

Manway Cover Does Not Meet Design Specifications (X30)

A study of error rates in quality control inspections of electrical components gives a probability of 0.003 that a defective component will not be detected. (2) Although not directly applicable to manufacturing defects for manway covers, it is assumed that this value is representative of quality control in a variety of manufacturing operations.

Fire Fails Manway Cover Gasket (X31)

The manway cover gasket is constructed of bonded asbestos which is resistant to fire. For this study, it was assumed that the gasket would survive 120 minutes in a fire. The probability of this event, given a fire exposure, was estimated from Figure 5.1 to be 0.1 . Releases from this type failure are expected to be small and would not effect the performance of the car in a fire. Improperly Installed Gas Valve Gasket Permits Chlorine Release (X32)

It was conservatively assumed that this operation is conducted before each trip. Both an error of commission during installation of the gasket and an error of omission during inspection must occur for this event. These errors each have probabilities ${ }^{(4)}$ of $3 \times 10^{-3}$ for a combined probability of $9 \times 10^{-6}$. Releases from this event are expected to be small and have a negligible effect on overall risk levels. 
Deteriorated Gas Valve Gasket Permits Chlorine Release (X33)

A bonded asbestos gasket is used in this service. It was assumed that the gasket would behave similar to phenolic material with a failure rate of $5 \times 10^{-8} / \mathrm{hr} .{ }^{(5)}$ For a $450-\mathrm{km}$ trip at $280 \mathrm{~km} /$ day, a failure probability of $1.9 \times 10^{-6}$ per trip is predicted. Releases from this event are expected to be small and have a negligible effect on overall risk levels.

Gas Valve Not Closed (X34)

A general rate of omission for human activity is reported in Reference 4 to be $10^{-2} /$ trial. Leaving the valve open is considered to be one trial. Inspection of the valve using visual, olefactory and chemical displays were considered to be another form of omission with a probability of $3 \times 10^{-3}$ / trial. (4) Combining these probabilities yields a probability of $3 \times 10^{-5}$ for this event.

Gas Valve Seat Faulty (X35)

A value of $3 \times 10^{-3}$ was used here to estimate the probability of a defective valve seat $($ see $\times 30) .{ }^{(4)}$ An error or omission using chemical leak detection equipment has a probability of $3 \times 10^{-3} /$ trial. (4) The probability of this event is $9 \times 10^{-6}$. Releases from this event are expected to be small and have a negligible effect on overall risk levels.

Gas Valve Packing Not Installed (X36)

A probability of $3.0 \times 10^{-5}$ was used for this event (see $\times 34$ ). Releases from this event are expected to be small and have a negligible effect on overall risk levels.

Gas Valve Plug Not Attached (X37)

An error of omission (not attaching plug) and commission (not observing omission of plug) are required for this event. A probability of $3 \times 10^{-5}$ was used. 
Gas Valve Plug Loose (X38)

The probability of activity omission at the end of a sequence of human actions is $10^{-2} /$ trial. (4) This rate was assumed valid for this event. Releases from this event are expected to be small and have a negligible effect on overall risk levels.

Pressure Forces Sufficient to Fail Gas Valve Meeting Design Specifications (X41)

A valve which meets design specs is expected to be stronger than other pressure retaining parts such as the tank walls. A probability of zero was assigned to this event.

Pressure Forces Sufficient to Fail Defective Gas Valve (X42)

The pressure failure threshold for a defective gas valve was assumed to be tank relief pressure (3.45 $\mathrm{MPa})$. An undamaged chlorine tank car must be exposed to a 100-minute or longer fire to reach this condition. Figure 5.1 was used to estimate a probability of 0.13 for this event.

Fire Sufficient to Fail Gas Valve Gasket (X43)

A 120-minute fire was assumed to fail the gasket. A probability of 0.1 was estimated for this event from Figure 5.1 (see $\times 31$ ). This event is expected to result in small releases and have a negligible effect on overall risk levels.

Valve Restricts Flow (X44)

A liquid valve that is partially closed or an end cap in place would restrict liquid flow and preclude proper excess flow valve operation. A probability of 1.0 was assumed for this event.

Excess Flow Valve Defective (X45)

A general rate of defective manufactured parts is given in event $\times 30$ as $3 \times 10^{-3} /$ part. It is believed that this value is conservative by a factor of 10 for valves in service since Chlorine Institute practice is to visually inspect the valves at least every other trip. A value of $3 \times 10^{-4}$ was used for this event. 
Accident Forces Fail Excess Flow Valve (X46)

Impact forces are representative of accident forces that the valve may experience. The excess flow valve is designed to survive accidents by its internal location in the tank and rugged construction. It was assumed that the valve would not fail at impact stress levels below that required to fail the tank shell. This failure was included in other events. A probability of zero was used for this event.

Improperly Installed Liquid Valve Gasket Permits Chlorine Release (X47)

A value of $9 \times 10^{-6}$ was used (see $\times 32$ ). Releases from this event are expected to be small and have a negligible effect on overall risk levels. Deteriorated Liquid Valve Gasket Permits Chlorine Release (X48)

A value of $1.9 \times 10^{-6}$ was used (see $\times 33$ ). Releases from this event are expected to be small and have a negligible effect on overall risk levels.

Liquid Valve Not Closed (X49)

This event has a probability of $3 \times 10^{-5}$ (see $\times 34$ ). Liquid Valve Seat Faulty (X50)

A probability of $9 \times 10^{-6}$ was used (see $\times 35$ ). Releases from this event are expected to be small and have negligible effect on overall risk levels. Liquid Valve Packing Not Installed (X51)

A probability of $3.0 \times 10^{-5}$ was used (see $\times 34$ ). Releases from this event are expected to be small and have a negligible effect on overall risk levels. Liquid Valve Plug Not Attached (X52)

A probability of $3.0 \times 10^{-5}$ was used (see $\times 34$ ). Liquid Valve Plug Loose (X53)

A probability of $10^{-2}$ was used (see $\times 38$ ). Releases from this event are expected to be small and have a negligible effect on overall risk levels. 
Pressure Forces Sufficient to Fail Gas Valve Meeting Design Specifications (X56)

Other pressure retaining parts are controlling for pressure failure when the tank is in a normal condition. A probability of zero was used for this event (see $\times 41$ ).

Pressure Forces Sufficient to Fail Defective Liquid Valve (X57)

A probability of 0.13 was used (see $\mathrm{X} 42$ ).

Fire Sufficient to Fail Liquid Valve Gasket (X58)

A probability of 0.1 was used for this event (see X43). Releases from this event are expected to be small and have negligible effects on overall risk levels.

Improperly Installed Relief Valve Gasket Permits Chlorine Release (X59)

A probability of $9 \times 10^{-6}$ was used (see $\times 32$ ). Releases from this event are expected to be small ahd have negligible effects on overall risk levels. Deteriorated Relief Valve Gasket Permits Chlorine Release (X60)

A probability of $1.9 \times 10^{-6}$ was used (see $\times 33$ ). Releases from this event are expected to be small ard have negligible effects on overall risk levels.

Chlorine Released from Defective Relief Valve During Transport (X61)

A general rate of manufacturing error is estimated in event $\times 30$ as $3 \times 10^{-3} /$ part. The reference relief valve consists of two separate sealing mechanisms. For this reason, a factor of $3 \times 10^{-3}$ was applied to each which results in a probability of $9 \times 10^{-6}$ for this event.

Chlorine Released When Faulty Relief Valve Opens During Normal Transport (X62)

Event 61 presents the probability of any size opening of a defective relief valve. This event considers the probability of a valve opening because of a major part failure or deterioration. No data are available. Regular inspections and testing of valves suggest that this event is less likely than X61. The probability used in X61 was reduced by a factor of 10 to account for these inspection practices. A probability of $9 \times 10^{-7}$ was used for this event. 
Fire Sufficient to Produce 375 psi Tank Pressure (X65)

The relief pressure of $2.6 \mathrm{MPa}$ (375 psi) was assumed to occur immediately after a shell full condition is achieved. Shell-full could occur in a 100-minute or longer fire. The probability of this event, given the car is involved in a fire, was estimated from Figure 5.1 to be 0.13 .

Fire Sufficient to Fail Relief Valve Gasket (X66)

A probability of 0.1 was used (see $\times 31$ ). Releases from this event are expected to be small and have a negligible effect on overall risk levels. Corroded Heads Fail During Normal Transport (X67)

The probability of this event was included in event $X 3$. A probability of zero was used here.

Fire Duration Results in Partial Emptying of the Tank (X68)

This event presents the probability of a fire of sufficient duration to empty an upright undamaged tank car to the point where the liquid chlorine does not suffsufficiently cool the tank shell. A fatigue failure results. No differentiation will be made in this analysis between tank walls or heads. Reference 6 states that during a full scale test with both uninsulated and insulated propane cars, half emptying of the tank in an enveloping fire was necessary for tank failure. This is estimated to require a 287 -minute fire. Fire duration in Figure 5.1 report probability information for fires lasting up to 160 minutes. The probability of a 160-minute or longer fire is 0.07 . This value was used here as a conservative estimate for a 287-minute or longer fire probability.

Relief Valve Opens When Pressure Rises (x70)

The value of this event was taken as a 1.0 ( see $\times 9$ ).

Crush Forces Fail Tank Head in Accident (X71)

The probability of a tank head failure due to crush forces was considered with the walls in events $X 14$ and $X 15$. A probability of zero was assigned to this event. 
Crush Forces Fail Manway Cover in Accident (X72)

The probability of a manway cover failure due to crush forces was considered with the walls in events $X 14$ and $X 75$. A probability of zero was assigned to this event.

Fire Forces Fail Tank Head in Accident (X73)

The probability of this event was combined with fire failure of the tank walls.

Tank Experiences End Impact (X74)

Sixteen percent of impact accidents involving the railcar are estimated to be side impacts (see $\times 6$ ). Assuming all impacts can be considered to act on either the side or end of the chlorine tank car the probability of an end impact given the car is involved in an impact accident is 0.834 . Impact Forces Sufficient to Fail Tank Meeting Design Specs (X75)

The failure threshold for a normal chlorine railcar in an end-impact situation is reported in Section 6 to be $52 \mathrm{kph}$. The probability of a $52 \mathrm{kph}$ or greater impact, given that an accident has occurred, is reported in Figure 5.2 to be $3.1 \times 10^{-3}$. Impact Forces Sufficient to Fail Tank Not Meeting Design Specs (X76)

The failure threshold for a defective railcar exposed to an end impact is reported in Section 6 to be $15 \mathrm{kph}$. The probability of this event given a train accident was taken from Figure 5.2 to be $2.9 \times 10^{-2}$.

Puncture Probe Strikes Tank Head (X77)

For the period 1965 to 1970 punctures were observed in 13 pressure type welded cars. Nine of these occurred in the tank heads. (3) The probability of this event was taken as $9 / 13$ or $6.9 \times 10^{-1}$.

Puncture Situation Sufficient to Fail Tank Heads Not Meeting Design Specs (X78)

It is expected that an off-design package condition will not appreciably alter its puncture resistance. Therefore, the probability of this event has been included in event X79. A value of zero was used here. 
Puncture Situation Sufficient to Fail Tank Heads Meeting Design Specs (X79)

The probability of a tank head puncture per reportable accident is estimated from Table 5.2 for a head thickness of $2.06 \mathrm{~cm}(0.81 \mathrm{in.})$ to be $5.6 \times 10^{-4}$.

As a sensitivity study, the effect on risk of adding protective head shields was examined (see Appendix A). An "effective thickness" of $2.93 \mathrm{~cm}$ (1.16 in.) was calculated as a basis of the probability (see Appendix C). A puncture probability of $4.4 \times 10^{-4}$ per reportable accident was determined for this thickness.

Fire Impinges on Tank Wal1s (X83)

Fires in this analysis were conservatively assumed to envelope the tank. A probability of 1.0 was assigned to this event.

Tank Upright (X84)

Reference 1 reports a probability of 0.75 for this event following a derailment accident. This value was assumed valid for all rail accidents involving mechanical forces.

Car Overturns $(x 85)$

A probability of $0.25^{(1)}$ was used (see $\times 84$ ). Tank Involved in Accident Sufficient to Remove Insulation from Tank Walls (X86)

It was assumed for this event that accidents capable of removing insulation are represented by impact and crush environments. Section 5.1 reports a probability per reportable accident of $2 \times 10^{-3}$ for crush forces and 0.15 for impact forces which act on the chlorine railcar. It was conservatively assumed that any significant impact or crush forces are capable of removing insulation. A probability of $1.52 \times 10^{-1}$ was used for this event.

Fire Duration Sufficient to Cause Lading Loss from Tank with Reduced Thermal Protection (X87)

Section 6 of this report states that a 100-minute fire is required to half empty an upright car with reduced thermal protection. The probability of a 100-minute or longer fire when combined with the probability that the car 
is in the fire is estimated to be $3 \times 10^{-4}$. This value will be used in the base case analysis. Information presented in Reference 1 states that fire occurs in $1 \%$ of derailment or collision accidents. These combination accidents are responsible for $46 \%$ of all accidental fire damage. It is assumed in this study that cars involved in the collision are also involved in a resultant fire. Based on the large amounts of damage from derail/collision fires, fire durations following a mechanical accident could be longer than the average. A sensitivity case will also be studied where a fire of sufficient duration to cause car failure is postulated to occur in $1 \%$ of accidents involving mechanical forces which act on the railcar. The probability of this event including the probability that the car is involved in the fire is 0.01 .

Fire Sufficient to Cause Excessive Liquid Relief Requirements (X89)

This event postulates a fire of sufficient duration to overpressurize an overturned railcar with normal thermal protection. See Section 6 for a discussion of this failure mode. A fire duration of 164 minutes is required for failure to occur. Figure 5.1 presents data on fire durations up to 160 minutes. The probability of a 160-minute fire or longer is 0.07 .

Two sensitivity cases were tried for this event. The first postulates a $13-\mathrm{kg} / \mathrm{sec} 1$ iquid discharge capacity for the relief valve. The tank is predicted to fail in a 175-minute fire with this valve. Figure 5.1 presents probabilities for fires up to 160 minutes. A 160-minute fire has essentially the same probability as a 174-minute fire. The second sensitivity case postulates a $36-\mathrm{kg} / \mathrm{sec}$ liquid discharge capacity relief valve. This valve would prevent excessive tank pressures, but the tank could still fail due to high temperature metal fatigue. A fire duration of 140 minutes with a probability from Figure 5.1 of 0.08 would be required for this failure mode.

Manway Cover Experiences Impact Forces (X91)

Based on the ratio of exposed areas of the manway cover and chlorine tank, it is estimated that the manway cover has a probability of being struck of $8.0 \times 10^{-4}$. 
Impact Forces Sufficient to Fail Manway Cover Meeting Design Specifications (X92)

An impact sufficient to fail the manway cover is assumed capable of failing the tank walls. The probability of this event is included in $X 12$ and X15. A value of zero was used for this event.

Impact Forces Sufficient to Fail Manway Cover Not Meeting Design Specs (X93)

It was conservatively assumed that any significant impact could fail a damaged manway cover. The probability of this event was estimated from Figure 5.2 to be 0.15 .

Manway Cover Does Not Meet Design Specs (X94)

A probability of $3 \times 10^{-3}$ was used as a general rate of manufacturing defects which escape detection.

Gasket Exposed to Fire Environment (X95)

A11 fires were assumed to envelop the tank car. Therefore from the discussion on event $X 2$ a probability of $2.3 \times 10^{-3}$ was used for this event.

Fire Sufficient to Overpressurize Weakened Manway Cover (X96)

A probability of 0.42 was used (see $\times 18$ ).

Manway Cover Experiences Accident Forces (X97)

Impact data were taken as representative of accident forces. A probability of $8 \times 10^{-4}$ was used (see $\times 91$ ).

Accident Forces Sufficient to Weaken Manway Cover (X98)

Impacts between the lower failure limit (for a defective tank) and the upper limit (for a normal tank) were assumed to be capable of weakening the manway cover. These probabilities are $3.0 \times 10^{-1}$ and $4.1 \times 10^{-2}$ respectively for accidents with non-zero impacts. ${ }^{1}$ The difference between these values $\left(2.5 \times 10^{-1}\right)$ was used as the probability of this event.

Relief Valve Gasket Exposed to Fire (X99)

Fires involving the tank car were assumed to completely envelop it. Therefore, a probability of one was used for this event. 
Liquid Valve Gasket Exposed to Thermal Environment (X100)

A probability of 1.0 was used (see X99).

Pressure Insufficient to Close Valve (X101)

All chlorine shipments are padded with air prior to shipment (if necessary) to provide enough pressure to activate the excess flow valve. The probability that a low pressure condition will go undetected is $3.0 \times 10^{-3}$ (see $\times 32$ ). The probability that the car will be shipped after a low pressure condition has been detected is $10^{-2}$ (see $\times 34$ ). A probability of $10^{-3}$ was assumed for the low pressure condition to exist since it requires a fill temperature of $-12^{\circ} \mathrm{C}$. The combination of these factors yielded a probability of $1.3 \times 10^{-5}$ for this event.

\section{Liquid Valve Defective (X102)}

A general rate of manufacturing defects was assumed applicable to the liquid valves. A probability of $3 \times 10^{-3}$ was used for this event (see $\times 30$ ). Liquid Valve Packing Faulty (X103)

A probability of $3.0 \times 10^{-5}$ was used (see $\times 34$ ). Releases from this event are expected to be overall and have a negligible effect on overall risk levels. Gas Valve Defective (X104)

A probability of $3.0 \times 10^{-3}$ was used (see $\times 30$ ).

Tank Heads Do Not Meet Design Specs (X107)

A probability of $3 \times 10^{-3}$ was assumed (see $\times 30$ ).

Fire Overpressurizes Normal Tank With Damaged Insulation (X109)

Section 6 reports that a 35 -minute fire duration is required to reach the shell full condition when the insulation is damaged. A probability of $9.2 \times 10^{-4}$ was used in the analysis including the probability that the tank is involved in a fire.

As a sensitivity case for this combination accident, a probability of 0.01 was used for this event including the probability that the car is involved in a fire (see $\times 87$ ). 
Fire Causes Excessive Relief Requirements When Insulation Damaged (X110)

Section 6 reports that a fire duration of 55 minutes or longer is required to overpressurize an overturned tank with damaged thermal protection. Figure 5.1 reports a probability of 0.2 for fires lasting 55 minutes or longer.

As a sensitivity case for this combination accident, a probability of 0.01 was also used for this event in combination with event $\times 3$ (see $\times 87$ ).

Two additional sensitivity cases were postulated for this event to determine the effect on risk of installing relief valves with $13 \mathrm{~kg} / \mathrm{sec}$ or $36 \mathrm{~kg} / \mathrm{sec}$ liquid discharge capacities. Fire durations of 60 minutes would be required for both cases. The probability of a 60-minute fire was determined from Figure 5.1 to be 0.18 (see $\times 89$ ).

Tank Walls Do Not Meet Design Specifications (X111)

A probability of $10^{-3}$ was assumed.

Tank Walls Involved in Accident Forces (X113)

Impacts were assumed representative of all accident forces. A value of 0.15 was used as an estimate of the probability that a particular car will experience impact forces given that a train accident occurs.

Accident Forces Sufficient to Weaken Tank Walls (X114)

A probability of $2.5 \times 10^{-1}$ was used (see $\mathrm{X} 98$ ). Gas Valve Packing Faulty (X115)

A probability of $3.0 \times 10^{-5}$ was used (see $\times 34$ ). Releases from this event are expected to be small and have a negligible effect on overall risk levels. Tank Dome Experiences Impact (X116)

Based on the ratio of exposed surface area for the dome and tank shell, a probability of $8.2 \times 10^{-3}$ is predicted.

Impact Sufficient to Fail Tank Dome (X117)

Any significant impact on the tank dome was assumed to cause a failure. Figure 5.2 estimates a probability of 0.15 for non-zero impacts given that an accident has occurred. 
Fire Duration Sufficient to Overpressurize Tank With Reduced Thermal Protection (X119)

Section 6 reports that the tank reaches shell full conditions after a 35 -minute fire with reduced thermal protection. This condition is sufficient for failure for a tank which cannot retain relief valve set pressures. Figure 5.1 reports a probability of 0.4 for this event.

As a sensitivity case a probability of 0.01 was also used for this event in combination with event $X 3$ (see $X 87$ ).

\subsection{RELEASE SEQUENCE PROBABILITIES}

The basic event probabilities presented in Section 8.1 provide the basis for evaluating the probability of each release sequence identified in the fault tree. The probabilities of the release sequences presented in Table 7.4 are shown in Table 8.1. Only the release sequences with a frequency of occurrence greater than $10^{-15}$ per shipment are listed in the table. The total probability per shipment that a release will occur is $1.9 \times 10^{-4}$.

\subsection{RELEASE MAGNITUDES}

The environmental consequence model presented in Section 9 requires information on potential chlorine release sizes and release rates. This information is used to predict the extent of lethal chlorine gas concentrations. In general, release magnitudes are only affected by the release type and available emergency response. This is because only the pressure relief valve and excess liquid flow valves are capable of terminating a release once it is initiated. Emergency response personnel and equipment are available at many places in the U.S. to deal with small chlorine releases. Most chlorine releases are terminated before they become a public hazard. However, if a release is beyond emergency response capabilities, the entire car will eventually be released.

Chlorine release rates depend on the thermodynamic state of the released chlorine and the tank failure mode. During a catastrophic tank failure, the chlorine releases can be characterized by a large initial "puff" due to adiabatic cooling of the depressurized liquid, followed by a period of evaporative 


\section{TABLE 8.1. Release Sequence Probabilities}

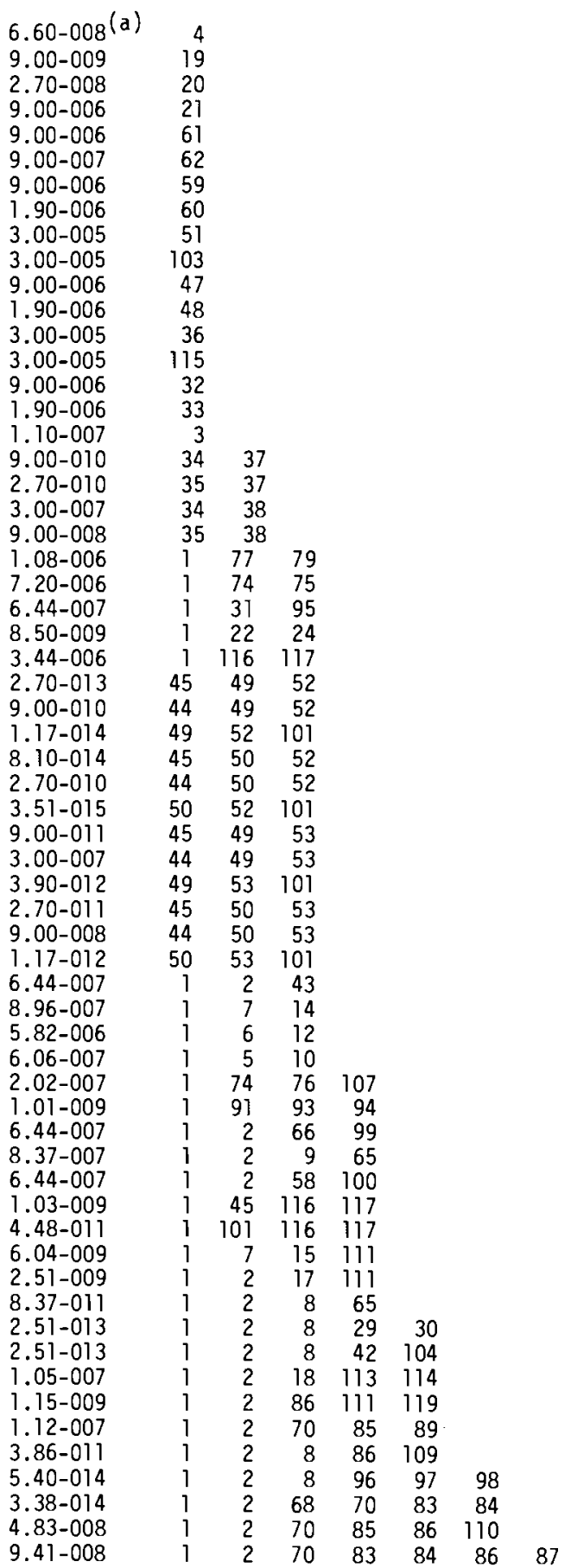

(a) Read $6.6 \times 10^{-8}$ 
releases from the remaining subcooled liquid. Areas covered with lethal concentrations from the evaporative releases are expected to be smaller than and enveloped by areas covered by the initial puff. Consequences of these evaporative releases were considered negligible. Puff release magnitudes are increased with increasing tank temperatures. Release rates through sma 11 openings in the tank shell depend mainly on the hole size and the phase (i.e., liquid or gas) of the released material. A hole below the liquid level line on the tank would release chlorine faster than a hole in communication with the vapor space.

Release magnitudes and rates are a continuous function of the tank failure mode and thermodynamic state of the chlorine liquid. Consideration of a continuous release function would be an extremely large task. For this reason, five release categories were selected for analysis, based on the above discussion, to represent the actual release spectrum:

- An instantaneous release of $32 \%$ of the tank contents. The nominal release size for this release is $2.6 \times 10^{4} \mathrm{~kg}$. This release could result from a catastrophic tank failure at the safety relief venting temperature $\left(60^{\circ} \mathrm{C}\right)$.

- An instantaneous release of $17 \%$ of the tank contents. The nominal release size for this release is $1.3 \times 10^{4} \mathrm{~kg}$. This release could result from a catastrophic tank failure at ambient temperature $\left(21^{\circ} \mathrm{C}\right)$.

- A continuous release of $9.8 \mathrm{~kg} / \mathrm{sec}$. This represents a liquid discharge from a relief value sized opening in the tank shell. Flash vaporization from the release stream and vaporization from the material on the ground are included.

- A continuous release of $3.9 \mathrm{~kg} / \mathrm{sec}$. This represents a gaseous discharge from the relief valve at sonic velocity.

- Other small releases. These releases would result in small areas of toxic concentrations. It was assumed in this analysis that these releases were less than $0.1 \mathrm{~kg} / \mathrm{sec}$ and have no consequences to the public.

It is convenient to assign release sizes to the release sequences by the portion of the tank from which the material is released and either the accident 
force that causes the release or the orientation of the tank during release. The release fractions used in this analysis are presented in Table 8.2. Only those with nontrivial consequences are included in this table.

TABLE 8.2. Release Magnitudes for Chlorine Tank Car Failure

Portion of Tank Failing

Tank Walls or Heads

Relief Valve

Manway Cover

Gas Valve

Liquid Valve
Failure Cause

(Orientation)

Puncture

Crush

Impact

Fire

Pressure (upright)

Pressure (overturn) Faulty (fire)

Fire

Impact

Puncture

A11 Causes in a transportation accident

A11 Causes in a transportation accident
Release

Fraction

$17 \%$

$17 \%$

$17 \%$

$32 \%$

$3.9 \mathrm{~kg} / \mathrm{sec}$

$9.8 \mathrm{~kg} / \mathrm{sec}$

$32 \%$

$32 \%$

$17 \%$

$17 \%$

$3.9 \mathrm{~kg} / \mathrm{sec}$

$9.8 \mathrm{~kg} / \mathrm{sec}$ 


\section{REFERENCES}

1. A. W. Dennis et a1., Severities of Transportation Accidents Involving Large Packages. SAND77-0001, Sandia Laboratories, A1buquerque, NM, May 1978.

2. B. J. Garrik et a1., The Effect of Human Error and Static Component Failure on Engineered Safety System Reliability. HN-194, Holmes and Narver, Inc., Los Angeles, CA, November 1967.

3. Railroad Tank Car Safety Research and Test Project, Final Phase 02 Report on Accident Review. RA-02-2-18, Association of American Railroads, Chicago Research Center, Chicago, IL, August 1972.

4. U.S. Nuclear Regulatory Commission, Reactor Safety Study. WASH-1400, Washington DC, October 1975.

5. B. J. Garrick et al., Reliability Analysis of Nuclear Power Plant Protective System. HN-190, May 1967 (Reference 5).

6. Railroad Tank Car Safety Research and Test Project, Phase II Report on Ful1 Scale Fire Tests. RA-11-6-31, Association of American Railroads, Chicago Research Center, Chicago, IL, December 1975. 


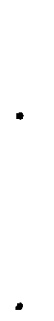

. 


\subsection{EVALUATION OF THE CONSEQUENCES OF CHLORINE RELEASES}

In Section 8 individual release sequences were identified and evaluated by determining their expected frequency of occurrence and the corresponding release fraction. At this point, a risk number could be obtained by multiplying the individual release sequence probabilities and release sizes together, and summing over a 11 release sequences. The resulting risk number, however, would not be in a form suitable for use in comparison with other societal risks. Such a comparison is one of the objectives of the risk assessment.

To express the risk in a more suitable form, conversion factors must be developed to allow modification of the consequence portion of the risk number (in this case, to fatalities). The purpose of this section is to develop these conversion factors. In general, a consequence model for toxic releases must address mechanisms of transport to areas of human contact, the number of persons potentially exposed and the health consequences of various exposure levels. Specific areas in this analysis include: health effects, meteorology, demography, evacuation, and quantity made airborne and dispersed. The final portion of this section will show how these factors are applied to the risk number to express the risk in a form suitable for comparisons.

\subsection{HEALTH EFFECTS}

When 1 iquid chlorine at ambient temperatures is released to the atmosphere, a vapor and liquid fraction are formed at low temperatures by adiabatic cooling. The relative fractions of the two depends on the initial temperature and pressure of the stored liquid. Appendix B contains both thermodynamic and toxilogical properties of chlorine.

The liquid fraction is a local hazard. Physical contact with this phase can cause burns due to its reactive nature and low temperature. Gas is continuously evolved at a rate that depends on the local soil conductivities.

A gas phase chlorine release may present a hazard to the general public. It is heavier than air and tends to form a dense layer near the ground and in 
low areas. If the duration of exposure or the concentration of chlorine is excessive, general excitement accompanied by restlessness, throat irritation, sneezing and copious salivation results. The symptoms of exposure to high concentrations are retching and vomitting, followed by difficult breathing. In extreme cases, the difficulty of breathing may increase to the point of death. (1)

Several investigators have attempted to quantify fatal chlorine exposure levels (see Appendix B). For purposes of this report, it was assumed that exposure to concentrations above 1,000 ppm are immediately fatal. Doses which exceed 1,000 ppm-min above concentrations of $35 \mathrm{ppm}$ are assumed fatal to $50 \%$ of those exposed. Exposures below $35 \mathrm{ppm}$ are assumed to induce no fatalities regardless of exposure durations.

\subsection{METEOROLOGY}

The diffusion climatology along the transport route can be incorporated into any risk analysis where the atmosphere is an important pathway for exposures to nearby populations. The important atmospheric variables are: 1) wind direction - indicates direction of trave1,2) wind speed - indicates the rate of transport; and 3) atmospheric stability - indicates the rate of dilution and plume spread potential. Certain characteristics of release e.g., height, temperature and gas densities) are also important in the evaluation of the atmospheric pathway.

Assuming a postulated accident with a surface release and little or no release-related plume rise, the immediate and greatest impact will be in the region surrounding the location of the event. Transport and diffusion are often determined by local influences on wind speeds, directions and stability. Examples of local influences include topography (surface roughness, channeling), heat island effects, and proximity to large bodies of water. The inclusion of such site specific influences in the present analysis is not feasible, principally because the information is not available either from a data base or from current modeling capabilities. Meteorological conditions modeled in this report represent a cross section of typical situations encountered in the U.S. and thus provide a representative sampling of potential spill environments. 
The meteorological data used in this analysis are shown in Table 9.1. The values were developed from micrometeorological data collected for diffusion calculations for nuclear power plant sites. Seven sets of micrometeorological data were selected from about 26 compilations from reactor sites to account for the range of conditions that could reasonably occur along transportation routes. The use of a single averaged distribution allows for the typical range of wind speeds without undue weighting to any particular site. Although this result cannot be expected to necessarily represent any particular portion of the route, it does represent the type of conditions that may be encountered on the average.

TABLE 9.1. Average Windspeed/Stability Characteristics

\begin{tabular}{|c|c|c|c|c|c|c|}
\hline \multicolumn{3}{|c|}{ Wind Speed } & \multicolumn{4}{|c|}{ Pasquill Stability Classification } \\
\hline$U_{k}$ & & & & $\pi$ & & \\
\hline $\mathrm{m} / \mathrm{sec}$ & $\mathrm{k}$ & $P_{K}$ & $B(j=1)$ & $D(j=2)$ & $E(J=3)$ & $F(J=4)$ \\
\hline 1 & 1 & 0.255 & 0.136 & 0.202 & 0.299 & 0.363 \\
\hline 3.5 & 2 & 0.508 & 0.243 & 0.274 & 0.272 & 0.211 \\
\hline 7 & 3 & 0.161 & 0.190 & 0.290 & 0.339 & 0.181 \\
\hline 10 & 4 & 0.052 & 0.240 & 0.312 & 0.358 & 0.090 \\
\hline 18 & 5 & 0.024 & 0.276 & 0.348 & 0.356 & 0.020 \\
\hline
\end{tabular}

\subsection{DEMOGRAPHY}

The purpose of this section is to characterize the population distribution in the United States in order to determine the frequency at which a given population would be exposed to an accident.

To do this, the United States was divided into the nine Census Bureau regions (excluding $A l$ aska and Hawai from the pacific division). These regions are shown in Figure 9.1. Data on population and land area were then collected for each region.

The population densities were grouped into three classes; Urbanized Areas, other urban and rural. An urbanized area is a city or connecting cities with a total population of 50,000 and contingent areas of 2,500 population. 0 ther 


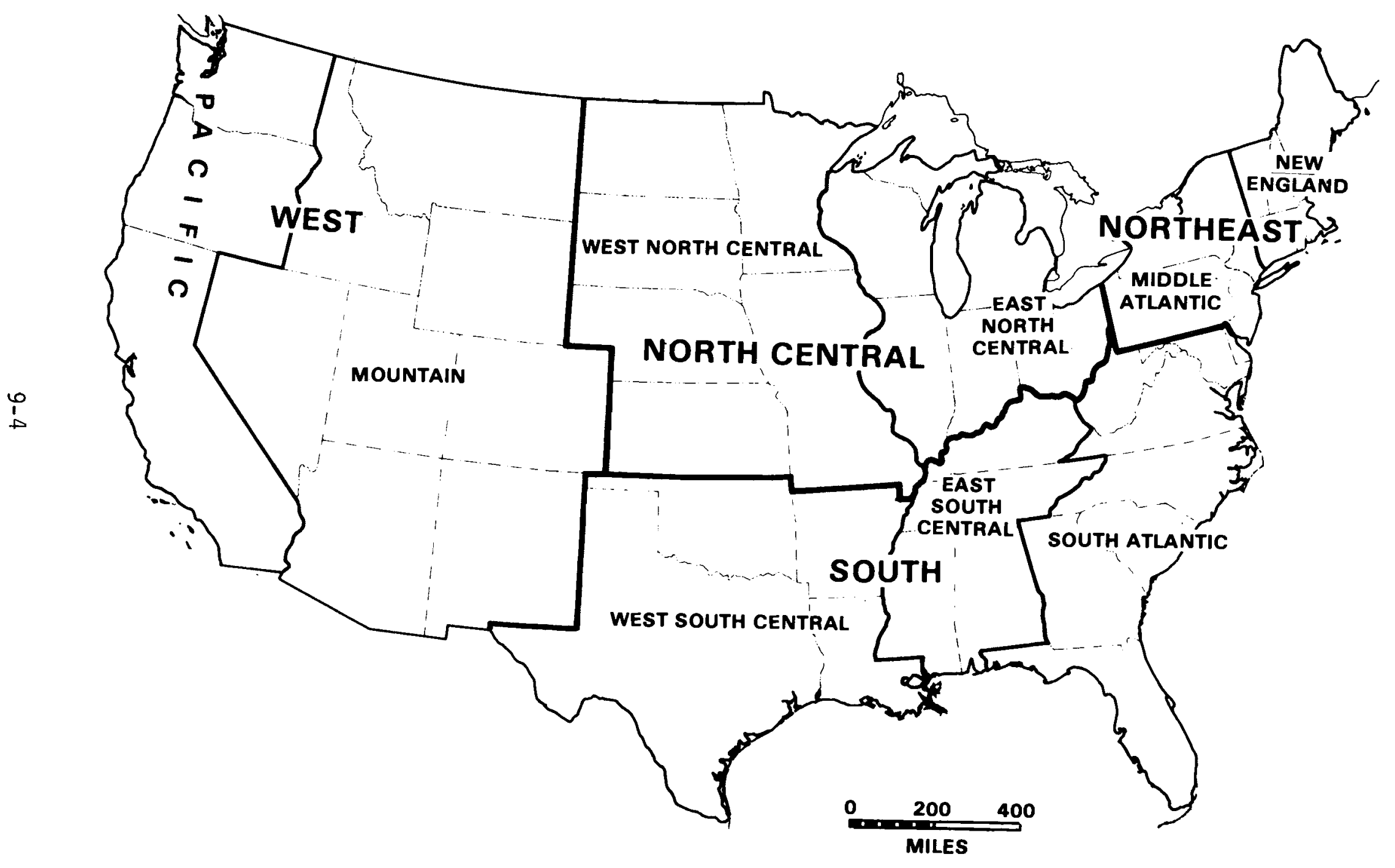

FIGURE 9.1. Map of the U.S. Showing Census Divisions and Regions 
urban areas are places with populations equal to or greater than 2,500 persons and are not included in the urbanized areas. Rural areas are assumed to be all other areas.

The total population and land area of each region in 1974 are given in the Statistical Abstract. (2) Land areas for urban regions (urbanized areas and other urban) in 1970 were obtained from a Department of Commerce Report ${ }^{(3)}$ and updated to 1974 using a supplementary report on areas established since 1970. (4) The supplementary report also provides 1974 population information on Urban regions. Rural population and land areas were found by subtraction from the totals. Densities and land area percents were calculated and the information summarized in Table 9.2.

The population and land areas were then extrapolated to 1985. A report by J. P. Pickard ${ }^{(5)}$ predicts that between 1975 and $2000,77 \%$ of the population growth will occur in urban regions. Using 1985 population projections given in the Statistical Abstract, $77 \%$ of the total growth was distributed between urbanized areas and other urban areas by the ratio of their 1974 populations. The remainder was added to the rural population. Figure 3.4 in Population and the American Future ${ }^{(6)}$ predicts that between 1974 and 1985 urban land area will grow approximately 25\%. Using this figure and the 1974 data, 1985 values were calculated. As before, rural land area was found by subtraction. Census data for 1985 are given in Table 9.3.

\subsection{EVACUATION MODELS}

Potential consequences following the release and dispersion of chiorine vapors in a transportation accident can be reduced by the actions of persons in the affected area. The maximum potential number of persons exposed to toxic chlorine levels is the product of the population density and dispersion areas. However, in the case of large releases, the cloud size may be significantly larger than the adjacent urban area. Thus assuming an urban population density for the entire cloud area yields overly conservative results. A correction was made for postulated releases in urban and other urban areas based on city size to reduce potential mortalities to more realistic levels (see Section 9.6). 


\section{TABLE 9.2. 1974 Census Data}

\begin{tabular}{|c|c|c|c|c|}
\hline & Population & Land Area $\left(\mathrm{kn}^{2}{ }^{2}\right)$ & Density (People $/ \mathrm{km}^{2}$ ) & Land Area $(\%)$ \\
\hline \multicolumn{5}{|l|}{ New England } \\
\hline Total & $12,150,000$ & 172,515 & 70.4 & $100.0 \%$ \\
\hline Urbanized Areas & $7,666,000$ & 6,843 & $1,120.0$ & $4.0 \%$ \\
\hline Other Urban & $1,409,000$ & 4,281 & 329.0 & $2.5 \%$ \\
\hline Rural & $3,075,000$ & 161,391 & 17.3 & $93.5 \%$ \\
\hline \multicolumn{5}{|l|}{ Middle Atlantic } \\
\hline Total & $37,401,000$ & 266,110 & 140 & $100.0 \%$ \\
\hline Urbanized Areas & $27,510,000$ & 13,996 & 1,970 & $5.3 \%$ \\
\hline Other Urban & $2,928,000$ & 3,386 & 865 & $1.3 \%$ \\
\hline Rural & $6,963,000$ & 248,728 & 28 & $93.4 \%$ \\
\hline \multicolumn{5}{|l|}{ East North Central } \\
\hline Total & $40,824,000$ & 643,053 & 62.7 & $100.0 \%$ \\
\hline Urbanized Areas & $24,818,000$ & 18,443 & $1,350.0$ & $2.9 \%$ \\
\hline Other Urban & $5,309,000$ & 6,355 & 835.0 & $1.0 \%$ \\
\hline Rural & $10,697,000$ & 618,255 & 17.3 & $96.1 \%$ \\
\hline \multicolumn{5}{|l|}{ West North Central } \\
\hline Total & $16,682,000$ & $1,339,670$ & 12.5 & $100.0 \%$ \\
\hline Urbanized Areas & $6,876,000$ & 6,716 & $1,020.0$ & $0.5 \%$ \\
\hline Other Urban & $3,517,000$ & 5,344 & 658.0 & $0.4 \%$ \\
\hline Rural & $6,289,000$ & $1,327,610$ & 4.7 & $99.1 \%$ \\
\hline \multicolumn{5}{|l|}{ South Atlantic } \\
\hline Total & $33,206,000$ & $7 \cdot 22,030$ & 46.0 & $100.0 \%$ \\
\hline Urbanized Areas & $15,196,000$ & 13,773 & 1,100 & $1.9 \%$ \\
\hline Other Urban & $4,454,000$ & 8,224 & 542 & $1.1 \%$ \\
\hline Rural & $13,556,000$ & 700,033 & 19.4 & $97.0 \%$ \\
\hline \multicolumn{5}{|l|}{ East South Central } \\
\hline Total & $13,387,000$ & 471,287 & 28.4 & $100.0 \%$ \\
\hline Urbanized Areas & $4,457,000$ & 5,281 & 844 & $1.1 \%$ \\
\hline Other Urban & $2,550,000$ & 5,924 & 430 & $1.3 \%$ \\
\hline Rural & $6,380,000$ & 460,082 & 13.9 & $97.6 \%$ \\
\hline \multicolumn{5}{|l|}{ West South Central } \\
\hline Total & $20,584,000$ & $1,136,710$ & 18.1 & $100.0 \%$ \\
\hline Urbanized Areas & $10,199,000$ & 11,305 & 902 & $1.0 \%$ \\
\hline Other Urban & $3,846,000$ & 7,469 & 515 & $0.7 \%$ \\
\hline Rural & $6,539,000$ & $1,117,936$ & 5.8 & $98.3 \%$ \\
\hline \multicolumn{5}{|l|}{ Mountain } \\
\hline Total & $9,411,000$ & $2,237,467$ & 4.2 & $100.0 \%$ \\
\hline Urbanized Areas & $4,176,000$ & 4,098 & 1,019 & $0.2 \%$ \\
\hline Other Urban & $1,879,000$ & 3,190 & 589 & $0.1 \%$ \\
\hline Rural & $3,356,000$ & $2,230,179$ & 1.5 & $99.7 \%$ \\
\hline \multicolumn{5}{|c|}{ Pacific (w/o Alaska and Hawaij) } \\
\hline Total & $26,649,000$ & 838,813 & 30.4 & $100.0 \%$ \\
\hline Urbanized Areas & $19,282,000$ & 13,067 & 1,476 & $1.6 \%$ \\
\hline Other Urban & $2,767,000$ & 4,527 & 611. & $0.5 \%$ \\
\hline Rural & $4,600,000$ & 821,219 & 5.6 & $97.9 \%$ \\
\hline
\end{tabular}




\section{TABLE 9.3. Projected 1985 Census Data}

\begin{tabular}{|c|c|c|c|c|}
\hline & Population & Land Area $(\mathrm{km} 2)$ & Density (people/ $/ \mathrm{km}^{2}$ ) & Land Area $(\%)$ \\
\hline \multicolumn{5}{|l|}{ New England } \\
\hline Total & $13,997,000$ & 172,510 & 81.1 & $100.0 \%$ \\
\hline Urbanized Areas & $8,867,000$ & 8,525 & 1,040 & $4.9 \%$ \\
\hline Other Urban & $1,630,000$ & 5,333 & 306 & $3.1 \%$ \\
\hline Rural & $3,500,000$ & 158,652 & 22.1 & $92.0 \%$ \\
\hline \multicolumn{5}{|l|}{ Middle Atlantic } \\
\hline Total & $41,930,000$ & 266,110 & 158 & $100.0 \%$ \\
\hline Urbanized Areas & $30,662,000$ & 17,436 & 1,760 & $6.6 \%$ \\
\hline Other Urban & $3,263,000$ & 4,218 & 774 & $1.6 \%$ \\
\hline Rural & $8,005,000$ & 244,456 & 32.7 & $91.8 \%$ \\
\hline \multicolumn{5}{|l|}{ East North Centra? } \\
\hline Total & $47,042,000$ & 643,053 & 73.2 & $100.0 \%$ \\
\hline Urbanized Areas & $28,762,000$ & 22,976 & 1,260 & $3.6 \%$ \\
\hline Other Urban & $6.753,000$ & 7,917 & 177 & $1.2 \%$ \\
\hline Rural & $12,127,000$ & 612,160 & 19.8 & $95.2 \%$ \\
\hline \multicolumn{5}{|l|}{ West North Central } \\
\hline Total & $17,995,000$ & $1,339,670$ & 13.4 & $100.0 \%$ \\
\hline Urbanized Areas & $7,545,000$ & 8,367 & 902 & $0.6 \%$ \\
\hline Other Urban & $3,859,000$ & 6,657 & 580 & $0.5 \%$ \\
\hline Rural & $6,591,000$ & $1,324,646$ & 5.0 & $98.9 \%$ \\
\hline \multicolumn{5}{|l|}{ South Atlantic } \\
\hline Total & $36,942,000$ & 722,030 & 51.2 & $100.0 \%$ \\
\hline Urbanized Areas & $17,421,000$ & 17,157 & 1,020 & $2.4 \%$ \\
\hline Other Urban & $5,106,000$ & 10,245 & 498 & $1.4 \%$ \\
\hline Rural & $14,415,000$ & 694,628 & 20.8 & $96.2 \%$ \\
\hline \multicolumn{5}{|l|}{ East South Central } \\
\hline Total & $13,793,000$ & 471,287 & 29.3 & $100.0 \%$ \\
\hline Urbanized Areas & $4,656,000$ & 6,579 & 708 & $1.4 \%$ \\
\hline Other Urban & $2,664,000$ & 7,380 & 361 & $1.6 \%$ \\
\hline Rural & $6,473,328$ & 457,328 & 14.2 & $97.0 \%$ \\
\hline \multicolumn{5}{|l|}{ West South Central } \\
\hline Total & $22,804,000$ & $1,736,710$ & 20.1 & $100.0 \%$ \\
\hline Urbanized Areas & $11,440,000$ & 14,083 & 812 & $1.2 \%$ \\
\hline Other Urban & $4,314,000$ & 9,305 & 464 & $0.8 \%$ \\
\hline Rural & $7,050,000$ & $1,113,322$ & 6.3 & $98.0 \%$ \\
\hline \multicolumn{5}{|l|}{ Mounta in } \\
\hline Total & $10,286,000$ & $2,237,467$ & 4.6 & $100.0 \%$ \\
\hline Urbanized Areas & $4,641,000$ & 5,105 & 909 & $0.2 \%$ \\
\hline Other Urban & $2,088,000$ & 3,974 & 524 & $0.2 \%$ \\
\hline Rural & $3,557,000$ & $2,228,388$ & 1.6 & $99.6 \%$ \\
\hline \multicolumn{5}{|c|}{ Pacific (w/o Alaska and Hawaij) } \\
\hline Total & $33,257,000$ & 838,813 & 39.6 & $100.0 \%$ \\
\hline Urbanized Areas & $23,732,000$ & 16,278 & 1,460 & $1.9 \%$ \\
\hline Other Urban & $3,406,000$ & 5,640 & 604 & $0.7 \%$ \\
\hline Rural & $6,120,000$ & 816,895 & 7.5 & $97.4 \stackrel{\%}{\mu}$ \\
\hline
\end{tabular}


Urban area sizes were determined by dividing total urban area in each census region (Table 9.3) by the number of urbanized areas in each region existing in 1970. (7) . Other urban area sizes were obtained by taking the population distribution of other urban places ${ }^{(2)}$ and finding the average population. The area of average other urban places is the quotient of the average other urban place population and the census region population densities. A rural area was assumed to be large enough to completely contain all release isopleths. Results of these calculations are presented in Table 9.4.

A study by the U.S. Environmental Protection Agency ${ }^{(8)}$ of historic evacuation data, indicates that during an evacuation, populations act rationally. If this is true, two courses of action exist for individuals in the path of a chlorine release; evacuate or seek shelter. The remainder of this section describes an evacuation and shelter model used in the analysis of consequences from chlorine releases. Evacuations may be initiated by two mechanisms. The first is a direct perceived hazard by individual. This type of threat may cause some persons to flee and others to seek shelter. No official coordination of public efforts is expected in this situation. The second is an evacuation, directed by public officials in the absence of perceived individual threats. This type of evacuation occurs when officials perceive a potential hazard and take timely action. This action requires relatively long lead times, but results in well coordinated population movements.

\section{TABLE 9.4. Average Sizes of Urban}

Places in the U.S. - 1985

\begin{tabular}{|c|c|c|}
\hline \multirow{2}{*}{ Region } & \multicolumn{2}{|c|}{ Area $\left(\mathrm{km}^{2}\right)$} \\
\hline & Urban & Other Urban \\
\hline New England & 370 & 52 \\
\hline Middle Atlantic & 700 & 21 \\
\hline East North Central & 420 & 21 \\
\hline West North Central & 520 & 28 \\
\hline South Atlantic & 450 & 32 \\
\hline East South Central & 390 & 44 \\
\hline West South Central & 390 & 35 \\
\hline Mountain & 340 & 31 \\
\hline Pacific & 740 & 27 \\
\hline
\end{tabular}


The officially coordinated evacuation may have a risk reducing effect in the event of a large chlorine release. To postulate a mathematical model, a linear regression was performed on transportation related evacuation data provided in Reference 7 and shown in Table 9.5.

Nine transportation accident related evacuations with sufficient data for analysis have been recorded. Most were done as a precaution since material was not always released. An average vehicle speed of $35 \mathrm{mph}^{(8)}$ was used with evacuation distances to estimate travel times. Travel time was then subtracted from the total evacuation time leaving the time required for notification and preparation prior to departure. Departure time as a function of population density was determined to be:

$$
\begin{aligned}
10 \mathrm{~g} \text { (departure time in hours })= & \left.-0.16 \log \text { (persons } / \mathrm{km}^{2}\right) \\
& +0.94
\end{aligned}
$$

\begin{tabular}{|c|c|c|c|c|c|c|}
\hline Events & $\begin{array}{c}\text { Area } \\
\text { Evacuated } \\
\text { (sq mile) }\end{array}$ & $\begin{array}{l}\text { Number of } \\
\text { Persons } \\
\text { Evacuated }\end{array}$ & $\begin{array}{c}\text { Evacuation } \\
\text { Distance } \\
\text { (mile) } \\
\end{array}$ & $\begin{array}{c}\text { Evacuation } \\
\text { Time } \\
\text { (hours) }\end{array}$ & $\begin{array}{l}\text { Population } \\
\text { Density } \\
\text { (Persons/ } \\
\text { (sq mile) } \\
\end{array}$ & $\begin{array}{l}\text { Departure } \\
\text { Time (hrs } \\
\text { o } 35 \mathrm{mph})\end{array}$ \\
\hline $\begin{array}{l}\text { Downington, PA } \\
2 / 5 / 73\end{array}$ & 0.25 & 700 & 1.0 & 2.0 & 3,200 & 1.9 \\
\hline $\begin{array}{l}\text { Chadbourne, NC } \\
1 / 13 / 68\end{array}$ & 0.5 & 350 & 1.0 & 5.0 & 700 & 4.9 \\
\hline $\begin{array}{l}\text { Wetanka, OK } \\
4 / 4 / 69\end{array}$ & 3.0 & 2,000 & 25 & 8.0 & 667 & 7.3 \\
\hline $\begin{array}{l}\text { Louisville, } \mathrm{KY} \\
3 / 19 / 72\end{array}$ & 0.35 & 4,000 & 1.0 & 3.0 & 11,400 & 2.9 \\
\hline $\begin{array}{l}\text { Urbana, } \mathrm{OH} \\
8 / 13 / 68\end{array}$ & 3.1 & 4,000 & 0.75 & 3.5 & 1,300 & 3.5 \\
\hline $\begin{array}{l}\text { Baton Rouge, LA } \\
8 / 65\end{array}$ & 8 & 150,000 & 30 & 2.0 & 19,000 & 1.1 \\
\hline $\begin{array}{l}\text { Morgan City, LA } \\
1 / 19 / 73\end{array}$ & 1.8 & 3,000 & 2 & 4 & 1,800 & 3.9 \\
\hline $\begin{array}{l}\text { Texarkana, TX } \\
8 / 27 / 67\end{array}$ & 9.0 & 5,000 & 3 & 4 & 550 & 3.9 \\
\hline $\begin{array}{l}\text { Glendora, MS } \\
9 / 11 / 69\end{array}$ & 1,200 & 35,000 & 20 & 4 & 29 & 3.4 \\
\hline
\end{tabular}

TABLE 9.5. Transportation Related Evacuations 
Using the demographic data for the nine census regions and the above departure time model, evacuation times were predicted for each region and type of community. Table 9.6 presents this information. These evacuation times are used in Section 9.6 to estimate areas covered by chlorine clouds before evacuation is initiated.

Other considerations of evacuation include the motivation of individuals to evacuate. The perceived risks of remaining in an evacuation zone must exceed those of leaving for a person to evacuate. Even in mandatory evacuations it was found that some people refuse to evacuate. For purposes of this report, it is estimated that $6 \%$ of the population remain in the release area by choice following an evacuation directed by public officials.

The individually motivated evacuation during a chlorine release may be controlled by a rational desire to flee the cloud. It was assumed in the base case of this study that $90 \%$ of the exposed population decide to attempt escape and $10 \%$ take refuge in their homes. Experiments with chlorine done in the Netherlands indicate that automobile engines will operate at levels of chlorine much higher than toxic levels. (9) However, automobiles are not

\section{TABLE 9.6. Predicted Regional Evacuation Times}

\begin{tabular}{|c|c|c|c|c|c|c|}
\hline Census Area (1974) & $\begin{array}{c}\text { Population } \\
\text { Per } \\
\text { Urbanized } \\
\text { Areas } \\
\end{array}$ & $\begin{array}{l}\text { Density } \\
\text { ons } / \mathrm{km}^{2} \\
\text { Other } \\
\text { Urban } \\
\end{array}$ & Rural & $\begin{array}{c}\text { Evacuation } \\
\text { (104 } \\
\text { Urbanized } \\
\text { Areas } \\
\end{array}$ & $\begin{array}{c}\text { Departur } \\
\text { Seconds) } \\
\text { Other } \\
\text { Urban } \\
\end{array}$ & Rural \\
\hline South Atlantic & 1,020 & 498 & 20.8 & 1.04 & 1.17 & 1.95 \\
\hline East South Central & 708 & 361 & 14.2 & 1.11 & 1.23 & 2.07 \\
\hline West South Central & 812 & 464 & 6.3 & 1.08 & 1.18 & 2.36 \\
\hline Mountain & 909 & 524 & 1.6 & 1.06 & 1.16 & 2.93 \\
\hline Pacific & 1,460 & 604 & 7.5 & 0.986 & 1.14 & 2.29 \\
\hline New England & 1,040 & 306 & 22.1 & 1.04 & 1.27 & 1.93 \\
\hline Middle Atlantic & 1,760 & 774 & 32.7 & 0.957 & 1.09 & 1.81 \\
\hline East North Central & 1,260 & 777 & 19.8 & 1.01 & 1.09 & 1.96 \\
\hline West North Central & 902 & 580 & 5.0 & 1.06 & 1.14 & 2.45 \\
\hline
\end{tabular}


expected to give passengers much protection against toxic gases. An extrapolation of data presented in Reference 9 predicts that given an outside lethal concentration it would take 1.5 hours for this concentration to exist in a house of normal construction. For a home with makeshift seals, 8 hours would be required to obtain dangerous concentrations inside. Under these conditions it was assumed that $90 \%$ of the people who take shelter in their homes and $90 \%$ of those who attempt to escape survive the chlorine cloud.

\subsection{ATMOSPHERIC DISPERSION MODEL}

To endanger human life, a chlorine release must reach a population via some pathway in the environment. For the purpose of this study, only air pathways were considered. Food chain and aquatic pathways were not considered for chlorine releases. Although material may reach man via these pathways, the amount of material following these pathways is expected to be insignificant when compared to the air pathway.

Gaussian diffusion models for continuous plumes and instantaneous puffs were used in this analysis. Corrections for negatively buoyant gases and area source specifications by virtual point source methods were made. The use of the puff model corresponds to a large instantaneous release of chlorine, while the continuous model was used for releases from pools and small leaks. A detailed discussion of the dispersion methodology and results for the four release magnitudes (see Section 8.3) are presented in Appendix $E$ of this report.

Results of the continuous release dispersion analysis contain estimates of maximum downwind centerline distances and total affected areas at two chlorine concentrations for each combination of stability class and wind speed. The two concentrations are 1,000 ppm and $35 \mathrm{ppm}$. For the 35-ppm isopleths, it was assumed in the risk analysis that the release duration is sufficient to accumulate a dose of 1,000 ppm-min. Results of the instantaneous puff calculation also report maximum downwind centerline distances and total affected areas for each windspeed and stability class. The 1,000 ppm areas are the integrated swept area of concentrations greater than 1,000 ppm over the pathway of the cloud. Areas with an accumulated dose of greater than 1,000 ppm-min from 
concentrations greater than $35 \mathrm{ppm}$ are also integrated over the cloud path length. Continuous releases from the remaining liquid chlorine pool following the large puff releases were not considered to contribute additional consequences over that of the puff release because of their smaller extent. The effects of instantaneous concentrations above or below the average were not considered. Exposures at a single location over a significant period of time would be of average concentrations. The uncertainty associated with these assumptions is believed to be within the overall accuracy of the study results.

\subsection{ESTIMATED EXPOSURE FREQUENCY}

The information presented in the previous subsections is used to calculate factors to convert release fractions developed in Section 9 to consequences. The remainder of this section will show how these factors are applied with the release sequence probabilities in the risk calculation. The risk calculation proceeds along two parallel and interrelated paths. One path characterizes the consequences of an accidental release, and the other path determines the frequency of occurrence for each event in the consequence analysis.

As briefly discussed in Section 3, risk is expressed by the equation:

$$
R_{i}=P_{R_{i}} \times \sum_{q}\left(C_{E_{i, q}} \times P_{E_{q}}\right)
$$

where $q$ represents a number of indices as indicated below.

The first term $\left(P_{R_{j}}\right)$ represents the probability of occurrence of the release sequence $i$. The information needed to evaluate this term was developed in Section 8. The two terms in the set of parentheses represent the consequences of a material release $\left(C_{E_{i, q}}\right)$ and the probability of encountering a given set of environmental and demographic conditions $\left(P_{E_{q}}\right)$. The purpose of preceding paragraphs in this section was to determine the factors required to evaluate the consequences of a release. Simultaneously, the information required to determine the expected frequency that a given environmental consequence will be encountered has been presented. This part of Section 9 will show the development of the frequency of release term. 
The analysis presented in this section treats the wind speed, atmospheric stability class and population class as distributed variables. The expected frequency of encountering a given set of environmental conditions can be expressed as:

$$
P_{E_{j, k, l, m}}=P_{j / k} P_{k} P_{\ell / m} P_{m}
$$

where:

$j$ is the atmospheric stability classification index

$k$ is the wind speed index

$l$ is the population density index in region $m$ of the U.S.

$m$ is the zone index from the shipping routes (population region).

The notation $j / k$ indicates that the expected frequency of encountering the $j^{\text {th }}$ stability class is a function of the wind speed existing at the time of release. Similarly, the expected frequency of encountering the $e^{\text {th }}$ population density is dependent on the expected frequency that a shipment will pass through zone $\mathrm{m}$.

The values for the "P" in Equation (9-3) are obtained from the following tables in this section:

$$
\begin{aligned}
& P_{k} \text { - Table } 9.1, \text { column } 3 \\
& P_{j / k} \text { - Table } 9.1, \text { columns } 4 \text { through } 7 \\
& P_{\ell / m} \text { - Table } 9.3 \text {, column } 5 \\
& P_{m} \text { - Table } 4.1, \text { column } 2
\end{aligned}
$$

By specifying a value for $j, k, l$, and $m$, one can obtain the expected frequency that an environmental and demographic condition will be experienced during a shipment.

All of the factors discussed in Sections 9.1 to 9.5 are considered in the calculation of potential consequences of liquid chlorine releases. Five combinations of isopleth size, city size and evacuation time are shown in Figure 9.2. A maximum of three zones can be defined within an isopleth and population zone with varying levels of consequence: 

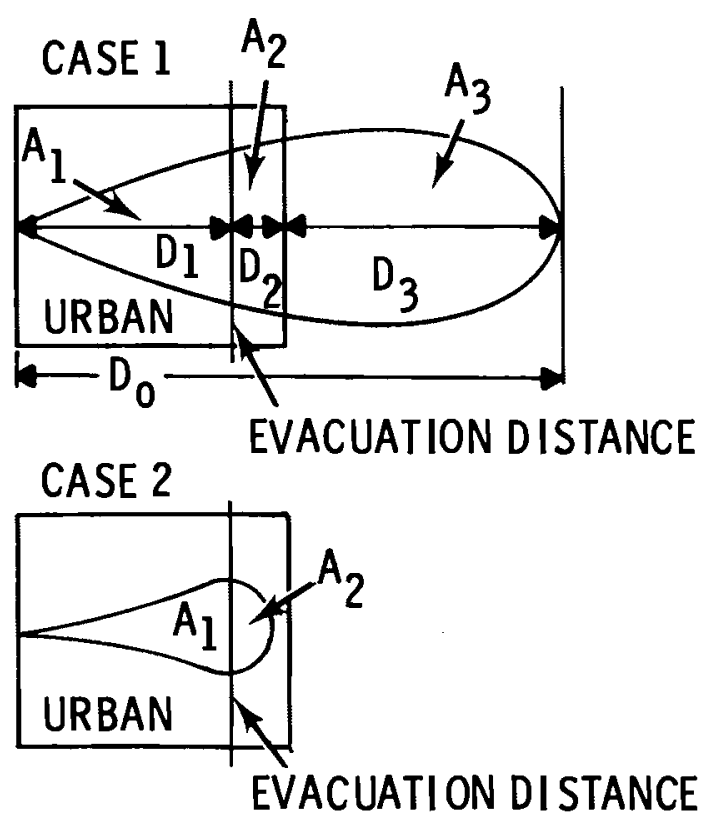

$$
\begin{aligned}
& A_{0}=A_{1}+A_{2}+A_{3} \\
& D_{0}=D_{1}+D_{2}+D_{3} \\
& A_{1}=\frac{D_{1}}{D_{0}} A_{0} \\
& A_{2}=\frac{D_{2}}{D_{0}} A_{0} \\
& A_{3}=\frac{D_{3}}{D_{0}} A_{0}
\end{aligned}
$$
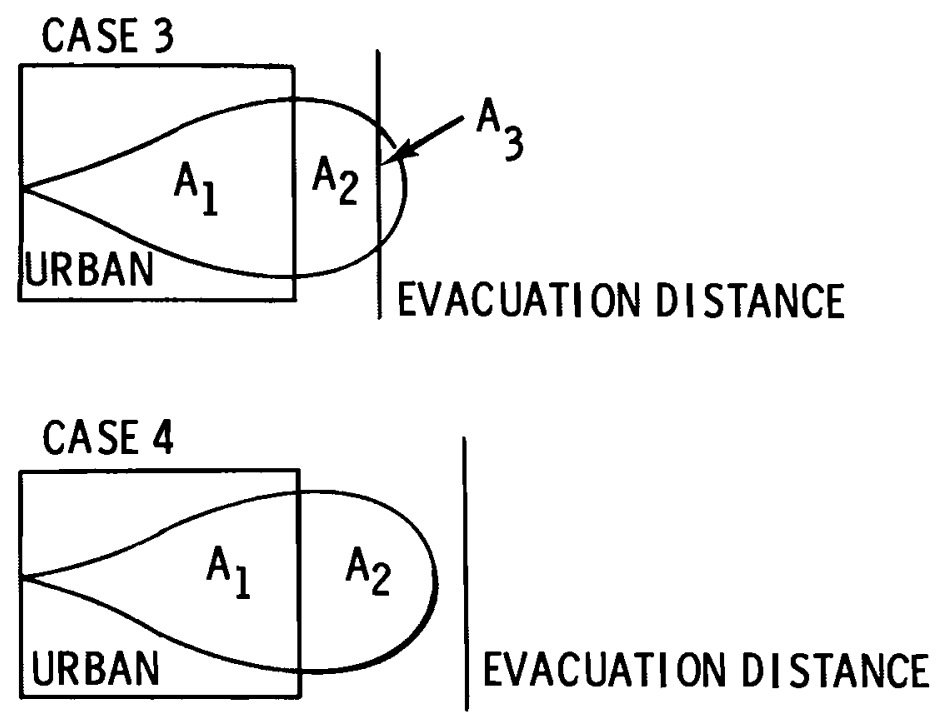

CASE 5

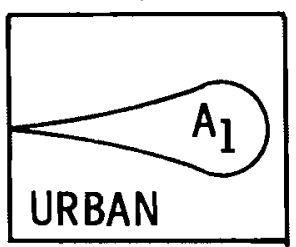

EVACUATI ON DISTANCE

FIGURE 9.2. Chlorine Release Consequence Analys is 
$A_{1}$ - Area one is in the population zone nearest the release point. Not enough time is available for an officially directed evacuation. Individuals in this area are assumed to flee or seek shelter on their own initiative. The maximum downwind centerline point in area one is defined either by officially guided evacuation times, the size of the city or the maximum downwind centerline isopleth distance. For the evacuation distance, the leading edge of the cloud is assumed to advance at the speed of the wind. The crosstown distances are defined by assuming a square shape and using urban area data.

$A_{2}$ - Area two has a reduced population density from area one. This could be due either to an officially initiated evacuation of an urban area or the cloud is covering a rural area. Individuals are assumed to evacuate on their own initiative if time is not available for an officially guided evacuation.

$\mathrm{A}_{3}$ - Area three is an evaluated rural area. An officially guided evacuation is assumed to be used in this area.

Stated mathematically, the probabilistic consequences of chlorine releases can be defined as:

$$
C_{E_{i, q}}=\sum_{m, j, k, n, \ell, p} T A_{j, k, n, p} \times P D_{m, \ell, p}
$$

where:

$$
\begin{aligned}
m & =\text { Population regions index }(9) \\
j & =\text { Wind stability classes index }(4) \\
k & =\text { Windspeed index }(5) \\
n & =\text { Lethal concentration index }(2) \\
l & =\text { Population zones within a population region (3) } \\
p & =\text { Toxic zones }\left(A_{1}, A_{2}, A_{3}\right) \\
T A & =\text { Toxic area }\left(\mathrm{km}^{2}\right) \\
\text { PD } & - \text { Population density (persons } / \mathrm{sq} \mathrm{km})
\end{aligned}
$$


Equations 9-4 and 9-5 summarize the information presented in this section. In Section 10, these results will be used in conjunction with the release sequences developed in Section 8 to obtain the risk of shipping liquid chlorine by rail in the United States.

\subsection{PROBABILISTIC CONSEQUENCES OF CHLORINE RELEASES}

Using the methodology and data described in Sections 9.1 to 9.6, probability versus expected fatality information was generated. Table 9.7 presents the probability of conditions which result in a minimum number of fatalities for each of the four release types assuming that a release occurs. The maximum consequence accident is expected to cause less than 1,000 fatalities. This result assumes that based on the evacuation models presented in Section 9.4 one in ten residents of the 1,000 ppm cloud area and one in twenty of the 1,000 ppm-min area above 35 ppm are killed.

\section{TABLE 9.7. Probabilistic Chlorine Fatalities}

Probability of conditions which result in $\mathrm{N}$ or more fatalities given that a chlorine release occurs

Deaths $(N)$ Release Size

$3.9 \mathrm{~kg} / \mathrm{sec} \quad 9.8 \mathrm{~kg} / \mathrm{sec} \quad 17.5 \%$ Puff $\quad 32 \%$ Puff

$\begin{array}{rllll}1 & 0.21 & 0.51 & 0.82 & 0.94 \\ 4 & 0.039 & 0.18 & 0.30 & 0.50 \\ 10 & 0.024 & 0.11 & 0.036 & 0.11 \\ 25 & 0.014 & 0.027 & 0.030 & 0.031 \\ 63 & 6.3 \mathrm{E}-3^{(a)} & 0.018 & 0.024 & 0.028 \\ 100 & 4.9 \mathrm{E}-3 & 0.013 & 0.019 & 0.023 \\ 250 & 5.57 \mathrm{E}-4 & 5.1 \mathrm{E}-3 & 6.3 \mathrm{E}-3 & 0.015 \\ 630 & 0 & 5.4 \mathrm{E}-4 & 0 & 1.6 \mathrm{E}-3 \\ 1,000 & --- & 0 & --- & 0\end{array}$

(a) Read $6.3 \times 10^{-3}$. 


\section{REFERENCES}

1. Chlorine Manual. Chlorine Institute Inc., 342 Madison Avenue, New York, NY, Apri 11976.

2. Statistical Abstracts of the U.S. 1975. Bureau of the Census, U.S. Dept. of Commerce, Washington DC, 1975.

3. Three-fourths of U.S. Population on 1.5 Percent of Nations Land, Census Bureau Reports. U.S. Dept. of Commerce News, CB72-100, Bureau of the Census, U.S. Dept. of Commerce, Apri1 21, 1972.

4. Population of Urbanized Areas Extablished Since the 1970 Census, for the U.S.: 1970. Supplementary Report 1970 Census of Population, PC(S1)-106, Bureau of the Census, U.S. Dept. of Commerce, October 1976.

5. J. P. Pickard, Appalachian Regional Commission, [Urban on National Population Growth and Projection, Summary Outline], for Presentation at Conference on "Complexity: A Challenge to the Adaptive Capacity of American Society", Society for General Systems Research, Metropolitan Washington Chapter, at Columbia, MD, March 25, 1977.

6. Population and the American Future. Volume $V$, The Report of the Commission on Population Growth and the American Future, 1972.

7. Population and Land Area of Urbanized Areas: 1970 and 1960. PC(S1)-6, U.S. Department of Commerce, Bureau of Census, Washington DC, February 1972.

8. J. M. Hans, Jr. and T. C. Se11, Evacuation Risks--An Evaluation. EPA-520/ 6-74-002, U.S. Environmenta1 Protection Agency, National Environmental Research Center, Las Vegas, NV, June 1974.

9. Experiments with Chlorine. Directorate-General of Labour of the Ministry of Social Affairs, P.0. Box 69, Voorburg, the Netherlands.

10. Bureau of Motor Carrier Safety, 1973 Accidents of Motor Carriers of Property. U.S. Department of Transportation, Washington DC, Ju1y 1975.

11. U.S. Bureau of the Census, Statistical Abstract of the United States: 1975. U.S. Department of Commerce, Washington DC, 1975, p. 66.

12. Accident Facts 1973. National Safety Counci1, Chicago, IL, 1974.

13. Reactor Safety Study. WASH-1400, U.S. Nuclear Regulatory Commission, Washington DC, October 1975, p. 3. 


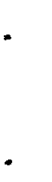

,
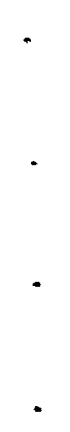


\subsection{THE RISK OF SHIPPING LIQUID CHLORINE BY RAIL}

In this section the risk of shipping chlorine by rail is calculated using the model described in Section 3.0. The probability that a release will occur during a shipment is presented in Section 8.0 and the consequences of the release were discussed in Section 9.0. The total risk of shipping liquid chlorine in the year 1985 is calculated in Section 10.1 using the industry characteristics presented in Section 4.0. Major contributors to the risk and the sensitivity of the assessment to the various parameters is presented in Section 10.2 .

\subsection{RISK EVALUATION FOR CHLORINE SHIPMENTS}

The sum of the probabilities of the release sequences presented in Section 8.2 is $1.96 \times 10^{-4}$ per shipment. Based on a total of $5.48 \times 10^{4}$ shipments per year in 1985 (see Section 4.0), chlorine rail cars would be expected to release various amounts of chlorine about 11 times per year. Of these releases an average of 1.8 per year would have the potential of releasing significant amounts of chlorine. Using the release fraction information in Section $8.3,0.93$ accidents per year would result in a $3.9 \mathrm{~kg} / \mathrm{sec}$ release and one accident per 103 years would result in a $9.8 \mathrm{~kg} / \mathrm{sec}$ release. Accidents with an instantaneous release of $17 \%$ of the tank would occur once every 1.1 years and a $32 \%$ instantaneous release would occur every 26 years.

The risk spectrum curve for all chlorine shipments in 1985 is shown in Figure 10.1. The curve was developed using the number of releases presented above and the consequence estimates presented in Section 9.7. It was not possible to determine the shape of the risk curve for events producing more than 1,000 fatalities. It is expected that such an event could occur in an area of locally very high population density, but the probability of such an event is believed to be low.

The expected number of fatalities in 1985 from the risk spectrum in Figure 10.1 is 9.4. These deaths are produced solely from the hazardous cargo carried in the tank. 


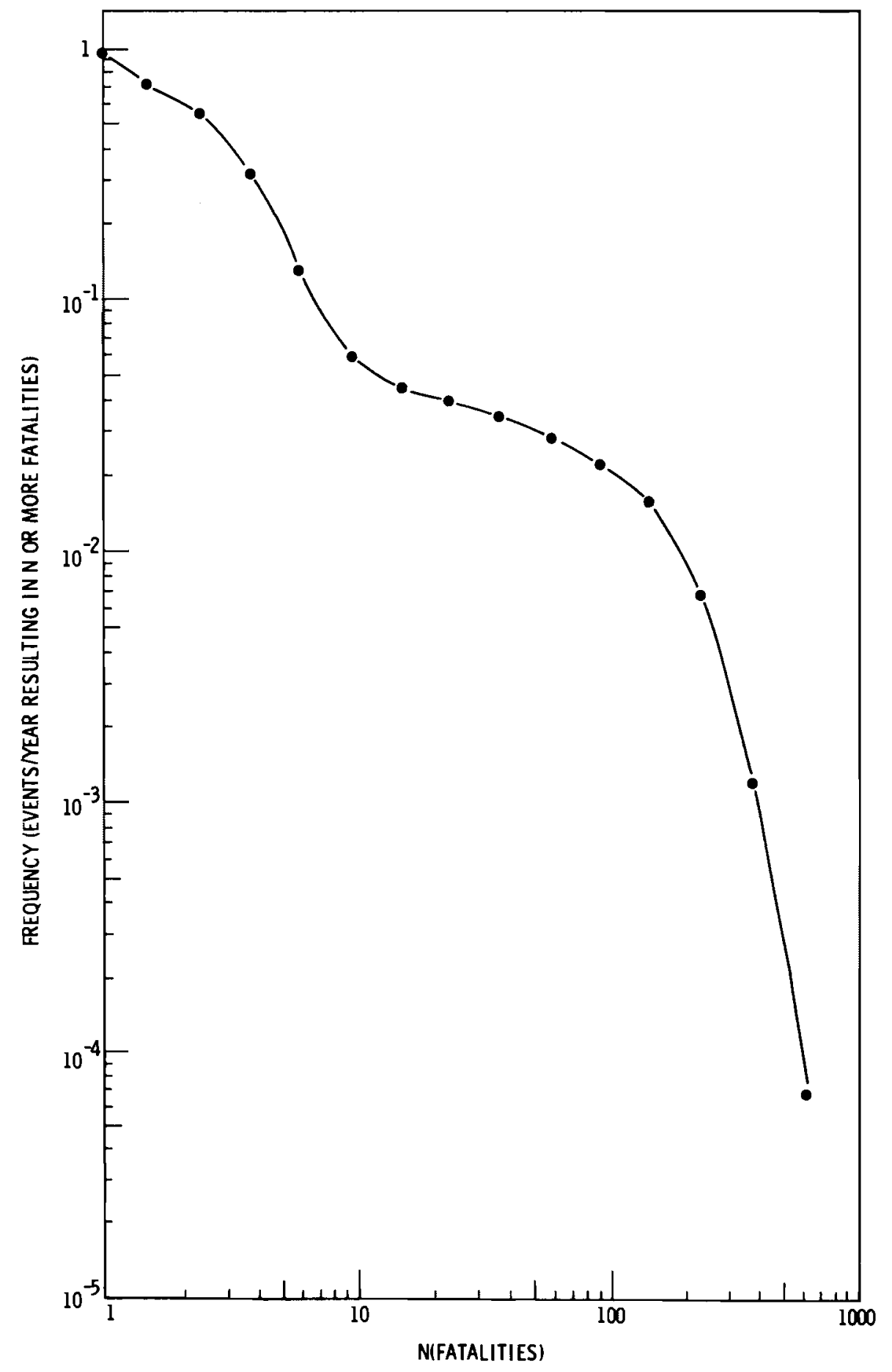

FIGURE 10.1. Risk Spectrum for Rail Shipments of Chlorine in 1985 
The risk assessment procedure used in this analysis predicts higher risks than those predicted by available historic accident data. Chlorine railroad tank car accident data from the Chlorine Institute indicates that nine large releases of liquid chlorine have occurred since 1935. Two have resulted in fatalities. The first was in 1961. Thirty tons were lost resulting in one fatality. The second fatal accident occurred in February of 1978 and resulted in 8 fatalities. Numerous non-fatal injuries occurred in four of the tank car releases. This injury data indicates other non-fatal health effects may be important in considering chlorine safety. However, modeling of non-fatal dose responses was beyond the scope of this study. Between 1961 and 1978 based on shipment volumes and assuming all 90-ton tank cars were used, 86 deaths are predicted by the risk model. This value is a factor of 10 above historic values.

Assumptions basic to the analysis contribute to the conservatism of the model. Some relate to mathematical models used to calculate consequences of chlorine releases and to determine the release sequence probabilities. Several assumptions are evaluated in Section 10.2 to determine their effect on risk. These sensitivity studies could be used to direct future analytical efforts if a better understanding of chlorine transportation risk magnitude is desired.

The expected number of leaks per year predicted by the risk model is also conservative relative to historic experience. A review of hazardous materials incident reports for 1971, 1972, 1973 and 1974 indicated that 10 incidents resulting in releases of chlorine occurred during this period. Four of these events resulted in releases of chlorine in excess of minor leakage. From this data, 2.5 releases are predicted per year with only one of any significance. For similar shipment volumes, the risk model predicts 6.8 releases per year with 1.2 releases per year having potential for significant consequences. Thus the model is conservative in its prediction of small releases. This is mainly due to a lack of detailed failure data in this area. Small releases considered in this report had a negligible effect on overall risk levels. The rate of larger releases predicted by the risk model is $20 \%$ higher than that of historic rates. 
The cursory comparison of results from the risk assessment model to historic accident data illustrates several advantages of the model. First, a comprehensive comparison could not be made due to a lack of historic information. A risk spectrum could not be constructed or changes in the chlorine shipping system evaluated based on historic accident data. Finally, the level of conservatism displayed by the study results indicates the utility of the risk assessment procedure when applied to systems with little or no operating experience.

The risk from releases of liquid chlorine in rail tank car accidents in 1985 is compared to the risk from other kinds of accidents and natural disasters in Table 10.1. The table illustrates that the individual risk from chlorine rail transportation is comparable to the risk from air crashes to persons on the ground. The chlorine transportation risks are less than the risk from gasoline tank truck accidents and more than a factor of ten below the risk of natural disasters such as tornadoes. The data in the table are from Reference 1 for the year 1973 except as otherwise indicated.

TABLE 10.1. Individual Risk From Various Accidents and Natural Disasters

\begin{tabular}{|c|c|}
\hline \multicolumn{2}{|l|}{ Accident Type } \\
\hline A11 Accidents & 115,821 \\
\hline Motor Vehicle Accident & 55,511 \\
\hline All Industrial Accidents (a) & 14,100 \\
\hline Falls & 16,506 \\
\hline Drowning & 7,152 \\
\hline Fires & 6,503 \\
\hline Poisoning & 5,335 \\
\hline Airplane Crashes & 1,668 \\
\hline Railway Accidents & 789 \\
\hline Lightning (c) & 160 \\
\hline Tornadoes $(d)$ & 90 \\
\hline Dam Failures $(c)$ & 35 \\
\hline Gasol ine Tank Truck Accidents (e) & 28 \\
\hline $\begin{array}{l}\text { Propane Transportation Acci- } \\
\text { dents }(f)\end{array}$ & 15 \\
\hline Chlorine Rail Car Accidents $(\mathrm{g})$ & 9.4 \\
\hline $\begin{array}{l}\text { Air Crashes (persons on } \\
\text { ground (d) }\end{array}$ & 6 \\
\hline $\begin{array}{l}\text { (a) Reference } 1 . \\
\text { (b) Only workers included in pop } \\
\text { (c) Reference } 2 . \\
\text { (d) Reference I. Average value } \\
\text { (e) in } 7980 . \text { (Reference 7) } \\
\text { (f) in 1985. (Reference 8) } \\
\text { (g) in 1985. }\end{array}$ & $\begin{array}{l}\text { pulation at risk. } \\
\text { for several years. }\end{array}$ \\
\hline
\end{tabular}




\subsection{RISK SENSITIVITY EVALUATIONS}

Risk sensitivity evaluations permit analysis of the importance of the various factors that contribute to the risk. They can be used: 1) to identify and quantify the effects of the major contributors to the risk, 2) to identify and quantify ways to decrease the uncertainty in the risk evaluation, 3) to study the effects of possible design or regulatory changes on the risk. Most sensitivity studies are performed by repeating the risk calculation with a changed value for the parameter of interest. In general, the dependence of the risk on a particular parameter is complex. In some cases, however, the parameter enters simply and directly into the risk calculation and the sensitivity can be determined directly.

Sensitivity cases presented in this study were designed to study the effects of fire, impact and puncture failure probabilities on chlorine transportation risks. Accident environments that are significant contributors to risk were identified. Results of the analysis were used to identify areas where additional data are required and to provide direction to designers so that resistance to significant failure modes can be improved.

Before discussing the sensitivity of the risk evaluation to the value of certain system parameters, it is important to point out a fundamental sensitivity of the risk evaluation. The calculated risk is a function of the shipping assumptions. Use of a different type of rail car, different shipping distances, changes in the predicted industry growth rate, etc., would result in a different risk. In general, reevaluation would be required to determine the risk under these conditions.

The results of the risk sensitivity studies for the shipment of liquid chlorine in DOT specification 105A5COW rail tank cars are presented in Table 10.2 and Figures 10.2 through 10.7. Table 10.2 shows the sensitivity of the expected number of fatalities to the parameter being studied, while the figures illustrate the sensitivity of the shape of the risk spectrum curve to changes in these parameters. 
TABLE 10.2. Sensitivity of the Expected Number of Fatalities from Chlorine Releases to the Value of Various System Parameters.

Description of Sensitivity Case Expected Fatalities Change from Base Case

$\begin{array}{lcc}\text { Base Case } & 9.4 & 0 \\ \text { Head Shields installed } & 9.0 & -4 \% \\ \begin{array}{l}\text { Fire probability per accident } \\ 2.3 \times 10^{-2}\end{array} & 19 & +103 \% \\ \begin{array}{l}\text { Accident probability per } \\ \text { kilometer }=6.2 \times 10^{-5}\end{array} & 86 & +816 \% \\ \begin{array}{l}\text { Faulty package probabilities } \\ \quad 10 \text { times Section 8.0 values }\end{array} & 21 & +129 \% \\ \begin{array}{l}95 \% \text { evacuation model } \\ \text { Joint fire/impact probability }\end{array} & 4.7 & -50 \% \\ \text { New Relief Valve } & 13 & +39 \% \\ \quad 13 \mathrm{~kg} / \mathrm{sec} & & \\ 36 \mathrm{~kg} / \mathrm{sec} & 9.4 & 0 \\ \text { Tank 10X impact resistance } & 9.4 & -54 \%\end{array}$

The base case for this analysis considered a car with no head shields, normal defective part and human error rates (see Section 8 ), and a relief valve capable of discharging $9.1 \mathrm{~kg} / \mathrm{sec}$ of liquid chlorine. Accident rates used in the base case are: $6.2 \times 10^{-6}$ train accidents per kilometer, $2.3 \times 10^{-3}$ car fires per train accident. Fire environments were assumed independent of impact environments and $90 \%$ of exposed populations were assumed to evacuate.

Figure 10.2 shows the sensitivity of risk to event XI (Transportation Accident 0ccurs). The expected fatalities in this case are 102. This information illustrates that accidental releases of chlorine are the primary contributor to public risks. The ratio of the risk curve for the increased accident rate to the base case varies from 0.14 for low consequences to 0.11 for high consequence events. This means that accidents are responsible for nearly all high consequence events and a slightly smaller fraction of low consequence events. 


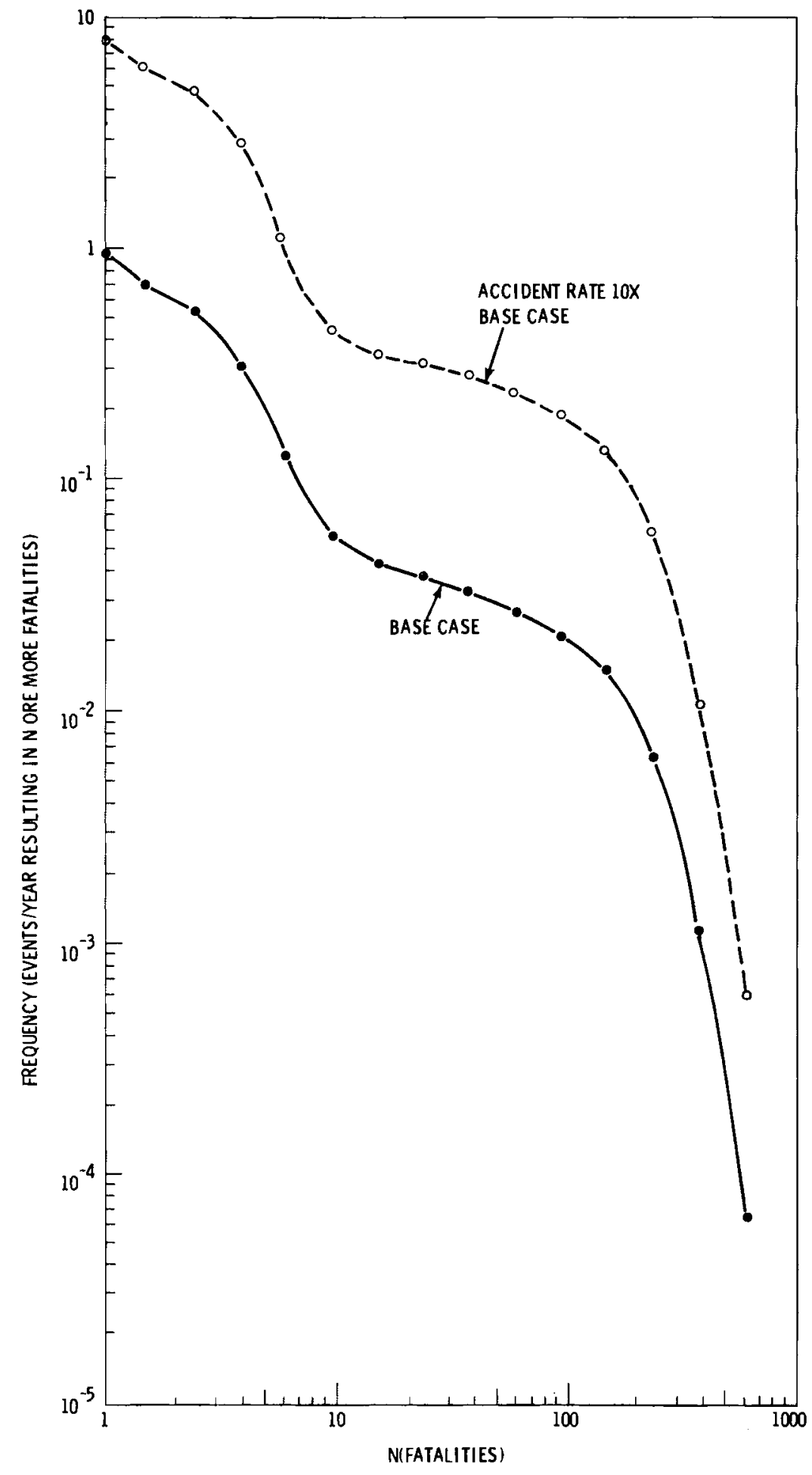

FIGURE 10.2. Effect on Risk of Increasing the Accident Rate by a Factor of 10 


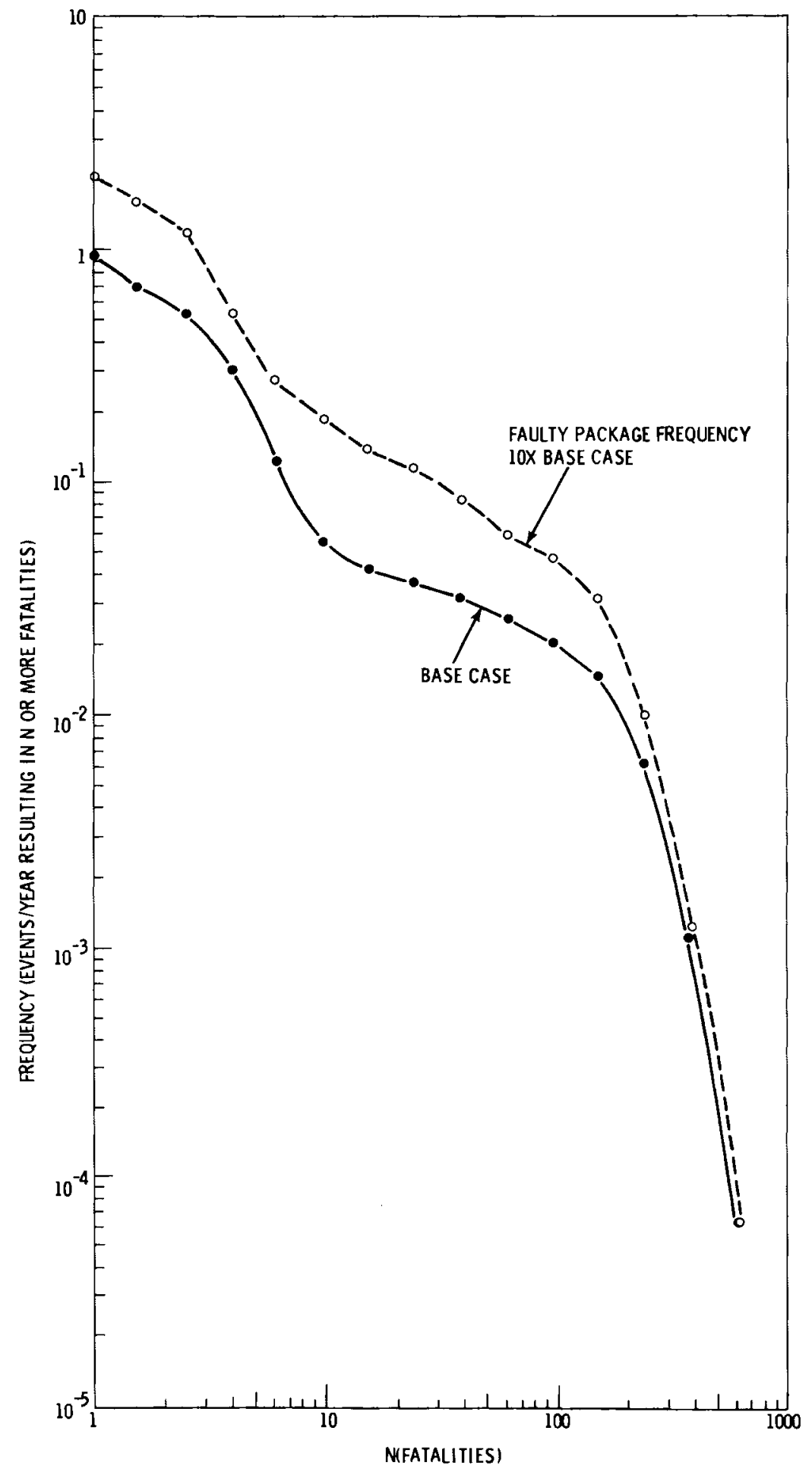

FIGURE 10.3. Effect on Risk of Increased Frequency of Off Design Package Conditions 


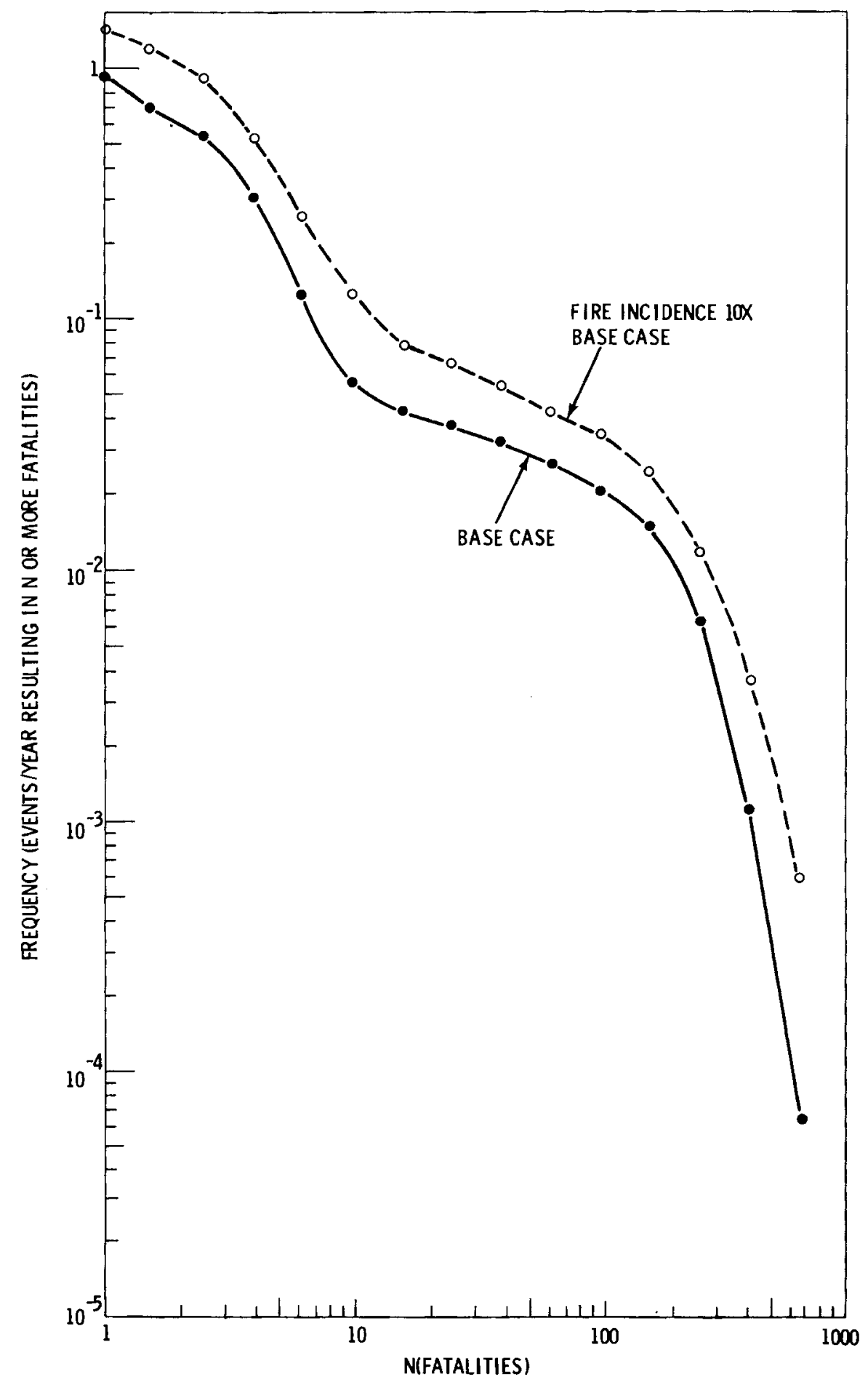

FIGURE 10.4. Sensitivity of Risk to Probability of Tank Being Involved in a Fire 


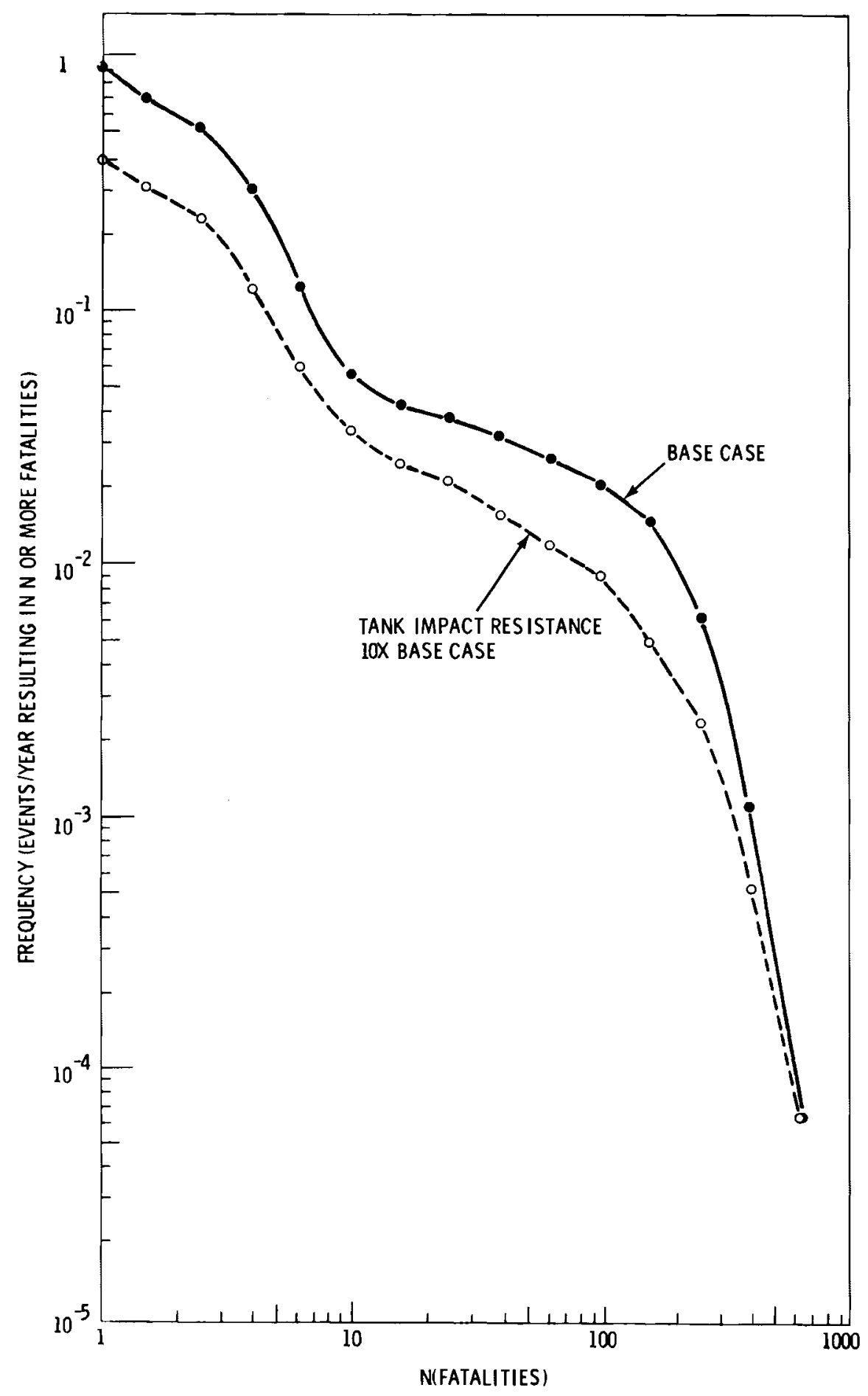

FIGURE 10.5. Effect on Risk of Increasing Tank Impact Resistance by a Factor of 10 


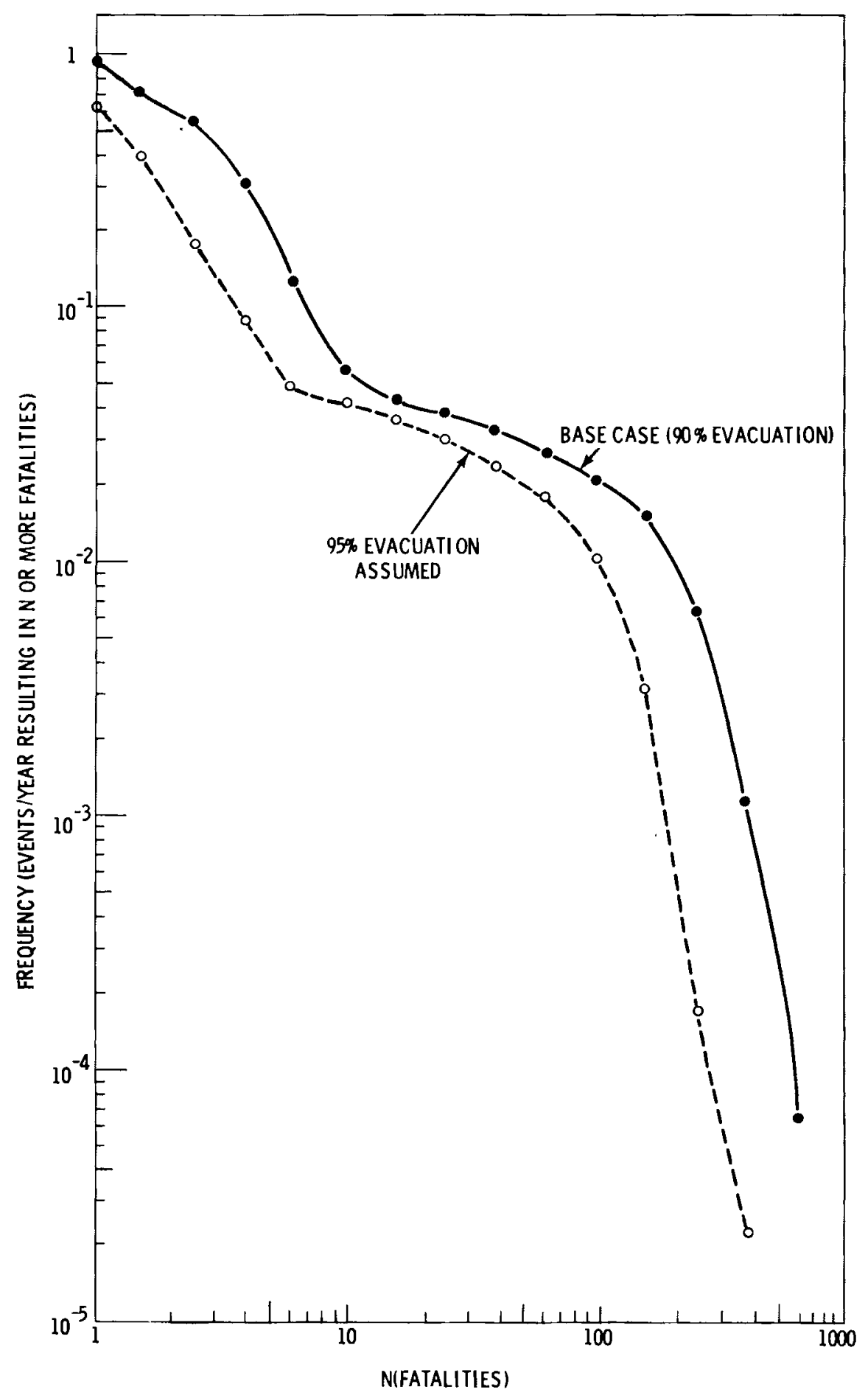

FIGURE 10.6. Sensitivity of Risk to Increased Evacuation Fraction 


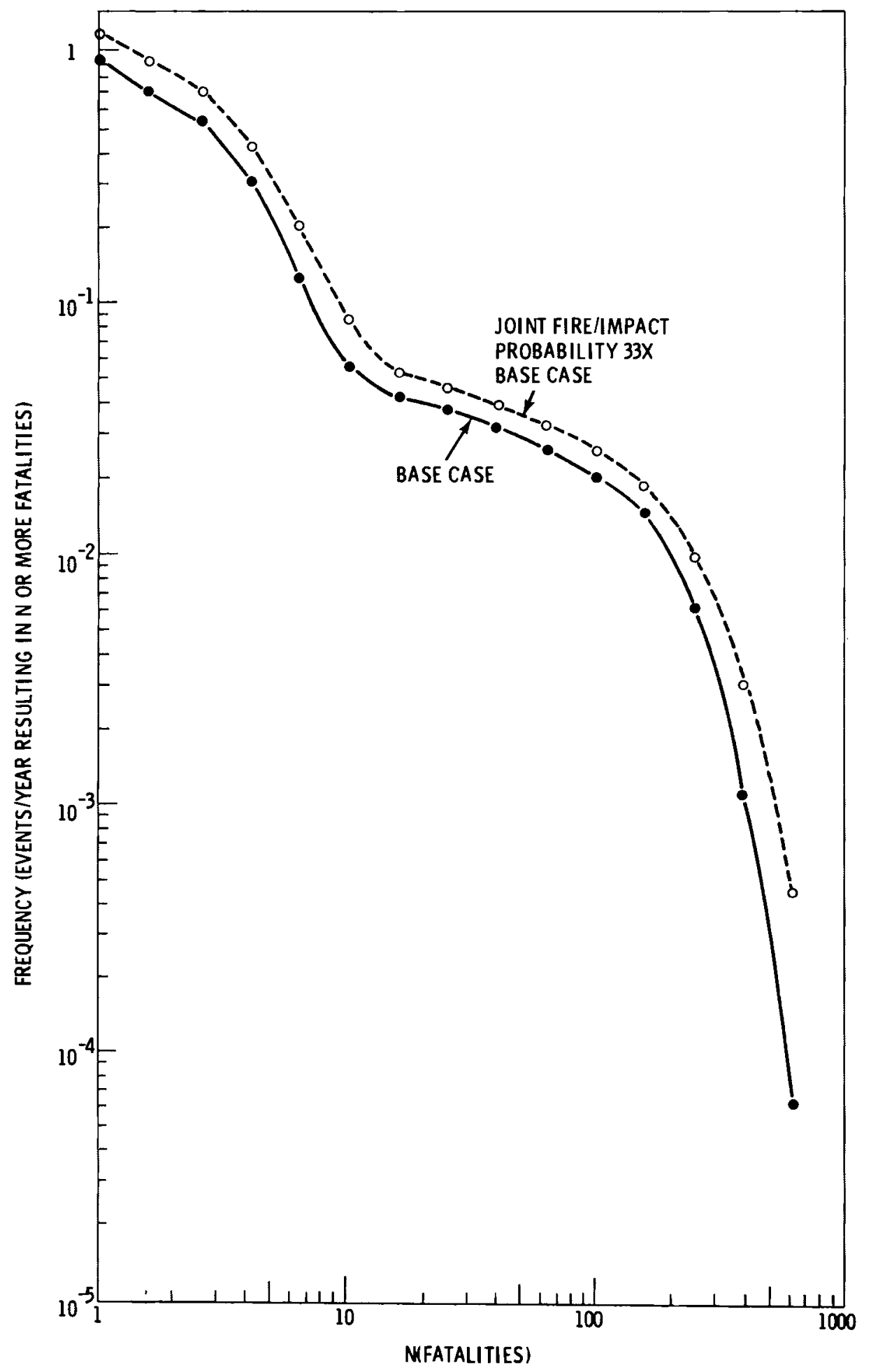

FIGURE 10.7. Effect on Risk of Increasing the Joint Fire/Impact Probability by a Factor of 33 
Figure 10.3 shows the sensitivity of risk to events describing the package conditions during transport. All frequencies dealing with faulty or otherwise off-design package conditions and human error rates in package closures were increased by a factor of 10. The total risk from the case is 21 deaths/year, about double the base case. The shape of the risk curve for this effect indicates an increased incidence of events resulting in less than 300 fatalities. Package conditions do not contribute significantly to events with consequences larger than this level but do have an observable effect on overall chlorine transportation risks.

Figure 10.4 shows the sensitivity of risk to the value of event $X 2$ (Chlorine Tank is Involved in Fire). This event frequency was increased by a factor of 10 to measure the effect. The location of the risk curve is higher and roughly the same shape as the base case curve. Fire is an important contributor to risk at all levels of consequences. The expected number of fatalities in this case is 19 .

Figure 10.5 shows the effect of reducing the impact probability of the tank by a factor of 10 . The shape of the risk curve is approximately the same as the base case but lower event frequencies result for all levels of consequences below 500 fatalities. Impact is an important contributor to the chlorine shipping risk. If the impact failure probability can be reduced by a factor of 10, expected fatalities fall to 4.3 per year. From Figure 5.2, a 10-fold reduction in failure probability requires the end and side failure thresholds to increase from $52 \mathrm{kph}$ and $29 \mathrm{kph}$ respectively to $78 \mathrm{kph}$ for end impacts and $57 \mathrm{kph}$ for side impacts. Feasability and cost studies are required to determine if this concept is desirable.

Figure 10.6 shows the effect on risk of increased evacuation by individual motivation. Ninety-five percent of the pre-accident population was assumed to escape. The consequences of any event are reduced by approximately half of the base case. The frequency of events resulting in 10 to 100 fatalities is not significantly reduced. Risk from this case is 4.7 deaths per year. An incident during 1979 in Toronto, Ontario where several hundred thousand persons were evacuated without loss following a chlorine tank car rupture suggests that evacuations can proceed more efficiently in urban areas than 
the base case of this study assumed. All eight of the fatalities in 1978 occurred prior to implementation of evacuation procedures following a release. Insufficient historical data on actual chlorine caused evacuations exists for quantitative evaluation in this report, but it appears that effective actions in this area can have a dramatic effect on risk.

Figure 10.7 presents the effect on risk of considering an impact to contribute to the probability of a rail car fire. Conservative assumptions in basic events $\times 87, \times 109, X 110$ and $\times 179$ increased their probability by a factor of 33 . Expected fatalities increased by $16 \%$ to 13 per year. The risk curve shape is similar to the base case but the ratio of the two risk curves shows that this assumption has a greater effect on events with large consequences.

Several additional sensitivity cases were postulated for potential risk reducing changes in the railcar design. These changes had no significant effects on risk. Replacement of the current pressure relief valve $(9.1 \mathrm{~kg} / \mathrm{sec})$ with one capable of preventing excessive pressures in an overturn and fire accident had little effect on tank failures due to an increased probability of metal fatigue failures when a larger valve is used.

The effect on risk of adding puncture resistant head shields to the tank cars was also determined to be smal1. Comments in Reference 6 on puncture probabilities suggest that a large uncertainty exists in this data. Historic accident data lists a high puncture rate relative to impact failures. This may be due to the independent treatment of impact and puncture in Reference 6 . An impact accident with a rough or jagged target may lead to a tank "puncture" being reported when an impact type failure would have been predicted by the model which assumes a smooth target. Additional data is required to define the uncertainty in the head shield sensitivity analysis. If impact and puncture events are strongly dependent, a decrease in tank punctures will result in an apparent increase in tank impact failures.

\subsection{COMPARISONS TO PREVIOUS STUDIES}

Several studies have been performed on the risks of transporting liquid chlorine by rail tank car. This section compares the results of these reports. 
Table 10.3 compares the expected number of fatalities from chlorine releases reported in each of the three reviewed studies to those of the current study. A shipping diștance was not reported by Simmons, so an average distance of $450 \mathrm{~km}$ was assumed. This assumption, along with data presented in the reports were used to develop the estimates of deaths per ton mile of transport. The table shows that Lautkaski ${ }^{(3)}$ and Simmons ${ }^{(4)}$ predict more fatalities per ton-mile than the current study. Westbrook ${ }^{(5)}$ predicts about one twentieth the fatalities of the current study. In 1978, the U.S. chlorine death rates were $6.3 \times 10^{-9}$ deaths/ton mile. Averaged from 1961 through 1978 the U.S. rate is $7.1 \times 10^{-10}$ deaths/ton mile.

Direct comparison of the current study with Westbrook ${ }^{(5)}$ and Lautkaski et al. (3) may be of little value since the shipping systems studied used 30-ton chlorine tankers of European design. Of interest, however, is the fact that these two studies bracket the range of risk calculations on U.S. shipping systems.

Further comparisons are made between the current study and the work by Simmons et a1. (4) in Figure 10.8. The risk spectrum reported by simmons is more conservative than the base case of this study for consequences greater than 300 fatalities but, the studies agree quite we 11 in a range of 50 to 300 fatalities. The maximum consequence reported by Simmons is larger than the current study. Simmons did not consider events with fewer than 50 fatalities. Given the effect of basic assumptions demonstrated by the sensitivity

TABLE 10.3. Chlorine Risk from Five Analyses

\begin{tabular}{|c|c|}
\hline Report & Risk \\
\hline & $\begin{array}{l}\text { Deaths per ton-mile of } \\
\text { liquid chlorine trans- } \\
\text { port (a) } \\
\end{array}$ \\
\hline Lautkaski ${ }^{(3)}$ et al. & $5.9 \times 10^{-8}$ \\
\hline Simmons et al. (4) & $1.5 \times 10^{-8}$ \\
\hline Current Study & $6.8 \times 10^{-9}$ \\
\hline Westbrook ${ }^{(5)}$ & $2.5 \times 10^{-10}$ \\
\hline
\end{tabular}

(a) 1 ton-mile $=1464 \mathrm{~kg} \mathrm{~km}$. 


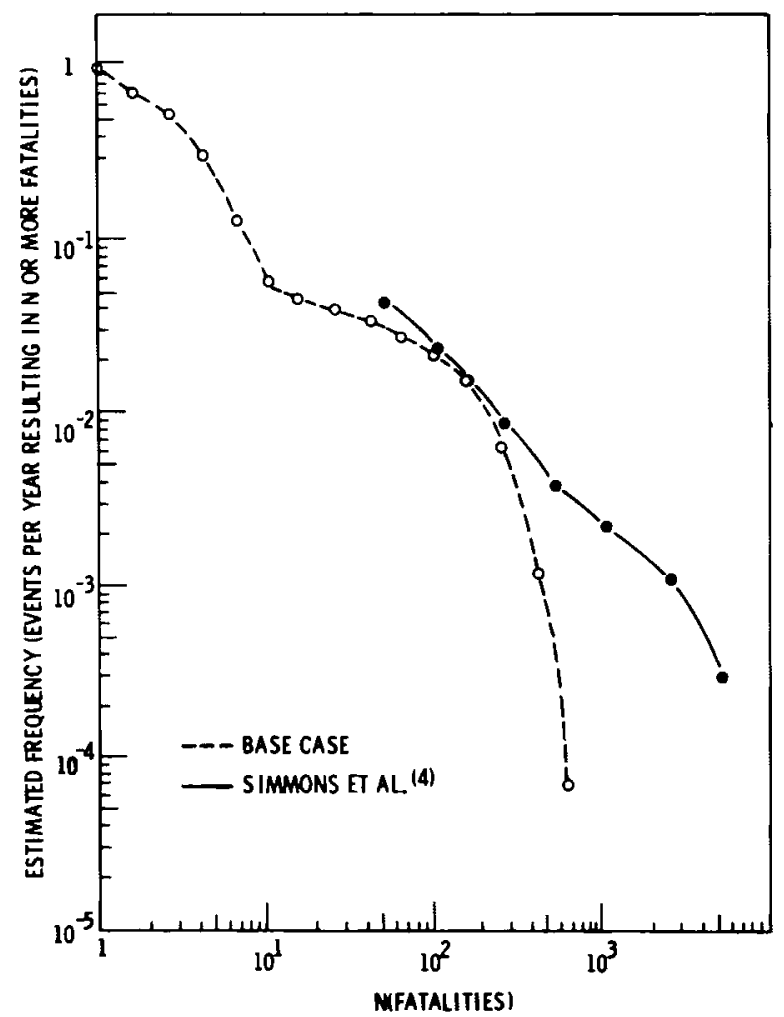

FIGURE 10.8. Comparison of Chlorine Risk Spectrums

studies in Section 10.2, the reports appear in good agreement. Both of these reports are conservative when compared to historic accident data presented in Section 10.1 .

In conclusion, the risk assessment methodology developed at PNL and applied to liquid chlorine rail transportation gave results which are less conservative than other studies of similar rail systems. This is due to predictive data that were used to determine release probabilities and consequences of material releases.

Historic data were used in other studies to predict chlorine tank failures. This data is inadequate to consider tank failure mechanisms individualiy and does not include enough information to consider low probability catastrophic events. The PNL methodology provides a risk spectrum for the entire range of potential consequences. No other study using historic data provides this information or the ability to conduct sensitivity studies of potential design changes. 


\section{REFERENCES}

1. Accident Facts 1973. National Safety Council, Chicago, IL, 1974.

2. Reactor Safety Study. WASH-1400, U.S. Nuclear Regulatory Commission, Washington DC, October 1974, p. 3.

3. R. Lautkaski and T. Mankamo, Chlorine Transportation Risk Assessment. Technical Research Centre of Finland, Draft, October 1976.

4. J. A. Simmons, R. C. Erdmann and B. A. Naft, Risk Assessment of Large Spills of Toxic Materials. Science Applications Inc., McLean, VA, From: Control of Hazardous Material Spills, Proceedings of the 1974 National Conference on Control of Hazardous Material Spil1s, American Institute of Chemical Engineers, San Francisco, CA, August 25-28, 1974.

5. G. W. Westbrook, The Bulk Distribution of Toxic Substances: A Safety Assessment of the Carriage of Liquid Chlorine. Management Services Department Mund Division, Imperial Chemical Industries Limited, the Heath, Runcorn, Cheshire, England, 1974.

6. A. W. Dennis et al., Severities of Transportation Accidents Involving Large Packages. SAND77-0001, Sandia Laboratories, ATbuquerque, NM, May 1978.

7. R. E. Rhoads et a1., An Assessment of the Risk of Transporting Gasoline by Truck. PNL-2133, Pacific Northwest Laboratory, Richland, WA, November 1978.

8. C. A. Geffen et a1., An Assessment of the Risk of Transporting Propane by Truck and Train. PNL-3308, Pacific Northwest Laboratory, Richland, WA, September 1980. 


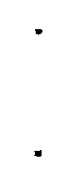


APPENDIX A

CHLORINE TANK CAR DESCRIPTION

AND OPERATING PROCEDURES 
APPENDIX A

CHLORINE TANK CAR DESCRIPTION

AND OPERATING PROCEDURES

\section{A.1 TANK CAR DESCRIPTION}

Chlorine is classified as a hazardous material by the Department of Transportation (DOT) and must be transported in containers meeting DOT specifications. Several DOT specification tank cars may be used to transport chlorine by rail, but tank car manufacturers indicate that the 90 -ton $\left(8.18 \times 10^{4} \mathrm{~kg}\right)-D 0 T$ 105A500W is the most common. The 1972 Census of Transportation (1) indicates that $70 \%$ of all chlorine moves in containers with a capacity greater than 45 tons $\left(4.09 \times 10^{4} \mathrm{~kg}\right)$. It was assumed for this study that all bulk rail shipments of liquid chlorine made in 1985 will be carried in the 90-ton DOT-105A500W tank car described below.

The most common configuration for the DOT-105A500W tank car is a single unit carrying 90 tons of liquid chlorine at the authorized filling density of $125 \%$. A photograph and assembly drawing of the typical car are presented in Figures A.1 and A.2. The loaded weight of the car is $118,800 \mathrm{~kg}(262,000 \mathrm{lb})$. The tank is loaded and unloaded through valves located in the car dome. A pressure relief valve is also located there. The tank is supported as a simple beam on either end by draft sills. To these sills are attached the trucks, couplers, running boards and braking mechanisms. All DOT specification tank cars built after January 1, 1971 are equipped with interlocking automatic couplers that will resist car telescoping and jackknifing in derailments and emergency stops. These couplers incorporate a "shelf" which resists upward car movement to prevent these types of accidents.

The tank has a circular cross section with a diameter of $259 \mathrm{~cm}$ (102 in.) and a length of $12.4 \mathrm{~m}(40.8 \mathrm{ft})$. The tank heads are dished outward in an ellipsoid form. The minor axis is one half the tank diameter. The head and wall thicknesses are $2.06 \mathrm{~cm}(0.81 \mathrm{in.})$ and $2.0 \mathrm{~cm}(0.787 \mathrm{in.})$ respectively. 


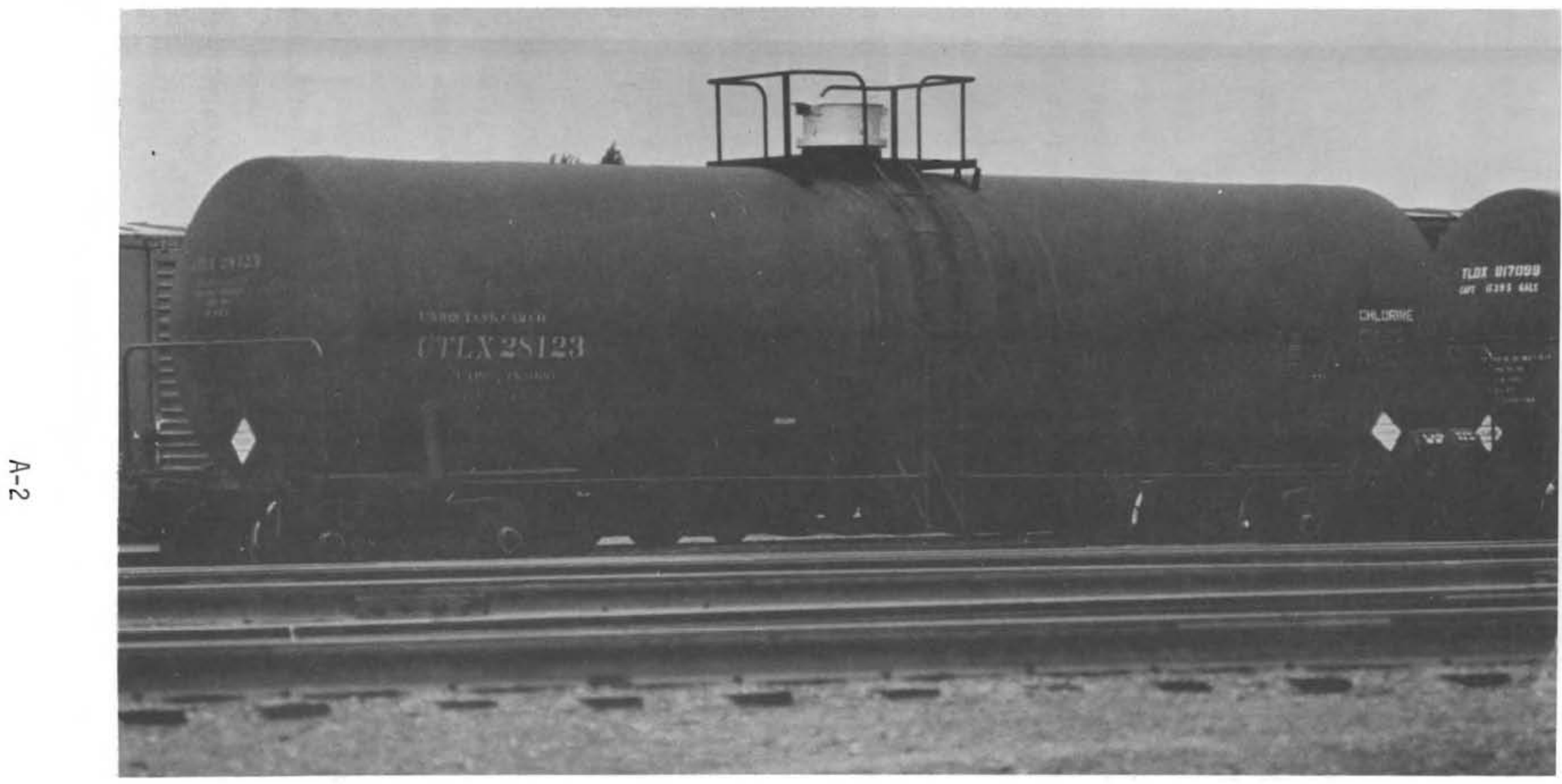

FIGURE A.1. Photograph of Chlorine Tank Car 
90 TON CAPACITY - INSULATED

DOT - 105A500W

TANK MATERIAL - AAR TC - 128 GRADE "B" FOR CHLORINE SERVICE
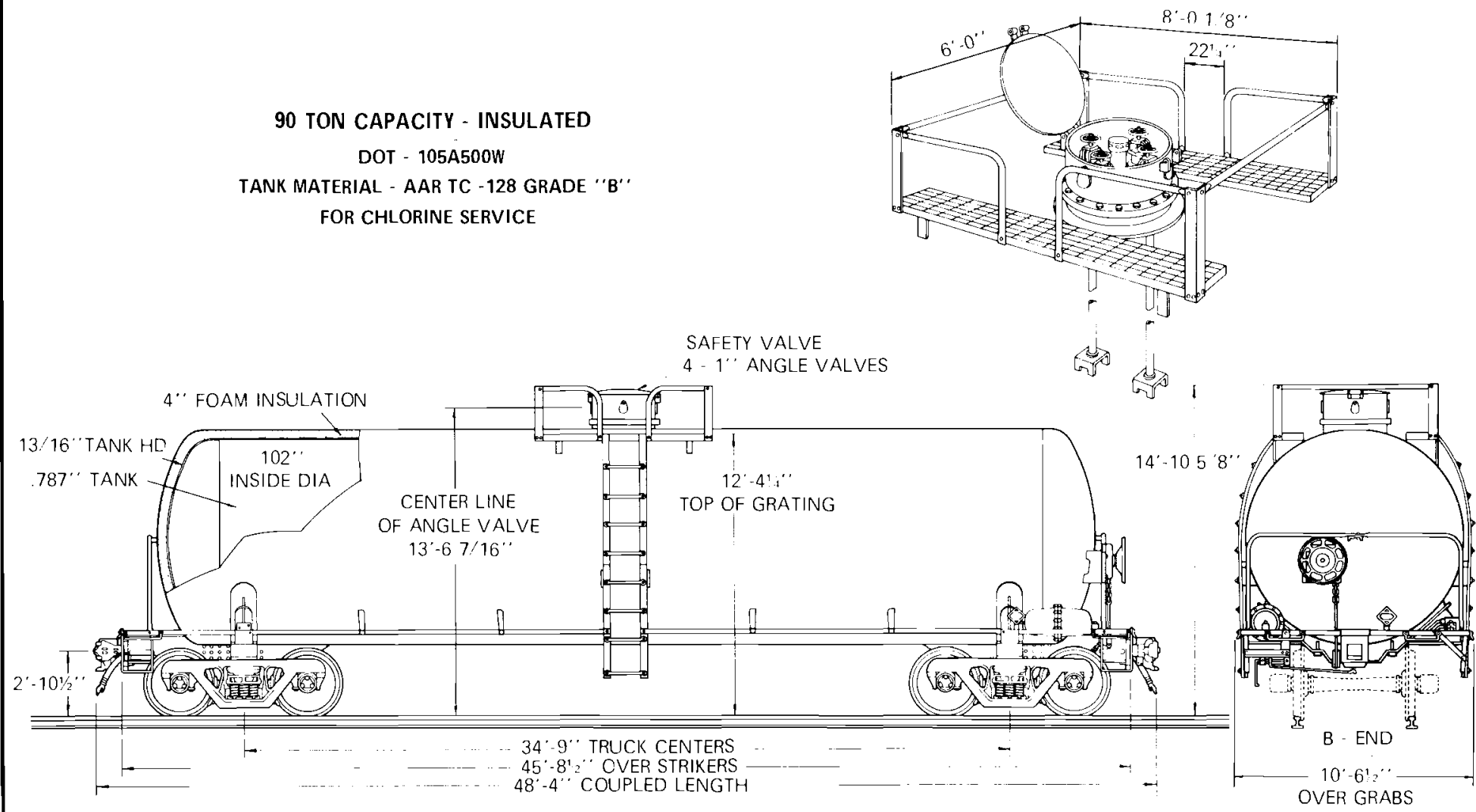

MINIMUM HORIZONTAL CURVE NEGOTIABILITY

1. TWO LIKE CARS COUPLED TOGETHER - $162 \mathrm{FT}$.

2. TANK CAR ON CURVE - STANDARD

FT.

CAPACITY \& WEIGHTS

CAR $\left(40^{\circ}-6^{\prime \prime}\right.$ ON TANGENT

$129 \mathrm{FT}$.

NOMINAL CAPACITY (1) 125\% FILLING DENSITY - 90 TONS

FSTIMATFD LIGHT WEIGHT - 81,200 LBS

RAIL LOAD LIMIT (100 TON TRUCKS) - (5 $5^{\circ}-10^{\prime \prime}$ WHEEL BASE) - 262,018 LBS.

FIGURE A.2. Chlorine Tank Car Assembly (From Reference 2) 
The shell is of welded construction in steel to specification AAR TC-128 Grade B. Test pressure for this tank is $3.49 \times 10^{6} \mathrm{~Pa}$ (500 psig) with a minimum burst rating of $8.62 \times 10^{6} \mathrm{~Pa}(1250 \mathrm{psig})$. A $10.2 \mathrm{~cm}$ (4 in.) layer of self extinguishing polyurethane foam insulation is applied to the outside of the tank and covered with a $0.34 \mathrm{~cm}(0.1196$ in.) steel jacket.

The valve arrangement for liquid chlorine cars is shown in Figure A.3. Five valves are mounted on the manway cover inside a protective housing.

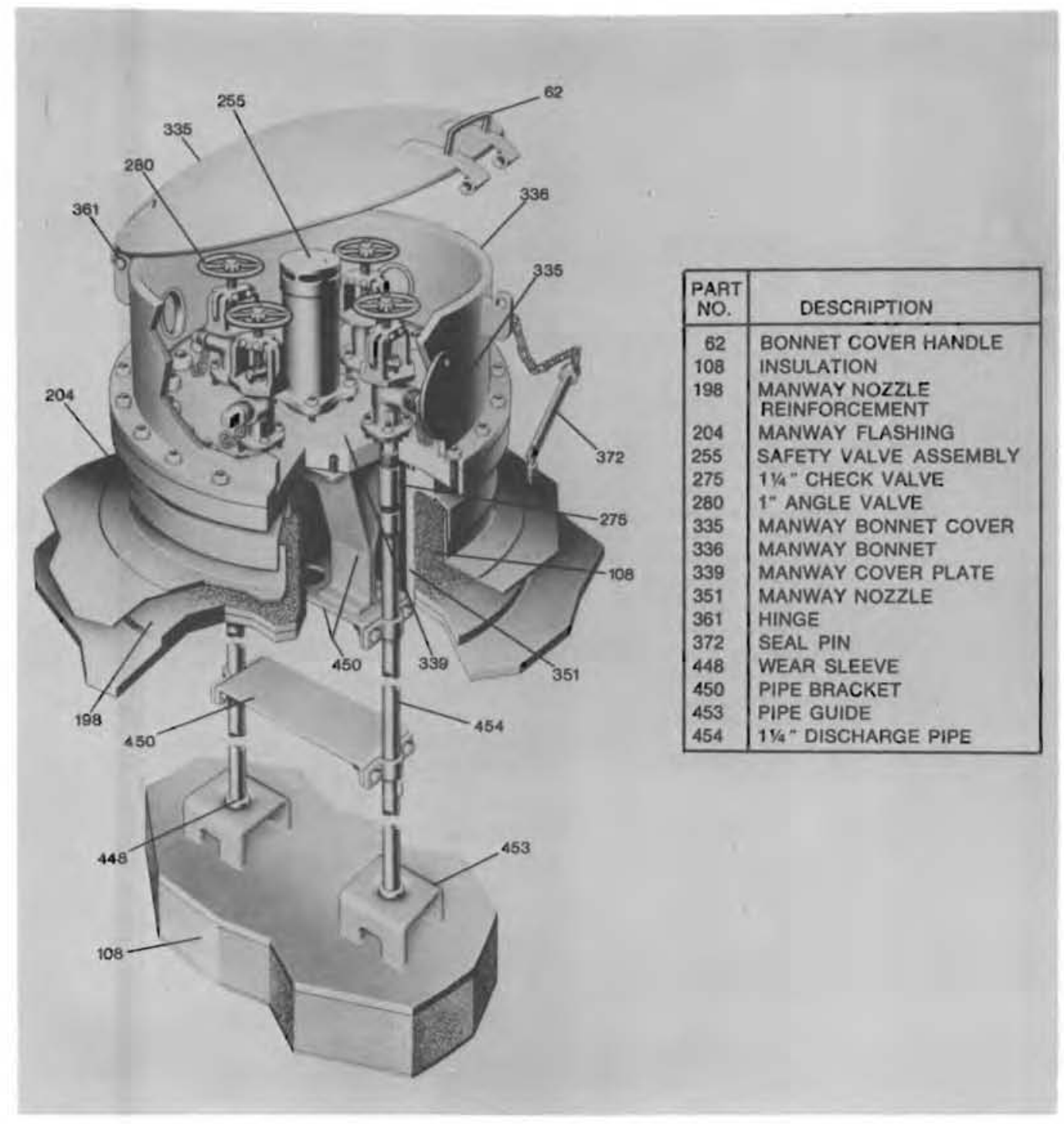

FIGURE A.3. Loading and Unloading Arrangement for Liquid Chlorine Cars (From Reference 2) 
Four of these are angle valves; the fifth mounted in the center, is a safety relief valve. Opposite each valve is an opening in the housing protected by a suitable cover through which the unloading lines are connected.

The manway cover must be a minimum of $5.7 \mathrm{~cm}(2.25 \mathrm{in}$.$) thick and 45.7 \mathrm{~cm}$ (18 in.) diameter. It is connected to a reinforced nozzle in the tank wall. The joint must be gasketed (bonded asbestos) and is secured with $20-2.86 \mathrm{~cm}$ ( 1.13 in.) studs. The protective housing must be a minimum of $1.9 \mathrm{~cm}(0.17 \mathrm{in.})$ thick and is attached to the manway cover with $20-1.9 \mathrm{~cm}(0.75 \mathrm{in}$.) studs. The housing is designed to break away at $70 \%$ of the shearing value of the studs attaching the manway cover to the manway nozzle. (3)

The four angle valves are of the Chlorine Institute Standard Angle Valve design $^{(4)}$ and pictured in Figure A.4. The valve has a forged steel body and a Monel valve stem. The outlet is a $2.54-\mathrm{cm}$ (1 in.) female U.S.A. standard taper pipe thread and is protected by pipe plugs. Two angle valves on the longitudinal center line of the car are for unloading liquid chlorine. The two angle valves on the transverse center line are connected to the vapor space. Each valve is attached to the tank with a gasketed joint and four studs.

Under each liquid valve is a pipe fastened to the manway cover and extending to the bottom of the tank. At the top of each pipe immediately below the manway cover is a rising-ball, excess flow valve (see Figure A.5) designed to close when the rate of flow of 1 iquid chlorine exceeds $1.89 \mathrm{~kg} / \mathrm{s}(4.171 \mathrm{bm} / \mathrm{s})$. This is a protective device designed to close automatically against the flow of liquid chlorine if the angle valve is broken off or if unrestricted flow occurs following the failure of a loading line.

The safety relief valve is of the spring loaded type and is combined with a breaking pin assembly (Figure A.6). The breaking pin assembly holds a disc of metal which closes the inlet of the safety relief valve and is designed to break in tension at a load caused by venting pressures. On 105A500W cars, the pin is designed to break at $2.59 \times 10^{6} \mathrm{~Pa}$ (375 psig). The rated flow at a full open condition $2.84 \times 10^{6} \mathrm{~Pa}(412 \mathrm{psig})$ is $1.383 \mathrm{~m}^{3} / \mathrm{s}$ (2930 scfm of air). 


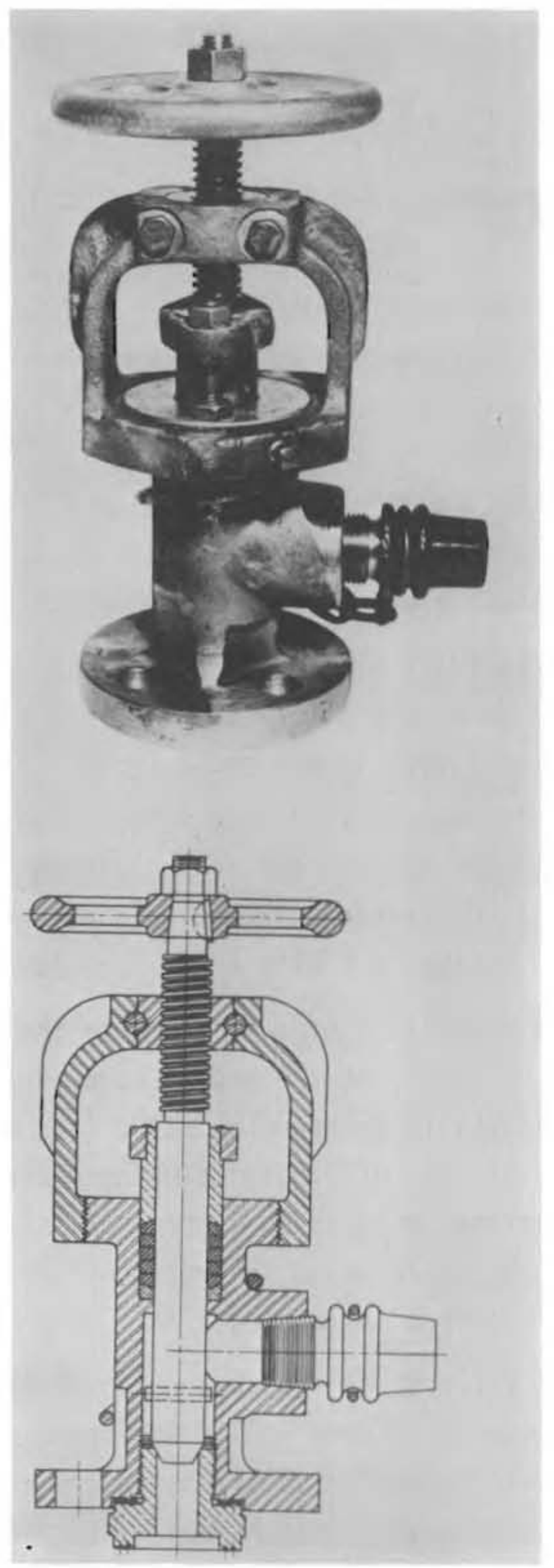

FIGURE A.4. Chlorine Institute Standard Angle Valve (From Reference 3) 


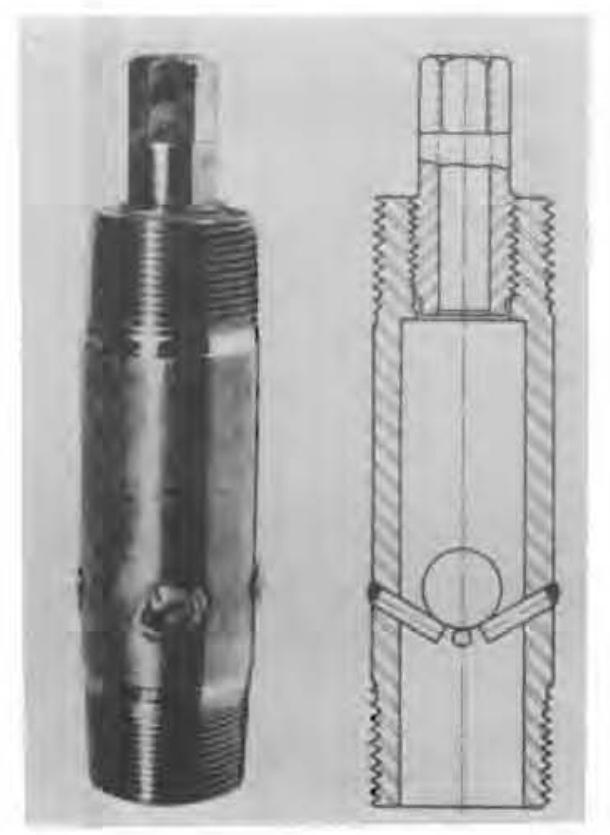

FIGURE A.5. Excess-Flow Valve for Single-Unit Tank Care (From Reference 3)

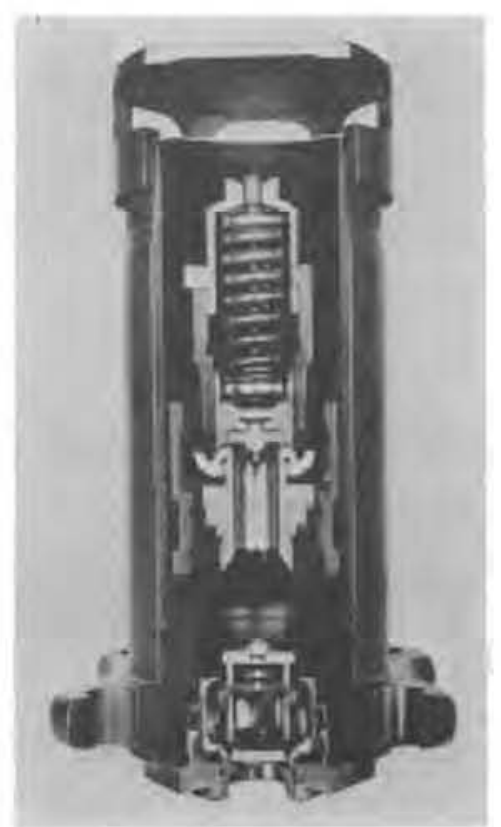

FIGURE A.6. Chlorine Institute Standard Safety Relief Valve (From Reference 3)

\section{A.2 OPERATING PROCEDURES}

Operating procedures for single unit tank cars are published by the Chlorine Institute Inc. (Reference 5). They stress a rigorous program of inspections and equipment maintenance to minimize leaks during transit and loading operations. A summary of this information is presented below. Emergency kits for tank cars are available at more than 600 locations in the U.S. and Canada to repair minor leaks should they occur.

All chlorine tank cars and relief valves are required to undergo a pressure test at least every two years. This involves filling the tank completely with water and holding the rated pressure $\left(3.4 \times 10^{6} \mathrm{~Pa}-500 \mathrm{psig}\right)$ for 20 minutes. Valves are tested with air or gas to assure compliance with the applicable regulations.

Various angle valve maintenance schedules are followed by companies loading chlorine cars. Some inspect or replace angle valves each trip and 
others every other trip. When they are removed for inspection prior to loading the car, the following procedures are followed:

1. All angle valves are removed for inspection and, if necessary, repaired or replaced.

2. The float balls in the excess flow valves are inspected for wear. If they require removal, the valve seat is also inspected and repaired or replaced, as necessary.

3. The relief valve is inspected for leakage or damage and removed for repair and testing if required.

4. Rubber plugs are used to prevent entry of moist air into the car during the time valves are removed.

5. The internal surfaces of the tank are visually inspected and cleaned or repaired as needed.

6. The valves are reinstalled using new gaskets.

Following loading, the tank pressure is checked. If it is below $1.38 \times 10^{5} \mathrm{~Pa}(20 \mathrm{psig})$, dry compressed air is added. This is to assure that the excess flow valves will operate properly in an accident. A leak test is made using commercial ammonia in the area of the valves. White "smoke" forms in the presence of chlorine. If there are no leaks, the entire car is visually inspected and the plugs replaced on all angle valves. The protective cover is then closed and sealed. Certified papers are prepared to verify the scale ticket and an inspection check 1ist. Figure A.7 is a copy of a typical list.

Tank cars are also weighed following loading. This information is used for billing purposes and to prevent overloading of cars. For this reason, the incidence of overloading is assumed to be rare.

Chlorine is shipped in sole-use cars. Thus, while chlorine is quite reactive, only small amounts of contaminants are potentially available. This means vigorous local reactions under some conditions may occur, having some consequences, but large catastrophic reactions or explosions within the tank are unlikely. 
INSPECTION DATA:

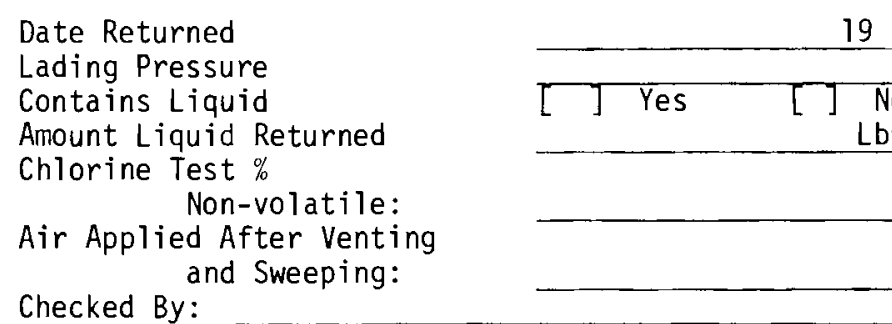

CONDITION OF:

Platforms

Handrails, Ladders, Grab Irons

Manway Cover:

Manway Bolts:
19 Car Number

\section{Date Built}

Tank Water Capacity

Tank Test Press:

SRV Open Press:

SRV Closed Press:

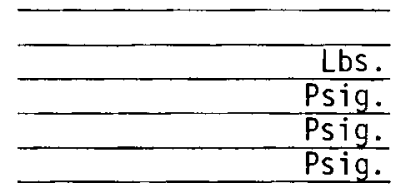

Date Last Tank Test

Date Last SRV Test

Date Last Head Pull

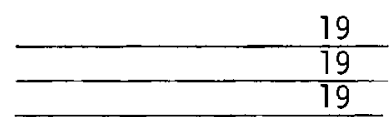

Paint

Stenciling

Inspected By:

RECONDITIONING WORK TO BE PERFORMED:

(TYPICAL MARKINGS)

RECONDITIONING AND INTERIOR INSPECTION DATA:

Did Both Excess Flow Valves Pop? Valves Tested with Air or Water Was Safety Valve Inspected? Condition of Tank:

Were Eduction Pipes Tested, Steam Cleaned and Dried? Were all Four Angle Valves Replaced? Inspected and Conditioned By:
No. 1

Air

Yes [] No [ ]

Before Cleaning

Yes [ ]
No. 2

Water

After $\ldots \ldots$

$+2$

Date

FIGURE A.7. Samples of Chlorine Tank Car Loading Check Lists 


\section{REFERENCES}

1. U.S. Bureau of Census, Census of Transportation, 1972. Vo1. III, Commodity Transportation Survey Part 3, Area Statistics, South and West Regions and U.S. Summary, U.S. Government Printing Office, Washington DC, 1976.

2. Code of Federal Regulations, 49 CFR 179, Specifications for Tank Cars. U.S. Government Printing Office, Washington DC, 1974.

3. Chlorine Manual. The Chlorine Institute Inc., 342 Madison Avenue, New York, NY, 1976.

4. Chlorine Tank Car Loading. MIR-123, Chlorine Institute Inc., 342 Madison Avenue, New York, NY, May 1973. 
APPENDIX B

PROPERTIES OF CHLORINE 
APPENDIX B

\section{PROPERTIES OF CHLORINE}

Elemental chlorine is a highly toxic material principally produced by the electrolysis of sodium chloride. It is widely used to purify water, as a disinfectant, a bleaching agent and in the manufacture of many commercial and consumer compounds. This appendix will provide information on chlorine for use in other portions of this report in the areas of commercial, physical, chemical, thermodynamic and toxilogical properties.

\section{B. 1 COMMERCIAL}

Chlorine, defined by the U.S. Department of Transportation, is a nonflammable compressed gas. (1) It is carried at near ambient temperatures in pressurized vessels built to DOT specifications. Only the transportation of liquified dry chlorine (less than $150 \mathrm{ppm}$ water by weight) will be considered in this report.

\section{B.2 PHYSICAL ${ }^{(2)}$}

Chlorine is a gas at atmospheric pressure with a boiling point of $-34^{\circ} \mathrm{C}$ $\left(-30^{\circ} \mathrm{F}\right)$. The vapors have a strong odor and have a characteristic greenish yellow color at concentrations above $1000 \mathrm{ppm}-\mathrm{m}^{(3)}$. The gas is 2.5 times as dense as air.

Liquid chlorine is clear, amber in color and is about $1 \frac{1}{2}$ times as heavy as water. One volume of 1 iquid chlorine, when vaporized, will yield about 460 volumes of gas.

\section{B.3 CHEMICAL ${ }^{(2)}$}

Chlorine is element number 17 in the periodic table. It has a molecular weight of 70.906. Two isotopes with atomic numbers 35 and 37 are naturally occurring. 
Chlorine, gas or liquid, is non-explosive and non-flammable; however, like oxygen it is capable of supporting combustion of certain substances. Many organic chemicals react readily with chlorine.

The reaction rate of dry chlorine with most metals increases rapidly above a temperature which is characteristic for the metal. Below $121^{\circ} \mathrm{C}\left(250^{\circ} \mathrm{F}\right)$ iron, copper, steel, lead, nickel, platinum, silver and tantalum are resistant to dry chlorine gas or liquid.

At ordinary temperatures dry chlorine reacts with aluminum, arsenic, gold, mercury, selenium, telurium, tin, and titanium. At certain temperatures sodium and potassium burn in chlorine gas. Carbon steel ignites at $251^{\circ} \mathrm{C}\left(483^{\circ} \mathrm{F}\right)$.

Moist chlorine, primarily because of hydrochloric and hypochlorous acids formed through hydrolysis, is very corrosive to most common metals. Platinum, silver, tantulum and titanium are resistant.

The preparation of soda and lime bleaches (sodium and calcium hypochlorite) are typical reactions of chlorine with the alkali and alkaline earth metal hydroxides; the hypochlorites formed are powerful oxidizing agents. Because of its great affinity for hydrogen, chlorine removes hydrogen from some of its compounds, such as the reaction with hydrogen sulfide to form hydrochloric acid and sulfur. Chlorine reacts with ammonia or ammonium compounds to form various mixtures of chloramines depending on the conditions. One of these, under proper conditions, is explosive nitrogen trichloride.

Chlorine reacts with organic compounds much the same as with inorganics to form chlorinated derivitives and hydrogen chloride. Some of these reactions can be explosive, including those with hydrocarbons, alcohols and ethers.

\section{B.4 THERMODYNAMIC}

The thermodynamic properties of enthalpy, volume and entropy for saturated chlorine liquid and vapor are presented in Table B.1. Table B.2 contains similar information for superheated vapor at a pressure of approximately one atmosphere. (4) 
Chlorine has a compressibility factor of 0.845 at $1.808 \times 10^{6} \mathrm{~Pa}$ (262.2 psig) and 0.770 at $2.945 \times 10^{6} \mathrm{~Pa}(427.2 \mathrm{psa})$. This factor is equal to unity at standard conditions.

TABLE B.1. Properties of Saturated Liquid and Vapor Chlorine ${ }^{(a)}$

\begin{tabular}{|c|c|c|c|c|c|c|c|c|c|c|}
\hline \multirow{2}{*}{$\begin{array}{c}\text { Temperature } \\
\text { of (a) }\end{array}$} & \multicolumn{2}{|c|}{ Pressure ${ }^{(c)}$} & \multicolumn{2}{|c|}{ Volume, cu $\mathrm{ft} / 1 \mathrm{~b}{ }^{(\mathrm{d})}$} & \multicolumn{3}{|c|}{ Enthalpy, Btu/1b ${ }^{(e)}$} & \multicolumn{3}{|c|}{ Entropy, Btu $/(1 \mathrm{~b})\left({ }^{\circ} R\right)^{(f)}$} \\
\hline & $\mathrm{atm}$ & $1 \mathrm{~b} / \mathrm{sq}$ in. & $v^{l}$ & $v^{8}$ & $\underline{H}^{2}$ & $\Delta \underline{H}^{v}$ & $H^{8}$ & $\underline{s}^{l}$ & $\Delta \underline{s}^{v}$ & $\underline{s}^{8}$ \\
\hline-30 & .98281 & 14.443 & .010242 & 4.4157 & 102.03 & 123.76 & 225.79 & .43719 & .28802 & .72522 \\
\hline-29.29 & 1.0000 & 14.696 & .010249 & 4.3458 & 102.19 & 123.67 & 225.86 & .43757 & .28733 & .72490 \\
\hline-20 & 1.2473 & 18.330 & .010341 & 3.5462 & 104.34 & 122.42 & 226.76 & .44249 & .27842 & .72091 \\
\hline-10 & 1.5640 & 22.985 & .010442 & 2.8793 & 106.65 & 121.06 & 227.70 & .44766 & .26920 & .71686 \\
\hline 0 & 1.9396 & 28.504 & .010548 & 2.3614 & 108.96 & 119.67 & 228.63 & .45272 & .26034 & .71305 \\
\hline 10 & 2.3808 & 34.988 & .010656 & 1.9545 & 111.27 & 118.26 & 229.54 & .45767 & .25179 & .70946 \\
\hline 20 & 2.8946 & 42.539 & .010769 & 1.6314 & 113.59 & 116.82 & 230.42 & .46263 & .24354 & .70607 \\
\hline 30 & 3.4884 & 51.265 & .010886 & 1.3723 & 115.92 & 115.35 & 231.27 & .46729 & .23556 & .70285 \\
\hline 40 & 4.1696 & 61.276 & .011007 & 1.1625 & 118.26 & 113.84 & 232.09 & .47197 & .22781 & .69979 \\
\hline 50 & 4.9459 & 72.685 & .011132 & .99128 & 120.60 & 112.28 & 232.88 & .47657 & .22029 & .69687 \\
\hline 60 & 5.8251 & 85.606 & .011263 & .85030 & 122.96 & 110.68 & 233.64 & .48110 & .21297 & .69407 \\
\hline 70 & 6.8153 & 100.16 & .011399 & .73336 & 125.33 & 109.03 & 234.35 & .48556 & .20583 & .69139 \\
\hline 80 & 7.9246 & 116.46 & .011542 & .63565 & 127.71 & 107.32 & 235.03 & .48995 & 19885 & .68880 \\
\hline 90 & 9.1613 & 134.63 & .011690 & .55347 & 130.11 & 105.54 & 235.66 & .49429 & 19201 & .68630 \\
\hline 100 & 10.534 & 154.80 & .011846 & .48389 & 132.54 & 103.70 & 236.24 & .49858 & .18529 & .68387 \\
\hline 110 & 12.051 & 177.10 & .012010 & .42463 & 134.98 & 101.79 & 236.77 & .50283 & .17867 & .68149 \\
\hline 120 & 13.721 & 201.65 & .012181 & .37387 & 137.46 & 99.783 & 237.24 & .50704 & .17213 & .67917 \\
\hline 130 & 15.554 & 228.58 & .012363 & .33015 & 139.97 & 97.686 & 237.65 & .51122 & .16566 & .67688 \\
\hline 140 & 17.558 & 258.03 & .012555 & .29229 & 142.51 & 95.483 & 237.99 & .51539 & .15922 & .67461 \\
\hline 150 & 19.743 & 290.14 & .012759 & .25934 & 145.10 & 93.163 & 238.26 & .51954 & .15280 & .67235 \\
\hline 160 & 22.119 & 325.05 & .012976 & .23053 & 147.74 & 90.710 & 238.45 & .52370 & .14638 & .67008 \\
\hline 170 & 24.695 & 362.91 & .013208 & .20521 & .150 .44 & 88.105 & 238.54 & .52788 & .13992 & .66780 \\
\hline 180 & 27.481 & 403.87 & .013458 & .18285 & 153.21 & 85.329 & 238.54 & .53208 & .13339 & .66547 \\
\hline 190 & 30.489 & 448.07 & .013729 & .16302 & 156.06 & 82.355 & 238.42 & .53633 & .12676 & .66309 \\
\hline 200 & 33.729 & 495.67 & .014024 & .14533 & 159.01 & 79.151 & 238.16 & .54065 & .11998 & .66064 \\
\hline
\end{tabular}

(a) Datum: $\mathrm{H}=0, \mathrm{~S}=0$ for solid $\mathrm{Cl}_{2}$ at $-459.69^{\circ} \mathrm{F}\left(0^{\circ} \mathrm{F}\right)$.

(b) ${ }^{\circ} \mathrm{C}=5 / 9\left({ }^{\circ} \mathrm{F}-32\right)$.

(c) $P a=(1 \mathrm{~b} /$ in. 2$)\left(6.8948 \times 10^{3}\right)$

(d) $\mathrm{m}^{3} / \mathrm{kg}=0.0624\left(\mathrm{ft}^{3} / 1 \mathrm{bm}\right)$.

(e) $\mathrm{J} / \mathrm{kg}=(2324.5) \mathrm{Btu} / \mathrm{bm}$.

(f) $\mathrm{J} / \mathrm{kg}^{\circ} \mathrm{K}=4184.1 \mathrm{Btu} / 1 \mathrm{bm}^{\circ} \mathrm{R}$. 
TABLE B.2. Properties of Superheated Chlorine Vapor (a)

\begin{tabular}{|c|c|c|c|c|}
\hline \multirow[b]{2}{*}{$\begin{array}{l}\text { Temperature } \\
{ }^{\circ} \mathrm{F}(\mathrm{b})\end{array}$} & \multirow[b]{2}{*}{$\begin{array}{l}\text { (Saturated } \\
\text { Pressure) } \\
\text { 1b/sq in.(c) }\end{array}$} & \multicolumn{3}{|c|}{$\frac{\text { Absolute Pressure, } 1 \mathrm{~b} / \mathrm{sq} \text { in. }}{15.0}$} \\
\hline & & $\begin{array}{l}\mathrm{v}(\mathrm{d}) \\
\mathrm{ft} / \mathrm{bm}\end{array}$ & $\frac{15.0}{\mathrm{BT} \overline{\mathrm{H}} / \mathrm{e} \mathrm{\textrm {mb }}}$ & $\begin{array}{c}\mathrm{S}(\mathrm{f}) \\
\mathrm{BT} \bar{U} / 7 \mathrm{bm}{ }^{\circ} \mathrm{R}\end{array}$ \\
\hline-20 & 18.330 & 4.3523 & 226.88 & .72669 \\
\hline-10 & 22.985 & 4.4559 & 228.00 & .72921 \\
\hline 0 & 28.504 & 4.5593 & 229.12 & .73767 \\
\hline 10 & 34.988 & 4.6626 & 230.25 & .73409 \\
\hline 20 & 42.539 & 4.7659 & 231.37 & .73646 \\
\hline 30 & 51.265 & 4.8690 & 232.50 & .73880 \\
\hline 40 & 61.276 & 4.9720 & 233.64 & .74109 \\
\hline 50 & 72.685 & 5.0749 & 234.77 & .74334 \\
\hline 60 & 85.606 & 5.1777 & 235.91 & .74555 \\
\hline 70 & 100.16 & 5.2805 & 237.06 & .74773 \\
\hline 80 & 116.46 & 5.3832 & 238.20 & .74987 \\
\hline 90 & 134.63 & 5.4858 & 239.35 & .75198 \\
\hline 100 & 154.80 & 5.5883 & 240.50 & .75406 \\
\hline 110 & 177.10 & 5.6908 & 241.66 & .75610 \\
\hline 120 & 201.65 & 5.7932 & 242.81 & .75812 \\
\hline 130 & 228.58 & 5.8955 & 243.97 & .76010 \\
\hline 140 & 258.03 & 5.9978 & 245.14 & .76205 \\
\hline 150 & 290.14 & 6.1001 & 246.30 & .76398 \\
\hline 160 & 325.05 & 6.2023 & 247.47 & .76588 \\
\hline 170 & 362.91 & 6.3045 & 248.64 & .76775 \\
\hline 180 & 403.87 & 6.4066 & 249.81 & .76960 \\
\hline 190 & 448.07 & 6.5086 & 250.98 & .77142 \\
\hline 200 & 495.67 & 6.6107 & 252.16 & .77322 \\
\hline 210 & 546.88 & 6.7127 & 253.34 & .77499 \\
\hline 220 & 601.83 & 6.8146 & 254.52 & .77675 \\
\hline
\end{tabular}

(a) Datum: $\mathrm{H}=0, \mathrm{~S}=0$ for solid $\mathrm{Cl}_{2}$ at $-459.69^{\circ} \mathrm{F}\left(0^{\circ} \mathrm{F}\right)$.

(b) ${ }^{\circ} \mathrm{C}=5 / 9\left({ }^{\circ} \mathrm{F}-32\right)$.

(c) $\mathrm{Pa}=\left(1 \mathrm{~b} / \mathrm{in.}^{2}\right)\left(6.8948 \times 10^{3}\right)$.

(d) $\mathrm{m}^{3} / \mathrm{kg}=0.0624\left(\mathrm{ft}^{3} / 1 \mathrm{bm}\right)$.

(e) $\mathrm{J} / \mathrm{kg}=(2324.5) \mathrm{Btu} / \mathrm{lbm}$.

(f) $\mathrm{J} / \mathrm{kg}^{\circ} \mathrm{K}=4184.1 \mathrm{Btu} / 7 \mathrm{bm}^{\circ} \mathrm{R}$. 
Specific heats of dry gas and liquid are shown in Table B.3 at constant pressure and volume. The specific heat ratio of the gas is 1.355 .

TABLE B.3. Specific Heat Data for Chlorine ${ }^{(2)}$

$$
\begin{array}{cc}
\text { Dry Gas } & \text { Liquid } \\
\mathrm{g} \mathrm{cal} / \mathrm{g} /{ }^{\circ} \mathrm{C} & \mathrm{g} \mathrm{cal} / \mathrm{g} /{ }^{\circ} \mathrm{C} \\
\hline
\end{array}
$$

Constant

Pressure $\left(C_{p}\right)$

Constant

Volume $\left(c_{v}\right)$
0.113

0.0832
0.236

0.236
Range

$<6.89 \times 10^{5} \mathrm{~Pa}$ $-1.1{ }^{\circ} \mathrm{C}-26.7^{\circ} \mathrm{C}$

$-1.1{ }^{\circ} \mathrm{C}-26.7^{\circ} \mathrm{C}$

\section{B.5 TOXILOGICAL}

Chlorine produces no known systemic effect. All symptoms and signs result directly or indirectly from local irritant action. When a sufficient concentration of chlorine gas is present, it will irritate mucous membranes of the respiratory system and skin. Large amounts cause irritation of eyes, coughing and labored breathing. If the duration of exposure or the concentration of chlorine is excessive, general excitement of the person affected, accompanied by restlessness, throat irritation, sneezing and copious salivation results. The symptoms of exposure to high concentrations are retching and vomiting, followed by difficult breathing. In extreme cases, the difficulty of breathing may increase to the point where death can occur from suffocation. Liquid chlorine in contact with the eyes or skin will cause local irritation and/or burns.

Low concentrations of chlorine gas in the air may have a minor irritating effect or may produce slight symptoms after several hours exposure, but careful examination of persons repeatedly exposed to such conditions reportedly have shown no chronic effect. Concentrations well below that necessary to cause significant damage are readily detectible by persons with normal olefactory capabilities.

Several sources of toxilogical data on chlorine are available. $(5,6,7)$ Plots of the data are shown in Figure B. 1. Curve 1 is based on a dose that would kill 50\% of those exposed. This is assumed to be $1000 \mathrm{ppm}$-min for 


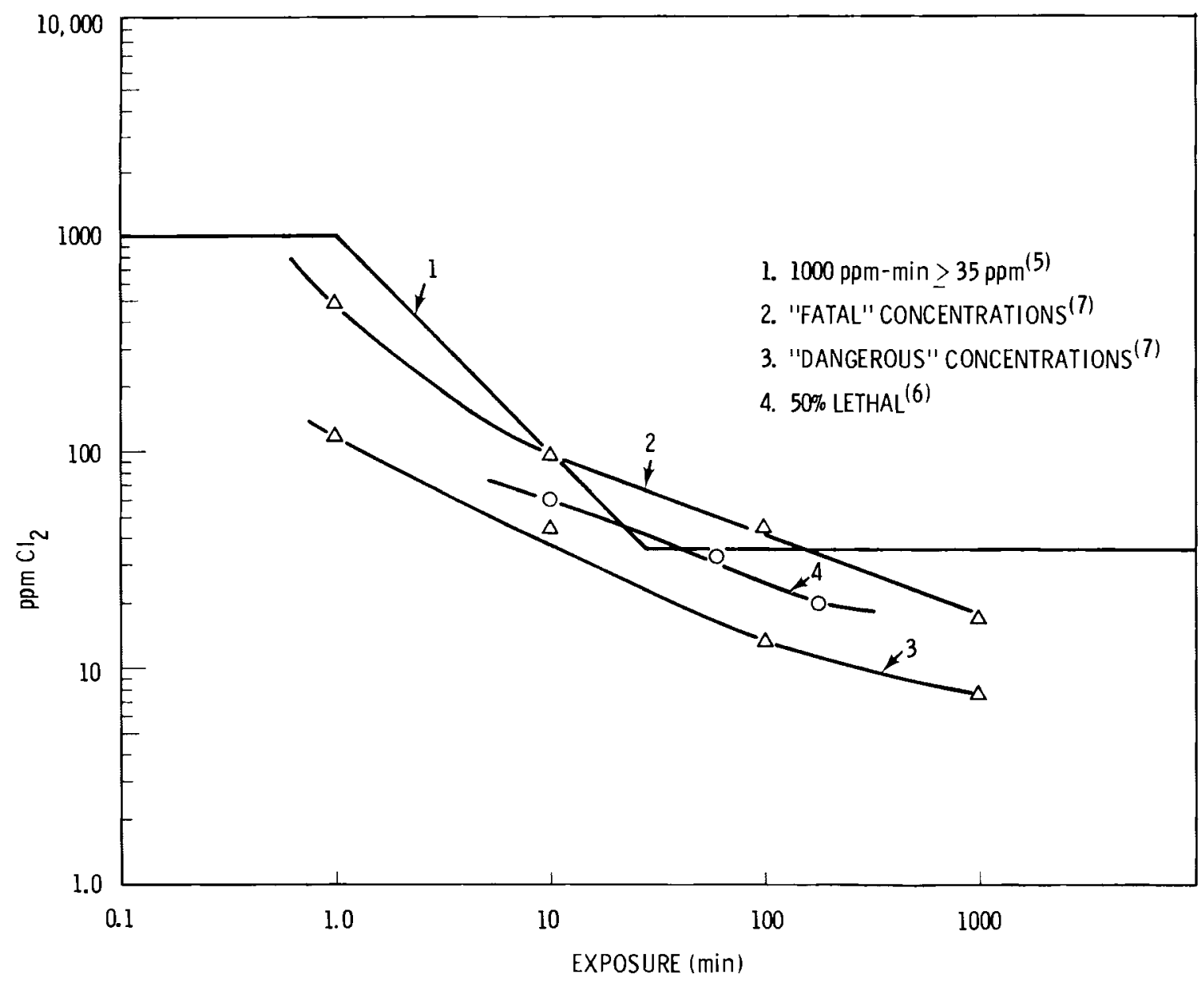

FIGURE B.1. Chlorine Gas Toxicity

concentrations above $35 \mathrm{ppm}$. Curves 2 and 3 showing "fatal" and "dangerous" exposures are from Reference 7 . Another $50 \%$ fatality dose derived from animal exposures is indicated by curve 4 from data in Reference 6 .

For purposes of this report it was assumed that all persons exposed to $1000 \mathrm{ppm}$ will sustain 100\% fatalities. A 50\% fatality rate will be assumed for al1 doses greater than 1000 ppm-min in areas of concentration between 35 and $1000 \mathrm{ppm}$. No fatalities are postulated to occur at concentrations below $35 \mathrm{ppm}$. This approach is nonconservative relative to Reference 7 data for exposure periods less than 10 minutes and greater than 150 minutes, but evacuation times (see Section 9.4) make escape unlikely for the times less than 10 minutes, but probable for exposures greater than 150 minutes. The $1000 \mathrm{ppm}-\mathrm{min}$ dose response agrees well with the animal data for times between 10 and 100 minutes. 


\section{REFERENCES}

1. Title 49, Code of Federal Regulations. Part 172, U.S. Government Printing Office, Washington DC, 1974.

2. Chlorine Manual. Chlorine Institute Inc., 342 Madison Ave, New York, NY, Apri1 1976.

3. Experiments with Chlorine. Directorate-General of Labour of the Ministry of Social Affiars, P.0. Box 69, Voorburg, the Netherlands, Apri1 1975.

4. R. M. Kapoor, J. J. Martin, Thermodynamic Properties of Chlorine. Engineering Research Institute, University of Michigan, 1957.

5. J. A. Simmons, R. C. Erdmann, B. N. Naft, Risk Assessment of Large Spil1s of Toxic Materials. Science Applications INc., presented at; 1974 National Conference on Control of Hazardous Material Spil1s, San Francisco, CA, August 1974.

6. N. A. Eisenberg et al., Vulnerability Model - A Simulation System for Assessing Damage Resulting from Marine Spil1s. Inviro Control Inc., Rockville, MD, June 1975.

7. A. W. A. Dicken, The Quantitative Assessment of Chlorine Emmission Hazards. ICI Limited, Mond Division, Runcorn, Cheshire, England. Presented in Chlorine Bicentennial Symposium. 
APPENDIX C

MECHANICAL AND THERMAL ANALYSIS OF

90-TON CHLORINE TANK CARS 
APPENDIX C

MECHANICAL AND THERMAL ANALYSIS OF

90-TON CHLORINE TANK CARS

A11 containers used in the transport of liquid chlorine are designed in accordance with regulations contained in the Code of Federal Regulations Title 49 relating to hazardous materials. Areas specifically addressed include pressure vessel design, relief value capacities, material specifications and minimum thermal protection. The reference system is described in Appendix $A$ and is assumed to meet or exceed all applicable regulations for a specification 105A500W tank car.

Several analytical approaches are available to determine the mechanical and thermal failure thresholds of the chlorine tank car inciuding: 1) forcedisplacement, 2) finite element analysis using computer codes, 3) mass spring models, 4) dynamic heat transfer and 5) steady-state heat transfer models. The use of more precise, but expensive, computer stress and dynamic heat transfer analyses was considered inappropriate for the purposes of the present study. The general analytical approaches used in this appendix are based on linear elastic structural behavior for stress calculations and steady-state one-dimensional heat transfer for thermal calculations. This approach is considered conservative and sufficiently accurate as to not control the risk assessment uncertainties.

This appendix presents the mechanical and thermal failure thresholds shown in Section 6 of this report. Impact, puncture, crush and thermal failure thresholds were estimated for a 90-ton single unit chlorine tank car. It was assumed that the car was fully loaded with $8.16 \times 10^{4} \mathrm{~kg}$ of chlorine giving a fully loaded car weight of $1.19 \times 10^{5} \mathrm{~kg}$. While a number of specific grades of steel are used in tank car construction. ${ }^{(2)}$ ASTM A515-70 was selected for purposes of this study. The yield and ultimate strengths of this steel at the assumed impact temperature of $49^{\circ} \mathrm{C}\left(120^{\circ} \mathrm{F}\right)$ are about $2.8 \times 10^{8} \mathrm{~N} / \mathrm{m}^{2}$ 
$(41,000 \mathrm{psi})$ and $4.7 \times 10^{8} \mathrm{~N} / \mathrm{m}^{2}(68,000 \mathrm{psi})$ respectively. Ninety ton tank cars can also be built using TC-128B material with an ultimate strength of $5.6 \times 10^{8} \mathrm{~N} / \mathrm{m}^{2}(81,000 \mathrm{psi})$. Thus, the material properties used in this analysis are conservative for alternative construction materials.

\section{IMPACT ANALYSIS}

In this analysis, the side and end collision of the tank car with a flat, unyielding surface was considered. By definition, this implies that the kinetic energy of the moving car and its contents is absorbed entirely by the structure of the rail car. Since damage to the car undercarriage is not of concern in the context of the present study, attention was focused on rupture of the primary chlorine tank. Preliminary considerations indicated that the rupture of the tank is governed by interaction of the liquid chlorine with its containment. At the time of impact, the kinetic energy of the chlorine payload is about five times that of the containing tank. Experimental data are available for failure thresholds of ductile metallic structures in general ${ }^{(5)}$ and hollow steel shells in particular. $(6,7)$ These data indicate allowable impact velocities up to 90 to $120 \mathrm{~m} / \mathrm{sec}$, which are well in excess of velocities encountered in rail transport. However, fluid interactions give much lower failure thresholds for the tank car situation.

For end impact the dynamic fluid response in impact was viewed first on the basis on equations for water hammer, ${ }^{(8)}$ which give

$$
P_{n}=(a v) / g
$$

where

$$
\begin{aligned}
P_{n} & =\text { excess pressure, meters of chlorine } \\
a & =\text { sonic velocity, } \mathrm{m} / \mathrm{s} \\
g & =\text { acceleration of gravity, } 9.8 \mathrm{~m} / \mathrm{s}^{2} \\
V & =\text { car velocity, } \mathrm{m} / \mathrm{s}
\end{aligned}
$$

The sonic velocity is governed by the elastic modulus of the tank as well as the density and bulk compressibility of chlorine, ${ }^{(9)}$ which at the conditions 
of temperature and pressure of interest are about $1.42 \times 10^{3} \mathrm{~kg} / \mathrm{m}^{3}$ $\left(88.8 \mathrm{lb} / \mathrm{ft}^{3}\right)$ and $8.62 \times 10^{8} \mathrm{~N} / \mathrm{m}^{2}(125,000 \mathrm{psi})$, respectively.

In the analysis, it was assumed that the liquid chlorine surges to one side of the tank. Impact can occur in the direct end-on or side-on mode. As a result, a pressure wave in the liquid chlorine propagates through the tank car, and stresses the wall of the tank over and above the level due to assumed ambient chlorine pressure of 200 psi. The level of the overpressure is proportional to the impact velocity. At an impact velocity of about $11.3 \mathrm{~km} / \mathrm{hr}$ (7 mph) a stress sufficient to exceed the yield strength of the tank wall will be produced in side or end impact. In the presence of a severe defect in the tank wall and at temperatures sufficiently low for the propagation of a brittle fracture, (2) catastrophic rupture of the tank could occur at velocities in this range.

At the onset of yield in the tank, the standard equations for water hammer no longer apply. A limiting impact velocity was estimated on the basis that kinetic energy is absorbed by inelastic expansion of the diameter of the tank. It was assumed that rupture of the tank will occur at a diametrical expansion of $5 \%$, which is the range of expansion observed in burst tests of pressure vessels. Furthermore, it was assumed that the pressure decreased in a linear fashion from the impacted end of the tank car, which corresponds to a deceleration over an extended time period. Under these assumptions, it was estimated that rupture of the wall of the tank car will occur for an impact of about $37 \mathrm{~km} / \mathrm{hr}(23 \mathrm{mph})$.

An assumption of a rigid target is believed to be overly conservative in the case of real impacts. The most likely target for a rail car is the rail car immediately in front of it. A rail car of equal mass and regidity could be expected to absorb some impact energy. Most environmental targets such as soil banks and gravel beds could also be expected to absorb significant impact energy. For these reasons, it was assumed in this analysis that $50 \%$ of the car preaccident kinetic energy is absorbed by the target and car supporting structures. This factor results in the following failure thresholds on end impact: 


\section{Minimum Velocity (kph)}

Defective Rail Car

Normar Rail Car
16

52

Side impact is also analyzed by using energy techniques. The work necessary to compress the chlorine from the allowable fill pressure $\left(P_{0}\right)$ to the critical pressure $\left(P_{y i e l d}\right)$ is equated to the change in car kinetic energy. The accident velocities are determined assuming a nearly full chlorine tank and neglecting the static head of the liquid.

The work per unit length to compress the chlorine from $P_{0}$ to $P_{y i e l d}$ is given by

$$
W=\frac{1}{2}\left(P_{f a i 1}+P_{0}\right) \frac{\Delta P}{k} A_{c s}
$$

where,

$$
\begin{aligned}
W & =\text { work per unit length } \\
P_{y i e l d} & =\text { gage pressure required to fail tank } \\
P_{0} & =\text { preaccident internal gage pressure } \\
\Delta P & =P_{\text {fail }}-P_{0} \\
k & =\text { chlorine bulk modulus }\left(1.25 \times 10^{5} 1 \mathrm{~b} / \mathrm{in} .{ }^{2}\right)\left(8.62 \times 10^{8} \mathrm{~N} / \mathrm{m}^{2}\right) \\
A_{C S} & =\text { cross-sectional area of the carrier }
\end{aligned}
$$

Equating the work with the tank kinetic energy (KE) yields

$$
\frac{1}{2} \frac{W_{C l}}{g} V_{0}^{2}=K E=W
$$

Equating the two work definitions and solving for the preimpact tank velocity yields:

$$
V_{0}=\left[\left(P_{f a i l}+P_{0}\right) \frac{P}{K} A_{c s} \frac{g}{W_{c l}}\right]^{\frac{1}{2}}
$$


Substituting the appropriate values and assuming that a defective tank fails at the yield stresses and a normal tank fails when rupture stresses are achieved results in failure thresholds of $9.9 \mathrm{~km} / \mathrm{hr}$ and $20.7 \mathrm{~km} / \mathrm{hr}$ respectively. If it is further assumed that $50 \%$ of the preaccident kinetic energy is absorbed the target the following failure thresholds for side impacts are obtained:

\section{Minimum Velocity $(\mathrm{km})$}

Defective Rail Car 14

Normal Rail Car 29

\section{PUNCTURE ANALYSIS}

Data exist in Reference 16 that relates a puncture probabilities to tank wall thicknesses. This data can be used directly for the reference system. Section 5 of this report summarizes applicable sections.

Although currently not required, head shields placed at either end of tank cars can absorb additional puncture energy from car couplers in the event of accidents in which cars decouple. Since accident data already exist relating puncture probabilities and wall thicknesses, an "equivalent" thickness of the shield and tank wall was sought to be used in a study of possible risk reducing design features.

The head shield design considered for this study complies with regulations prescribed in 49 CFR $179.100-23$. The material must be at least $1.3 \mathrm{~cm}(0.5 \mathrm{in.})$ thick and is assumed to have strengths equivalent to the tank walls.

The concept of an equivalent thickness is equivalence (e.g., a single shell thickness, $t_{e q}$, was sought which would require the same puncture energy as the sum of the shield and tank puncture energies). Energy required to puncture a ductile shell is typically expressed as a power of shell thickness. $(1,4)$

Puncture Energy $=A t^{n}$

$A$ and $n$ dependent on shell material and mounting conditions.

Reference 1 utilizes experimental data obtained from elliptical tank head punctures to arrive a value for $n$ of 1.333 . 
The equivalent thickness of the head shield and tank head can be estimated as follows:

$$
\begin{aligned}
t_{\text {eq }}^{1.333} & =t_{\text {shield }}^{1.333}+t_{\text {tank }}^{1.333} \\
t_{\text {shield }} & =1.3 \mathrm{~cm}(0.5 \mathrm{in.}) \\
t_{\text {tank }} & =2.1 \mathrm{~cm}(0.8125 \mathrm{in.})(105 \mathrm{~A} 500 \text { tank }) \\
t_{\text {eq }} & =2.93 \mathrm{~cm}(1.16 \mathrm{in.})
\end{aligned}
$$

\section{CRUSH ANALYSIS}

The loading configuration assumed for the crush environment is shown in Figure C.1. The crush load is assumed to be uniformly distributed along the entire length of the tank and is assumed to result from the weight of a heavy relatively flat object; e.g., a flat car. The point considered for stress calculations was the top of the tank directly beneath the crush load. The tank bottom will most likely be supported in a relatively compliant fashion such as by soil or gravel forces. Such support will tend to prevent excessive flexure strains due to hydrostatic and crush loading. Since hydrostatic loading has little influence on stress levels at the top of the tank, it was neglected in this analysis.

The stiffening effects of the elliptical tank heads was also neglected in this analysis. This assumption is probably conservative since end stiffness will most likely tend to "shelter" mid-tank regions for most crush loading environments.

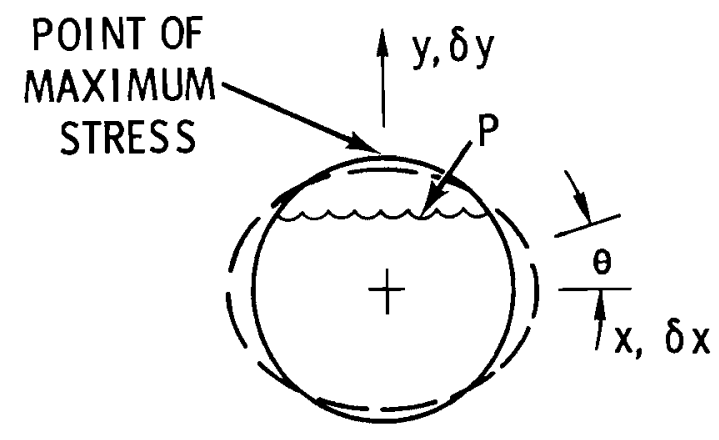

CRUSH LOAD, F (FORCE/UNIT LENGTH)

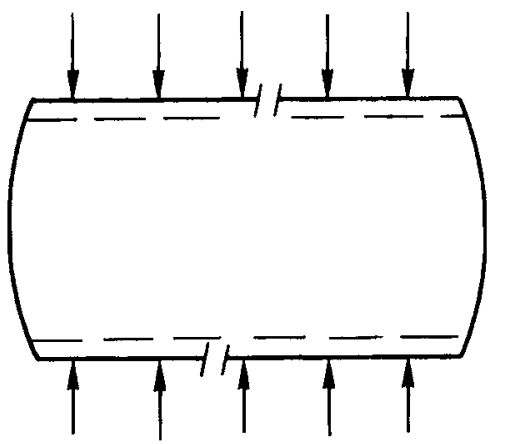

FIGURE C.1. Crush Configuration 
Chlorine shipments are made with relatively full tank cars. (1) Some void is left in order to allow for thermal expansion of the liquid. In a crush environment, the tank deflection will tend to reduce this void, and an increased gas pressure will result. The degree of pressure increase will depend on the volumetric stiffness of the gas with respect to pressure and volumetric stiffness of the tank with respect to pressure and crush loading.

For a given pressure and crush loading, the circumferential tensile stress at the inside surface of the tank is: ${ }^{(3)}$

$$
\sigma=\frac{P R}{t}+\frac{1.908 F R}{t^{2}}
$$

$$
\begin{aligned}
& \mathrm{R}=\text { tank radius }(51 \mathrm{in.}, 129.54 \mathrm{~cm}) \\
& \mathrm{t}=\text { tank thickness }(1.99 \mathrm{~cm}, 0.787 \mathrm{in.}) \\
& \mathrm{P}=\text { internal pressure }(\text { gage }) \\
& \mathrm{F}=\text { crush loading (force/length) }
\end{aligned}
$$

The crush load was assumed to be applied with sufficient speed so as to preclude pressure relief due to pressure relief valve actuation. In addition, gas behavior was assumed to be adiabatic and the liquid chlorine was assumed to be incompressible. Pressure-volume relations in this case take the form:

$$
\frac{(P+1 \text { atmos })}{\left(P_{0}+1 \text { atmos }\right)}=\frac{1}{1+\frac{\Delta V_{P}}{V_{i}}+\frac{\Delta V_{F}}{V_{i}}} C_{P} / C_{V}
$$

$$
\begin{aligned}
V_{i} & =\text { initial gas volume } \\
C_{P} / C_{V} & =\text { specific heat ratio for chlorine }(1.355 \text { from Reference } 1) \\
\Delta V_{P} & =\text { volume change due to pressure increase } \\
\Delta V_{F} & =\text { volume change due to crush loading } \\
P_{0} & =\text { initial gas pressure (gage) }
\end{aligned}
$$


It can be shown that the term relating volumetric increase and pressure takes the form:

$$
\frac{\Delta V_{P P}}{V_{i}} \frac{P P}{t E}(2.5-2 v)
$$

$E=$ Young's modulus of tank material $30 \times 10^{6} \mathrm{psi}, 2.066 \times 10^{11} \mathrm{~N} / \mathrm{m}^{2}$

$v=$ Poisson's ration ( 0.3 assumed)

The term relating volumetric change resulting from crush loading is somewhat more complex. Using techniques similar to those found in Reference 3 , it can be shown that the transverse tank motion in the first quadrant of Figure C.l takes the form:

$$
\begin{aligned}
& \delta_{x}=\frac{F R^{3}}{D_{E}}\left[\frac{\theta \sin \theta}{\pi}+\frac{1}{\pi} \cos \theta-\frac{\sin ^{2} \theta}{2}-\frac{\cos ^{2} \theta}{4}\right] \\
& \delta_{y}=\frac{F R^{3}}{D_{E}}\left[-\frac{\theta}{4}-\frac{\sin 2 \theta}{8}+\frac{\sin \theta}{\pi}+\frac{\sin \theta \cos \theta}{2}-\frac{\theta \cos \theta}{\pi}\right] \\
& D_{E}=\text { shell stiffness } \frac{E t}{12\left(1-v^{2}\right)}
\end{aligned}
$$

It should be emphasized that equations $4 \mathrm{a}$ and $4 \mathrm{~b}$ apply only when the angle $\theta$ in Figure $C .1$ is between 0 and $\pi / 2$. Deflections for other ranges of $\theta$ may be determined from symmetry.

By use of Equations 2 through 4, tank pressures were determined in an iterative fashion for various initial pressure conditions and crush load values. With these pressure values, stress values were computed by use of Equation 1.

The results of these calculations are shown in Figure C.2. Various void volume fractions were considered. These fractions correspond to gas volumes at various temperatures (indicated in Figure C.2) when the tank is filled with 


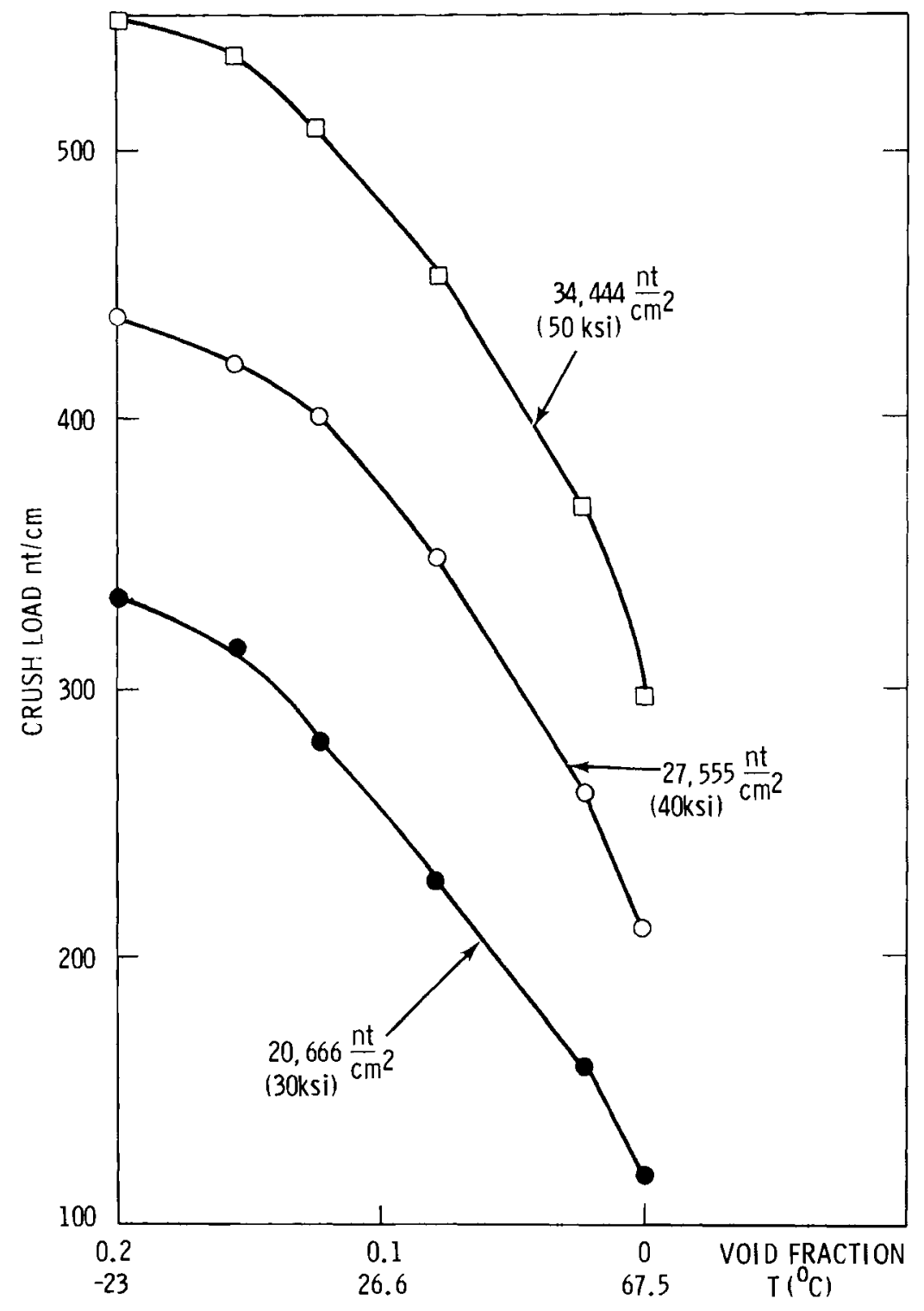

FIGURE C.2. Crush Load versus Gas Void Fraction

its authorized limit as specified in Reference 1 . The $3.45 \times 10^{8} \mathrm{~N} / \mathrm{m}^{2}$ (50,000 psi) stress value was taken as the failure threshold for tank car material deformed in a quasi-static operation. A temperature of $26.6^{\circ} \mathrm{C}$ was selected as the ambient temperature. 
THERMAL ANALYSIS

Calculations were performed to determine the fire durations required to release chlorine for various car conditions. The railroad tank car is assumed exposed to a $1010^{\circ} \mathrm{C}\left(1850^{\circ} \mathrm{F}\right)$ fire. Chlorine tank cars are designed to withstand high temperature environments. The tank cars are insulated with 4 in. of cork or polyurethane surrounded by a steel jacket. In addition, a safety relief valve is provided to vent chlorine to the atmosphere if internal pressure becomes excessive.

Calculations were performed for the following conditions:

- the safety relief valve fails to operate and the tank ruptures at some fire duration time

- the safety relief valves function properly on an upright car and the car ruptures from local high temperature metal fatigue

- the safety relief valve functions properly on an overturned car and the car ruptures due to excessive internal pressure.

Two cases were examined for each of the above conditions;

1) $100 \%$ insulation intact

2) $90 \%$ insulation intact

The percent insulation damage was assumed to represent an upper limit of impact damage. This value was calculated assuming a raking collision with a planar target which just grazes the tank shell along the length of the car.

A conservative estimate of heat flux in an $1010^{\circ} \mathrm{C}\left(1850^{\circ} \mathrm{F}\right)$ fire transmitted to the tank through the insulation thickness can be made by neglecting the thermal resistance due to radiation. This essentially assumes that the external surface of the insulation is at the fire temperature of $1010^{\circ} \mathrm{C}$.

$$
q_{C}=\frac{1010^{\circ} \mathrm{C}-T_{C l}}{L} K
$$




$$
\begin{aligned}
\mathrm{q}_{\mathrm{C}} & =\text { heat transmitted by conduction } \frac{\mathrm{W}}{\mathrm{m}^{2}} \\
\mathrm{~T}_{\mathrm{Cl}} & =\text { temperature of chlorine }\left(37.8^{\circ} \mathrm{C}-100^{\circ} \mathrm{F} \text { assumed }\right) \\
\mathrm{K} & =\text { thermal conductivity of insulating material } \\
\text { cork } & =0.048 \frac{\mathrm{W}}{\mathrm{m}^{\circ} \mathrm{C}}\left(0.028 \frac{\mathrm{Btu}}{\mathrm{ft} \mathrm{hr}}{ }^{\circ} \mathrm{F}\right)(3) \\
\text { polyurethane } & =0.310 \frac{\mathrm{W}}{\mathrm{m}^{\circ} \mathrm{C}}\left(0.179 \frac{\mathrm{Btu}}{\mathrm{hr} \mathrm{ft}}{ }^{\circ} \mathrm{F}\right) \\
\mathrm{L} & =\text { insulation thickness }-0.102 \mathrm{~m}(4 \mathrm{in.})
\end{aligned}
$$

Since the conductivity of polyurethane is greater than that of cork, a conservative estimate of conduction heat flux can be made by assuming polyurethane insulation. This heat flux entering the tank through an insulated region of the tank is:

$$
q_{C}=2960 \frac{W}{m^{2}}\left(940 \frac{B t u}{h r f t^{2}}\right)
$$

A conservative estimate of heat flux for a region of the tank with insulation removed can be made by neglecting thermal resistance due to conduction through the primary tank wall.

$$
\begin{aligned}
\left.q_{r}=0.1714\left(\frac{1}{\varepsilon_{f}}+\frac{1}{\varepsilon_{W}}-1\right)-1\left[\left(\frac{1850+460}{100}\right)^{4}\right)-\left(\frac{T_{c l}+460}{100}\right)\right] \\
\varepsilon_{f}=\text { emissivity of fire } 0.9 \text { (assumed) } \\
\varepsilon_{W}=\text { emissivity of tank wal1 } 0.8 \text { (assumed) } \\
T_{c l}=\text { temperature of chlorine } 100^{\circ} \mathrm{F} \text { (assumed) } \\
q_{r}=1.13 \times 10^{5} \frac{W}{\mathrm{~m}^{2}}\left(35,700 \frac{\text { Btu }}{\mathrm{hr} \mathrm{ft}}\right. \text { ) }
\end{aligned}
$$

The surface area of a typical chlorine tank car is approximately $110 \mathrm{~m}^{2}$ $\left(1186 \mathrm{ft}^{2}\right)$. The heat load for various amounts of insulation removed assuming no tank penetrations is

$$
Q_{T}=q_{C}(1186-A f)+q_{r} A_{r}
$$

This value is tabulated in Table $C .1$ for various values of $A_{r}$. 


\section{TABLE C.1. Heat Load from a $1010^{\circ} \mathrm{C}$ Fire}

\begin{tabular}{|c|c|c|}
\hline $\begin{array}{c}Q T \\
B t u / h r(a) \\
\end{array}$ & $\begin{array}{r}\mathrm{Ar} \\
\left(\mathrm{ft}{ }^{2}\right)(\mathrm{b})\end{array}$ & $\begin{array}{l}\text { Insulation } \\
\text { Removed \% } \\
\end{array}$ \\
\hline $1.11 \times 10^{6}$ & 0 & 0 \\
\hline $4.59 \times 10^{6}$ & 100 & 8.4 \\
\hline $5.25 \times 10^{6}$ & 118.6 & 10 \\
\hline $8.07 \times 10^{6}$ & 200 & 16.9 \\
\hline $1.15 \times 10^{7}$ & 300 & 25.3 \\
\hline $1.50 \times 10^{7}$ & 400 & 33.7 \\
\hline $1.85 \times 10^{7}$ & 500 & 42.2 \\
\hline
\end{tabular}
(a) $1 \frac{\mathrm{Btu}}{\mathrm{hr}}=0.2929 \mathrm{~W}$
(b) $1 \mathrm{ft}^{2}=0.0929 \mathrm{~m}^{2}$.

The maximum weight of chlorine for a tank car shipment is specified in Reference 1 as $125 \%$ of the weight of water the tank car can hold at $160^{\circ} \mathrm{F}$. Assuming that the tank car was filled at $37.8^{\circ} \mathrm{C}\left(100^{\circ} \mathrm{F}\right)$ to the authorized limit means that the volume of the tank car contains $92 \% 1$ iquid and $8 \%$ void. (1)

Actuation pressure for the safety valve used in 90 ton chlorine cars is $2.59 \times 10^{6} \mathrm{~N} / \mathrm{m}^{2}$ (375 psig). Assuming that the void space in the tank car consists primarily of chlorine vapor, the tank car volume will consist totally of liquid chlorine at $67.8^{\circ} \mathrm{C}\left(154^{\circ} \mathrm{F}\right)$ and $2 \times 10^{6} \mathrm{~N} / \mathrm{m}^{2}$ (290 psig). This pressure is assumed to represent an approximate threshold pressure for chlorine release.

The time required for the liquid chlorine to expand and completely fill the tank car volume is:

$$
t=\frac{M\left(67.8^{\circ} \mathrm{C}-{ }_{c}\right) C}{2 Q}
$$

$t=$ release threshold time $(\mathrm{sec})$

$M=$ initial mass of chlorine contained in the tank car $-8.16 \times 10^{4} \mathrm{~kg}$

$T_{C}=$ temperature of chlorine before fire starts $\left(38^{\circ} \mathrm{C}\right)$ 
$\mathrm{C}=$ specific heat of liquid chlorine $946 \frac{\mathrm{J}}{\mathrm{kg}{ }^{\circ} \mathrm{C}}\left(0.226 \frac{\mathrm{Btu}}{1 \mathrm{bm}{ }^{\circ} \mathrm{F}}\right)(1)$ $2 Q=$ heat load during fire $W$ (typical values shown in Table C.1)

The heat load to the car lading was doubled to account for normal penetrations in the tank insulation. A shell full condition could occur in a 100 minute fire if all insulation performs as predicted or in a 35 minute fire if $10 \%$ of the insulation is removed. If the safety relief valve malfunctions, these values represent conservative estimates of the time required to rupture the tank car. It should be mentioned that these values assume that the tank is essentially rigid and that liquid chlorine is essentially incompressible. For these reasons, actual rupture times could be substantially greater than those predicted by this model.

If the safety relief value does not malfunction, chlorine will be released by some combination of thermal expansion or vaporization. The exact mode of release (vapor or liquid) would depend on the heating load and the flow characteristics of the valve configuration. If the release mode is vapor, then an estimate of the release rate is:

$$
\begin{aligned}
\dot{M}=\frac{2 Q}{\mathrm{~h} f \mathrm{~g}} \cdot & = \\
\dot{M} & =\text { release rate } \mathrm{kg} / \mathrm{s} \\
2 \mathrm{Q} & =\text { heating rate } \mathrm{W} \mathrm{J} / \mathrm{kg} \text { (doubled for penetrations) } \\
\mathrm{h}_{\mathrm{fg}} & =\text { heat of vaporization } 2.88 \times 10^{5}\left(\frac{123.7}{\mathrm{Btu}}\right)(1) \\
\dot{\mathrm{M}} \mathrm{kg} / \mathrm{s} & =6.96 \times 10^{-6} \mathrm{Q}(\mathrm{W})
\end{aligned}
$$

If the release mode is governed by liquid expulsion through the valve, the release rate takes the form:

$$
\begin{aligned}
\dot{M} & =-v \frac{d p}{d t} \\
& =-v \frac{d p}{d t} \frac{d T}{d t} \\
& =-v \frac{d p}{d T} \frac{2 Q}{M C}
\end{aligned}
$$




$$
\begin{aligned}
\dot{M} & =-\frac{1}{\mathrm{P}} \frac{\mathrm{dp}}{\mathrm{dT}} \frac{2 \mathrm{Q}}{\mathrm{C}} \\
\mathrm{N} & =\text { release rate } \\
\mathrm{P} & =\text { instantaneous density } \\
\mathrm{T} & =\text { temperature } \\
2 Q & =\text { heat load (doubled for penetrations) } \\
\mathrm{C} & =\text { specific heat of liquid chlorine }(1)
\end{aligned}
$$

If the tank is upright, liquid will be expelled through the valve as the tank temperature rises from $68^{\circ} \mathrm{C}$ to $78^{\circ} \mathrm{C}$. Above this temperature a vapor discharge will begin. A long duration vapor discharge could lead to tank rupture by creep failure of metal no longer backed by liquid chlorine.

Full scale tank car tests with propane cars have indicated that fatigue failure of the tank shell does not occur until half the lading has been vaporized. (4) In propane cars this is due to metal fatigue. This mechanism, plus corrosion is possible for chlorine cars when local temperatures exceed $250^{\circ} \mathrm{C}$. Using the half full failure point assumption and the above formulae on liquid and vapor discharges, a 290 minute fire is required for failure if all insulation is intact. If $10 \%$ of the insulation is damaged a 100 minute fire is required.

If the tank car is overturned and involved in a fire, a liquid discharge begins when the car reaches $68^{\circ} \mathrm{C}$ and continues until the internal liquid level is reduced to that of the valve. Using analysis presented by Bullerdiek et al. the pressure in the car may continue to rise during the liquid discharge. If the fire duration is sufficient, tank rupture could occur from excessive internal pressure. Details of this analysis as applied to chlorine tank cars is presented below.

Appendix $D$ presents an analysis of the maximum isentropic flow of liquid chlorine through an orifice. The maximum flow at a tank pressure of $2.59 \mathrm{MPa}$ is $14 \mathrm{~kg} / \mathrm{sec}$. Actual flow through the valve is related to this theoretical maximum by the relationship:

$$
\begin{aligned}
& \dot{\mathrm{M}}_{\ell \mathrm{a}}=14 \mathrm{C}_{1}(\mathrm{~kg} / \mathrm{s}) \\
& \dot{\mathrm{M}}_{\text {la }}=\text { Actual liquid chlorine flow }(\mathrm{kg} / \mathrm{sec}) \\
& C_{1}=1 \text { iquid flow coefficient for the relief valve }(\leq 1) .
\end{aligned}
$$


If this actual liquid venting rate is less than that required by the rate of heat gain to the car, the pressure must rise in the tank. The thermodynamic properties of the material in the tank follow the saturation line as the tank temperature and pressure rise. At any tank condition, the volume change in the vapor space (when the liquid is being dischanged) is given by:

$$
\frac{d v \text { space }}{d t}=\dot{M}_{l} v_{f}+M_{v} v_{f}
$$

where

$$
\begin{aligned}
\frac{\mathrm{d} v \text { space }}{\mathrm{dt}} & =\text { rate of change of vapor space volume neglecting liquid expansion } \\
\dot{M}_{\ell} v_{f} & =\text { volume of liquid discharged }\left(\mathrm{m}^{3} / \mathrm{s}\right) \\
\dot{M}_{\ell} & =\text { mass flow of liquid discharge }(\mathrm{kg} / \mathrm{s}) \\
v_{f} & =1 \text { iquid specific volume }\left(\mathrm{m}^{3} / \mathrm{kg}\right) \\
\dot{M}_{v} v_{f} & =\text { volume due to liquid evaporation }\left(\mathrm{m}^{3} / \mathrm{s}\right) \\
\dot{M}_{v} & =\text { evaporation from liquid survace }(\mathrm{kg} / \mathrm{s})
\end{aligned}
$$

The vapor space is continuously filled with vapor at specific volume $\nu_{g}$. Hence,

$$
\begin{aligned}
\frac{d v \text { space }}{d t}=\dot{M}_{v} \nu_{g} & =\dot{M}_{f} \nu_{f}+\dot{M}_{v} \nu_{f} \\
\dot{M}_{v} & =\dot{M}\left(\frac{\nu_{f}}{v_{g}-v_{f}}\right)
\end{aligned}
$$

The energy used in this vaporization is:

$$
\begin{aligned}
& \qquad Q_{v}=\dot{M}_{v} 1=\dot{M}_{\ell} L\left(\frac{\nu_{f}}{\nu_{g}-\nu_{f}}\right) \\
& L=\text { latent heat of vaporization }(\mathrm{J} / \mathrm{kg})
\end{aligned}
$$


The energy input to the tank is $Q_{\text {in }}$. The excess energy over that used in vaporization is absorbed by the liquid-vapor mixture resulting in an increase in tank pressure. Along the chlorine liquid saturation line between $2.24 \mathrm{MPa}$ and $7.04 \mathrm{MPa}$ the average pressure increase per unit internal energy increase is $4.77 \times 10^{-5} \mathrm{MPa} / \frac{\mathrm{J}}{\mathrm{kg}}$. Hence

$$
\frac{\mathrm{dp}}{\mathrm{du}} \simeq 4.77 \times 10^{-5} \mathrm{MPa} / \frac{\mathrm{J}}{\mathrm{kg}}
$$

but

$$
Q_{\text {in }}-Q_{v} \stackrel{v}{=} M_{\text {tot }} \frac{d u}{d t}
$$

where

$$
M_{\text {tot }}=\text { mass of chlorine in tank }(\mathrm{kg}) \text { (1iquid and vapor) }
$$

From the above equations:

$$
Q_{\text {in }} \approx \frac{M_{\text {tot }}}{4.77 \times 10-5} \frac{d p}{d t}+\dot{M}_{1} L\left(\frac{\nu_{f}}{\nu_{g}-\nu_{f}}\right)
$$

This equation indicates the required amount of liquid flow to limit the rate of pressure rise for any $Q_{i n}$. To prevent tank rupture, the rate of pressure rise must be 1 imited to prevent tank rupture pressure being achieved before all the liquid can be discharged. Thus for each liquid discharge rate and tank burst pressure there is a specific maximum rate of energy gain.

The maximum discharge duration is approximately:

$$
t_{0}=M_{\text {tot } / \dot{M}_{L}}
$$


If the maximum allowable pressure is $P_{\max }(\mathrm{MPa})$ and the set pressure of the valve is $P_{0}(\mathrm{MPa})$ :

$$
Q_{\text {in allowable }}=\left[\frac{P_{\text {max }}-P_{0}}{4.77 \times 10-5}+\frac{L v_{f}}{\nu_{g}-\nu_{f}}\right] \dot{M}_{\max } C_{1}
$$

Assuming a liquid discharge coefficient of 0.65 and a rupture pressure of $3.45 \mathrm{MPa}$ (500 psi) the maximum allowable head rate for the car is $0.325 \mathrm{MW}$. Heat loads for 100\% insulation and 90\% insulation are $0.662 \mathrm{MW}$ and $1.88 \mathrm{MW}$ respectively. Thus this model predicts a finite fire duration for tank rupture. Rupture time from the onset of vapor space formation is estimated from:

$$
\frac{d p}{d t} \simeq\left[Q_{i n}-\dot{M}_{1 \max } C_{1} L\left(\frac{\nu_{l}}{\nu_{g}-\nu_{l}}\right)\right] \frac{4.77 \times 10^{-5}}{M_{\text {tot }}}
$$

For $100 \%$ insulation this pressure rise is predicted to be $0.324 \mathrm{kPa} / \mathrm{s}$; pressure failure is predicted to occur in $44 \mathrm{~min}$. For 90\% insulation, the rise is $1.05 \mathrm{kPa} / \mathrm{s}$. Pressure failure could occur in $13 \mathrm{~min}$. By adding these times to those required to achieve shell full and the compressed liquid state, fire durations to failure can be predicted:

$$
\begin{aligned}
100 \% \text { insulation } & =164 \mathrm{~min} \\
90 \% \text { insulation } & =55 \mathrm{~min} .
\end{aligned}
$$

These failure times are conservative if local shell temperatures are low enough to preclude metal fatigue. Chlorine tank cars are designed to withstand $6.90 \mathrm{MPa}$ (1000 psi) and are tested periodically to $3.45 \mathrm{MPa}$ (500 psi). The degree of conservatism of this assumption under actual fire conditions is unknown.

To measure the effect on risk of potentially unfavorable relief valve liquid discharge characteristics, several sensitivity cases were postulated where discharge rates sufficient to preclude tank overpressurization were allowed. The first case postulated zero pressure increase after relief pressure was obtained. Solving the above equation for the required mass flow 
after requiring that $d p / d t=0$ results in the following relief valve requirements:

$$
\begin{aligned}
100 \% \text { insulation } & =47 \mathrm{~kg} / \mathrm{sec} \\
90 \% \text { insulation } & =133 \mathrm{~kg} / \mathrm{sec} .
\end{aligned}
$$

Under either of these conditions, high temperature metal fatigue is the controlling failure mode. The half full tank condition required for this failure could occur 14 minutes after the relief valve opens in the $100 \%$ insulated case or after 5 minutes in the $90 \%$ insulated case. In both cases, this is a net decrease in tolerable fire exposure times.

In the second sensitivity case, tank pressure was allowed to rise such that a pressure of $3.45 \mathrm{MPa}$ is achieved just as the tank reaches a half full state. Failure, in this case, could occur from either overpressurization or metal fatigue. Two discharge rates could result in this condition depending on the amount of insulation available:

$$
\begin{aligned}
100 \% \text { insulation } & =13 \mathrm{~kg} / \mathrm{sec} \\
90 \% \text { insulation } & =36 \mathrm{~kb} / \mathrm{sec} .
\end{aligned}
$$

If $13 \mathrm{~kg} / \mathrm{sec}$ is selected for the relief valve design, then the following fire failure times are predicted:

$$
\begin{aligned}
100 \% \text { insulation } & =175 \mathrm{~min} \\
90 \% \text { insulation } & =57 \mathrm{~min} .
\end{aligned}
$$

Failure in the $90 \%$ insulation case for this discharge rate would occur from overpressurization. However, failure times in both cases are increased from that of a $9.1 \mathrm{~kg} / \mathrm{sec}$ discharge rate.

If $37 \mathrm{~kg} / \mathrm{sec}$ is selected for the relief valve design, then the following fire failure times are predicted:

$$
\begin{aligned}
100 \% \text { insulation } & =140 \mathrm{~min} \\
90 \% \text { insulation } & =60 \mathrm{~min} .
\end{aligned}
$$

The $100 \%$ insulation case fails from fatigue at pressures below $3.45 \mathrm{MPa}$. Failure times are decreased from that of a $9.1 \mathrm{~kg} / \mathrm{sec}$ discharge rate in the $100 \%$ insulation case, but increased slightly for the $90 \%$ insulation case. 


\section{REFERENCES}

1. Chlorine Manual--Fourth Edition. The Chlorine Institute, New York, 1969.

2. Eiber, R. J., W. A. Maxey, and A. R. Duffy, Analysis of Fracture Behavior of Tank Cars in Accidents. to RPI-AAR Railroad Tank Car Safety Research and Test Project by Battelle Columbus Laboratories, September 20, 1972.

3. Strength of Materials. J. P. Den Hartog, Dover Publications, Inc., 1961, New York, NY.

4. Railroad Tank Car Safety Research and Test Project, Phase II Report on Fu11 Scale Fire Tests, RA-11-6-31, Association of American Railroads, Chicago Research Center, Chicago, IL, December 1975.

5. W. A. Bullerdiek, F. A. Bassalig, D. L. Adams and C. W. Matheis, A Study to Reduce the Hazards of Tank Car Transportation, FRA-RT-71-74, Department of Transportation.

6. 1970 Annual Book of ASTM Standards - Part 4. American Society for Testing and Materials, Philadelphia, PA.

7. ASME Boiler and Pressure Vessel Code. Section VIII, Rules for Construction of Pressure Vessels, Division 2, Alternate Rules, July 1, 1974.

8. M. Kornhauser, Structural Effects of Impact. Spartan Books, Baltimore, 1974.

9. Simonis, J. C., and C. E. Stoneking, A Study of Impact Effects on Spherical Shells, Part II: A Theoretical and Experimental Study of the Response of Spherical Shells to Impact Loads. SC-CR-67-2540 to Sandia Corporation by Georgia Institute of Technology, December 1966.

10. R. E. Morris, Experimental Stress Analysis of Large Plastic Deformations in a Hollow Sphere Deformed by Impact Against a Concrete Block. NASA TMX-68270, Lewis Research Center, July 1973.

11. Kent's Mechanical Engineers' Handbook. 12th Edition, Wiley, 1965.

12. Chlorine. Hooker Electrochemical Company, Bulletin 125, 1952.

13. Association of Americal Railroads Report No. RA-05-1-17. Final Phase 05 of Report on Tank Car Study, July 14, 1972.

14. Chlorine Manual. The Chlorine Institute, Inc., 342 Madison Ave., New York, NY.

15. L. B. Shappert, Cask Designer's Guide. ORNL-NSIC-68, February 1970, Oak Ridge National Laboratories, Oak Ridge, TN. 
16. A. W. Dennis et al., Severities of Transportation Accidents Involving Large Packages. SAND 77-0001, Sandia Laboratories, ATbuquerque, NM, May 1978.

17. Hilado, Carlos, J., Flammability Handbook for Plastics. Technomic Publishing Co., Stamford, CT, 1969.

18. Banmeuster, Theodore, Mark's Standard Handbook for Mechanical Engineers. 7th Edition, McGraw Hi17 Book Co., New York, NY, 1967.

19. Kreith, Frank, Principles of Heat Transfer. Internal Textbook Co., Scranton, PA, 1965. 
APPENDIX D

CHLORINE VAPORS RELEASED FROM 90-TON

CAPACITY RAILROAD TANK CARS 
APPENDIX D

\section{CHLORINE VAPORS RELEASED FROM 90-TON}

CAPACITY RAILROAD TANK CARS

The release of chlorine vapors from various $8.16 \times 10^{4} \mathrm{~kg}$ (90-ton) capacity tank car accident scenarios has been calculated for use in estimating the downwind areas subject to health hazards.

Two general types of releases have been considered:

- Release of chlorine vapor from the catastrophic failure of the tank car wa11 due to mechanical impacts or excessive hydrostatic pressures. In order to maintain the liquid phase within the tank car, chlorine is initially contained at an elevated pressure. Excessive pressures due to liquid expansion and safety valve failure may result upon exposure to a thermal environment. The sudden release of this pressure causes flash vaporization which continues until the liquid has cooled to its boiling point at one atmosphere, $-34^{\circ} \mathrm{C}$. A highly concentrated cloud of chlorine vapor is created which may represent a significant fraction of the total tank car lading.

- Escape of chlorine through a smal1 tank opening. Tank-car wa11 puncture or pressure relief valve venting are two examples. Either single or twophase flow is possible through these openings. Thermodynamic properties of chlorine were considered to estimate release rates.

\section{D.1 INSTANTANEOUS RELEASE OF CHLORINE VAPOR FROM CATASTROPHIC FAILURE OF TANK CAR WALL}

The quantity of chlorine available for release as an instantaneous vapor cloud due to catastrophic tank-wall failure is dependent upon the initial liquid temperature as shown in Figure D.1. The vapor cloud released is both colder and of a higher molecular weight than the ambient atmosphere resulting 


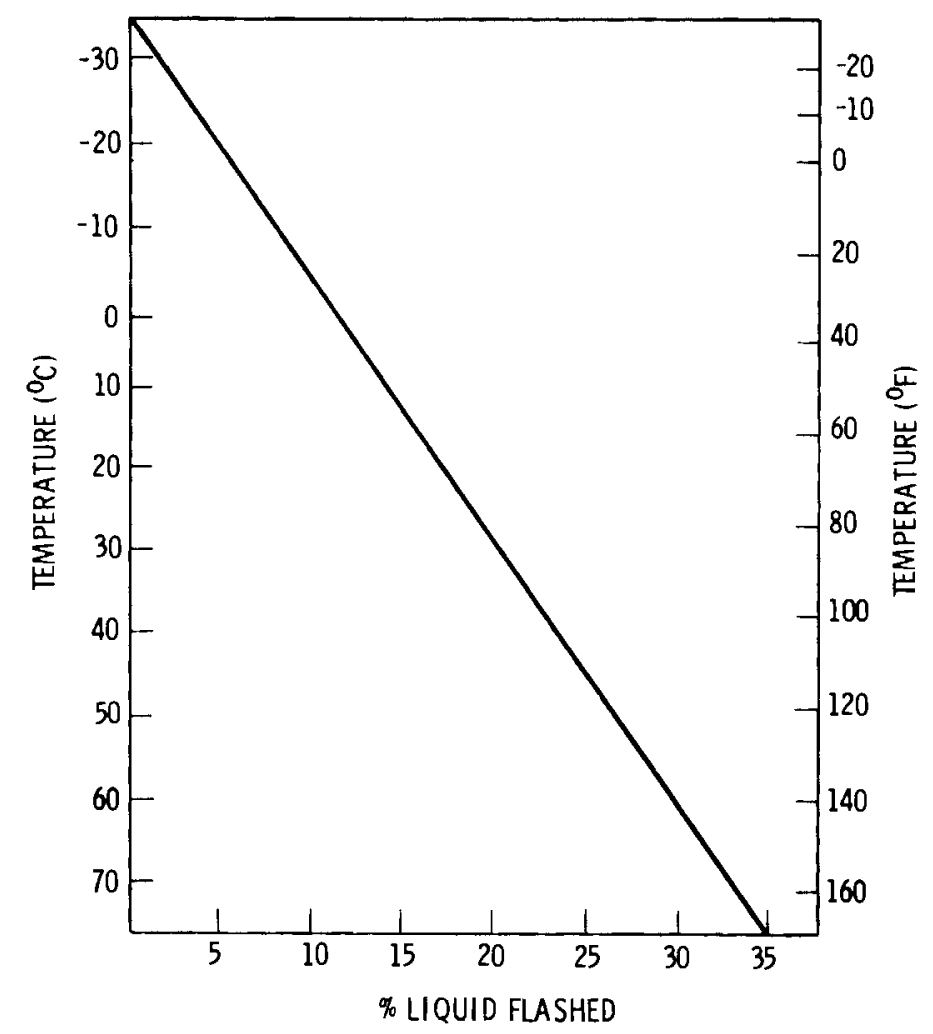

FIGURE D.1. Percent Liquid Chlorine Flashed versus Liquid Temperature ${ }^{(4)}$

in negative buoyancy. The remaining chlorine forms a liquid pool which evaporates at a rate dependent upon the heat transfer between the liquid and the ground surface.

From Figure $\mathrm{D} .1$ at a normal ambient temperature of $21^{\circ} \mathrm{C}$, rupture of a tank car wall would release 17.5 percent of the chlorine as a vapor cloud. For a 90 -ton $\left(8.16 \times 10^{4} \mathrm{~kg}\right)$ railcar, this translates to the "flashing" of $1.43 \times 10^{4} \mathrm{~kg}$ of gas. Assuming an ambient temperature range of from $4^{\circ} \mathrm{C}$ to $33^{\circ} \mathrm{C}$, the amount of chlorine flashed can vary from 14 to $23 \%$.

Upon exposure to a fire, however, the amount of chlorine flashed could be much greater. Should the safety relief valve fail, the volumetric expansion of liquid chlorine would completely fill the car vapor void at $\sim 68^{\circ} \mathrm{C}$. At this temperature, hydrostatic pressure can be expected to rupture the tank car wal1 releasing $32 \%\left(2.61 \times 10^{9} \mathrm{~kg}\right)$ of the chlorine as a vapor "puff". 
The entire 90-ton load of car could conceivably vaporize instantaneously. Such a release may occur if a tank car derails into a body of water and ruptures. Experiments by the Bureau of Mines ${ }^{(1)}$ demonstrate that chlorine spills into water have accelerated vaporization due to the intimate contact between the colder chlorine liquid and warmer water allowing rapid heat transfer and near-total instantaneous vaporization.

\section{D.2 CONTINUOUS RELEASE OF CHLORINE VAPOR}

A constant release rate discharge of chlorine vapor can result from accidents involving tank-car puncture or relief-venting due to exposure to fire.

Two accident scenarios are postulated to demonstrate the maximum compressed liquid flow rates for continuous releases through a pressure relief valve. This analysis considers the rollover of a 90-ton $\left(8.16 \times 10^{4} \mathrm{~kg}\right)$ capacity car equipped with a $375 \mathrm{psi}(2.59 \mathrm{MPa})$ relief-valve. The car is exposed to fire and the liquid within the tank expands due to heat input completely filling the car at $155^{\circ} \mathrm{F}\left(68^{\circ} \mathrm{C}\right)$. Shortly thereafter, the relief valve opens and liquid chlorine is ejected. The maximum flow of liquid through the valve has been calculated by the method suggested in Bullerdiek ${ }^{(2)}$ for two-phase flow: Proceeding with the energy equation:

$$
\frac{v_{1}^{2}}{2 g}+n_{1}=\frac{v_{2}^{2}}{2 g}+n_{2}
$$

Where $V$ is the fluid velocity, $h$ the enthalpy, $g$ the gravitational acceleration and the subscripts refer to flow entering (1) and leaving (2) an orifice. Since the fluid velocity within the tank is zero, the equation reduces to:

$$
v_{2}=\left[2 g\left(h_{1}-h_{2}\right)\right]^{1 / 2}
$$

The mass flow rate for assumed frictionless flow is:

$$
\frac{d M}{d t}=A \frac{V_{2}}{V_{2}}
$$


where $A$ is the cross-sectional area of the orifice and $v_{2}$ the specific liquid volume at the orifice. Equating expressions:

$$
\frac{1}{A} \frac{d M}{d t}=\left[2 g\left(h_{2}-h_{2}\right)\right]^{1 / 2}
$$

The enthalpy of the saturated liquid $\left(h_{1}\right)$ within the tank can be found in tables of thermodynamic properties for chlorine. ${ }^{(3)}$ Enthalpy $\left(h_{2}\right)$ and specific volume $\left(v_{2}\right)$ at the valve exits have been calculated for isentropic flow by utilizing the following relationships:

$$
\begin{aligned}
& \qquad x=\frac{S-s_{f}}{s_{g}-s_{f}} \\
& S=\begin{array}{l}
\text { saturated liquid entropy from thermodynamic tables for any } \\
\text { given tank pressure }
\end{array} \\
& s_{f}, s_{g}=\begin{array}{l}
\text { saturated fluid }(f) \text { and gas }(g) \text { entropies at any assumed ori- } \\
\text { fice pressure }
\end{array}
\end{aligned}
$$

The enthalpy and specific volume are then determined from:

$$
\begin{aligned}
& h_{2}=x\left(h_{g}-h_{f}\right)+h_{f} \\
& v_{2}=x\left(v_{g}-v_{f}\right)+f_{v}
\end{aligned}
$$

Substitution into Equation (D.4) for different assumed orifice pressures leads to a plot of $\frac{1}{A} \frac{d M}{d t}$ versus orifice pressure. A series of such curves for different tank pressures leads to the relation shown in Figure D.2.

At the pressure relief setting $2.59 \mathrm{MPa}$ (375 psig)

$$
\frac{d M}{A d t}=2.27 \times 10^{4} \frac{\mathrm{kg}}{\mathrm{m}^{2} \mathrm{sec}}
$$




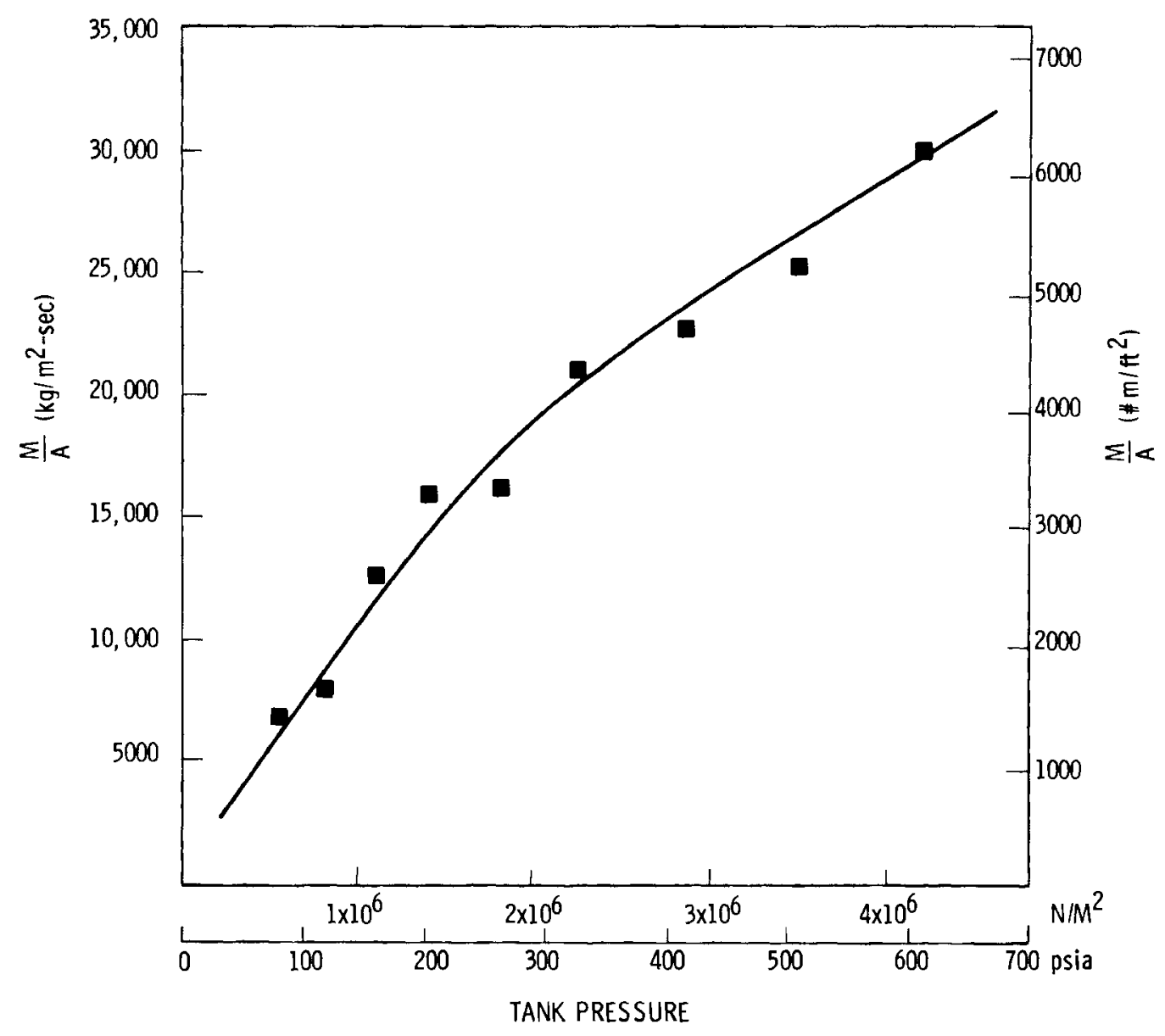

FIGURE D.2. $\mathrm{Cl}_{2}-$ Maximum Flow of Liquid Chlorine Through an Orifice

The assumed diameter of the relief valve is $2.86 \times 10^{-2} \mathrm{~m}(1 \mathrm{1} / 8 \mathrm{in.})$ and the cross sectional area $6.5 \times 10^{-4} \mathrm{~m}^{2}$, therefore the maximum flow is:

$$
\frac{d M}{d t}=\frac{d M}{A d t} A=14.5 \mathrm{~kg} / \mathrm{sec}
$$

Based on a liquid temperature of $68^{\circ} \mathrm{C}$, it can be expected that $32 \%$ of the release (from Figure 0.1 ) would instantly flash as a vapor with the remainder available for pool formation at a rate:

$$
\frac{d M}{d t}=(1-0.32) \frac{d M}{d t}=9.9 \mathrm{~kg} / \mathrm{sec}
$$


Pool growth is governed by the length of time liquid flows into the pool and the rate of vaporization from the pool surface. Pool growth ceases when equilibrium is established between the mass flow rate in and the mass flow rate out. If it can be assumed that the liquid flow rate from the emptying tank car provides a constant $9.9 \mathrm{~kg} / \mathrm{sec}$ of liquid chlorine for pool formation and the rate of vaporization for liquid chlorine from a flat surface is $7.8 \times 10^{-3} \mathrm{~kg} / \mathrm{m}^{2} \mathrm{sec}$ (determined from Bureau of Mines experiment), (1) then equilibrium is established when:

$$
\text { Area }=1.27 \times 10^{3} \mathrm{~m}^{2}
$$

Figure D. 3 shows the relationship between pool surface area and time for an assumed average pool depth of $2.54 \mathrm{~cm}$.

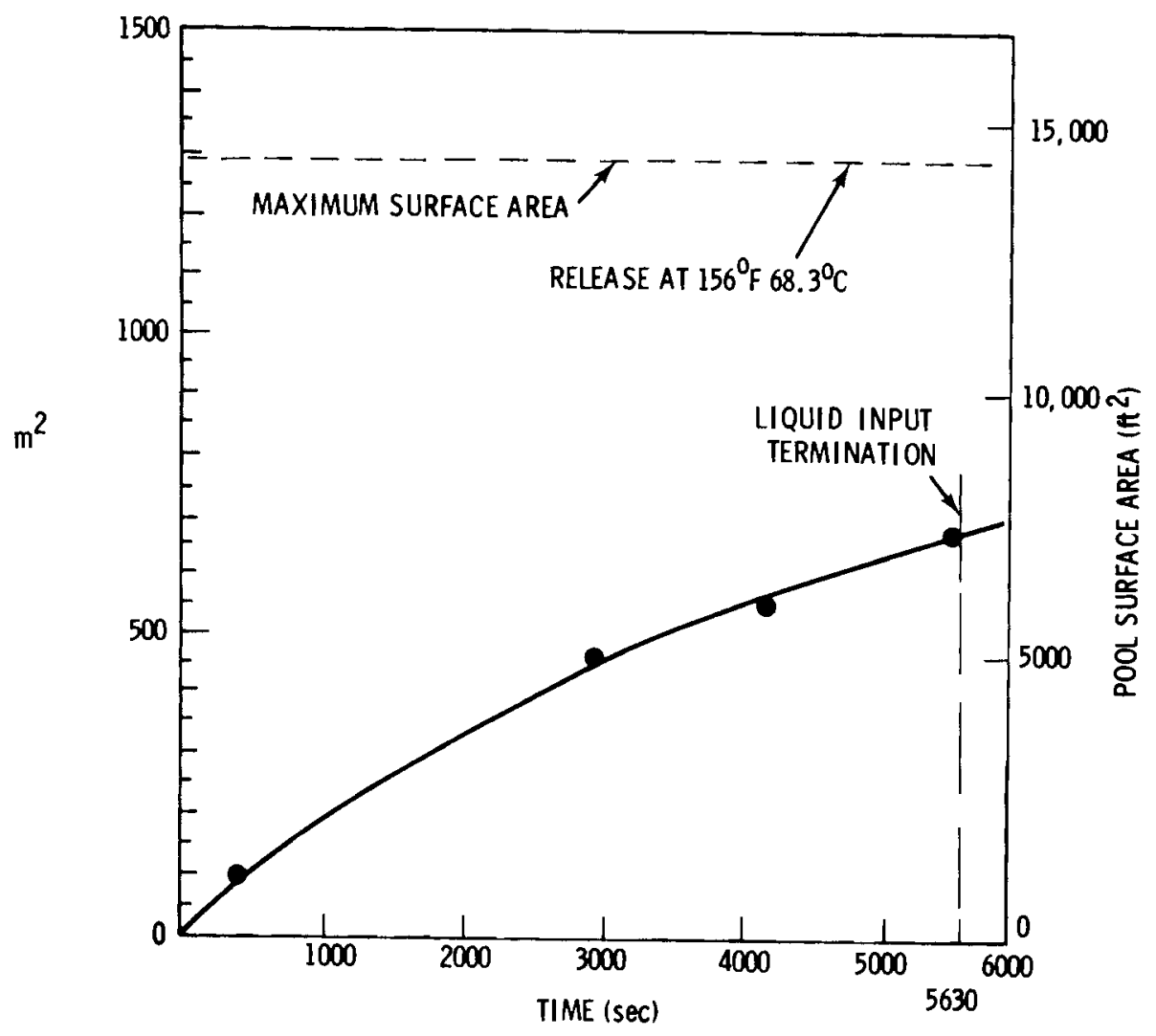

FIGURE D.3. Rate of Pool Surface Area Growth versus Time of Pool Liquid Input for $2.54 \times 10^{-2} \mathrm{~m}$ ( 1 in.) Deep Pool (assumed) 
The increase in pool surface area ceases when the tank car has emptied, i.e., when:

$$
t=\frac{8.16 \times 10^{4} \mathrm{~kg}}{14.5 \mathrm{~kg} / \mathrm{sec}}=5.63 \times 10^{3} \mathrm{sec}
$$

Figure D. 3 shows that for this time, equilibrium is not established at the maximum surface area attainable.

The time required to vaporize the pool remaining at cessation of liquid input is dependent on the assumed average pool depth:

$$
t=\frac{\text { assumed depth } \times \text { liquid density }}{\text { vaporization rate }}
$$

For the above conditions:

$$
T=\frac{\left(2.54 \times 10^{-2} \mathrm{~m}\right)\left(1.56 \times 10^{3} \mathrm{~kg} / \mathrm{m}^{3}\right)}{\left(7.8 \times 10^{-3} \mathrm{~kg} / \mathrm{m}^{2} \mathrm{sec}\right.}=5.08 \times 10^{3}
$$

The total time of chlorine emission is:

$$
t=\left(5.63 \times 10^{3}+5.08 \times 10^{3}\right) \mathrm{sec}=1.07 \times 10^{4} \mathrm{sec}
$$

The chlorine emissions consist of the parts discussed previously, pool evaporation and flash vaporization. For $1.07 \times 10^{4}$ seconds, both stages of vaporization occur. When all the liquid in the tank car is emitted, only pool vaporization will take place. The highest emission rate occurs when both forms of vaporization occur. The flash vaporization rate is $4.64 \mathrm{~kg} / \mathrm{sec}$.

The average pool evaporation is:

$$
\frac{(1-0.32) \times 8.16 \times 10^{4} \mathrm{~kg}}{(5.63+5.08) \times 10^{3} \mathrm{~s}}=5.18 \mathrm{~kg} / \mathrm{s}
$$


where the corresponding average pool size is:

$$
\frac{5.18 \mathrm{~kg} / \mathrm{s}}{7.8 \times 10-3} \frac{\mathrm{kg}}{\mathrm{sm}}=664 \mathrm{~m}^{2}
$$

The total emission rate is therefore $9.82 \mathrm{~kg} / \mathrm{s}$.

The second case represents a gas rather than liquid release by the relief valve. This could occur if the car is upright and exposed to a thermal environment. The average flow rate for this situation was calculated by dividing to heat rate to by tank car by the latent heat of vaporization of liquid chlorine at $2.58 \mathrm{MPa}$ (relief valve set pressure). For a heat rate of $0.662 \mathrm{MW}$ due to a $1010^{\circ} \mathrm{C}$ fire exposure and a latent heat of $0.171 \mathrm{MJ} / \mathrm{kg}$ a gas flow rate of $3.9 \mathrm{~kg} / \mathrm{sec}$ is predicted.

\section{REFERENCES}

1. J. N. Murphy, M. E. Harris, and D. Burgess, Hazards of Marine Transportation of Liquid Chlorine. PMSCR Report S-4155, Bureau of Mines, Pittsburg, PA, 1970.

2. W. A. Bullerdiek, F. A. Vassalo, D. E. Adams, and C. W. Matheis, A Study to Reduce the Hazards of Tank Car Transportation. PB-199 154, National Technical Information Service, Springfield, VA 22151, 1970.

3. R. M. Kapoor, Thermodynamic Properties of Chlorine. University of Michigan Press, 1957.

4. Chlorine Manual. The Chlorine Institute, New York, NY, 1976. 
APPENDIX E

ATMOSPHERIC DISPERSION OF VAPORS FROM CHLORINE SPILLS 
APPENDIX E

\section{ATMOSPHERIC DISPERSION OF VAPORS FROM CHLORINE SPILLS}

Estimates of chlorine vapor concentrations are made for two types of accidental spill situations, catastrophic failure of chlorine rail tank cars and slower continuous leaks of chlorine liquid which might occur from valve failure or relief valve venting. The toxic effects of chlorine vary with concentration (Appendix B) suggesting concentration analysis bounds of $1000 \mathrm{ppm}$ and $35 \mathrm{ppm}$. Calculation of release rates leading to these concentrations at various distances are discussed in Appendix $D$.

As noted in previous sections, the tank car failure and the leak both cause liquid spillage and eventual vapor cloud formation. The mechanism for vapor generation for the tank failure consists of a reduction of pressure to the atmospheric pressure, and an initial flash vaporization of a portion of the spilled liquid due to the pressure drop, pool formation and slower vaporization of the remaining pool contents. In the valve release case, the initial flash vaporization and pool formation occurs but in contrast to the larger spi11, vaporization of the pool contents is more constant due to a uniform replacement of liquid to the pool. In both cases, pressurized releases would cause extensive initial cloud dilution with the atmosphere.

For the purposes of this analysis, several assumptions have been made regarding chlorine spill concentrations and properties. These assumptions can be summarized as follows:

- Chlorine with a molecular weight of 70.9 remains negatively buoyant with respect to air.

- Gas release from a catastrophic tank car spill takes place in two phases. An initial flash vaporized cloud behaves as a puff and its dispersion can be simulated using a Gaussian puff equation. During the second phase, liquid chlorine evaporates continuously from the surface of the sub-cooled pool. 
- Gas release from relief valve venting also causes a vapor plume which disperses in two phases. During the first phase, liquid is emitted from the valve and a portion is continuously flash vaporized while the remainder forms a pool. The resultant emission of chlorine is the sum of the two emission rates for pool evaporation, flash vaporization. The second phase occurs after the liquid in the tank is exhausted and all evaporation takes place from the pool surface.

- Due to the density of chlorine gas, the gas disperses in the vertical as a trace gas in an extremely stable atmosphere.

The assumption that the released chlorine disperses vertically as a trace gas in a stable environment was made to simplify computations while maintaining reasonable dispersion estimates. Alternative models are available (McNaughton 1979) which simulate dense case gravity spreading and dispersion but they are applicable to ambient pressure releases with other limiting formulations and are unproven for full scale releases. Additional assumptions are discussed in the following sections.

The remainder of this section includes a discussion of dispersion models and dispersion results of summations of a catastrophic tank car spill and a relief valve venting.

\section{E.1 DISPERSION MODELS}

This section describes the simulation models used to provide estimates of chlorine gas concentrations in the accident situations presented. The models presented are Gaussian diffusion models for continuous plumes and instantaneous puffs representing chlorine leaks and catastrophic gas spills. A second section discusses empirical diffusion parameters used in the models, while a last section details calculations of cloud area, a critical result of the analysis in evaluating hazardous zones.

\section{E.1.1 Dispersion Equations}

Two Gaussian dispersion equations are used to describe dispersion downwind of an accident site. Initial conditions and input for each case studied consist of emissions, fixed meteorological conditions, (windspeed and stability), 
and a spill type. In Section E.2, concentrations for a continuous valve release of chlorine were calculated by specifying a continuous emission rate in a continuous plume model while catastrophic spill simulations used in a Gaussian puff model. In the puff equation, the spill was considered to be an area source and was modeled as a virtual point source. Virtual point source modifications allow the use of point source equations in evaluating area emission sources by determining the upwind distance that a ficticious point source would be located to produce an area source at the actual release point with a crosswind plume spread equal to the area source width at the area source edge. In other words, since crosswind plume standard deviation $\sigma_{y}$ is proportional to distance $x$, a distance, $x_{0}$, upwind of the area of emission a point could be found such that:

$$
w=4.3 \sigma_{y}
$$

where $w$ is the source width and the coefficient is used to consider all the mass in the Gaussian plume. The area source width for the tank failure case was calculated by assuming it was represented by the diameter of hemispheric cloud or formed from the initial flash vaporized gas.

Resultant concentrations from an instantaneous tank car failure were calculated using Gaussian point source puff equation:

$$
c=\frac{\left.Q(2 \pi)^{3}\right)^{-\frac{1}{2}}}{\sigma_{x} \sigma_{y} \sigma_{z}} \exp \cdot \frac{1}{2}\left[\frac{(x-\bar{u} t)^{2}}{\sigma_{x}^{2}}+\frac{y^{2}}{\sigma_{y}^{2}}+\frac{z^{2}}{\sigma_{z}^{2}}\right]
$$

where:

$$
\begin{aligned}
C= & \text { concentration (mass/length }{ }^{2} \text { ) } \\
Q= & \text { total emissions (mass) } \\
x, y, z= & \text { downwind crosswind, and vertical distance (length) } \\
\bar{u}= & \text { mean wind speed over the period of calculation (length/time) } \\
t= & \text { time after release (time) } \\
\sigma_{x}, \sigma_{y}, \sigma_{z}= & \text { downwind, crosswind and vertical dispersion parameters } \\
& \text { (Section } E .1 .2) .
\end{aligned}
$$


The maximum distance to which the cloud is toxic from a short exposure can be determined from Equation (1) by determining the distance at which:

$$
C \max =\frac{Q\left(2 \pi^{3}\right)^{-\frac{1}{2}}}{\sigma_{x} \sigma_{y} \sigma_{z}}=C_{T L}
$$

where:

$$
\begin{aligned}
C \max & =\text { maximum center line concentration } \\
C_{T L} & =\text { toxicity limit }(1000 \mathrm{ppm}) \\
\sigma & =\text { dispersion parameters which are functions of } x .
\end{aligned}
$$

The area of cloud within a certain toxic limit is calculated using equations in Section B.2.3.

In the continuous leak case, the Gaussian point source diffusion equation is given by:

$$
c=\frac{Q}{\pi \sigma \sigma_{y} z^{\bar{u}}} \exp .-\frac{1}{2}\left(\frac{y^{2}}{\sigma y^{2}}+\frac{z^{2}}{\sigma z^{2}}\right)
$$

Calculational methods for the area within isopleths are provided in Section B.2.3. Equation (3) represents dispersion of a continuous release under steady-state conditions so that area calculations are not time dependent.

\section{E.1.2 Dispersion Parameters}

The calculation of chiorine concentrations using instantaneous puff or continuous plume equations require the use of empirical dispersion parameters determined from experiments of trace gas dispersion in air. This section describes the two collections of dispersion data used in this study along with the modifications used to extend the relations to the dense gas case.

In the instantaneous puff equation used to simulate the effects of dispersion from a catastrophic gas release, dispersion parameters are given in the 
crosswind, downwind, and vertical directions and are defined as $\sigma_{y}, \sigma_{x}$ and $\sigma_{z}$. The parameters used are of the form:

$$
\sigma=a x^{b}
$$

where $x$ represents the downwind distance, and the coefficients vary with atmospheric stability. The downwind and crosswind parameters are related.

$$
\sigma x=4 \sigma_{y}
$$

To correct the decreased vertical spread of the gas cloud due to the negative buoyancy, the vertical dispersion parameter, $\sigma_{z}$, is assumed to vary with distance using coefficients for stable atmospheric conditions. (3) The coefficients used for the simulations ${ }^{(4)}$ are given in Table E. 1 .

\begin{tabular}{|c|c|c|c|c|}
\hline \multirow[b]{2}{*}{ Stability } & \multicolumn{2}{|c|}{$\sigma_{y}$} & \multicolumn{2}{|c|}{$\sigma_{z}$} \\
\hline & $\mathrm{a}$ & $\mathrm{b}$ & $a$ & $b$ \\
\hline$A^{(a)}$ & 0.14 & 0.92 & & \\
\hline B & 0.14 & 0.92 & & \\
\hline C & 0.14 & 0.92 & 0.05 & 0.61 \\
\hline D & 0.06 & 0.92 & & \\
\hline$E$ & 0.04 & 0.91 & & \\
\hline $\mathrm{F}$ & 0.02 & 0.89 & & \\
\hline
\end{tabular}

TABLE E.1. Dispersion Paramieters for an Instantaneous Chlorine Release

(a)Pasquill stability categories. (4)

Dispersion of continuous plumes proceeds at a slower rate than that of the puff due to less axial mixing. The set of dispersion parameters used in the continuous leak case are given in Table E.2. (1) The high density of the gas was simulated by assuming stable mixing occurred in the vertical direction. 
TABLE E.2. Dispersion Parameters for a Continuous Chlorine Release

\begin{tabular}{|c|c|c|c|c|}
\hline \multirow[b]{2}{*}{ Stability } & \multicolumn{2}{|c|}{$\sigma_{y}$} & \multicolumn{2}{|c|}{$\sigma_{z}$} \\
\hline & $a$ & $b$ & $a$ & $b$ \\
\hline A & 0.37 & 0.90 & For $x$ & $1200 \mathrm{~m}$ \\
\hline B & 0.28 & 0.90 & 0.06 & 0.78 \\
\hline C & 0.21 & 0.90 & & \\
\hline D & 0.15 & 0.90 & & \\
\hline$E$ & 0.10 & 0.90 & For $x$ & 12000 \\
\hline $\mathrm{F}$ & 0.07 & $0.90)$ & 0.44 & 0.51 \\
\hline
\end{tabular}

Parameters given in the table represent plumes over approximately 3 to 10 minutes duration. Plumes lasting for longer periods are in the average more disperse making this a conservative assumption for the simulations.

\section{E.1.3 Cloud Areas}

Areas of concentration isopleths are important in predicting hazard zones for spills of chlorine. Two areas were calculated for the continuous spill case; these were the areas of the $35 \mathrm{ppm}$ and $1000 \mathrm{ppm}$ isopleths. For the puff resulting from a catastrophic release, the area swept out by the $1000 \mathrm{ppm}$ isopleth as the puff traveled downwind was calculated. In addition, the area of concentration greater than $35 \mathrm{ppm}$ and a dose greater than $1000 \mathrm{ppm}$ min was calculated. Areas were calculated using an approximate equation by Nishiwaka(4) Swept areas for puffs and dose calculations were made by integrating the concentration equations over time.

\section{E.2 RESULTS}

Results were calculated for continuous leaks, releases from a rail tank car or the failure of the car. In the leak case, the relief valve release was simulated using a continuous liquid emission rate. The latter case represented the worst emission, assuming flash vaporization and evaporation from a chlorine pool. The tank failure cases were simulated by calculating dispersion from an instantaneous flash vaporization of chlorine with the chlorine 
initially at $70^{\circ} \mathrm{F}$ and $155^{\circ} \mathrm{F}$. Temperatures represent ambient temperatures and temperatures expected if a fire heats the tank contents. Since calculations are steady state, times and distances can be related by the wind speed (i.e., $x=u t$ ).

\section{E.2.2 Continuous Leak}

Calculations were made to simulate the maximum chlorine release from a 375 psig relief valve on a rail tank car (Section D.3). Resultant emissions from the chlorine release were continuous at $9.8 \mathrm{~kg} / \mathrm{s}$ for roughly $500 \mathrm{sec}$, and then decreased as flash evaporation from the valve ended after the tank car was emptied and only pool evaporation occurred. Resultant dispersion of the gas under various meteorological conditions produced toxic gas concentrations of $1000 \mathrm{ppm}$ and $35 \mathrm{ppm}$ extending to distances shown in Table E.3. The maximum downwind extent of the cloud calculated was $17 \mathrm{~km}$ to reach $35 \mathrm{ppm}$ or $1.6 \mathrm{~km}$ to reach the end of the $1000 \mathrm{ppm}$ zone. Areas for the $1000 \mathrm{ppm}$ and 35 ppm plume concentration isopleths are also given in the table. The most hazardous times for relief valve venting are during stable atmospheric conditions with low wind speed.

Results for a continuous release of gas are given in Table E.4. The $3.9 \mathrm{~kg} \mathrm{~s}^{-1}$ emission rate results in maximum hazardous zones extenting to $400 \mathrm{~m}$ for $1000 \mathrm{ppm}$ area and $8.9 \mathrm{~km}$ for the $35 \mathrm{ppm}$ area. The maximum isopleth areas are $0.04 \mathrm{~km}^{2}$ for the $1000 \mathrm{ppm}$ isopleth and $3.2 \mathrm{~km}^{2}$ for the $35 \mathrm{ppm}$ isopleth. The continuous release results represent 10 minute analyses. Occurrences of $1000 \mathrm{ppm} / \mathrm{min}$ for concentrations in excess of $35 \mathrm{ppm}$ depend on the amount of time the plume is over a point.

Summarizing results for the case of tank car collapse are given in Tables E.5 and E.6. Table E.5 gives results from a puff of chlorine flashed from liquid at ambient temperature while Table E.6 reports results from a puff resulting when liquid heated to $155^{\circ} \mathrm{F}$ before collapse. The vapor cloud moves with the wind spread dispersing from its center of mass. Results show the maximum distances from the source the cloud is hazardous and the total area over the life cycle of the cloud in which hazardous concentrations occur. As noted earlier, only the flash vaporization resulting from the car collapse was simulated. Later evaporation from the pool results in areas comparable to the case of relief valve venting $155^{\circ} \mathrm{F}$ liquid at 375 psi. 
TABLE E.3. Furthest Extent and Area of Hazardous Concentrations:

Relief Valve Venting Liquid Temperature $155^{\circ} \mathrm{F}(9.8 \mathrm{~kg} / \mathrm{s})$

\begin{tabular}{|c|c|c|c|c|c|}
\hline $\begin{array}{r}\text { Meteor } \\
\text { Cond } \\
\end{array}$ & $\begin{array}{l}\text { ological } \\
\text { itions }\end{array}$ & $\begin{array}{r}\text { Maximum So } \\
\text { Isopleth D } \\
\quad(\mathrm{km} \\
\end{array}$ & $\begin{array}{l}\text { urce to } \\
\text { istance } \\
\end{array}$ & $\begin{array}{l}\text { Area En } \\
\text { Isoplet }\end{array}$ & $\begin{array}{l}\text { osed by } \\
\left(\mathrm{km}^{2}\right)\end{array}$ \\
\hline Stability & $\begin{array}{c}\text { Wind Speed } \\
(\mathrm{m} / \mathrm{s})\end{array}$ & $1000 \mathrm{ppm}$ & $35 \mathrm{ppm}$ & $1000 \mathrm{ppm}$ & $35 \mathrm{ppm}$ \\
\hline B & 1.0 & 0.70 & 6.65 & 0.097 & 6.98 \\
\hline B & 3.5 & 0.33 & 2.74 & 0.023 & 1.29 \\
\hline B & 7.0 & 0.22 & 1.67 & 0.107 & 0.51 \\
\hline B & 10.0 & 0.18 & 1.30 & 0.007 & 0.31 \\
\hline B & 18.5 & 0.12 & 0.89 & 0.004 & 0.15 \\
\hline D & 1.0 & 1.02 & 10.36 & 0.113 & 9.59 \\
\hline D & 3.5 & 0.48 & 4.26 & 0.027 & 1.75 \\
\hline D & 7.0 & 0.32 & 2.61 & 0.012 & 0.68 \\
\hline D & 10.0 & 0.26 & 2.03 & 0.003 & 0.42 \\
\hline D & 18.5 & 0.18 & 1.31 & 0.004 & 0.18 \\
\hline$E$ & 1.0 & 1.26 & 13.20 & 0.121 & 10.85 \\
\hline$E$ & 3.5 & 0.59 & 5.43 & 0.029 & 1.98 \\
\hline$E$ & 7.0 & 6.39 & 3.32 & 0.013 & 0.77 \\
\hline$E$ & 10.0 & 0.32 & 2.58 & 0.009 & 0.48 \\
\hline$E$ & 18.5 & 0.22 & 1.61 & 0.004 & 0.21 \\
\hline $\mathrm{F}$ & 1.0 & 1.63 & 17.15 & 0.127 & 11.12 \\
\hline$F$ & 3.5 & 0.74 & 7.06 & 0.028 & 2.05 \\
\hline$F$ & 7.0 & 0.49 & 4.32 & 0.013 & 0.81 \\
\hline$F$ & 10.0 & 0.40 & 3.36 & 0.009 & 0.50 \\
\hline $\mathrm{F}$ & 15.5 & 0.27 & 2.17 & 0.004 & 0.22 \\
\hline
\end{tabular}


TABLE E.4. Furthest Extent and Areas of Hazardous Concentrations: Continuous Gas Release $(3.9 \mathrm{~kg} / \mathrm{s})$

\begin{tabular}{|c|c|c|c|c|c|}
\hline \multicolumn{2}{|c|}{$\begin{array}{l}\text { Meteorological } \\
\text { Conditions }\end{array}$} & \multicolumn{2}{|c|}{$\begin{array}{c}\text { Maximum Source to } \\
\text { Isopleth Distance } \\
(\mathrm{km})\end{array}$} & \multicolumn{2}{|c|}{$\begin{array}{l}\text { Area Enclosed by } \\
\text { Isopleths }\left(\mathrm{m}^{2}\right)\end{array}$} \\
\hline Stability & $\begin{array}{l}\text { Wind speed } \\
(\mathrm{m} / \mathrm{s})\end{array}$ & $1000 \mathrm{ppm}$ & $35 \mathrm{ppm}$ & $1000 \mathrm{ppm}$ & $35 \mathrm{ppm}$ \\
\hline B & 1.0 & 0.41 & 3.46 & 34,040 & $2.01 \times 10^{6}$ \\
\hline B & 3.5 & 0.19 & 1.42 & 8,273 & $3.71 \times 10^{5}$ \\
\hline B & 7.0 & 0.13 & 0.92 & 3,779 & $1.69 \times 10^{5}$ \\
\hline B & 10.0 & 0.10 & 0.74 & 2,525 & $1.07 \times 10^{5}$ \\
\hline B & 18.5 & 0.07 & 0.51 & 1,260 & $0.54 \times 10^{5}$ \\
\hline D & 1.0 & 0.59 & 5.39 & 39,610 & $2.74 \times 10^{6}$ \\
\hline$D$ & 3.5 & 0.28 & 2.22 & 9,536 & $5.01 \times 10^{5}$ \\
\hline D & 7.0 & 0.19 & 1.36 & 4,337 & $1.96 \times 10^{5}$ \\
\hline D & 10.0 & 0.15 & 1.0 & 2,891 & $1.26 \times 10^{5}$ \\
\hline$D$ & 18.5 & 0.10 & 0.75 & 1,437 & $0.62 \times 10^{5}$ \\
\hline E & 1.0 & 0.72 & 6.86 & 41,580 & $2.10 \times 10^{6}$ \\
\hline$E$ & 3.5 & 0.34 & 2.82 & 10,010 & $5.67 \times 10^{5}$ \\
\hline$E$ & 7.0 & 0.23 & 1.73 & 4,551 & $2.22 \times 10^{5}$ \\
\hline$E$ & 10.0 & 0.18 & 1.34 & 3,034 & $1.36 \times 10^{5}$ \\
\hline E & 18.5 & 0.13 & 0.91 & 1,507 & $0.66 \times 10^{5}$ \\
\hline$F$ & 1.0 & 0.90 & 8.92 & 40,590 & $3.26 \times 10^{6}$ \\
\hline $\mathrm{F}$ & 3.5 & 0.43 & 3.67 & 9,844 & $5.91 \times 10^{5}$ \\
\hline $\mathrm{F}$ & 7.0 & 0.28 & 2.25 & 4,499 & $2.32 \times 10^{5}$ \\
\hline $\mathrm{F}$ & 10.0 & 0.29 & 1.74 & 3,006 & $1.44 \times 10^{5}$ \\
\hline $\mathrm{F}$ & 18.5 & 0.16 & 1.14 & 1,500 & $0.64 \times 10^{5}$ \\
\hline
\end{tabular}


TABLE E.5. Furthest Extent and Areas of Hazardous Concentrations: Tank Collapse; Liquid Temperature $70^{\circ} \mathrm{F}$ (17\% release)

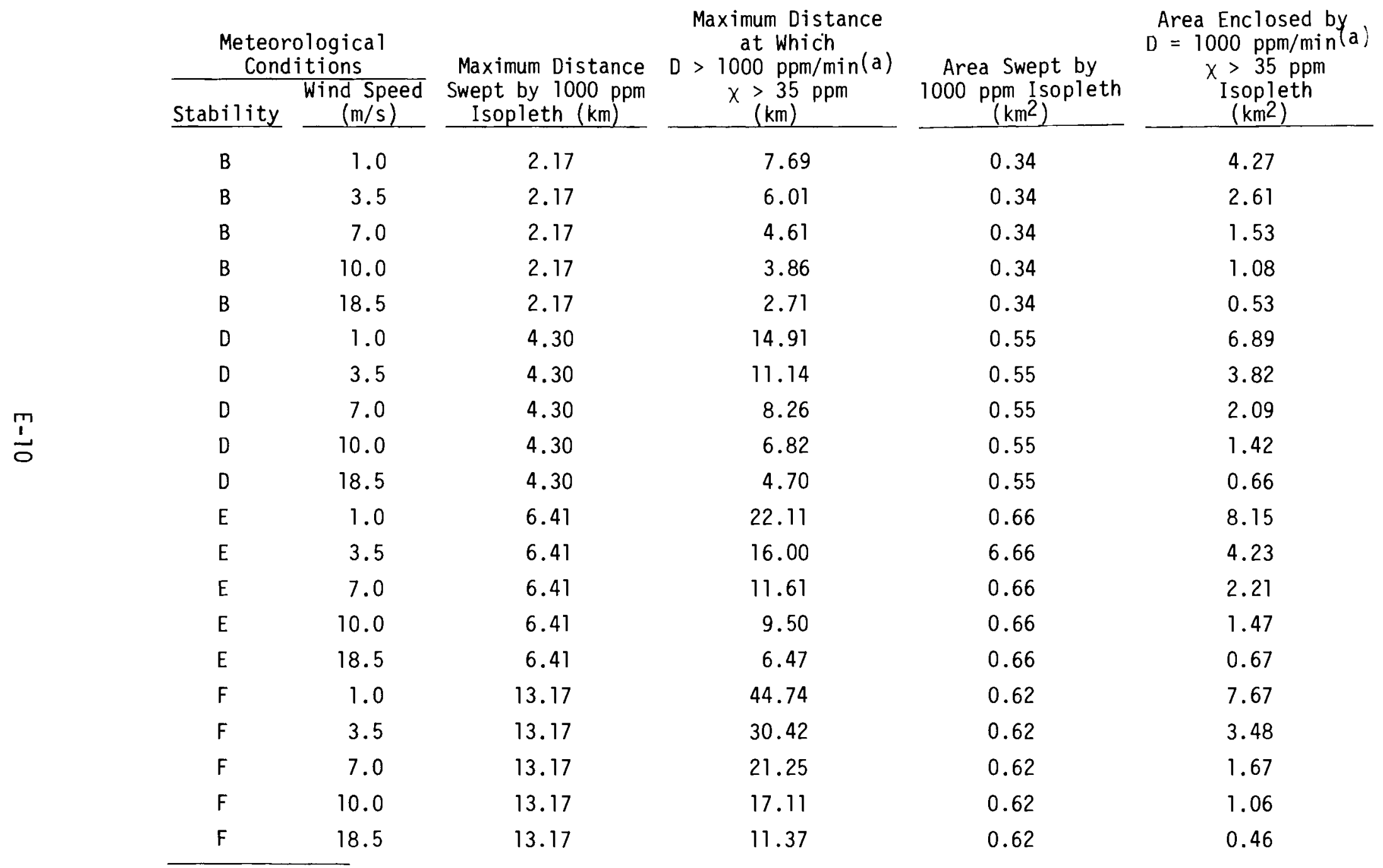

(a)D - Dose, $x$ - Concentration - A dose of 1000 ppm-min for concentrations $x>35$ ppm represents 30 minute exposures at $35 \mathrm{ppm}$ concentrations. 
TABLE E.6. Furthest Extent and Areas of Hazardous Concentrations: Tank Collapse; Liquid Temperature $155^{\circ} \mathrm{F}$ (32\% release)

\begin{tabular}{|c|c|c|c|c|c|}
\hline $\begin{array}{r}\begin{array}{r}\text { Meteor } \\
\text { Cond }\end{array} \\
\text { Stability }\end{array}$ & $\begin{array}{l}\text { ological } \\
\text { itions } \\
\text { Wind Speed } \\
(\mathrm{m} / \mathrm{s}) \\
\end{array}$ & $\begin{array}{l}\text { Maximum Distance } \\
\text { Swept by } 1000 \mathrm{ppm} \\
\text { Isopleth }(\mathrm{km}) \\
\end{array}$ & $\begin{array}{c}\text { Maximum Distance } \\
\text { at Which } \\
\text { D> } 1000 \mathrm{ppm} / \mathrm{min}(\mathrm{a}) \\
x>35 \mathrm{ppm} \\
(\mathrm{km}) \\
\end{array}$ & $\begin{array}{c}\text { Area Swept by } \\
1000 \mathrm{ppm} \text { Isopleth } \\
\left(\mathrm{km}^{2}\right)\end{array}$ & $\begin{array}{c}\text { Area Enclosed by } \\
D=1000 \mathrm{ppm} / \mathrm{min}(\mathrm{a}) \\
x>35 \mathrm{ppm} \\
\text { Isopleth } \\
\left(\mathrm{km}^{2}\right)\end{array}$ \\
\hline B & 1.0 & 2.775 & 10.05 & 6.54 & 7.17 \\
\hline B & 3.5 & 2.77 & 8.20 & 6.54 & 4.77 \\
\hline B & 7.0 & 2.77 & 6.50 & 6.54 & 2.99 \\
\hline B & 10.0 & 2.77 & 5.54 & 6.54 & 2.18 \\
\hline B & 18.5 & 2.77 & 3.48 & 6.54 & 1.12 \\
\hline$D$ & 1.0 & 5.50 & 14.60 & 0.89 & 11.73 \\
\hline$D$ & 3.5 & 5.50 & 15.36 & 0.89 & 7.17 \\
\hline$D$ & 7.0 & 5.50 & 11.78 & 0.89 & 4.20 \\
\hline$D$ & 10.0 & 5.50 & 9.88 & 0.89 & 2.94 \\
\hline$D$ & 18.5 & 5.50 & 6.94 & 0.89 & 1.43 \\
\hline$E$ & 1.0 & 8.22 & 29.21 & 1.06 & 14.00 \\
\hline$E$ & 3.5 & 8.22 & 22.25 & 1.06 & 8.07 \\
\hline$E$ & 7.0 & 8.22 & 16.70 & 1.06 & 4.51 \\
\hline$E$ & 10.0 & 8.22 & 13.86 & 1.06 & 3.08 \\
\hline$E$ & 18.5 & 8.22 & 9.60 & 1.06 & 1.46 \\
\hline$F$ & 1.0 & 16.96 & 59.87 & 1.00 & 13.41 \\
\hline$F$ & 3.5 & 16.96 & 43.02 & 1.00 & 6.83 \\
\hline$F$ & 7.0 & 16.96 & 31.04 & 1.00 & 3.50 \\
\hline $\mathrm{F}$ & 10.0 & 16.96 & 25.31 & 1.00 & 2.30 \\
\hline$F$ & 18.5 & 16.96 & 17.08 & 1.00 & 1.02 \\
\hline
\end{tabular}




\section{REFERENCES}

1. D. B. Turner, Workbook of Atmospheric Dispersion Estimates. PB-191, 482, NTIS, Springfield, VA, 1972.

2. P. W. Nickola, "Measurements of the Movement, Concentration and Dimensions of Clouds Resulting from Instantaneous Point Sources." Journal of Applied Meteorology, 10:967-973, October 1971.

3. J. N. Murphy, M. E. Harris and D. Burgess, Hazards of Marine Transportation of Liquid Chlorine. PMSRC No. S-4158, U.S. Bureau of Mines, Pittsburgh, PA, 1970.

4. D. H. Slade, (ed), Meteorology and Atomic Energy, 1968. U.S. Atomic Energy Commission, Oak Ridge, TN, 1968.

5. D. J. McNaughton and C. M. Berkowitz, "Overview of U.S. Research Activities in the Dispersion of Dense Gases," Symposium Schwere Case, Frankfurt, Germany, September, 1979. 


\section{DISTRIBUTION}

No. of

Copies

Mr. A. M. Albera

Director, Distribution

Development

PPG Industries, Inc.

1 Gateway Center

Pittsburgh, PA 15222

Tom Alexander

Department of Energy

Office of Technology Impacts

EV-212, MS-4G085

Forrestal Bldg.

Washington, DC 20585

G. C. Allen, Jr.

Sandia National Laboratories

Division 4552

Albuquerque, NM 87185

\section{S. Aoki}

Research Laboratory for Nuclear Reactors

Tokyo Institute of Technology

Oookayama, Meguroku, Tokyo 152 JAPAN

T. Anderson

Department of Energy

Mai1 Stop B/107

Washington, DC 20545

\section{A. L. Babb}

Department of Nuclear

Engineering

Benson $\mathrm{Hall}$

University of Washington

Seattle, WA 98195
No. of

Copies

Mr. George Bailey

Technical Studies

Washington Public Power

Supply System

3000 George Washington Way

Richland, WA 99352

Hubert Baker

E. I. DuPont de Nemours \& Co.

Savannah River Laboratory

Aiken, SC 29801

G. D. Bell

United Kingdom Atomic Energy Authority

Safety and Reliability

Directorate

Warrington WA3 4NE

UNITED KINGDOM

L. Benner

National Transportation

Safety Board

Department of Transportation

Washington, DC 20594

Dr. K. M. Bertram

Argonne National Laboratory

(EES-17)

9700 S. Cass Avenue

Argonne, IL 60514

W. F. Black

Hazardous Materials Branch

Nassif Building

Federal Railroad Administration

Department of Transportation

Washington, DC 20590 
No. of

Copies

W. A. Brobst

The Transport Environment

SR 285 01d Squaw Drive

Kitty Hawk, NC 27949

Ms. T. Buckingham

1704 Lincoln Ave.

Apt. 2

San Rafael, CA 94901

T. A. Butler

University of California

Los Alamos Scientific Laboratory

P.0. Box 1663

Los Alamos, NM 87545
A. Carson
General Electric Company
175 Curtner Avenue
San Jose, CA 95125
Dr. J. M. Cece
DOE/ESED
M/S EV-132, E-201
Washington, DC 20545
R. B. Chitwood
Division of Transportation and Fuel Storage
M/S B-107
Department of Energy
Washington, DC 20545
A. A. Churm
Chicago Patent Group
DOE Chicago Operations Office
9800 South Cass Avenue
Argonne, IL 50439
C. Comar
Electric Power Research Inst.
P.0. 10412
Palo Alto, CA 94304
J. S. Corbett
Chemnuclear Systems, Inc.
P.0. Box 1866
Bellevue, WA 98009

No. of

Copies

\section{J. Counts \\ DOE/ESED}

$M / S E V-132, E-201$

Washington, DC 20545

164 DOE Technical Information Center

J. W. Doty

Mound Laboratories

P.0. Box 32

Miamisburg, OH 45342

Dr. C. W. Draffin

Planning and Evaluation

U.S. Department of Energy

20 Massachusetts Avenue N. W.

Washington, DC 20545

D. A. Edling

Mound Laboratories

P.0. Box 32

Miamisburg, OH 45342

J. Edlow

Edlow International

110017 th Street N. W.

Washington, DC 20036

R. C. Erdman

Science Applications, Inc.

2680 Hanover St.

Palo Alto, CA 94304

F. P. Falci

Department of Energy

M/S B/107

Washington, DC 20545

W. S. Fellows

Southern Interstate Nuclear Board

One Exchange Place, Suite 1230

Atlanta, GA 30341

Ms. Nancy C. Finley

Fuel Cycle Risk Analysis

Division 4413

Sandia National Laboratories

Albuquerque, NM 87185 
No. of

Copies

J. T. Foley

Sandia National Laboratories

Div 5522

Albuquerque, NM 87185

I. A. Forbes

Energy Research Group, Inc.

1661 Worchester Road

Fromingham, MA 01701

Dr. C. P. Furber

Research and Test Department

Association of American

Railroads

1920 "L" Street N.W.

Washington, DC 20036

R. F. Garrison

DOE/ESED

EV-132, E-201

Washington, DC 20545

T. Glickman

Transportation Systems Center

Kendall Square

Cambridge, MA 62142

E. P. Goldfinch

Safeguards Branch

Nuclear Health and Safety Department

Courtenay House

18 Warwick Lane

London F C4P 4EB

UNITED KINGDOM

M. Gordon

Atomic Industrial Forum

7101 Wiscons in Avenue

Washington, DC 20014

A. Grella

Office of Inspection and Enforcement

USNRC

Washington, DC 20555
Mo. of

Copies

E. C. Hardin, Jr.

DOE Albuquerque

Operations office

P.0. Box 5400

Albuquerque, NM 87115

N. C. Harris

Imperial Chemical Industries, Ltd.

Mond Division

P.0. Box 47 Brunner House

Winnington Northwich

Cheshire CW8 40J

ENGLAND

Mr. W. Harris

Association of American

Railroads

1920 L. Street, N. W.

Washington, DC 20036

W. F. Hartman

Sandia National Laboratories

Department $1760 \mathrm{~A}$

Albuquerque, NM 87185

S. Hartwig

Battelle Institute, e.v.

Am Romerhof 35

600 Frankfurt Main 90

GERMANY

Brad Holloman

Office of Technology Assessment

U.S. Congress

Washington, DC 20510

Mr. Richard Horn

Office of Systems Research and Analysis

Transportation Systems Center

Department of Transportation

Cambridge, Massachusetts 02142 
No. of

Copies

H. Hubner

Bundesanstalt für Materialprufung Unter den Eichen 87

D-1000 Berlin 45 (West)

GERMANY, FED. REPUBLIC

J. L. Ivie

City of Portland Fire Department

$55 \mathrm{SW}$ Ash Street

Portland, OR 97204

R. M. Jefferson

Sandia National Laboratories

Department 4550

ATTN TTC Library (3)

TTC Master File (1)

Albuquerque, NM 87185

Mr. Don B. Jenks

Hazardous Materials Control

Santa Fe Railroad

Room 902

80 E. Jackson Blvd.

Chicago, IL 60604

John Jimison

Library of Congress

Congressional Research Service

First and Independence S.E.

Washington, DC 20540

Mr. Will Johns

American Trucking Association

1616 P street, N.W.

Washington, DC 20036

Mr. Walter Johnson

Vice President of Technical

Services

National LP-Gas Association

1301 West 22nd Street

Oak Brook, IL 60521
No. of

Copies

G. P. Jones

University of Southern

California

University Park

Los Angeles, CA 90007

R. H. Jones

P.0. Box 24036

San Jose, CA 95125

B. Jost

Mail Stop 18

Cal ifornia Energy Commission

1111 Howe Avenue

Sacramento, CA 95825

Dr. Thomas J. Kabele

The Analytical Sciences Corporation 6 Jacob Way

Reading, MA 01867

T. K. Keenan

University of California

Los Alamos Scientific Laboratory

P.0. Box 1663

Los Alamos, NM 87545

G. Kinchin

UKAEA

Risley, Lancaster

ENGLAND

Franklin King

Savannah River Laboratory

Aiken, SC 29801

Mr. Klyde Klinstiver

Accident Analys is Branch

Materials Transportation Bureau

U.S. Department of Transportation

2100 2nd Street, N.W.

Washington, DC 20590 
No. of

Copies

M. Kostolich

General American Transportation Corporation

120 South Riverside Plaza

Chicago, IL 60606

R. A. Koynenburg University of California Lawrence Livermore Laboratories P.0. Box 808

Livermore, CA 94551

W. E. Kreger

Chief Radiological Assessment Branch

Nuclear Regulatory Commission Washington, DC 20555

I. N. Lafontaine Belgonucleaire Rue de Champ de Mars 25

B-1050 Bruzelles

BELGIUM

Mr. Edmond J. Laubusch

The Chlorine Institute, Inc.

342 Madison Avenue

New York, NY 10017

M. J. Lawrence

Department of Energy

Mail Stop B/107

Washington, D.C. 20545

J. K. Les $7 i e$ Assistant Chief of Transportation

CP Rai1

P.0. Box 6042, Station "A"

Montrea1, Quebec H3C3E4

CANADA

R. Y. Lowrey

Department of Energy

Mail Stop B/107

Washington, D.C. 20545
No. of

Copies

R. E. Luna

Sandia National Laboratories

Division 4551

Albuquerque, NM 87185

M. E. Lyden

The Chlorine Institute

342 Madison Avenue

New York, NY 10017

A. J. Mallen

Office of Hazardous Materials

Department of Transportation

4007 th St. SW

Washinton, DC 20590

M. M. Maltempo

Associate Professor, Physics

University of Colorado at Denver

1100 Fourteenth Street

Denver, CO 90202

0.V. Martini

James F. MacLaren Limited

1220 Sheppard Avenue East

Suite 100

Willowdale, Ontario CANADA M2K 2T8

Dr. D. P. Maxfield

Nonhighway Transport Systems and Special Projects

Department of Energy

20 Massachusetts Avenue N.W.

Washington, DC 20545

R. Maxwel1

Office of Technology Assessment

U.S. Congress

Washington, DC 20510

D. G. Maxwel1

N. L. Industries

Nuclear Division

Foot of West Street

Wilmington, DE 19801 
C. A. Mayer

Tri-State Motor Transit Co., Inc. P.0. Box 113

Joplin, MO 64801

S. A. Mayman

Fuel Recycle Waste Management Program

Whiteshell Nuclear Research Establ ishment

Pinewa, Manitoba ROE ILO CANADA

P. E. McBurnett

Aerojet-General Corporation

P.0. Box 13222

Sacramento, CA 95813

J. D. MCClure

Sandia National Laboratories

Division 4551

A1buquerque, NM 87185

N. J. McCormack

Department of Nuclear Engineering Benson Hall

University of Washington

Seattle, WA 98195

C. McDonald

Nuclear Regulatory Commission

Washington, DC 20555

H. F. McDonald

CEGB

Berkeley Nuclear Labs

Berkeley

Gloucestershire GL139BP

UNITED KINGDOM

Mr. C. W. McGuire

Office of Secretary

U.S. Department of Transportation

Washington, DC 20590
Susan Metzler

System Communications

N.E. Utilities

P.0. Box 270

Hartford, CT 06101

S. Meyers

Department of Energy

Mai1 Stop B/107

Washington, DC 20545

R. B. Minogue

Nuclear Regulatory Commission

Washington, DC 20555

R. M. Moser

DOE Chicago Operations Office

9800 South Cass Avenue

Argonne, IL 60439

Dick Moyer

Savannah River Lab

Aiken, South Carolina 29801

Major General John Murray

Vice President - Assistant to the President

Association of American Railroads

1929 L Street, N.W.

Washington, DC 20036

Mr. Joe Nalevanko

Materials Transportation Bureau

Department of Transportation

Room 6220

2100 2nd Street, S.W.

Washington, DC 20590

D. Okrent

Department of Engineering and Applied Science

University of California

Los Angeles, CA 90024 
No. of

Copies

No. of

Copies

\author{
Alice Packard \\ Division of Environmental Impact \\ Studies \\ Argonne National Laboratory \\ Argonne, IL 60439 \\ Bill Pardue \\ Office of Nuclear Waste Isolation \\ 505 King Ave. \\ Columbus, OH 43201 \\ R. W. Peterson \\ Battelle Memorial Institute \\ Office of Nuclear Waste Isolation \\ 505 King Avenue \\ Columbus, $\mathrm{OH} 43201$ \\ Mr. T. A. Phemister \\ Bureau of Explosives \\ Association of American Railroads \\ 1920 L. Street, N.W. \\ Washington, DC 20036 \\ Ms. Marlene Phillips \\ Maritime Research Board \\ National Academy of Sciences \\ 2101 Constitution Avenue N.W. \\ Washington, DC 20418
M. Pollock
Oregon Department of Energy
Salem, OR 97301 \\ R. B. Pope \\ Sandia National Laboratories \\ Division 4552 \\ Albuquerque, NM 87185 \\ B. Posik \\ Chem-Nuclear Systems, Inc. \\ Barnwel1, SC \\ Prof. Norman C. Rasmussen \\ Massachusetts Institute of \\ Technology \\ Cambridge, MA 02139
}

R. R. Rawl

Materials Transportation Bureau

U.S. Department of Transportation Washington, DC 20545

R. T. Reese

Division 4557

Sandia National Laboratories

Albuquerque, NM 87185

W. R. Rhyne

Science Applications Inc.

P.0. Box 843

Oak Ridge, TN 37830

W. M. Rogers

Western Interstate Nuclear Board 1300 Carr

Denver, C0 80226

B. A. Ross

414 Sailfish Court

Richland, WA 99352

Prof. G. Russell

Civil Engineering Department

Kansas State University

Manhattan, Kansas 66506

J. L. Russell

Office of Radiation Programs

AW-459, EPA

401 M. Street S.W.

Washington, DC 20460

L. D. Santman

Materials Transportation Bureau

Department of Transportation

2100 Second Street S.W.

Washington, DC 20590

A. L. Schmeig

National Transportation Safety Board

Department of Transportation

Washington, DC 20594 
No. of

Copies

Dr. Schmidt-Kuester

Beim Bundesminister für Forschung and Technologie

Stresemannstrasse 2

5300 Bonn

GERMANY

B. Schulz-Forberg

Bundesanstalt für Materialprufung

Unter den Eichen 87

D-1000 Berlin 45 (West)

GERMANY, FED. REPUBLIC

L. Shappert

Union Carbide Corporation

Oak Ridge National Laboratories

P.0. Box $X$

Oak Ridge, TN 37830

H. G. Shealy

Bureau of Radiological Health

South Carolina Department of Health and Environmental Control Columbia, SC 29405

E. W. Shepard

Sandia National Laboratories

Division 4551

Albuquerque, NM 81785

Robert Shober

Burlington Northern

176 East Fifth Street

St. Paul, MN 55101

K. R. Shultz

Atomic Energy Control

Board

P.0. Box 1046

Ottawa KIP $5 S 9$

CANADA
No. of

Copies

J. A. Sisler

Mail Stop/B107

Transportation and Fuel Storage

Department of Energy

Washington, DC 20545

M. Stammler

Battelle Institute, e.v.

Am Romerhof 35

600 Frankfurt Main 90

GERMANY

C. Starr

Electrical Power Research Inst.

P.0. Box 10412

Palo Alto, CA 94304

M. J. Steindler

Argonne National Laboratory

9800 South Cass Avenue

Argonne, IL 60439

N. Stetson

DOE Savannah River Operations Office

P.0. Box A

Aiken, SC 29801

B. A. Straker

Science Applications, Inc.

P.0. Box 2351

La Jolla, CA 92038

G. R. Swinde 11

International Atomic Energy Agency

A-1011 Vienna, Austria

W. R. Taylor

Atomic Energy of Canada Ltd.

Chalk River Laboratories

Chalk River, Ontario KOJIJO

CANADA 
No. of

Copies

D. H. Teeter

Puget Sound Council of Governments

216 First Avenue S.

Seattle, WA 98104

M. Toml inson

White Shell Nuclear Research Establ ishment

Pinewa, Manitoba ROE ILO

CANADA

P. T. Tuite

Hittman Nuclear and Development Corporation

9190 Red Branch Road

Columbia, MD 21045

L. L. Turner

DOE Savannah River Operations

P.0. Box A

Aiken, SC 29801

W. E. Vesely

Nuclear Regulatory Commission

Washington, DC 20555

J. Walker

California Energy Resources Conservation and Development Commission

1111 Howe Avenue

Sacramento, CA 95825

Dr. Henry Walter

DOE/ESED

EV-132, E-102

Washington, DC 20545

Dan Wedderburn

Office of Resource Applications

Department of Energy

MS 3344

1200 Pennsylvania Avenue

Washington, DC 20461
No. of

Copies

$\mathrm{Mr}$. Don F. White, $\mathrm{CH} 2-6$

Manager of Transportation Safety

Weyerhauser Corporation

Tacoma, WA 98477

R. Williams

Electrical Power Research Inst.

P.0. Box 10412

Palo Alto, CA 94304

E. J. Wilson

Department of Transport

Dangerous Goods Branch

2 Marsham St.

London SW 1

ENGLAND

E. L. Wilmot

Sandia National Laboratories

Division 4551

Albuquerque, NM 87185

Joe Wolfson

DOT/TSC 533

Kenda 11 Square

Cambridge, MA 02142

\section{ONSITE}

5 DOE-Richland Operations Office

M. W. Shupe

J. C. Cummings

J. M. Peterson

H. E. Ransom

J. J. Schreiber 
No. of

Copies

54 Pacific Northwest Laboratory

W. B. Andrews (5)

W. J. Bair

N. M. Burleigh (25)

T. Chikalla

M. L. Clark

R. M. Fleischman

A. L. Frankl in

J. R. Friley

C. A. Geffen-Fowler

H. Harty

M. R. Kreiter

R. C. Liikala

J. W. Litchfield

D. J. McNaughton

D. W. Murphy

E. S. Murphy

J. M. Oylear

R. E. Rhoads

L. D. Williams

Technical Information (5)

Publishing Coordination (2)

4 Battelle-Human Affairs Research Center

C. Gluett

J. A. Hebert

F. A. Morris

C. R. Schuller 